\title{
Meteorological and Air Quality Impacts of Increased Urban Surface Albedo and Vegetative Cover in the Greater Toronto Area, Canada
}

\author{
Haider Taha, Hillel Hammer, Hashem Akbari \\ Heat Island Group \\ Environmental Energy Technologies Division \\ Lawrence Berkeley National Laboratory \\ Berkeley, California \\ USA
}

April 2002

This study has been sponsored by the Toronto Atmospheric Fund, under contract number: 01-128[00], and by the Assistant Secretary for Energy Efficiency and Renewable Energy, of the U.S. Department of Energy, under contract number: AC03-76SF00098. 



\section{ACKNOWLEDGEMENTS}

This study has been sponsored by the Toronto Atmospheric Fund, under contract number: 01-128[00], and by the Assistant Secretary for Energy Efficiency and Renewable Energy, of the U.S. Department of Energy, under contract number: AC03-76SF00098. We would like to thank the Toronto Atmospheric Fund (TAF) for sponsoring this study. We would also like to thank Eva Ligeti (TAF) for leading and guiding this project. We thank Dr. Robert Bornstein (San Jose State University), Dr. David Sailor (Tulane University), Eva Wong (U.S. EPA), and Saeed Sheshehgar (TAF), for reviewing this report and providing comments and suggestions. 



\section{TABLE OF CONTENTS}

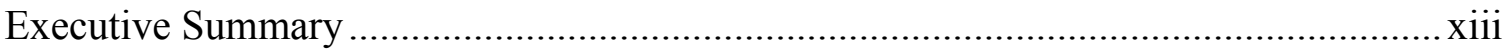

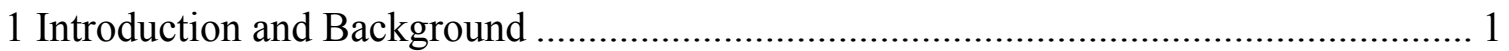

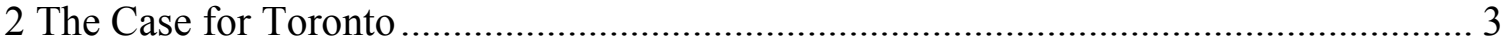

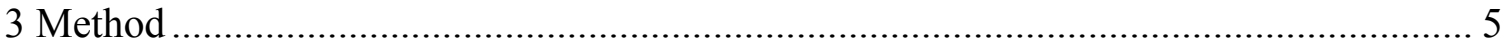

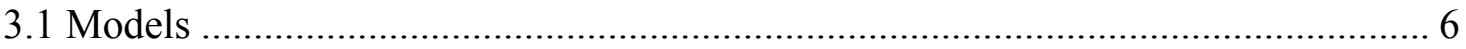

3.1.1 Mesoscale Meteorological Model (PSU/NCAR MM5) ………………............ 6

3.1.2 Meteorological Trajectory Model ................................................................ 7

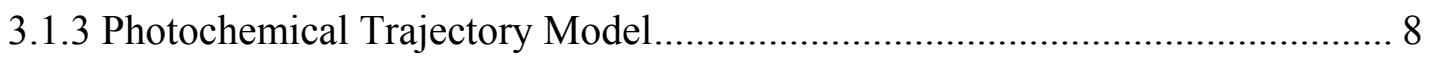

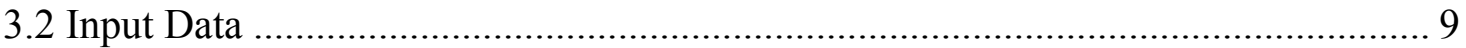

3.2.1 Meteorological Data........................................................................... 9

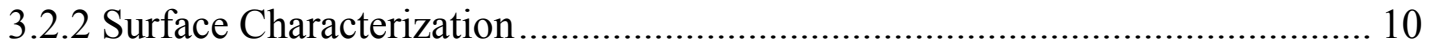

3.2.2.1 Base-Case Surface Scenario …………….......................................... 11

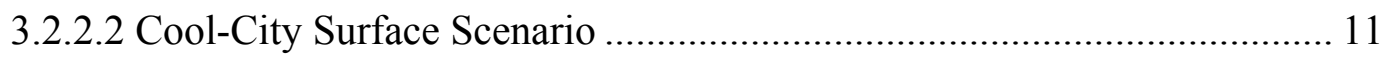

3.2.3 Emissions and Air Quality (Initial Conditions) Data........................................ 14

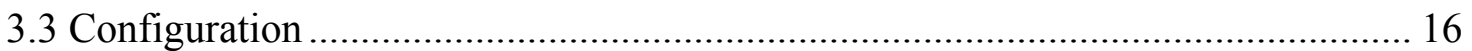

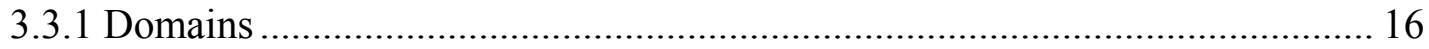

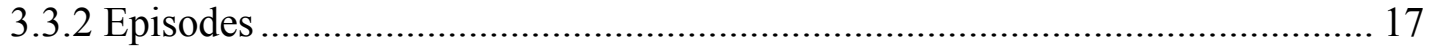

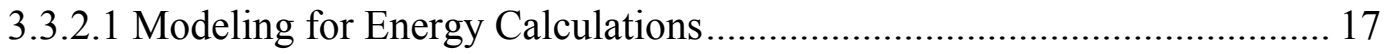

3.3.2.2 Modeling for Meteorological/Air Quality Simulations ............................. 17

3.3.3 Model Setups and Options ........................................................................ 17

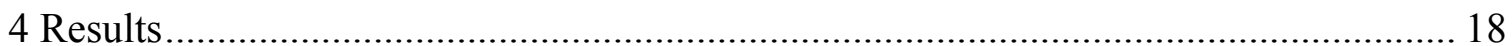

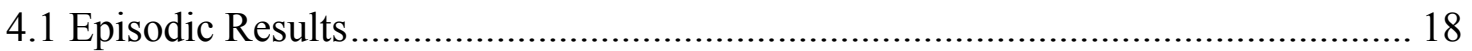

4.1.1 Meteorological Aspects .................................................................. 18

4.1.2 Meteorological Trajectories ............................................................. 22

4.1.3 Air Quality Trajectories ........................................................................ 24

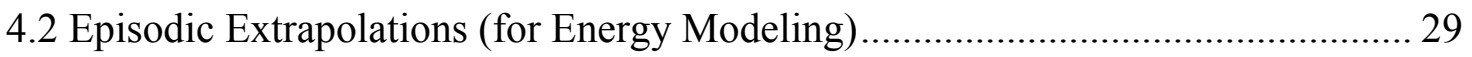

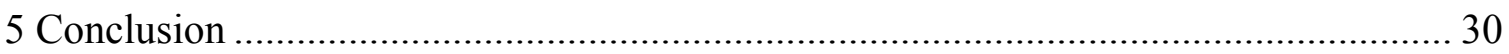

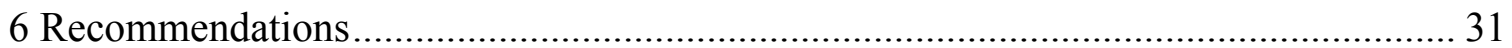

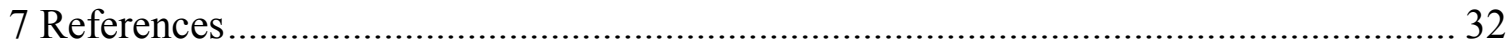





\section{TABLE OF FIGURES}

Figure 2.1: Monthly averages of mean and mean daily maximum ozone, ppb, (1986-1993) in Toronto. Source: Environment Canada, 1996.

Figure 2.2: Hourly average ozone mixing ratios, ppb, for summer and winter (1986-1993) in Toronto. Source: Environment Canada, 1996. (Horizontal axis is time, LST).

Figure 2.3: Percentage occurrence of hours with ozone mixing ratios greater than 82 ppb by time of day (1986-1993) Toronto. Source: Environment Canada, 1996.

Figure 3.1. Modeling domains for the MM5 simulations. D01 has a resolution of 8 $\mathrm{km}$ and D02 a resolution of $2 \mathrm{~km}$.

Figure 3.2. Land-use and land-cover categories in the coarse domain. Red color denotes urban areas.

Figure 3.3. Land-use and land-cover distribution in the fine domain. Red color denotes urban areas.

Figure 3.4. Initial conditions (doubled initial mixing ratios) for NMHC at Hastings, Canada in the summer.

Figure 4.1. July 11, 1995 at 0000 LST base case scenario: Simulated temperature and wind-vector field, for the inner, fine-resolution $(2-\mathrm{km})$ domain.

Figure 4.2. July 11, 1995 at 0900 LST base case scenario: Simulated temperature and wind-vector field, for the inner, fine-resolution $(2-\mathrm{km})$ domain.

Figure 4.3. July 11, 1995 at 1000 LST base case scenario: Simulated temperature and wind-vector field, for the inner, fine-resolution $(2-\mathrm{km})$ domain.

Figure 4.4. July 11, 1995 at 1100 LST base case scenario: Simulated temperature and wind-vector field, for the inner, fine-resolution $(2-\mathrm{km})$ domain.

Figure 4.5. July 11, 1995 at 1200 LST base case scenario: Simulated temperature and wind-vector field, for the inner, fine-resolution $(2-\mathrm{km})$ domain.

Figure 4.6. July 11, 1995 at 1400 LST base case scenario: Simulated temperature and wind-vector field, for the inner, fine-resolution $(2-\mathrm{km})$ domain.

Figure 4.7. July 11, 1995 at 2000 LST base case scenario: Simulated temperature and wind-vector field, for the inner, fine-resolution $(2-\mathrm{km})$ domain.

Figure 4.8. July 12, 1995 at 0800 LST base case scenario: Simulated temperature and wind-vector field, for the inner, fine-resolution $(2-\mathrm{km})$ domain.

Figure 4.9. July 12, 1995 at 0900 LST base case scenario: Simulated temperature and wind-vector field, for the inner, fine-resolution $(2-\mathrm{km})$ domain.

Figure 4.10. July 12, 1995 at 1000 LST base case scenario: Simulated temperature and wind-vector field, for the inner, fine-resolution (2-km) domain.

Figure 4.11. July 12, 1995 at 1100 LST base case scenario: Simulated temperature and wind-vector field, for the inner, fine-resolution (2-km) domain.

Figure 4.12. July 12, 1995 at 1200 LST base case scenario: Simulated temperature and wind-vector field, for the inner, fine-resolution $(2-\mathrm{km})$ domain. 
Figure 4.13. July 13, 1995 at 0800 LST base case scenario: Simulated temperature and wind-vector field, for the inner, fine-resolution $(2-\mathrm{km})$ domain............53

Figure 4.14. July 13, 1995 at 0900 LST base case scenario: Simulated temperature and wind-vector field, for the inner, fine-resolution (2-km) domain............54

Figure 4.15. July 13, 1995 at 1000 LST base case scenario: Simulated temperature and wind-vector field, for the inner, fine-resolution $(2-\mathrm{km})$ domain.............55

Figure 4.16. July 13, 1995 at 1100 LST base case scenario: Simulated temperature and wind-vector field, for the inner, fine-resolution $(2-\mathrm{km})$ domain. 56

Figure 4.17. July 13, 1995 at 1200 LST base case scenario: Simulated temperature and wind-vector field, for the inner, fine-resolution $(2-\mathrm{km})$ domain.

Figure 4.18. July 11, 1995 at 0000 LST cool-city scenario: Simulated temperature and wind-vector field, for the inner, fine-resolution (2-km) domain.

Figure 4.19. July 11, 1995 at 0900 LST cool-city scenario: Simulated temperature and wind-vector field, for the inner, fine-resolution $(2-\mathrm{km})$ domain.

Figure 4.20. July 11, 1995 at 1000 LST cool-city scenario: Simulated temperature and wind-vector field, for the inner, fine-resolution $(2-\mathrm{km})$ domain.

Figure 4.21. July 11, 1995 at 1100 LST cool-city scenario: Simulated temperature and wind-vector field, for the inner, fine-resolution (2-km) domain.

Figure 4.22. July 11, 1995 at 1200 LST cool-city scenario: Simulated temperature and wind-vector field, for the inner, fine-resolution (2-km) domain.

Figure 4.23. July 11, 1995 at 1400 LST cool-city scenario: Simulated temperature and wind-vector field, for the inner, fine-resolution $(2-\mathrm{km})$ domain.

Figure 4.24. July 11, 1995 at 2000 LST cool-city scenario: Simulated temperature and wind-vector field, for the inner, fine-resolution $(2-\mathrm{km})$ domain.....

Figure 4.25. July 12, 1995 at 0800 LST cool-city scenario: Simulated temperature and wind-vector field, for the inner, fine-resolution $(2-\mathrm{km})$ domain.

Figure 4.26. July 12, 1995 at 0900 LST cool-city scenario: Simulated temperature and wind-vector field, for the inner, fine-resolution $(2-\mathrm{km})$ domain.

Figure 4.27. July 12, 1995 at 1000 LST cool-city scenario: Simulated temperature and wind-vector field, for the inner, fine-resolution $(2-\mathrm{km})$ domain.

Figure 4.28. July 12, 1995 at 1100 LST cool-city scenario: Simulated temperature and wind-vector field, for the inner, fine-resolution $(2-\mathrm{km})$ domain.

Figure 4.29. July 12, 1995 at 1200 LST cool-city scenario: Simulated temperature and wind-vector field, for the inner, fine-resolution (2-km) domain.

Figure 4.30. July 13, 1995 at 0800 LST cool-city scenario: Simulated temperature and wind-vector field, for the inner, fine-resolution (2-km) domain. . .70

Figure 4.31. July 13, 1995 at 0900 LST cool-city scenario: Simulated temperature and wind-vector field, for the inner, fine-resolution (2-km) domain. .71

Figure 4.32. July 13, 1995 at 1000 LST cool-city scenario: Simulated temperature and wind-vector field, for the inner, fine-resolution $(2-\mathrm{km})$ domain. .72 
Figure 4.33. July 13, 1995 at 1100 LST cool-city scenario: Simulated temperature and wind-vector field, for the inner, fine-resolution $(2-\mathrm{km})$ domain.............73

Figure 4.34. July 13, 1995 at 1200 LST cool-city scenario: Simulated temperature and wind-vector field, for the inner, fine-resolution $(2-\mathrm{km})$ domain.............74

Figure 4.35. July 15, 1995 at 1200 LST base case scenario: Simulated temperature and wind-vector field, for the inner, fine-resolution $(2-\mathrm{km})$ domain.............75

Figure 4.36. July 15, 1995 at 1300 LST base case scenario: Simulated temperature and wind-vector field, for the inner, fine-resolution $(2-\mathrm{km})$ domain. .76

Figure 4.37. July 15, 1995 at 1400 LST base case scenario: Simulated temperature and wind-vector field, for the inner, fine-resolution $(2-\mathrm{km})$ domain. .77

Figure 4.38. July 15, 1995 at 1500 LST base case scenario: Simulated temperature and wind-vector field, for the inner, fine-resolution (2-km) domain. .78

Figure 4.39. July 15, 1995 at 1600 LST base case scenario: Simulated temperature and wind-vector field, for the inner, fine-resolution $(2-\mathrm{km})$ domain.

Figure 4.40. July 15, 1995 at 1700 LST base case scenario: Simulated temperature and wind-vector field, for the inner, fine-resolution (2-km) domain.

Figure 4.41. July 15, 1995 at 1800 LST base case scenario: Simulated temperature and wind-vector field, for the inner, fine-resolution (2-km) domain.

Figure 4.42. July 15, 1995 at 1900 LST base case scenario: Simulated temperature and wind-vector field, for the inner, fine-resolution (2-km) domain.

Figure 4.43. July 15, 1995 at 2000 LST base case scenario: Simulated temperature and wind-vector field, for the inner, fine-resolution $(2-\mathrm{km})$ domain.

Figure 4.44. July 16, 1995 at 1000 LST base case scenario: Simulated temperature and wind-vector field, for the inner, fine-resolution $(2-\mathrm{km})$ domain.

Figure 4.45. July 16, 1995 at 1200 LST base case scenario: Simulated temperature and wind-vector field, for the inner, fine-resolution $(2-\mathrm{km})$ domain. .85

Figure 4.46. July 16, 1995 at 1300 LST base case scenario: Simulated temperature and wind-vector field, for the inner, fine-resolution $(2-\mathrm{km})$ domain

Figure 4.47. July 16, 1995 at 1400 LST base case scenario: Simulated temperature and wind-vector field, for the inner, fine-resolution $(2-\mathrm{km})$ domain.

Figure 4.48. July 16, 1995 at 1500 LST base case scenario: Simulated temperature and wind-vector field, for the inner, fine-resolution (2-km) domain .88

Figure 4.49. July 17, 1995 at 0000 LST base case scenario: Simulated temperature and wind-vector field, for the inner, fine-resolution $(2-\mathrm{km})$ domain.

Figure 4.50. July 17, 1995 at 1000 LST base case scenario: Simulated temperature and wind-vector field, for the inner, fine-resolution (2-km) domain.

Figure 4.51. July 17, 1995 at 1100 LST base case scenario: Simulated temperature and wind-vector field, for the inner, fine-resolution (2-km) domain. .91

Figure 4.52. July 17, 1995 at 1200 LST base case scenario: Simulated temperature and wind-vector field, for the inner, fine-resolution $(2-\mathrm{km})$ domain. 
Figure 4.53. July 17, 1995 at 1300 LST base case scenario: Simulated temperature and wind-vector field, for the inner, fine-resolution $(2-\mathrm{km})$ domain

Figure 4.54. July 17, 1995 at 1400 LST base case scenario: Simulated temperature and wind-vector field, for the inner, fine-resolution (2-km) domain.

Figure 4.55. July 17, 1995 at 1500 LST base case scenario: Simulated temperature and wind-vector field, for the inner, fine-resolution $(2-\mathrm{km})$ domain. .95

Figure 4.56. July 17, 1995 at 1600 LST base case scenario: Simulated temperature and wind-vector field, for the inner, fine-resolution $(2-\mathrm{km})$ domain. .96

Figure 4.57. July 17, 1995 at 1700 LST base case scenario: Simulated temperature and wind-vector field, for the inner, fine-resolution $(2-\mathrm{km})$ domain.

Figure 4.58. July 17, 1995 at 1800 LST base case scenario: Simulated temperature and wind-vector field, for the inner, fine-resolution (2-km) domain. .98

Figure 4.59. July 15, 1995 at 1200 LST cool-city scenario: Simulated temperature and wind-vector field, for the inner, fine-resolution $(2-\mathrm{km})$ domain.

Figure 4.60. July 15, 1995 at 1300 LST cool-city scenario: Simulated temperature and wind-vector field, for the inner, fine-resolution $(2-\mathrm{km})$ domain.

Figure 4.61. July 15, 1995 at 1400 LST cool-city scenario: Simulated temperature and wind-vector field, for the inner, fine-resolution (2-km) domain.

Figure 4.62. July 15, 1995 at 1500 LST cool-city scenario: Simulated temperature and wind-vector field, for the inner, fine-resolution (2-km) domain.

Figure 4.63. July 15, 1995 at 1600 LST cool-city scenario: Simulated temperature and wind-vector field, for the inner, fine-resolution $(2-\mathrm{km})$ domain.

Figure 4.64. July 15, 1995 at 1700 LST cool-city scenario: Simulated temperature and wind-vector field, for the inner, fine-resolution $(2-\mathrm{km})$ domain.

Figure 4.65. July 15, 1995 at 1800 LST cool-city scenario: Simulated temperature and wind-vector field, for the inner, fine-resolution $(2-\mathrm{km})$ domain. 105

Figure 4.66. July 15, 1995 at 1900 LST cool-city scenario: Simulated temperature and wind-vector field, for the inner, fine-resolution $(2-\mathrm{km})$ domain. 106

Figure 4.67. July 15, 1995 at 2000 LST cool-city scenario: Simulated temperature and wind-vector field, for the inner, fine-resolution $(2-\mathrm{km})$ domain.

Figure 4.68. July 16, 1995 at 1000 LST cool-city scenario: Simulated temperature and wind-vector field, for the inner, fine-resolution $(2-\mathrm{km})$ domain. 108

Figure 4.69. July 16, 1995 at 1200 LST cool-city scenario: Simulated temperature and wind-vector field, for the inner, fine-resolution (2-km) domain.

Figure 4.70. July 16, 1995 at 1300 LST cool-city scenario: Simulated temperature and wind-vector field, for the inner, fine-resolution $(2-\mathrm{km})$ domain

Figure 4.71. July 16, 1995 at 1400 LST cool-city scenario: Simulated temperature and wind-vector field, for the inner, fine-resolution (2-km) domain.

Figure 4.72. July 16, 1995 at 1500 LST cool-city scenario: Simulated temperature and wind-vector field, for the inner, fine-resolution $(2-\mathrm{km})$ domain. 
Figure 4.73. July 17, 1995 at 0000 LST cool-city scenario: Simulated temperature and wind-vector field, for the inner, fine-resolution $(2-\mathrm{km})$ domain.

Figure 4.74. July 17, 1995 at 1000 LST cool-city scenario: Simulated temperature and wind-vector field, for the inner, fine-resolution $(2-\mathrm{km})$ domain.

Figure 4.75. July 17, 1995 at 1100 LST cool-city scenario: Simulated temperature and wind-vector field, for the inner, fine-resolution $(2-\mathrm{km})$ domain.

Figure 4.76. July 17, 1995 at 1200 LST cool-city scenario: Simulated temperature and wind-vector field, for the inner, fine-resolution $(2-\mathrm{km})$ domain.

Figure 4.77. July 17, 1995 at 1300 LST cool-city scenario: Simulated temperature and wind-vector field, for the inner, fine-resolution (2-km) domain.

Figure 4.78. July 17, 1995 at 1400 LST cool-city scenario: Simulated temperature and wind-vector field, for the inner, fine-resolution (2-km) domain.

Figure 4.79. July 17, 1995 at 1500 LST cool-city scenario: Simulated temperature and wind-vector field, for the inner, fine-resolution $(2-\mathrm{km})$ domain.

Figure 4.80. July 17, 1995 at 1600 LST cool-city scenario: Simulated temperature and wind-vector field, for the inner, fine-resolution $(2-\mathrm{km})$ domain.

Figure 4.81. July 17, 1995 at 1700 LST cool-city scenario: Simulated temperature and wind-vector field, for the inner, fine-resolution $(2-\mathrm{km})$ domain.

Figure 4.82. July 17, 1995 at 1800 LST cool-city scenario: Simulated temperature and wind-vector field, for the inner, fine-resolution $(2-\mathrm{km})$ domain.

Figure 4.83: UHI time series for case 039 for base (solid) and cool-city (broken) scenarios. Time series are for averaged urban temperatures vs. averaged rural temperatures.

Figure 4.84: UHI time series for case 035 for base (solid) and cool-city (broken) scenarios. Time series are for averaged urban temperatures vs. Averaged rural temperatures.

Figure 4.85: Change in UHI (with respect to base-case UHI) for cases 039 and 035 as a result of cool-city scenarios.

Figure 4.86: Change in absolute air temperature (not UHI) at six random urban locations.

Figure 4.87: Change in absolute air temperature (not UHI) at six random urban locations.

Figure 4.88: Selected meteorological trajectories (from ensemble generated in this study). These trajectories arrive urban Toronto (shown with red pluses) 48-72 hours later.

Figure 4.89: Trajectories for case 039.

Figure 4.90: Selection of trajectories for case 039. 127

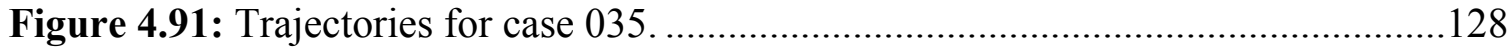

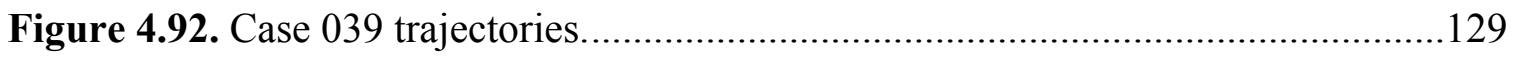

Figure 4.93: Selected trajectories for case 035 and 039. 130 
Figure 4.94: Selected trajectories for case 039.

Figure 4.95: Photochemical trajectory for case 039. Observed ozone concentrations (contour values) are for 15 LST on July $13 .$.

Figure 4.96: Photochemical trajectory for case 039 . Observed ozone concentrations (contour values) are for 20 LST on July $13 .$.

Figure 4.97: Photochemical trajectory for case 035. Observed ozone

concentrations (contour values) are for 17 LST on July 17.

Figure 4.98: Simulated temperature and wind-vector fields

Figure 4.99: Simulated temperature and wind-vector fields

Figure 4.100: Simulated ozone concentrations (ppm) along trajectories 039 (bottom) and 035 (top). Solid line is base case, thick broken line is case A, thin short-broken line is case B, and thin long-broken line is case C. See text for discussion of these cases.

Figure 4.101: Simulated ozone concentrations (ppm) along trajectories 039 (bottom) and 035 (top). This set was simulated with doubled initial mixing ratios. Solid line is base case, thick broken line is case A, thin short-broken line is case B, and thin long-broken line is case $\mathrm{C}$. See text for discussion of these cases

Figure 4.102: Air temperature ( $2 \mathrm{~m}$ above ground) for last 12 hours of trajectory........138

Figure 4.103: Scatter plot of ozone changes and temperature changes for case $039 \ldots . .138$

Figure 4.104: Air temperature ( $2 \mathrm{~m}$ above ground) for last 10 hours of trajectory........139

Figure 4.105: Scatter plot of ozone change vs. temperature change for case $035 \ldots \ldots . . .139$

Figure 4.106: Simulated air temperature change and solar radiation. ........................... 140

Figure 4.107: Simulated air temperature change and solar radiation. 140 


\section{Executive Summary}

The meteorological and air quality modeling study described in this report is one component of a project sponsored by the Toronto Atmospheric Fund (TAF). The purpose of this study, performed at the Lawrence Berkeley National Laboratory, is to assess the potential role of surface property modifications on energy, meteorology, and air quality in the Greater Toronto Area (GTA). This study is both preliminary and relatively qualitative in nature. The component discussed here uses numerical models to establish the possible meteorological and ozone air quality impacts that could result from increased urban albedo and vegetative fraction, the so-called "cool-city" strategies. More specifically, the purpose of this study is to investigate whether it is worth pursuing this idea further. Based on results reported here, the answer appears to be affirmative and future, more detailed studies should be carried out in this direction.

Adopting cool-city strategies, such as increasing urban vegetation and the use of highalbedo building and urban materials, can significantly reduce urban energy consumption and improve pedestrian-level thermal comfort, particularly during periods of hot weather in summer. This can be even more critical during heat wave periods when heat-related hospitalization and mortality can increase. It is noteworthy that, while improving comfort in the summer, reducing the urban heat island (UHI) does not influence thermal comfort in the winter. The reduction in UHI is negligible during the winter. This is due to smaller amounts of incoming solar radiation, stronger winds, increased precipitation, snow cover, and general cloudiness in this season. Thus, on an annual basis, cool-city strategies seem to be beneficial. As a result, the implementation of such strategies is currently being investigated in the U.S. and Canada.

Changing surface properties in large urban areas and the ensuing local meteorological changes are expected to affect air quality. The reduction of the urban heat-island effect, expressed as changes in mixing height, temperature, wind speed and direction, as well as possible changes in precipitation, will play a role in the chemical processes producing ozone. For example, the potential increased reflectance of ultraviolet (UV) radiation will directly increase photochemical reaction rates. The reduced temperature will decrease emissions of VOCs and other fugitive gases from evaporative sources such as fuel storage and handling facilities. Furthermore, diminished energy consumption from the urban area will result in reduced emissions from power generation facilities. The general trend of the expected changes mentioned above suggests an expected overall reduction of ozone production rates in the vicinity and near downwind region of the modified urban areas. The specific local effects, however, are the result of a complex set of chemical reactions as well as the perturbed variables affecting the reactions. Some reactions may be slowed, and there may also be changes in reservoir species such as peroxyacetylnitrate (PAN); thus, exporting pollutants to form ozone at downwind locations.

The objective of this study was to simulate possible scenarios for urban heat-island mitigation in the GTA and to investigate the consequent meteorological changes. The second objective was to perform limited air quality analysis to get an initial assessment of possible impacts. The available air quality and emissions data is incompatible with models, 
such as UAM, ${ }^{1}$ UAM-V, and CAMx, ${ }^{2}$ we currently use. So instead, the air quality analysis was based on photochemical trajectory modeling. This approach probably is not accurate or appropriate enough to capture the regional conditions and impacts. This is the reason why we believe that the air quality results discussed in this report should be viewed as relatively qualitative. This aspect of the study can be improved upon in the future.

The present study was based on a combination of mesoscale meteorological modeling, Lagrangian (trajectory), and photochemical trajectory modeling to assess the potential meteorological and ozone air-quality impacts of cool-city strategies in Toronto, Canada. The results are discussed in detail in the body of this report. The meteorological model (MM5) predicts a UHI in the GTA, which tends to occur relatively more frequently during the daytime than nighttime. The MM5 predicts a UHI in the order of 2 to $3{ }^{\circ} \mathrm{C}$ in locations of maxima, and about $1{ }^{\circ} \mathrm{C}$ as a typical value over most of the urban area. While such a UHI seems typical, the simulations also suggest that the city can be cooler than the rural surrounds at times. A related note here is that heat islands can vary significantly depending on location, season, weather conditions, and urban properties, such as energy use, anthropogenic heating, building geometry, and other factors. Thus some UHIs peak at night, others during the day, some in summer, others in winter, and so on. The simulation of the episode used and related conditions suggests a relatively more prevalent daytime heat island compared to its nighttime counterpart.

The meteorological simulations suggest that the effects of cool-city strategies are to reduce local urban air temperature by a typical level of $0.5-1{ }^{\circ} \mathrm{C}$. In separate instances, larger decreases in air temperature, such as $1.5^{\circ} \mathrm{C}$, and some decreases on the order of 2.5-2.7 ${ }^{\circ} \mathrm{C}$ and $4-6{ }^{\circ} \mathrm{C}$ are also simulated. The larger decreases appear as more sporadic events than physically justifiable ones and are thus ignored in this analysis.

In terms of ozone mixing ratios along the simulated trajectories, the effects of cool-city strategies appear to be on the order of $2 \mathrm{ppb}$, a typical decrease. The photochemical trajectory model CIT (California Institute of Technology) also simulates larger decreases, such as 4 to $8 \mathrm{ppb}$. However, these are not taken as representative of the potential impacts in this report. While a decrease of $2 \mathrm{ppb}$ in ozone concentration may seem like a small change, a comparison with other simulations suggest very crudely that a decrease of this magnitude corresponds to significant "equivalent" decreases in both NOx and VOCs emissions in the region.

This study is very preliminary; it serves as an initial step towards more comprehensive and detailed studies of this type. Based on the preliminary results reported here, it appears that UHI control in the GTA is significant and, therefore, is worth further study. It is recommended that better input data and more accurate modeling schemes be used to carry out future studies in the same direction.

\footnotetext{
${ }^{1}$ Urban Airshed Model

${ }^{2}$ Comprehensive Air Quality Model with extensions
} 


\section{Introduction and Background}

The energy balance in urban areas is strongly affected by urban geometry, surface properties, and release of anthropogenic heat, all of which interact to produce urban heat islands (Taha, 1997a). Of course, the extent and intensities of urban heat islands depend strongly on temporal aspects (diurnal and seasonal) of the weather and synoptic conditions. It also depends on other factors such as the location, topography, size of the city and its population density (Oke, 1987; 1988).

Most urban surfaces are constructed of dark materials. The interaction of these materials with incoming solar radiation is characterized by relatively high absorption coefficients. In addition, urban areas are characteristically less vegetated than their surroundings and, as such, have a reduced rate of evapotranspiration. Both of these characteristics result in the warming of urban air relative to that of the rural surroundings. Urban heat islands also seem to grow over time. In California, for example, Goodridge (1989) has shown that before 1940, the average urban-rural temperature differences for 31 locations in California were all negative. After 1940, as paved surfaces replaced vegetation in large areas, the urban temperatures surpassed rural temperatures, leading to a clear temperature increase of approximately $1^{\circ} \mathrm{C}$ from 1965 to 1989 (averaged over all 31 urban areas in California). Adopting "cool city" strategies, such as increasing urban vegetation and the use of high-albedo building materials, can significantly reduce urban energy consumption (by reducing both direct radiative heating of buildings and ambient temperatures) and improve pedestrian comfort levels, particularly in hot climates.

Because of the complex nature of the urban photochemical system, i.e., meteorology and chemistry, the combination of changes in meteorological and emission conditions might lead to various outcomes. For example, the main driver for the decrease in ozone mixing ratios is the temperature, which can reduce chemical reaction rates. Slower reactions will cause precursors to be carried further downwind, spreading out the ozone production over a longer distance. This phenomenon reduces local ozone mixing ratios while possibly producing higher levels of ozone by enhancing these ratios downwind. Other meteorological changes, such as reduced mixing height and wind speed, can cause both increases and decreases in ozone mixing ratios.

Modeling studies suggest that increased surface albedo and vegetation fraction in urban areas can reduce surface and air temperatures near the ground and affect related meteorological parameters such as winds and the depth of the mixed boundary layer. The general impacts of relatively lower ambient temperatures on air quality and energy use include: 1) a reduction in temperature-dependent photochemical reaction rates; 2) a decrease in temperature-dependent biogenic hydrocarbon emissions; 3) a decrease in evaporative losses of organic compounds from mobile and stationary sources; and 4) a decreased need for cooling energy and electricity generating capacity, which ultimately leads to less emissions from power plants. For example, Taha $(1996 ; 1997 b)$ and Taha et al. (1999) show that, through controlling urban heat islands, it is possible to reduce air temperatures by 2 to $4{ }^{\circ} \mathrm{C}$ in summer in urban areas of the United States; thus, reducing "exceedance" exposure to ozone (above the national air quality standard) by $10-20 \%$. 
Taha et al. (2000) show that the effects of heat-island reduction (HIR) strategies in Salt Lake City (UT), Baton Rouge (LA), and Sacramento (CA), tend to be generally positive, though negative effects, such as increased ozone concentrations, can still occur. In similar modeling of episodes in Atlanta, Nashville, and Dallas, Taha (1998) shows virtually no change using a conservative scenario, and net ozone mixing ratio reductions of $2 \%, 0.4 \%$ and $5 \%$ respectively in a larger-modifications scenario. In these studies the maximal reduction is always larger than the greatest increase in ozone mixing ratio and it occurs in the area with the highest predicted mixing ratios.

Preliminary results by Taha et al. (2001) show that the impacts of cool-cities in Houston, Texas, amount to some $\pm 3{ }^{\circ} \mathrm{C}$ in air temperature and detectable changes in air quality. The effects of cool-city strategies are mostly cooling. However, warming can also occur. For example, warming can occur downwind due to changes in winds and mixing. In Sacramento California, Taha et al. (2000) show that a peak of $139 \mathrm{ppb}$ can be decreased to $130 \mathrm{ppb}$ as a result of increased surface albedo and vegetative cover in the region.

Following the above studies, the Toronto Atmospheric Fund (TAF) funded a limited study at Lawrence Berkeley National Laboratory (LBNL) to assess the effects of UHI control on Toronto's climate, energy use, and ozone air pollution. Described in this report, the purpose of the meteorological modeling and air quality analysis sub-task of the TAF project was to understand the factors leading to ozone air pollution problems in the GTA and to quantify the potential impacts that could result from implementing the coolcity strategies.

This study investigates the possible impacts of heat-island mitigation efforts on the air quality in the GTA. Given the fact that the GTA is located at relatively high latitude, the effect on the air quality is expected to be small. Nonetheless, in the context of major efforts to reduce ozone levels to "acceptable" levels, this small effect should not be ignored. In places such as Los Angeles, where other strategies have already made relatively low-cost ozone reductions without having achieved the goals set, any further reduction in ozone level has a high cost-to-benefit ratio. Therefore, strategies such as cool-cities may be considered a valuable advancement in the right direction. For example, the potential savings based on population-weighted ozone mixing ratios simulated for the Los Angeles basin, where the pollution is especially serious, is estimated to be $\$ 360$ million per year (Rosenfeld et al., 1998). 


\section{The Case for Toronto}

Three major regions in Canada, namely the Lower Fraser Valley (LFV), Southern Atlantic Region (SAR), and Windsor-Quebec City Corridor (WQC), often experience ozone air pollution levels that are above the acceptable level, an $82 \mathrm{ppb}$ cutoff ozone mixing ratio adopted in Canada. Toronto is located in the WQC region. The main ozone precursor sources in this region include transportation, power plants, and industry. Another considerable source of ozone is industrial activity in the United States, which is particularly important in summer when winds are mainly from the southwest. Environment Canada (1996) estimates that about $20-40 \mathrm{ppb}$ of the local ozone mixing ratio in Toronto and Southern Ontario is transported from the U.S. In other words, the United States contributes around $50-60 \%$ to the ozone levels in southern Ontario.

As with any other area, meteorology plays a significant role in Toronto's ozone air quality. Wind speed and direction, thickness of the boundary layer, solar radiation, air temperature, and atmospheric water vapor all affect the rate of photochemical smog production. Temperature is of particular interest in this study since the focus is on urban heat islands and their potential mitigation. In a Classification And Regression Tree (CART) type analysis, Burrows et al. (1995) found that for WQC, the most important predictor for ozone mixing ratio, especially the maxima, was the maximum air temperature. Burrows et al. found that, for WQC, the maximum air temperature should reach at least $25^{\circ} \mathrm{C}$ before there was any statistically significant probability that ozone-mixing ratios exceeded $80 \mathrm{ppb}$. They also found that near the lakes, such as in the GTA, wind direction and speed became important factors in air temperature as well as transport of pollutants. Synoptic weather conditions are also critical and various studies have examined the response in ozone production to various aspects of atmospheric circulation and conditions. Yap et al. (1988) studied ozone formation conditions in southern Ontario. They found, for example, that higher mixing ratios of ozone in this region tend to occur in the backside of a slowmoving high-pressure system (anti-cyclonic). In such incidences, the winds also would have traveled over major precursor sources in the northeastern the United States and arrived in Toronto on a southwesterly path.

The ozone air quality in the GTA, while not severe in comparison with some cities in the U.S., Mexico, or Brazil, could get worse in the future if no action is taken now. There are two reasons for this prediction: 1) the expansion and urbanization trend in the area, and 2) potential effects of urban warming, urban heat islands, and climate change. So while absolute ozone concentrations my not be very high at present, the trend in ozone is relatively important. Even without climate change or urban heat-island effects, the ozone trend is significant in Toronto. For example, Xu et al. (1995) filtered out the impacts of meteorology on ozone production to compute meteorologically-adjusted trends in daily maximum ozone mixing ratios. They found out that the trend was $2.5 \% / y$ ear for the GTA and $1.2 \% / \mathrm{yr}$ for the province of Ontario. If the effect of a growing urban heat island was added to that trend, the results could be much worse. In addition, the effects of future climate change could also become important once the environment had warmed by some

$3{ }^{\circ} \mathrm{C}$ or more, as some General Circulation Models (GCMs) predict. In this case, the region could benefit if some local cooling, such as via cool-city strategies, could be 
implemented to help offset the local, non-transport air quality implications of such warming.

In general, ozone-mixing ratios in the GTA are relatively low compared to other areas in North America. With some exceptions during bad air-quality episodes, the typical ozone mixing ratios in Toronto are in the order of 30 to $80 \mathrm{ppb}$. For example, from 1986 to 1993, the monthly mean maximum ozone in the GTA was the highest, 55 to $75 \mathrm{ppb}$, in July (Figure 2.1). Figure 2.2 shows the hourly average ozone-mixing ratios for 19861993, segregating summer and winter components. During the same period, the average number of days with ozone higher than $82 \mathrm{ppb}$ was about 15 per year, and the number of hours was about 70 per year (Environment Canada, 1996). In the GTA, ozone concentrations peaked at about 1500 LST (local standard time) while mixing-ratios greater than $82 \mathrm{ppb}$ could linger through 2100 LST (Figure 2.3). In some specific sites in the GTA, such as the CN Tower, high mixing-ratios could be experienced throughout day and night. The worst air quality years in Toronto have occurred since 1993. To capture this fact, the present study uses data from and simulates a time period in July 1995.

Even though the GTA is located at relatively higher latitude, it would still be beneficial to develop a mitigation strategy based on increased urban albedo and vegetative cover. On short- (meteorological) and long-term (climatological) scales, reducing urban air temperatures will provide health, biospheric, atmospheric, and economic benefits. For example, health problems and hospitalizations from heat stress or poor ozone air quality can be relieved if urban temperatures are reduced (Rosenfeld et al., 1998). In addition, reduction of air temperatures positively affects the thermal comfort as well as the health of the respiratory system, when temperature-related emission of precursors and production of atmospheric ozone are slowed down. In terms of biospheric benefits, the impacts of reduced heat stress and reduced formation of oxidants, such as ozone, can directly reduce damage to forests and sensitive crops. In terms of economic benefits, lowering urban air temperatures in summer lowers cooling bills without compromising thermal comfort in winter.

Changing surface properties in large urban areas and the ensuing local climatic change are expected to affect the air quality. The reduction of the urban heat-island effect, expressed as changes in mixing height, temperature, wind speed and direction, as well as possible changes in precipitation, will play a role in the chemical process. For example, increased reflectance of UV radiation will directly increase photochemical reaction rates. However, the reduced temperature will decrease emissions of VOCs from biogenic and evaporative sources. Furthermore, diminished energy consumption from the urban area will result in reduced emissions from power generation facilities.

The general trend of the expected meteorological changes mentioned above indicates an expected net reduction of ozone production rates in the vicinity and the near downwind region of the altered urban area. The specific local impact, however, is the result of a complex set of chemical reactions as well as the perturbed meteorological variables affecting these reactions. Some reactions may be slowed, and there may also be changes in reservoir species such as peroxyacetylnitrate (PAN). Each of these effects, however, may help export pollutants to form ozone at downwind locations. 
Ideally, modeling and estimating the effects of cool-city strategies on ozone air quality would be based on parallel runs of an air shed photochemical grid model. This type of investigation would be based on regional modeling similar to the type often performed in the U.S. for regulatory purposes by the EPA. But it appears that only limited photochemical modeling currently exists for the GTA that could be compatible with this approach. The following is a list of photochemical simulation available for the GTA:

- Model simulations performed on a region-wide scale using the Acid Deposition and Oxidants Model (ADOM). The detail for the input and output in the GTA is quite small, using only a few pixels for the city itself. Various working groups for Environment Canada performed these runs for episodes in 1988 as a basis to compare different $\mathrm{NOx} / \mathrm{VOCs}$ emission scenarios.

- Photochemical modeling on the regional scale performed using the Canadian Hemispheric and Regional Ozone NOx System (CHRONOS) model in semioperational mode to produce daily forecasts of ground-level ozone over eastern Canada. This effort has been going on over the past three summers. The model is still in the test phase and is not yet considered reliable for result publication or data transfer for use in this study.

- A detailed modeling task using MODELS3 (Byun and Ching, 1999) ordered by the Toronto Municipality. This project is currently underway and thus the data is still preliminary. Also, the resolution of the data is coarse for this type of study.

None of the above modeling setups met the needs of the current project as a basis for modeling air quality implications of urban albedo and forest modifications. The Canadian air quality modeling efforts described above were performed with modeling systems different from UAM, UAM-V, CAMx, CIT currently used at LBNL. Due to the limited resources for this study, instead of using a 3-D photochemical grid model, a mesoscale meteorological model in conjunction with a trajectory air quality model had to be used. Accordingly, all obtained emissions and air quality data were extracted along the trajectory for each time-space step before they could be used as input into a trajectory photochemical model.

\section{Method}

Ideally, a study of urban meteorology and heat islands would employ fine-resolution modeling to capture various small-scale phenomena and impacts, e.g., Taha (1998); Taha and Bornsetin (1999); Martilli (2001); Mestayer and Bornstein (1998). However, in this preliminary study, a more general meteorological (mesoscale) and trajectory air quality modeling approach is used in the study. This can be improved upon in the future.

Thus, the method employed in this preliminary modeling project involves using a mesoscale meteorological model to simulate selected episodes in the GTA. The resulting fourdimensional meteorological fields are then used to generate forward, backward, and other sets of trajectories to and from the GTA. Meteorological parameters are then extracted for each time step along each generated trajectory. These meteorological parameters and tra- 
jectory information are then used as input to a Lagrangian photochemical (trajectory) model, along with other emissions and related input, to assess the base air quality conditions, such as ozone-mixing ratios, along each trajectory. The entire process is then repeated to simulate the effects of cool-city scenarios and assess the resulting changes in meteorological and air quality conditions. In this study, the meteorological model used is the Pennsylvania State university/National Center for Atmospheric Research (PSU/NCAR) MM5 v3.4. The "meteorological" trajectory model is based on the Flextra model. Finally, the photochemical trajectory model is the trajectory version of the CIT air shed model. These models are described in the following sections.

\subsection{Models}

This section briefly describes the meteorological, trajectory, and photochemical models used in this study.

\subsubsection{Mesoscale Meteorological Model (PSU/NCAR MM5)}

The meteorological modeling in this study was performed with the most recent version of the PSU/NCAR MM5 (version 3.4). The MM5 is a state-of-science, non-hydrostatic, three-dimensional (Eulerian) primitive equation grid model that is gaining wide acceptance in the scientific and regulatory communities in the U.S. The MM5 has been used by researchers, meteorologists, and scientists in numerous applications including: weather forecasting; air pollution forecasting; frontogenesis, thunderstorms; hurricanes; urbanscale phenomena, such as urban heat islands and related convective circulations; land-sea breeze circulations; and topographically-induced flows. Though utilized worldwide, the MM5 is mostly used in the United States in both research and forecast/operational modes.

The modeling system is comprised of several components collectively referred to as the MM5. The model has been under continuous development since the late 70s and is based on an original formulation (Anthes and Warner, 1978; Anthes et al., 1987) that was developed and maintained by the Pennsylvania State University in collaboration with the National Center for Atmospheric Research. More recently, the model has undergone significant changes and improvements (Dudhia, 1993; Grell et al., 1994).

The MM5 can be run on a variety of Unix-variants platforms, ranging from supercomputers to workstations to high-speed PCs in standalone or parallel modes, such as Beowulf clusters. In this particular modeling study, the MM5 was run on a quadprocessor SUN workstation running the Solaris 8 operating system. The model is relatively computing-intensive, especially if fine grids and multi-level nests are used. The model includes the following features: one- or two-way multi-level nesting capabilities; a "moving-nest" option that can track weather phenomena of interest; Four-Dimensional Data Assimilation (FDDA); and a variety of physical options and parameterizations.

The model is based on the prognostic equations for momentum, heat, water vapor, and perturbation pressure. The model equations are solved using finite-differencing schemes, such as leapfrog and semi-implicit. For this purpose, the model staggers the variables (velocity vs. scalars) on an Arakawa-B grid. The model features various options for 
physics, explicit moisture treatment, cumulus and convective parameterization, boundary-layer formulations, and an ability to incorporate a land surface model (OSU or PX). The model is also capable of incorporating observational data or analyses (FDDA) during model equation integration (Seaman et al., 1995).

As will be explained later in this report, the initial and boundary meteorological conditions used by the MM5 can be obtained from archived three-dimensional analyses at the National Center for Atmospheric Research (NCAR). These are then mapped onto the coarse domain of the simulation during the initial pre-processing steps in the MM5 modeling system. The lateral boundary conditions are then digested in the model using a relaxation technique applied to outermost five rows and columns of the mother domain. The model can map information in various projection systems, such as Mercator, Lambert Conformal, and Polar stereographic.

The input to the MM5 includes: gridded surface characterization; topography; land-water boundaries; land-use and land-cover; sea-surface temperature; initial and boundary meteorological conditions, analyzed on pressure levels; and observations, when using observational nudging FDDA. The output from the MM5 is a complete four-dimensional description of the state of the atmosphere and the ground, if desired. Typical forecast variables include temperature, winds, pressure, water vapor mixing ratios, cloud/rain, water and ice, mixing height, and a host of other derivatives based on or extracted from these variables.

\subsubsection{Meteorological Trajectory Model}

In order to prepare the needed input to the CIT trajectory model, the output from the PSU/NCAR MM5 was used to drive a meteorological trajectory model as an intermediate step. The purpose of this intermediate step was to identify the trajectories by specifying the air parcel location $(\mathrm{x}, \mathrm{y}, \mathrm{z}, \mathrm{t})$ at each step, extracting the associated meteorological fields along the trajectories, and use them as input to the CIT model. The Flextra model, used here, is a Lagrangian trajectory model originally developed for use with the models of the European Center for Medium-Range Weather Forecasts (ECMWF) (Stohl et al., 1997; Stohl, 1999; Wotawa and Stohl, 2000). In this study, a special version was applied to the MM5 model. The MM5 v3.4 hourly output was first converted into MM5 v2 and then fed into the trajectory model.

In simple terms, a trajectory is defined as a succession of points that are obtained from computing the position vector at given time steps. Thus:

$$
\mathrm{P}(\mathrm{t})=\mathrm{P}(\mathrm{t}-1)+1 / 2 \Delta \mathrm{t}[\mathrm{V}(\mathrm{t}-1)+\mathrm{V}(\mathrm{t})]
$$

where $\mathrm{P}$ and $\mathrm{V}$ are the position and velocity vectors, respectively; $\mathrm{t}$ and $\mathrm{t}-1$ are time intervals and $\Delta t$ is time step. In this application, the minimum time step is 1 second. However, the model uses a flexible time step determined by the CFL (Courant-Friedrichs-Lewy) stability criterion, such that $\mathrm{V} \Delta \mathrm{t} / \Delta \mathrm{x}<<1$. Equation (1) is referred to as Petterssen's scheme (Petterssen, 1940), and is solved iteratively. Convergence is reached when the difference in trajectory position between two iterations is smaller than 0.0001 grid units. 
The Flextra model allows for computation of different types of trajectories including: three-dimensional, iso-eta, mixing-layer, isentropic, and isobaric trajectories. The results presented here were obtained from running the model in back-trajectory mode, using isobaric trajectories at $1000-\mathrm{mb}$ pressure level. Then, at each time step, the model calculated the $\sigma_{\mathrm{p}}$ level associated with $1000-\mathrm{mb}$ pressure to follow that level for the trajectory advection. The model had the capability to handle the various nests from the MM5 model, as it could import all the meteorological fields according to nest location and resolution and handle the trajectory exit from one domain to another accordingly. Finally, a combination of tools and codes were put together to extract the meteorological parameters along the trajectory for each time step and location and prepare the input to the CIT photochemical trajectory model.

\subsubsection{Photochemical Trajectory Model}

The complex and interactive nature of the process involved in assessing the net effect of large-scale albedo changes on the air quality necessitated the use of numerical photochemical modeling. As mentioned earlier, the preferred tool for such assessments would have normally been a regional three-dimensional photochemical airshed model. However, the objective of this study was to perform only a limited, short-term air quality analysis whereby the use of a 3-D model would not be possible. As a result, a photochemical trajectory model was used to conduct this study.

The CIT photochemical trajectory model was used in this study to perform multiple runs and to analyze the sensitivity of the output to variations in certain input parameters such as emissions and meteorological conditions. The model was also used to assess the changes in the air quality within urban areas, such as Toronto, as well as their downwind following the implementation of cool-city strategies.

Within the column of the trajectory photochemical model, mixing ratios of species are computed from equation 2:

$$
\partial \mathrm{C}_{\mathrm{i}} / \partial \mathrm{t}=\partial / \partial \mathrm{z}\left[\mathrm{K}_{\mathrm{z}} \partial \mathrm{C}_{\mathrm{i}} / \partial \mathrm{z}\right]+\mathrm{R}_{\mathrm{i}}+\mathrm{S}_{\mathrm{i}}
$$

where $\mathrm{C}$ is concentration of species $\mathrm{i}, \mathrm{t}$ is time, $\mathrm{z}$ is height, $\mathrm{K}_{\mathrm{z}}$ is the vertical eddy diffusivity, $\mathrm{R}$ is production or scavenging by chemical reaction, and $\mathrm{S}$ is source/sink term for species $i$. The equation is subject to initial conditions or concentrations, as well as surface and top boundary conditions as:

$$
\begin{aligned}
& \mathrm{V}_{\mathrm{d}} \mathrm{C}_{\mathrm{i}}-\mathrm{K}_{\mathrm{z}} \partial \mathrm{C}_{\mathrm{i}} / \partial \mathrm{z}=\left.\mathrm{E}_{\mathrm{i}}\right|_{\mathrm{z}=0,}, \\
& \mathrm{~K}_{\mathrm{z}} \partial \mathrm{C}_{\mathrm{i}} / \partial \mathrm{z}=\left.0\right|_{\mathrm{z}=\mathrm{Ztop}},
\end{aligned}
$$

where $V_{d}$ is deposition velocity, and $E_{i}$ is emissions of species $i$ at the surface. The model does not account for horizontal diffusion within the column. Lateral inflow and outflow is assumed zero. The model equations are integrated using finite-difference methods. 
The CIT air quality trajectory version model uses the SAPRC $99^{3}$ chemistry solver. SAPRC99 is a widely used solver implemented in many three-dimensional models. It uses a lumping scheme based on weighting chemical reactivity, and also enables input of specific compounds. A full description of the chemical mechanism can be found in Carter et al. (1997). The model utilizes a vertically stacked column of fixed-altitude cells, five vertical layers, coupled by parameterized turbulent mixing. Emissions occur in any cell and each cell is well mixed. A no-flux boundary condition is applied at the top of the column (equation 4), which is set to be above the mixing height. The model also implements the hybrid algorithm numerical integration (Young and Boris, 1977). This model has been described in detail by Reynolds et al. (1973); McRae and Russell (1981); McRae and Seinfeld (1982); McRae and Seinfeld (1983); and Bergin et al. (1999).

At LBNL, certain aspects of the model were modified to create a more appropriate tool for use in this modeling study. For example, in order to better simulate and quantify the response to 'cool city' changes, the model was modified to calculate actinic flux. The integration scheme was modified so as to recalculate the actinic flux for each calculated cell elevation; thus, improving the accuracy of the model in that regard. The previous version used less accurate lookup tables for this purpose. In addition, the new calculation would be sensitive to wavelength-specific surface reflectivity. The model previously used clear-skies actinic flux approximated by a radiative transfer model as a function of wavelength and zenith angle, as described by Peterson (1976). This data could then be scaled for cloud cover and/or aerosol column if better specific data were available.

In order to assess the impact of variations in actinic flux resulting from localized changes in surface reflectance, the actinic flux routines from the Tropospheric Ultraviolet Visible (TUV) model were incorporated in the model (Madronich and Flocke, 1998). This incorporation allowed for modeling local actinic flux according to spectral surface reflectance, wavelength, zenith angle, cloud cover and latitude, as well as enabling the replacement of the atmospheric aerosol profile if specific data were available for the modeled conditions. As a result, the model earned an increased sensitivity to changes in urban and ground albedo. It is noteworthy that the changes described above made the model predict impacts of cool-city strategies more conservatively.

\subsection{Input Data}

The input data types used in this modeling study are discussed next. These include meteorological data, surface characterization, land-use distribution, emissions, and ambient air-quality data.

\subsubsection{Meteorological Data}

The initial- and boundary-condition data needed to run the model were obtained from the US NCAR/NCEP Reanalysis Project (NNRP) for the episode of interest in this study (July 10 through 17, 1995). The NNRP is a global analysis with data available every six hours and archived on a $2.5^{\circ} \times 2.5^{\circ}$ grid of latitude and longitude. The gridded data are in

\footnotetext{
${ }^{3}$ Statewide Air Pollution Research Center Model.
} 
GRIB format and contains an archive of analyses for all meteorological parameters on pressure levels. NNRP also contains skin sea surface temperature (SST) for major water bodies. Although the difference is perhaps not so relevant for this study, NNRP does not contain real SST as other data sources might contain.

The period selected for simulation in this study coincides broadly with the timing of the Chicago heat wave period of 1995. There existed many reasons for selecting this period for this study. The main reasons were that 1) the emission data we obtained in this study were specific to the July 1995 episode; 2) this episode is one (among others) that Environment Canada and affiliates use in photochemical modeling; and 3) an argument can be made that it is sometimes useful to simulate the meteorological effects of heat-island control under relatively extreme conditions such as those encountered during this episode.

The initial and boundary conditions were selected to coincide with the sub-episodes discussed in section 3.3.2. While the meteorological analyses were quite extensive, they were typically gridded at low resolutions $(\sim 250 \mathrm{~km})$ and thus might not have captured atmospheric phenomena of fine scale or local detail unless additional observational data were assimilated in the model run. Due to the limited scope and resources for this study, instead of assimilating observational data nudging, the option of analysis nudging was pursued. The lateral boundary conditions were those of time and inflow-outflow relaxation. The top boundary conditions were those of an absorbing layer. The surface boundary conditions were those for prognostic surface temperature and SST.

\subsubsection{Surface Characterization}

Historically, our simulations of the effects of cool-cities have relied on fine-resolution land-use information to develop both base line and modified-case scenarios. Base line conditions represent the surface properties in a region as it currently is, whereas the modified-scenario conditions represent the updated surface characteristics of the region after the "implementation" of heat-island control strategies, such as increased surface albedo and urban reforestation. The land-use information used in the past is typically based on the US Geological Survey (USGS) Land-Use/Land-Cover (LULC) data for the coarser-resolution domains of the meteorological simulations. For the finer-resolution domains, and around urban areas of interest, previous modeling work has relied on local data and project-specific information, such as those obtained from low-altitude, aircraftbased orthophotography or region-specific field campaigns. Examples of orthophotography-based characterizations include the flyovers in Sacramento, CA and Salt Lake City, UT (Akbari et al., 2002).

Taha (1997a, b; 1996) and Taha et al. $(2000 ; 2001)$ used the above approach in modeling Los Angeles, California; Houston, Texas; Sacramento, California; Baton Rouge, Louisiana; and Salt Lake City, Utah. In the past, the typical resolution of such data ranged from $30 \mathrm{~cm}$ in aerial orthophotos to $200 \mathrm{~m}$ in USGS LULC and $1 \mathrm{~km}$ in LULC for Houston and Los Angeles. When appropriate, coarser-remotely-sensed data, such as 
$\mathrm{AVHRR}^{4}$ and GOES ${ }^{5}$, were used. Of course, the data would typically be geo-referenced, such as in Universal Transverse Mercator (UTM) system or other map projections.

Because of limited resources, only default land-use and land-cover information, such as that typically used in MM5 modeling, was used in this modeling effort. While some of it could be outdated, such data would be typically based on the USGS LULC classification system and could have a fine resolution as low as 30 seconds. The use of additional and higher-quality data could improve the accuracy of the results in future studies.

In this study, as in the previous UHI modeling work, the land-use information was converted into a set of gridded thermophysical properties such as albedo, thermal inertia, emissivity, soil moisture content, roughness length, specific heat, soil type and so on. Thus, the surface characterization served as a basis for computing the values of such parameters that were needed to specify the lower boundary (surface) at each grid in the meteorological and air-quality models. In addition, some parameters were computed and re-specified for each modification scenario, such as changes in albedo and urban vegetation fraction. These changes were then re-mapped onto the model's grid accordingly. In this study, the twenty-four-category MM5 USGS LULC data was used as a basis for characterizing the surface in the modeling domain. These LULCs are listed in section 3.3.3.

\subsubsection{Base-Case Surface Scenario}

Two types of data are typically needed for this kind of analysis. The first is regionspecific surface characterization information, such as land-use and land-cover. The second is surface-type classification, such as distribution of roofs, pavements, and other impervious areas. The first dataset is used to establish a region-specific base-line meteorology, for example, specific to the GTA. The second dataset is used in developing regionspecific scenarios for UHI control in the urban areas of interest.

Figure 3.1 shows the meteorological modeling domain selected for this study. The outer and inner domains have grid resolutions of 8 and $2 \mathrm{~km}$, respectively. Figures 3.2 and 3.3 show the current default USGS Land-Use/Land-Cover information used in the meteorological simulations to date. Again, with more recent and finer-resolution data, this simulation could produce more reliable results. In these figures, the land-use category denoted with red is urban. Toronto, Hamilton, St. Catharines, and Buffalo are easily identifiable in Figure 3.3. Based on the dominant LULC, thermophysical properties are assigned internally to each of grid cell in the domains.

\subsubsection{Cool-City Surface Scenario}

Since there was a lack of fine-resolution LULC data for Toronto, earlier modeling methodologies were followed to develop a cool-city scenario for Toronto. Therefore, the UHIcontrol assumptions would be based on certain levels of modifications per surface type

\footnotetext{
${ }^{4}$ Advanced Very High Resolution Radiometer

${ }^{5}$ Geosynchronous Operational Environmental Sattelite
} 
used for other North American regions (Taha, 1996; 1997a, b; Taha et al., 2000; 2001). The bases for such modifications were then detailed in the following tables where Case 1 and Case 2 represented a moderate and a higher level of modifications, respectively. For albedo, the assumptions were:

Table 1. Base \& Cool-City Albedo Values per Surface Type after Aging, Weathering, \& Soiling.

\begin{tabular}{|l|l|l|l|}
\hline \multirow{2}{*}{ Surface Type } & \multicolumn{2}{|l|}{ Albedo } & Case 2 \\
\cline { 2 - 4 } & Base & Case 1 & 0.45 \\
\hline Residential Roof & 0.15 & 0.25 & 0.60 \\
\hline Commercial/Industrial Roof & 0.20 & 0.40 & 0.35 \\
\hline Road & 0.10 & 0.25 & 0.35 \\
\hline Sidewalk & 0.15 & 0.25 & 0.35 \\
\hline Parking Lot & 0.10 & 0.25 & \\
\hline
\end{tabular}

Surface-type albedo increases in Table 1 were averaged on the 200-m USGS LULC grid to obtain the resulting increases in land-use type albedo organized in Table 2:

Table 2: Base \& Cool-City Albedo Values per Land-Use Type

\begin{tabular}{|l|l|l|}
\hline \multirow{2}{*}{$\begin{array}{l}\text { USGS LULC-m Grid } \\
\text { 200-| }\end{array}$} & Albedo increase per 200-m Grid \\
\cline { 2 - 3 } & Case 1 & Case 2 \\
\hline Residential & 0.053 & 0.118 \\
\hline Commercial & 0.104 & 0.175 \\
\hline Industrial & 0.083 & 0.145 \\
\hline Transport/Communication & 0.143 & 0.237 \\
\hline Industrial/Commercial & 0.094 & 0.162 \\
\hline Mixed Urban/Built-Up & 0.074 & 0.136 \\
\hline Other Built-Up & 0.086 & 0.155 \\
\hline
\end{tabular}

Once applied to U.S. urban areas, such as Los Angeles, Sacramento, Salt Lake City, Baton Rouge, Houston, and Chicago, these assumptions resulted in an average increase of 0.07 and 0.13 in albedo for Case 1 and Case 2, respectively. Of course, these results were obtained after averaging the $200-\mathrm{m}$ values onto the mesoscale model grid. Obviously, these averages were computed over the modified urban cells only. In this study, the averages from Case 2 were used in the simulations of the cool-city surface scenario for Toronto. Table 3 shows the assumptions for vegetation cover increases: 
Table 3. Vegetation-Cover Increase Scenarios \& Assumptions

\begin{tabular}{|l|c|c|c|c|}
\hline \multirow{2}{*}{ USGS LULC } & \multicolumn{2}{|c|}{$\begin{array}{c}\text { Vegetation Increase (e.g., \# of } \\
\text { additional trees per unit) }\end{array}$} & \multicolumn{2}{c|}{\begin{tabular}{c} 
Percent Increase per 200-m Grid \\
\cline { 2 - 5 }
\end{tabular}} \\
\cline { 2 - 5 } & Case 1 & Case 2 & Case 1 & Case 2 \\
\hline Residential & 2 & 4 & $9 \%$ & $18 \%$ \\
\hline Commercial & 2 & 4 & $9 \%$ & $18 \%$ \\
\hline Industrial & 3 & 6 & $4 \%$ & $8 \%$ \\
\hline Transport/Communication & 0 & 0 & $2 \%$ & $4 \%$ \\
\hline Industrial/Commercial & 2 & 4 & $6 \%$ & $12 \%$ \\
\hline Mixed Urban/Built-Up & 2 & 4 & $5.5 \%$ & $11 \%$ \\
\hline Other Built-Up & 2 & 4 & $5.5 \%$ & $11 \%$ \\
\hline
\end{tabular}

Table 3 provides the number of additional trees per unit (a "unit" can be a residence, a commercial building, an office building, and so on) and the percent increase per USGS grid after averaging back onto 200-m USGS LULC. Based on this table, it was assumed that the increase in vegetation at the meteorological model grid was $10 \%$. As a qualitative indicator, this change in vegetative cover was crudely converted into the number of additional trees needed to achieve the effect. Assuming each tree covered an area of $50 \mathrm{~m}^{2}$ at maturity (this is an average small-sized tree), the number of additional trees would be around 920,000 in both the Toronto and Hamilton areas. This increase would correspond to an additional 20 trees per hectare of urban land.

Surface roughness in cool-city scenario changes only slightly in urban grids where vegetation is increased, since building and vegetation roughness lengths are about equal. In addition, the displacement height is not changed as it is assumed that only sparse vegetation is being added. Another important note here is that the additional vegetation introduced in the area is assumed to be of the low- or zero-emitting types. Thus isoprene and monoteropene emissions along the trajectories do not change as a result of additional vegetation. However, biogenic emissions from existing vegetation along the trajectories change as a function of meteorological conditions, such as temperature as discussed in section 3.2.3. Note that increasing any of the thermophsical parameters, such as albedo, thermal inertia, roughness length, and soil moisture, can cause both direct and indirect decreases and increases in the air temperature of the affected areas.

The cool-city scenario being discussed here corresponds to levels of modifications given by Case 2 in Tables 1-3. In terms of input to MM5 for simulating cool-city scenario in the GTA, the changes translate into the following:

- The albedo over urban grids is increased from a base-case value of 0.15 to a new value of 0.28 .

- Soil moisture content is increased from a base-case value of 0.10 to a new value of 0.15 .

- Roughness length is increased from a value of $50 \mathrm{~cm}$ to a new value of $60 \mathrm{~cm}$. 
- Thermal inertia is increased in value from 3 to 4 cal. $\mathrm{cm}^{-2} \mathrm{~K}^{-1} \mathrm{~s}^{-0.5}$.

In the MM5 land-use processing system, the above modifications affect only those grid cells that represent the core of urban Toronto. In Figure 3.3, the grid cells identified as "urban" do not include the entire Greater Toronto Area that stretches from Oshawa to Hamilton. Therefore, these modifications affect a total area of only about $420 \mathrm{~km}^{2}$ in the GTA and about $40 \mathrm{~km}^{2}$ in the Hamilton area. This is relatively a very small area to modify. By comparison, the modifiable area in Los Angeles is well above $7,000 \mathrm{~km}^{2}$, for example. Thus, one would expect smaller effects here. In addition, the results should be viewed as conservative, even though the increases in albedo and vegetation (in Case 2, Tables 1-3) may seem large. Two reasons may explain this observation: 1) the total modified area is relatively very small (some $460 \mathrm{~km}^{2}$ ) compared to modifications in other regions; and 2) the modified areas in this study are smaller than the actual total urbanized area in the Hamilton-Toronto-Oshawa corridor.

As described above, the overall modification of albedo in an urban setting is directly proportional to the increase in use of high-reflectance surfaces as well as to the fraction of the surfaces changed. The same applies to spectral reflectance in the UV waveband, which influences actinic flux and affects photochemical reaction rates. While most reflective materials exhibit the same reflectivity as dark materials do in the UV range, some reflective materials may reflect a lot more in the UV range than dark materials do. Thus, careful selection of high-albedo materials may help reduce the negative air quality consequences related to increased reflectance of UV radiation.

Several available materials may be used as "cool surfaces." In addition, two simple measures may be used to reduce dark-colored surfaces: 1) replace dark surface with any light-colored surface, or 2) use light-colored paint to cover the dark surfaces. Most surfaces that are visibly light-colored are also more reflective than dark-colored surfaces. In some cases, however, appearances can be deceptive. Many commercially available white shingles, for example, are fairly low-level reflectors $(\sim 25 \%)$. Coating black acrylic paint with a thin low- $\varepsilon$ polymer film, on the other hand, can increase the overall reflectance from $5 \%$ to $33 \%$ by increasing reflectance in the near infrared (Berdahl and Bretz, 1997). Similar effects have been demonstrated using green and red coatings with added pigments. These pigments are all highly reflective in the near infrared, producing coatings with overall reflectance of $50 \%$. White coating membranes on smooth surfaces have an overall reflectance of $80 \%$. However, the use of such membranes for roofing currently involves the use of gravel or other ballast, which reduces the reflectance.

\subsubsection{Emissions and Air Quality (Initial Conditions) Data}

The emissions used for the purpose of this study were based on the Ontario July 1995 Community Multi-Scale Air Quality (CMAQ) model database. The dataset included detailed lumped emissions modeled according to the RADM2 photochemical mechanism system. The Regional Acid Deposition Model (RADM2) mechanism is a lumped species type that uses a reactivity-based weighting scheme to adjust for lumping (Stockwell et al., 1990; 1994). The photochemical model (CIT) used in this study utilized the SAPRC99 lumping scheme. The SAPRC-99 mechanism, which is an update of SAPRC-97 
(Carter et al., 1997) employ the lumped surrogate species approach, but offer the capability to incorporate semi-explicit chemistry of selected organics. The data were mapped out to the SAPRC-99 scheme using lumping information.

Due to the lack of finer resolution emissions data for the region, the approach used in preparing emission boundary conditions in this study is as follows. Based on the abovementioned coarse data set, coupled with a summation of daily mean total emissions in each census region, an assessment was made as to the variability of emissions in the Toronto region. This variability was then used to vary the emissions on a local scale. These data, together with meteorological input produced using the MM5 model, were then used as input in the CIT trajectory photochemical model.

Biogenic emissions of isoprene and monoterpenes from plants fluctuate on daily and longer time scales due to various factors. The main factors for these fluctuations are the physiological responses of plants to varying temperature, humidity, light, and $\mathrm{CO}_{2}$ mixing ratios. The variations due to changes in urban surface properties will be mainly reflected in temperature changes. Expressed as fluctuations in isoprene emissions and excluding seasonal variation, the short-term response of vegetation to temperature is modeled as (Guenther et al., 1999):

$$
\gamma_{T}=\frac{E_{o p t} C_{T 2} \exp \left(C_{T_{1}} x\right)}{C_{T 2}-C_{T 1}\left\{1-\exp \left(C_{T_{1}} x\right)\right\}},
$$

where $\mathrm{x}=\left[\left(1 / \mathrm{T}_{\text {opt }}\right)-(1 / \mathrm{T})\right] / \mathrm{R}, \mathrm{T}$ is current leaf temperature, $\mathrm{R}$ is a constant $(\mathrm{R}=$ $0.00831), \mathrm{T}_{\text {opt }}$ is the temperature at which $\mathrm{E}_{\text {opt }}$ occurs, $\mathrm{E}_{\text {opt }}$ is the maximum normalized emission capacity, $\mathrm{C}_{\mathrm{T} 1}\left(95 \mathrm{KJ} \mathrm{mol}^{-1}\right)$ and $\mathrm{C}_{\mathrm{T} 2}\left(230 \mathrm{KJ} \mathrm{mol}^{-1}\right)$ are empirical coefficients representing energy of activation and deactivation, respectively. $\mathrm{C}_{\mathrm{T} 1}$ and $\mathrm{C}_{\mathrm{T} 2}$ were obtained from studies of emission rates and are considered to be largely independent of vegetation species. Equations 6 and 7 estimate the influence of past temperatures:

$$
\begin{aligned}
& \mathrm{E}_{\mathrm{opt}}=1.9 \cdot \exp \left\{0.125\left(\mathrm{~T}_{\mathrm{d}}-301\right)\right\}, \\
& \mathrm{T}_{\mathrm{opt}}=312.5+0.5\left(\mathrm{~T}_{\mathrm{d}}-301\right)
\end{aligned}
$$

where $T_{d}$ is mean temperature $(K)$ of the past 15 days. The diurnal temperature variation of the biogenic emission of monoterpene is modeled by equation 8 :

$$
\mathrm{M}=\mathrm{M}_{\mathrm{S}} \cdot \exp \left[\beta\left(\mathrm{T}-\mathrm{T}_{\mathrm{S}}\right)\right]
$$

where $M$ is monoterpenes emission rate at temperature $T(K), M_{S}$ is monoterpenes emission rate at a standard temperature $\mathrm{T}_{\mathrm{S}}(\mathrm{K})$, and $\beta\left(\mathrm{K}^{-1}\right)$ is an empirical coefficient, typically $0.09 \pm 0.025 \mathrm{~K}^{-1}$. In this study, the above corrections were needed to estimate the temperature-dependent variation in biogenic emissions, and other changes caused by cool-city scenarios, along the trajectories.

The issue of reduction in emissions is complex, as a consequence of diminished energy consumption because of direct and indirect cooling of buildings and urban areas. Esti- 
mates of this effect are highly uncertain, as power stations could be located within the same airshed, upwind or downwind. In addition, structural factors, such as effective stack height, and operational factors, such as the response time of the power generation system to reduced consumption and peak power demands, further complicate the estimates. Although reduced energy consumption could significantly reduce emissions from power plants (estimated at around 10 metric tons per day or more), the reduction in emissions will have a small influence on ozone mixing ratios (Taha et al., 1998). For this reason, the impact of reduced energy consumption on ozone mixing ratio has been ignored in this study.

Initial conditions (mixing ratios) for initializing the photochemical trajectory model were based on observational data from the rural area of Hastings, Ontario. Hastings is a flatland site about $150 \mathrm{~km}$ northeast of Toronto. The data were compiled from the Southern Ontario Oxidant Study (SONTOS) in Hastings (Hastie et al., 1996). The mixing ratios from Hastings were used for capturing representative rural conditions in Canada, even if trajectories start from other locations. Initial conditions were observed mean concentrations for summer. Concentrations of individual hydrocarbons were back calculated from the observed individual compounds as propylene equivalent ppb carbon (Seinfeld and Pandis, 1998). Two sets of initial conditions were used in this study, $1 \mathrm{x}$ and $2 \mathrm{x}$ (doubled). For $\mathrm{NO}$ and $\mathrm{NO}_{2}$ the corresponding initial mixing ratios were 3.7 and $0.4 \mathrm{ppb}$, respectively. The doubled initial mixing ratios for non-methane hydrocarbons (NMHC) concentrations are shown in Figure 3.4.

The data from Hastings were used only in developing initial conditions (air quality) for the trajectory simulations, not in emissions or other calculations. The purpose was to initialize the trajectory model with some regional average profiles. The effect of initial conditions is typically negligible after $48 \mathrm{~h}$ of simulations (length of the trajectories in this study is $72 \mathrm{~h}$ ). The effect on the final simulated ozone mixing ratios in the Toronto area was tested with $1 \mathrm{x}$ and $2 \mathrm{x}$ initial concentrations and was found to be small. Also, as will be discussed later in this report, the potential impacts of heat-island control were basically unchanged (unaffected by doubling the initial concentrations).

\subsection{Configuration}

This section provides an overview of the model configuration and setup adopted in this study.

\subsubsection{Domains}

As mentioned earlier, three models were used in this initial effort: one Eulerian 3-D mesoscale meteorological model and two Lagrangian trajectory models. The computational domains for the latter two were two-dimensional $(\mathrm{x}-\mathrm{z})$ and followed trajectories based on the wind fields generated in the meteorological model.

Initially, a domain setup was selected to encompass the entire North and Central American regions as well as surrounding oceans. This setup consisted of 4 nested domains at grid resolutions of $108,36,12$, and $4 \mathrm{~km}$. The intention was to capture all domains that 
might have been used by various Canadian agencies. However, to modify some $460 \mathrm{~km}^{2}$, in surface albedo and vegetative fraction, such a setup was unnecessarily large (see section 3.2.2). Hence, a smaller domain combination had to be selected. This smaller setup, shown in Figure 3.1, was used in developing the air quality modeling trajectories and analyses. These domains are described further in section 3.3.3.

\subsubsection{Episodes}

\subsubsection{Modeling for Energy Calculations}

For the purpose of energy modeling and assessing the indirect effects of cool-city strategies, two episodes were selected: one to represent winter conditions (January 15 through 17, 1995) and another to represent summer conditions (July 15-17, 1995). Ideally, at least one episode per month would have been used for this modeling purpose. These periods in the year 1995 were selected solely because the emissions data are for that year (see below).

\subsubsection{Modeling for Meteorological/Air Quality Simulations}

The July 10-17 episode was selected to model the potential ozone air-quality implications of cool-city scenarios in the GTA. The reasons for this selection were: 1) the available corresponding air quality and emissions data that were needed in this project, and 2) the episode was representative of summer ozone-mixing ratios, though not the worst conditions. The highest concentrations during the July 1995 episode were in the range of 90$110 \mathrm{ppb}$ in the lakes region, whereas they were only about $90 \mathrm{ppb}$ in Toronto. By comparison, mixing ratios higher than 140 ppb ozone were observed on July 8, 1988 in the region.

In general, observational data suggested that most ozone exceedances in the GTA and WQC occurred during the month of July. However, even though this study appears to be episodic in nature, the simulations were intended to show the potential benefits of heatisland control without too much emphasis on the episode itself. In the Results sections, this episode would be described in two parts: July 10 through 14 (referred to as Case 039) and July 15 through 17 (referred to as Case 035).

\subsubsection{Model Setups and Options}

The PSU/NCAR MM5 (v3.4) was used to assess the potential impacts of cool-city strategies, such as UHI on meteorological conditions in the GTA. The simulations were run with two domains (Figure 3.1). The outer (mother) domain was run with a resolution of 8 $\mathrm{km}$ and dimensions of $86 \times 98$ grids (about $527000 \mathrm{~km}^{2}$ ). The inner (nest) domain was run with a resolution of $2 \mathrm{~km}$ and dimensions of $101 \times 121$ grids (about $48000 \mathrm{~km}^{2}$ ). The Lambert Conformal map projection system was used to handle the terrain, land-use, and topography (5 and 2 minute) data. The USGS 24-category LULC data were used as a basis for surface characterization. The USGS twenty-four categories were: 1) urban and built-up, 2) dry land cropland/pasture, 3) irrigated cropland/pasture, 4) mixed dryland/irrigated cropland/pasture, 5) cropland/grassland, 6) cropland/woodland, 7) grassland, 8) shrub land, 9) mixed shrub land/grassland, 10) savanna, 11) deciduous broadleaf 
forest, 12) deciduous needle leaf forest, 13) evergreen broadleaf forest, 14) evergreen needle leaf forest, 15) mixed forest, 16) water bodies, 17) herbaceous wetland, 18) wooded wetland, 19) barren land, 20) herbaceous tundra, 21) wooded tundra, 22) mixed tundra, 23) bare ground tundra, and 24) snow or ice cover.

In the vertical direction, the model was run with 21 atmospheric levels and six soil levels. The model top was set at $100 \mathrm{mb}$, a typical setup for MM5 model simulations. The inner and outer domains were not run simultaneously in this study. The simulations were run by "downscaling" the output from the coarse domain (via NESTDOWN) to the finer domain. The coarse domain was run with the FDDA option (analysis nudging) for both upper air and the surface variables. The analysis nudging was applied to temperature, water vapor mixing ration, and the wind field. Two explicit moisture schemes were used. Results presented in this report are based on the stable precipitation option only. No cumulus parameterization schemes were selected. These simulations used a multi-layer soil model, and the time step for the coarse domain integration was 15 seconds.

The inner domain was run after the output from the coarse domain was processed. The inner domain's resolution was $2 \mathrm{~km}$ and had the same number of vertical levels as the mother domain. However, to capture the effects of urban heat island and perturbations caused by cool-city scenarios, no FDDA was used in the inner domain. The same coarse domain physics and moisture scheme were also used in the inner domain. While other options were also similar to those of the coarse domain, the time step for inner domain model integration was 7.5 seconds. In addition, the MRF PBL (medium range forecast model) option was employed in both domains.

The Lambert conformal projection system was used in preparing the terrain and land-use information and in running the MM5 forecast module. No expanded grid was used and the 24-category USGS LULC was employed and modified in the simulations to date. In this initial modeling work, no land-surface model option was used. Since the assumed land physical property changes occurred in urbanized areas, it was not necessary to run this option.

\section{Results}

In this section, the modeling results are presented for base and modified scenarios. The results are discussed in terms of meteorological aspects and air quality conditions.

\subsection{Episodic Results}

\subsubsection{Meteorological Aspects}

This section describes the general outcome of the mesoscale meteorological modeling effort. As mentioned earlier, the July episode is discussed in two parts here. While the simulations appear to be episodic in nature, no attempt is made to reproduce the observations exactly. In addition, no model performance evaluation is performed on this particular simulation. For this limited-scope study, the focus is on the relative, not absolute, impacts of changes in surface properties. 
In addition to different air quality conditions, these two sub-episodes also differ in the general wind flow pattern as simulated by the MM5. In the following discussion and figures, only the inner domain (fine mesh) and a few selected hours during the episodes are presented. Although UHI control affects many meteorological parameters, such as wind, mixing, boundary-layer height, and moisture, the discussion focuses mostly on air temperature as the variable of interest. In the following qualitative analysis of the temperature field, the UHI is reported at its maximum location during each discussed hour.

\section{Case 039 (July 10-14 Sub-Episode)}

Starting with Figure 4.1, two-dimensional plots of air temperature and wind vector fields are shown at roughly $40 \mathrm{~m}$ above ground level. The figures show various urban areas in the inner domain, such as major areas of Oshawa, Toronto, Hamilton, St. Catharines, and Buffalo. The UHIs associated with these cities can be seen, more or less consistently, throughout the modeling episode. This section, however, discusses the UHI that is associated with Toronto only.

To begin, one may ask what constitutes an ideal reference point for UHI estimation. The answer is to choose an undeveloped area that is upwind of the urban region. However, the selection of the reference point or area is subjective to a certain extent, especially if meteorological conditions change and the wind flow reverses often. In the following figures and discussion, the reference area is qualitatively defined as the envelope surrounding the GTA.

In general the simulation suggests both daytime and nighttime heat islands. However, the daytime heat islands are generally larger and more persistent than those of the nighttime. In addition, the UHI seems to be better developed when the overland flow into Toronto is westerly, southwesterly, or northerly. The UHI is smaller or non-existent with southeasterly or easterly flows.

Figure 4.1 shows the temperature and wind fields for the inner domain, with grid resolution of $2 \mathrm{~km}$, at $0000 \mathrm{LST}$ (local standard time) on July 11. At this hour, the temperature around Toronto is in the range of $20-22{ }^{\circ} \mathrm{C}$. The offshore high temperature at $24.2{ }^{\circ} \mathrm{C}$ is possibly a remnant of a UHI from the southeast advection the day before. The warm core advection continues in that direction until it vanishes a few hours later. Figures 4.2 through 4.5, representing hours 0900 through 1200 LST, show the growth of a UHI around Toronto. At 0900 through $1200 \mathrm{LST}$, the UHI, at its maximum location is about $1.9^{\circ} \mathrm{C}\left(22.9^{\circ} \mathrm{C}\right), 1.5^{\circ} \mathrm{C}\left(23.5^{\circ} \mathrm{C}\right), 1.6^{\circ} \mathrm{C}\left(23.6^{\circ} \mathrm{C}\right)$, and $1.7{ }^{\circ} \mathrm{C}\left(23.7^{\circ} \mathrm{C}\right)$, respectively (numbers given in parentheses are the absolute temperatures at the locations of the reported UHIs). The UHI outline follows the shoreline and then, because of a northwesterly wind, is displaced to the southeast over Lake Ontario. The UHI reaches about $2.3{ }^{\circ} \mathrm{C}\left(24.3{ }^{\circ} \mathrm{C}\right)$ at $1400 \mathrm{LST}$ in its maximum location (Figure 4.6). It then starts decreasing until it vanishes at 2000 LST (Figure 4.7).

Roughly, the same cycle repeats itself over the other days of this episode. Figure 4.8 shows that the start of the UHI, at its maximum at 0800 LST on July 12 is about $0.9{ }^{\circ} \mathrm{C}$ $\left(20.9^{\circ} \mathrm{C}\right)$. Figures 4.9 through 4.12 show that the UHI at 0900 through 1200 LST is about 
$2.0^{\circ} \mathrm{C}\left(23^{\circ} \mathrm{C}\right), 1.8{ }^{\circ} \mathrm{C}\left(23.8{ }^{\circ} \mathrm{C}\right), 1.2^{\circ} \mathrm{C}\left(24.2^{\circ} \mathrm{C}\right)$, and $1.6{ }^{\circ} \mathrm{C}\left(24.6^{\circ} \mathrm{C}\right)$. However, unlike the day before, the flow near Toronto is southerly on July 12 . As a result, the UHI on July 12 is advected northerly, whereas on July 11 it is advected southeasterly.

The same pattern is seen again on July 13, starting at 0800 LST with a UHI of about 1.1 ${ }^{\circ} \mathrm{C}\left(24.1{ }^{\circ} \mathrm{C}\right)$ (Figure 4.13). On July 13, the winds are relatively stronger. Therefore, the $\mathrm{UHI}$ on this day is smaller than it is on July 11 and 12. Consequently, as seen in Figures 4.14 through 4.17, at hours 0900 through 1200 LST on July 13 , the UHI is about $1.1^{\circ} \mathrm{C}$ $\left(25.1^{\circ} \mathrm{C}\right), 0.6^{\circ} \mathrm{C}\left(26.6^{\circ} \mathrm{C}\right), 0.1{ }^{\circ} \mathrm{C}\left(28.1^{\circ} \mathrm{C}\right)$, and $1.5^{\circ} \mathrm{C}\left(29.5^{\circ} \mathrm{C}\right)$. In addition, a southwesterly wind causes the northeasterly advection of UHI on this day.

Figures 4.18 through 4.34 show the corresponding time intervals after the "implementation" of the cool-city strategies as defined earlier. On July 11, except for some negligible differences in the flow and temperatures over Lake Ontario, the conditions in the GTA at 0000 LST (Figure 4.18) are identical to the base-case conditions (Figure 4.1). However, the UHI is smaller in space and intensity at 0900 LST (Figure 4.19) than it is at the basecase (about $0.4{ }^{\circ} \mathrm{C}$ smaller, at $22.5^{\circ} \mathrm{C}$ ). At 1000 LST (Figure 4.20), the UHI is again smaller in space than it is at the base-case (about $0.2{ }^{\circ} \mathrm{C}$ smaller, at $23.3{ }^{\circ} \mathrm{C}$ ). At $1100 \mathrm{LST}$ (Figure 4.21), the UHI is relatively the same as that of the base (only $0.1{ }^{\circ} \mathrm{C}$ smaller UHI). At 1200 LST (Figure 4.22), the UHI is not different from that of the base-case. At 1400 LST (Figure 4.23), there is only a negligible warming of about $0.1{ }^{\circ} \mathrm{C}$ (at $24.4{ }^{\circ} \mathrm{C}$ ). Finally, at night (Figure 4.24), representing $2000 \mathrm{LST}$, the UHI is not different from the base-case conditions. These observations suggest that the effects of cool-city strategies are relatively more beneficial during morning hours until noon local time.

On July 12 at 0800 LST (Figure 4.25), the UHI is reduced by about $0.9^{\circ} \mathrm{C}\left(20^{\circ} \mathrm{C}\right.$ instead of $20.9^{\circ} \mathrm{C}$ in the base-case). At hours 0900 through 1200 LST (Figures 4.26 through $4.29)$, the UHI at $20 \mathrm{~m}$ level is reduced by $0.9^{\circ} \mathrm{C}\left(22.1^{\circ} \mathrm{C}\right), 0.3^{\circ} \mathrm{C}\left(23.5^{\circ} \mathrm{C}\right), 0.2^{\circ} \mathrm{C}(24.0$ $\left.{ }^{\circ} \mathrm{C}\right)$, and $0.4{ }^{\circ} \mathrm{C}\left(24.2^{\circ} \mathrm{C}\right)$, respectively. Finally, on July 13 , at 0800 through $1200 \mathrm{LST}$ (Figures 4.30 through 4.34$)$, the $\mathrm{UHI}$ is reduced by about $0.4^{\circ} \mathrm{C}\left(23.7^{\circ} \mathrm{C}\right), 1.0^{\circ} \mathrm{C}(24.0$ $\left.{ }^{\circ} \mathrm{C}\right), 0.2{ }^{\circ} \mathrm{C}\left(26.4{ }^{\circ} \mathrm{C}\right), 0.1{ }^{\circ} \mathrm{C}\left(28.0^{\circ} \mathrm{C}\right)$, and $0.5^{\circ} \mathrm{C}\left(29.0^{\circ} \mathrm{C}\right)$.

\section{Case 035 (July 15-17 Sub-Episode)}

As with the discussion above, the following figures show two-dimensional plots of air temperature and wind vector fields at roughly $40 \mathrm{~m}$ above ground level.

On July 15, at 1200 LST (Figure 4.35), the flow into Toronto is northerly and the UHI is about $2.0^{\circ} \mathrm{C}\left(32.0^{\circ} \mathrm{C}\right)$. In the next hours (Figures 4.36 through 4.43$)$, the UHI at hours 1300 through $2000 \mathrm{LST}$ are $2.5^{\circ} \mathrm{C}\left(31.5^{\circ} \mathrm{C}\right), 2.0^{\circ} \mathrm{C}\left(31.0^{\circ} \mathrm{C}\right), 1.8^{\circ} \mathrm{C}\left(31.8^{\circ} \mathrm{C}\right), 1.3^{\circ} \mathrm{C}$ $\left(31.3^{\circ} \mathrm{C}\right), 2.5^{\circ} \mathrm{C}\left(30.5^{\circ} \mathrm{C}\right), 1.0^{\circ} \mathrm{C}\left(28.0^{\circ} \mathrm{C}\right), 1.6^{\circ} \mathrm{C}\left(27.6^{\circ} \mathrm{C}\right)$, and $1.8^{\circ} \mathrm{C}\left(26.8^{\circ} \mathrm{C}\right)$.

On July 16, a strong easterly and southeasterly flow, from over Lake Ontario into Toronto, causes the UHI to shrink and even disappear during daytime. For example, at 1000 LST on July 16 (Figure 4.44), there appears a small UHI of about $0.8^{\circ} \mathrm{C}\left(25.3^{\circ} \mathrm{C}\right)$ which gradually disappears during the rest of the daytime hours. From 1200 to 1500 LST (Figures 4.45 through 4.48), there is negligible or no UHI in Toronto. 
On July 17, the wind flow into Toronto reverts to its land type (westerly or southwesterly) at 0000 LST (Figure 4.49) and by 1000 LST the UHI reappears. From 1000 to 1800 LST (Figures 4.50 through 4.58), the UHI is about $2.1{ }^{\circ} \mathrm{C}\left(27.1{ }^{\circ} \mathrm{C}\right), 1.6{ }^{\circ} \mathrm{C}\left(27.6^{\circ} \mathrm{C}\right), 1.9$ ${ }^{\circ} \mathrm{C}\left(27.9^{\circ} \mathrm{C}\right), 2.1{ }^{\circ} \mathrm{C}\left(28.1{ }^{\circ} \mathrm{C}\right), 1.5^{\circ} \mathrm{C}\left(28.5^{\circ} \mathrm{C}\right), 1.7^{\circ} \mathrm{C}\left(28.7^{\circ} \mathrm{C}\right), 1.5^{\circ} \mathrm{C}\left(28.5^{\circ} \mathrm{C}\right), 1.7^{\circ} \mathrm{C}$ $\left(28.7^{\circ} \mathrm{C}\right)$, and $1.4^{\circ} \mathrm{C}\left(28.4^{\circ} \mathrm{C}\right)$, respectively. With the westerly winds after $1800 \mathrm{LST}$, the $\mathrm{UHI}$ is advected offshore onto Lake Ontario.

Figures 4.59 through 4.82 show the corresponding time intervals after the "implementation" of cool-city strategies. On July 15 , the implementation of cool-city strategies results in reducing the UHI at $40 \mathrm{~m}$ above ground level. For example, at hours 1200 through 2000 LST (Figures 4.59-4.67), the UHI is reduced by about $0.5^{\circ} \mathrm{C}\left(31.5^{\circ} \mathrm{C}\right), 0.5^{\circ} \mathrm{C}(31.0$ $\left.{ }^{\circ} \mathrm{C}\right), 1.0^{\circ} \mathrm{C}\left(30.0^{\circ} \mathrm{C}\right), 0.4^{\circ} \mathrm{C}\left(31.4^{\circ} \mathrm{C}\right), 0.3^{\circ} \mathrm{C}\left(31.0^{\circ} \mathrm{C}\right), 1.5^{\circ} \mathrm{C}\left(29.0^{\circ} \mathrm{C}\right), 0.0^{\circ} \mathrm{C}\left(28.6^{\circ} \mathrm{C}\right)$, $0.1{ }^{\circ} \mathrm{C}\left(27.5^{\circ} \mathrm{C}\right)$, and $0.2^{\circ} \mathrm{C}\left(28.6^{\circ} \mathrm{C}\right)$, respectively.

On July 16, the effects of cool-city strategies are small just as the UHI is small when the winds are stronger and from over Lake Ontario (Figures 4.44 through 4.48). For example, at 1000 LST (Figure 4.68), the UHI is reduced by $0.3{ }^{\circ} \mathrm{C}\left(25.0^{\circ} \mathrm{C}\right)$. However, from 1200 to 1500 LST (Figures 4.45 through 4.48), a cool-city strategy has no impacts on air temperature at this height (Compare Figures 4.69 through 4.72 with corresponding Figures 4.45 through 4.48 ).

On July 17, as the wind flow into Toronto reverts to westerly, the effect of cool-city strategies becomes detectable again. At 0000 LST (Figure 4.73), the conditions are identical to that of the base-case. This suggests that there is no UHI control effect during nighttime hours. At hours 1000 through 1800 LST (Figures 4.74 through 4.82), the UHI is reduced by about $0.2^{\circ} \mathrm{C}\left(26.9^{\circ} \mathrm{C}\right),-0.1{ }^{\circ} \mathrm{C}\left(27.7^{\circ} \mathrm{C}\right), 0.3{ }^{\circ} \mathrm{C}\left(27.6{ }^{\circ} \mathrm{C}\right), 0.1^{\circ} \mathrm{C}\left(28.0^{\circ} \mathrm{C}\right)$, $0.2^{\circ} \mathrm{C}\left(28.3^{\circ} \mathrm{C}\right), 0.2^{\circ} \mathrm{C}\left(28.5^{\circ} \mathrm{C}\right), 0.0^{\circ} \mathrm{C}\left(28.5^{\circ} \mathrm{C}\right), 0.3^{\circ} \mathrm{C}\left(28.4^{\circ} \mathrm{C}\right)$, and $0.4^{\circ} \mathrm{C}\left(28.0^{\circ} \mathrm{C}\right)$, respectively.

\section{$\underline{\text { Time-Series Analysis for Cases } 035 \text { and } 039}$}

Another way to examine the mesoscale model results is to analyze time series of urban heat island and air temperature changes for base scenario, cool-city scenario, and absolute air temperatures. The time series are for air temperature at $2 \mathrm{~m}$ above ground level. Figures 4.83 and 4.84 show the simulated urban heat island for Case 039 (July 10-14) and Case 035 (July 15-17), respectively. The horizontal axis represents local time (LST) and the vertical axis represents temperature $\left({ }^{\circ} \mathrm{C}\right)$. Here, the UHI is defined as the difference between urban-averaged air temperature and rural-averaged air temperature at $2 \mathrm{~m}$. For this analysis, the total area over which urban temperature is averaged is $320 \mathrm{~km}^{2}$ ( 80 grid cells of $4 \mathrm{~km}^{2}$ ) while that of the rural land (60 grid cells of $\left.4 \mathrm{~km}^{2}\right)$ is $240 \mathrm{~km}^{2}$. In addition, the selected reference rural area is about $40 \mathrm{~km}$ to the west of Toronto which is mostly upwind and, therefore, is not directly influenced by Toronto's "heat plume."

The MM5 simulations suggest the existence of a UHI in the GTA through most of the July 10-17 episode (Figure 4.83). However, there are times when the UHI is negative, meaning that the urban area is cooler than the rural ones. While a negative UHI could also be a result of defining the rural reference point, it is important to note that the ab- 
solute UHI is not very critical. The important aspect is the relative change in UHI, which is a measure of the impact of cool-city strategies on air temperature. For example, even though the absolute UHI can be positive or negative, the implementation of cool-city strategies reduces the UHI during the daytime without affecting it as much at night (Figure 4.83). However, there are a few hours during this episode when the nighttime UHI is larger in the cool-city scenario (warming relative to base) and smaller (cooling relative to base) in other hours. Averaged over the entire urban area, a typical daytime reduction (cooling) in the UHI is between 0.5 and approximately $1.0^{\circ} \mathrm{C}$ while a typical nighttime increase (warming) is smaller than $0.25^{\circ} \mathrm{C}$.

Figure 4.84 shows the above same information for Case 035 (July 15-17). Again, though it can be negative, the UHI in Case 035 is also positive most of the time. In general, as seen in Case 039, the cool-city strategies reduce the UHI during the day and have minimal effect at night. A typical daytime UHI reduction is $0.25-0.5{ }^{\circ} \mathrm{C}$, while a typical nighttime UHI increase is $0.1{ }^{\circ} \mathrm{C}$. Thus, the effects of cool-city strategies on air temperature are smaller during sub-episode 035 than they are during sub-episode 039. Figure 4.85 helps clarify this aspect further. The figure refers to both cases and shows the changes in the UHI with respect to the base-case conditions. Averaged over $320 \mathrm{~km}^{2}$, the UHI is typically decreased by $0.6{ }^{\circ} \mathrm{C}$ for Case 039 and by $0.4{ }^{\circ} \mathrm{C}$ for Case 035 . At few times in Case 039, however, the UHI is decreased up to $0.82^{\circ} \mathrm{C}$.

Figures 4.86 and 4.87 show the change in absolute air temperature (not the UHI) at randomly selected grids in the urban area, which may not necessarily capture the largest cool-city effect. For Case 039, Figure 4.86 shows the change in absolute air temperature for six random urban grids at $2 \mathrm{~m}$. Clearly, the urban areas are cooler during the day and warmer at night as a result of cool-city implementation. The cooling reaches up to $1.4{ }^{\circ} \mathrm{C}$ on the first day, $1.25^{\circ} \mathrm{C}$ on the second day, $2.7{ }^{\circ} \mathrm{C}$ on the third day, and $1.4{ }^{\circ} \mathrm{C}$ on the fourth day. The warming reaches up to $0.5^{\circ} \mathrm{C}$ during the first night, $0.7^{\circ} \mathrm{C}$ during the second night, and $0.4{ }^{\circ} \mathrm{C}$ during the third night. However, even at night, the figures generally indicate more frequent cooling than warming.

Finally, Figure 4.87 shows the temperature change for Case 035 at the same six random urban areas used in Case 039. It is obvious that the effects of cool-city strategies in Case 035 are smaller than those in Case 039. Aside from a somewhat questionable spike of $-6.0{ }^{\circ} \mathrm{C}$ (most likely a result of surface modifications during a time of transitional boundary-layer regime), the figure suggests a typical cooling of between 0.5 and $0.75{ }^{\circ} \mathrm{C}$, which may reach up to $1.0^{\circ} \mathrm{C}$. The warming reaches up to $1.4{ }^{\circ} \mathrm{C}$ at one hour, when there is large cooling, and about $1.0^{\circ} \mathrm{C}$ during the last night of this sub-episode.

\subsubsection{Meteorological Trajectories}

The meteorological fields produced by the MM5 were used to compute various trajectories in space and time. The purpose of this step was to identify the trajectories and extract the meteorological parameters at each time step. The extracted data would then be used to drive the photochemical trajectory model (CIT), described below. All trajectories simulated for this modeling episode were indicative of transport conditions. Therefore, as UHI control would be more beneficial during non-transport conditions, the air quality impacts 
of cool-city strategies might have been underestimated. Ideally, the impacts of cool-city strategies should have been assessed under a simulated local ozone-formation regime.

For each sub-episode, a set of trajectories was computed. Each back trajectory was 72 hours long. Figure 4.88 shows an ensemble of some of the trajectories generated in this study. The cluster of pluses $(+)$ outlines the urban area of Toronto. These are some of the random urban locations selected for time series analyses in section 4.1.1. Figures 4.89 through 4.94 show these trajectories in more detail. In all cases, the trajectories appear to be generally southerly and southwesterly into the GTA. As well, Figure 4.91 shows two cases of westerly flow after a southerly stretch in the GTA. Qualitatively, this agrees with observational studies that suggest, in more than $95 \%$ of the cases, trajectories arrive in southern Ontario and Toronto from the south and southwest after having crossed the United States Midwest (Yap et al., 1988).

To begin, one may notice that the flow is different in the 039 and 035 sub-episodes. In Case 039 (July 10-14), the trajectories arrive in Toronto in roughly a southerly flow (Figure 4.89). Though their paths are somewhat different, they retain the relative orientation, reversals, and rotations. Some of these trajectories are generated over Lake Huron, while others are generated over Lake Erie. In Case 035 (July 15-17), the flow is westerly into Toronto, after a southerly leg emanating in a rural region southwest of Detroit, Michigan (Figure 4.91). More often than not, the July 10-14 sub-episode trajectories are generated and flow over Lake Erie and Lake Ontario before arriving in Toronto, whereas those of the July 15-17 sub-episode are generated over land (compare Figure 4.89 vs. Figure 4.91).

Nonetheless, it was difficult to construct trajectories that capture the worst air quality conditions of each episode. It was also difficult to generate trajectories that remain over the city long enough to produce relevant results. In most cases, the trajectories hovered over the city for less than an hour. For this analysis, two trajectories were constructed to represent each of the sub-episodes. These trajectories would go through urban Toronto, or at least the nearby area, during the afternoon or evening hours (1400 through 2000 LST).

The trajectories used for the air quality analysis are:

1. For the July 10-14 episode (Case 039), the trajectories are shown in Figure 4.94. In the CIT simulations (discussed in the next section), the left trajectory is used. For both trajectories, the flow is southerly through Toronto. The trajectories go through the urban area at about 1500 LST on July 13 and continue for eight more hours to the north. There is also a flow reversal at the end of the trajectory. As noted earlier, more than $70 \%$ of this trajectory is over water. The left trajectory is composed of a backward slice ending at the city and a forward slice departing the city. The junction is at 1500 LST and at a location defined by longitude -79.38 and latitude 43.75. In terms of the MM5 modeling domains, this trajectory resides in the inner domain (D02) during the last $12 \mathrm{~h}$, while the rest of the trajectory is in the outer domain (D01). 
2. For the July 15-17 episode (Case 035), the trajectories are shown in Figure 4.93. In the CIT simulations (discussed in the next section), the middle trajectory is used (middle of the three westerly trajectories). The flow in this case is westerly near Toronto. The trajectories arrive in the urban area at about 1600-1800 LST on July 17. Except for a portion over Lake Huron, this trajectory is about $80 \%$ over land. The trajectory consists of one backward slice ending in the GTA. With respect to the MM5 modeling domains, this trajectory resides in the inner domain (D02) during the last $10 \mathrm{~h}$, while the rest of the trajectory is in the outer domain (D01).

Following selection of these trajectories, the meteorological parameters along the trajectory at each space/time step are extracted and used as input into the emission preprocessor to adjust biogenic emissions and to drive the CIT photochemical model. Thus, the CIT model receives time-space location information from the meteorological trajectories, as well as relevant meteorological parameters such as temperature, winds, mixing height, water vapor mixing ratio, and the rest.

\subsubsection{Air Quality Trajectories}

From a certain number of trajectories generated, the two identified in section 4.1 .2 will be discussed. These trajectories are shown in Figures 4.95, 4.96, and 4.97. The figures also show observed ozone mixing ratios (contours) and wind vectors (arrows).

Figures 4.95 and 4.96 depict the July 10-14 trajectory (Case 039), overlaid on the contours of observed ozone mixing ratios and the wind vectors. Figure 4.95 depicts 1500 LST on July 13, whereas Figure 4.96 depicts 2000 LST. The observed mixing ratios near urban Toronto are around $90 \mathrm{ppb}$ at 1500 LST and $40 \mathrm{ppb}$ at $2000 \mathrm{LST}$. At 1500 LST, the observed wind appears to be westerly and southwesterly in the Toronto area and southerly in the Hamilton area. At 2000 LST, however, the wind appears less consistent: roughly westerly north of Toronto, northeasterly in Toronto, and easterly near Hamilton. The corresponding MM5 simulated winds compares favorably at 1500 LST (Figure 4.98), and unfavorably at 2000 LST (Figure 4.99). At 2000 LST, the MM5 simulated flow is southwesterly. While the MM5 does generally simulate comparable rotations in the wind, it does not reproduce the "chaotic" nature of the observed flow at 2000 LST.

For July 15-17 (Case 035, Figure 4.97), the observed ozone mixing ratios near Toronto are about $40 \mathrm{ppb}$ at 1700 LST. The wind appears to be southeasterly in both the Toronto and Hamilton areas. The MM5 simulations for this hour, however, show southwesterly flow in these areas (Figure 4.57). Again, it must be emphasized that the scale of the modeling versus that of observations may influence these qualitative comparisons.

Figures 4.100 and 4.101 show the simulated ozone mixing ratios along the last legs of the trajectories depicted in Figures 4.95 and 4.97. The trajectories in Figure 4.100 use initial conditions that are half of the values shown in Figure 4.4. Figure 4.101, on the other hand, shows trajectories that were initialized with concentrations (shown in Figure 4.4) that are double those of trajectories in Figure 4.100. The purpose of these runs was to test the sensitivity of the results at the end of the trajectories to the initial conditions. 
In Figure 4.100, the mixing ratios are shown in ppm ozone for the last $20 \mathrm{~h}$ of trajectory 039 (bottom curve) and the last $17 \mathrm{~h}$ of trajectory 035 (upper curve). The CIT simulates higher mixing ratios for trajectory 035 than it does for trajectory 039 . This is probably because the former's path is mostly over land, where emissions exist, whereas the latter path is mostly over water, where there are no significant emissions. This could also explain why, compared to the observations, the model overestimates mixing ratios in trajectory 035 and underestimates them for trajectory 039 . In the urban area, for example, at 1500 LST in trajectory 039 , the model predicts $60 \mathrm{ppb}$ ozone whereas observations are around $90 \mathrm{ppb}$. On that same trajectory, the model simulates $30 \mathrm{ppb}$ ozone upwind of the urban area whereas the observations indicate $40 \mathrm{ppb}$. In trajectory 035 , the model predicts $80 \mathrm{ppb}$ ozone in the urban area whereas the observations are around $40 \mathrm{ppb}$.

In general, it cannot be expected that a trajectory model capture the mixing ratios of the peaks in fully dynamic three-dimensional situation as well as a grid model. The trajectory is subject to space and time differences from the time and location of the peak and thus may not capture it (e.g., a few grids away or an hour or two apart, etc.). In addition, the data we obtained was not initially intended for use in a trajectory model and thus some assumptions and interpolations, such as using $32 \mathrm{~km}$ grid emissions in preparing $2 \mathrm{~km}$ grid emissions, had to be made; these may explain the loss of detail

\section{$\underline{\text { Case } 039}$}

The portion of trajectory 039 shown in Figure 4.100 starts over Lake Erie. The trajectory continues over the lake until about 1000 LST. Between 1000 LST and 1200 LST the trajectory is over land (the land portion between Lake Erie and Lake Ontario). At about 1400 and 1500 LST, the trajectory reaches the urban area and continues until about 1600 LST. After 1600 LST, the trajectory continues north and reverses direction towards the city at about 1700 LST.

The base-line simulated mixing ratios range from $10 \mathrm{ppb}$ ozone at night over Lake Erie to about $62 \mathrm{ppb}$ slightly downwind of urban Toronto at about 1600 LST. To the north of Toronto, mixing ratios drop again to about $32 \mathrm{ppb}$ and start increasing afterwards until 1900 LST, a time interval when the trajectory turns back towards the city. The mixing ratios reach another peak of about $52 \mathrm{ppb}$ ozone and then fall all the way down to about $25 \mathrm{ppb}$ at the end of the trajectory.

To estimate the effects of cool-city strategies on this trajectory, the entire process (MM5, meteorological trajectories, and air quality trajectories) was repeated after "implementation" of increased surface albedo and urban reforestation. With respect to the CIT trajectories, three cool-city scenarios were analyzed. One scenario, referred to as Case A, corresponds to the cool-city trajectory exactly as predicted by the model. The second scenario, referred to as Case B, is similar to Case A but with the last portion of the trajectory moved over urban grids where the effects of cool-city strategies were larger. Finally, a third scenario, referred to as Case $\mathrm{C}$, is also analyzed where the last portion of the trajectory is modified to reflect the maximum temperature effects of cool-city strategies. The reason for developing Cases B and C is that Case A, as predicted by the model, 
does not go through the areas with largest modification effects and does not remain over the city long enough to produce significant effect.

The base case, Case A, Case B, and Case C are depicted by a thin solid line, a thick broken line, a thin short-broken line, and a thin long-broken line, respectively (Figure 4.100). The photochemical model suggests that the effects of cool city-strategies on trajectory 039 (bottom set of curves in the figure) is to increase mixing ratios by up to $3 \mathrm{ppb}$ over Lake Ontario starting at 1300 LST. This increase is caused by the slower winds. However, the mixing ratios are decreased by 1-4 ppb ozone in and immediately downwind of the city. Later on, the mixing ratios are further decreased by up to $8 \mathrm{ppb}$ ozone north of the city after the flow reverses course towards urban Toronto.

The increase in mixing ratios upwind also results from the differing trajectory and is subsequently corrected in the trajectories for Cases B and C. Case B shows that the mixing ratios do not change up until the urban area is reached. The mixing ratios decrease by some 1 to $2 \mathrm{ppb}$ ozone in the urban area and up to about $2.5 \mathrm{ppb}$ ozone immediately downwind. However, the cool-city effects are smaller and almost negligible after the flow reverses towards urban Toronto. In fact, as after 1800 LST, there could be even a small increase in mixing ratios. In Case $\mathrm{C}$, the mixing ratios start decreasing slowly once the flow passes the lake. The largest differences here are about 1.3 to $2 \mathrm{ppb}$ ozone over the urban area and about 1.5 ppb ozone its downwind.

Percentage-wise, these numbers show that there can be increases of up to $5 \%$ over the lake (in one trajectory) and decreases of 3 to $7 \%$ in and immediately downwind of the urban area. After the flow reversal, the decrease can reach $15 \%$ north of Toronto. However, as in this study, it is generally difficult to draw a final conclusion from these results because a trajectory model was used with a new setup. For example, it is not known how the change in ozone level fluctuates during the course of a day or episode without running additional trajectories. This can be improved upon in the future.

Figure 4.101 shows the same trajectories (bottom set of lines) repeated with doubled initial mixing ratios at the beginning of each trajectory. The impact of changes in initial conditions is small and there are very minor changes from Figure 4.100. In Figure 4.101, the mixing ratios are slightly higher. For example, they show a peak of $63.6 \mathrm{ppb}$ ozone instead of $60.8 \mathrm{ppb}$ ozone. However, the changes in mixing ratios, caused by cool-city strategies, are relatively similar in both figures. For example, in Case A, the mixing ratio increase is small; it is at most $2.3 \mathrm{ppb}(3.8 \%)$. In Case A, the mixing ratio decrease is up to $1 \mathrm{ppb}(2 \%)$ in the urban area at $1600 \mathrm{LST}, 3.4 \mathrm{ppb}(7.5 \%)$ at $1700 \mathrm{LST}$, and $2.5 \mathrm{ppb}$ (7\%) immediately downwind of Toronto urban area. After the flow reversal, the decrease reaches up to $7 \mathrm{ppb}(13 \%)$. Other numbers for cases $\mathrm{B}$ and $\mathrm{C}$ are also changed, but by so small amounts which are not worth discussing here.

The temperature and ozone mixing ratio profiles along the trajectory are analyzed to develop ozone-temperature correlations. Figure 4.102 shows the air temperature along the last $12 \mathrm{~h}$ of this trajectory for the base case as well as Cases A, B, and C. In developing such correlation, temperature is used as a surrogate for the effects of wind speed and direction, boundary-layer height and mixing, and photochemical production rate. It 
should be stated very clearly here that this is a correlation along the trajectory, and it does not represent a correlation for the urban area. The correlation along the trajectory includes an overwhelmingly large area not affected by surface modifications, as well as areas affected by these modifications.

A period of six hours near the end of this trajectory is examined to find out whether developing such a correlation is feasible. Figure 4.103 depicts a scatter plot of temperature versus ozone during these six hours. As shown in this figure, it is difficult to find such a correlation. This difficulty is partly created by the large change in ozone levels at very small temperature changes. There is also an issue of time scale for chemical reactions: some changes occur after temperature is modified. Without getting into this aspect, and after removing the large changes in ozone level (outlier data), the statistical regression yields a slope of $\Delta\left[\mathrm{O}_{3}\right] / \Delta \mathrm{T}$ of $0.65 \mathrm{ppb} / \mathrm{K}$. However, the correlation is weak and its $\mathrm{R}^{2}$ is only 0.21 .

\section{$\underline{\text { Case } 035}$}

The upper curves in Figure 4.100 show the portion of this trajectory that starts in a rural area southwest of Detroit, Michigan, half way between Lansing, Michigan, and Toledo, Ohio. The first half of the trajectory is roughly southerly and the second half is westerly, after turning east over Lake Huron. It reaches urban Toronto at about 1400-1700 LST on July 17 . The simulated base mixing ratios range from $15 \mathrm{ppb}$ ozone at night to about 80 ppb ozone in the surrounds of urban Toronto at about 1600 LST. To estimate the effects of cool-city strategies on ozone air quality in Toronto, the entire process (MM5, meteorological trajectories, and air quality trajectories) is repeated after "implementation" of increased surface albedo and urban reforestation. With respect to the CIT trajectories, the same cool-city scenarios A, B, and C (discussed above for Case 039) are used again for Case 035 .

Figure 4.100 depicts the base case, Case A, Case B, and Case C in a thin solid line, a thick broken line, a thin short-broken line, and a thin long-broken line, respectively. The trajectory model suggests that the effects of cool city-strategies on trajectory 035 (top set of curves in the figure) are smaller than $1 \mathrm{ppb}$ ozone. Again, this is probably because the trajectory does not capture the full effect of meteorological changes at locations of interest. In Case B, the mixing ratios begin to decrease at about 1400 LST until the end of the trajectory. The mixing ratios decrease by 1 to 2 ppb ozone in the urban area and its surround. At $1600 \mathrm{LST}$, the decrease is $1.6 \mathrm{ppb}$ ozone and about a half-hour later it is 1.8 ppb ozone. In Case C, the mixing ratios start decreasing at the same time as in Case B. However, in Case $\mathrm{C}$ the decreases in mixing ratios reach $1.9 \mathrm{ppb}$ ozone at 1500 LST and $2.4 \mathrm{ppb}$ ozone at 1600 LST and beyond. In general, trajectory 035 does not show increases in mixing ratios (as in Case 039), possibly because the trajectory does not go over the lake where winds are slowed. Percentage-wise, the decrease in mixing ratios for trajectory 035 can reach up to $2.5 \%$ at 1500 LST and up to about $3 \%$ at 1600 LST and onwards.

Figure 4.101 shows the same trajectories (top set of lines) repeated with doubled initial mixing ratios (those in Figure 4.4) at the beginning of each trajectory. Compared to tra- 
jectories in Figure 4.100, there are minor changes suggesting small impacts from changing initial conditions. The mixing ratios show slightly higher peaks, such as $83.8 \mathrm{ppb}$ instead of 79.9 ppb ozone. In Figure 4.101, the changes in mixing ratios, as a result of coolcity strategies, are relatively similar to the changes in Figure 4.100. For example, at 1600 LST, the base-case mixing ratio is $84.2 \mathrm{ppb}$, while Cases $\mathrm{A}, \mathrm{B}$, and $\mathrm{C}$ reduce mixing ratios by $0.4 \mathrm{ppb}(0.5 \%), 1.9 \mathrm{ppb}(2.2 \%)$, and $2.5 \mathrm{ppb}(3 \%)$, respectively. This is, in part, due to the fact that the initial conditions are $72 \mathrm{~h}$ earlier. Consequently, the model "forgets" the initial conditions by the time the trajectories reach the urban area.

As in Case 039, an attempt is made to develop an ozone-temperature correlation for Case 035. Figure 4.104 shows the air temperature along the last $10 \mathrm{~h}$ of this trajectory for the base case as well as Cases A, B, and C. Again, it should be stated clearly that this is a correlation along the trajectory, and it does not represent a correlation for the urban area. A period of $6 \mathrm{~h}$ near the end of this trajectory is examined for this purpose. Figure 4.105 depicts a scatter of temperature versus ozone during these $6 \mathrm{~h}$. Making the same assumptions as in Case 039, a regression of this data set suggests a relatively better correlation in Case 035, with an $\mathrm{R}^{2}$ of 0.87 and the $\Delta\left[\mathrm{O}_{3}\right] / \Delta \mathrm{T}$ slope of $0.50 \mathrm{ppb} / \mathrm{K}$.

\section{Significance of Cool-City Air Quality Impacts}

The impacts of cool-city strategies may seem small at first. However, to appreciate the significance of cool-city strategies, their impacts should be compared with the impacts of other such strategies. For example, the air quality impacts of cool-city strategies could be compared to the reductions in NOx and/or VOCs emissions that would be needed to produce the same ozone air-quality effects. It should be emphasized that these comparisons are very qualitative and should not be used explicitly.

For this purpose, the results from the trajectory simulations are compared to simulated air quality impacts of emission reduction strategies for the 1-6 August 1988 episode in WQC from a previous study (Environment Canada, 1996). Acid Deposition and Oxidants Model (ADOM) in combination with Mesoscale Community Model (MC2) were the modeling systems selected for that study. These models were run at a resolution of 40 and $20 \mathrm{~km}$, using this combined system. Those simulations suggested that a decrease of $30 \%$ in regional NOx emissions causes ozone mixing ratios to decrease by $5-10 \%$ in southern Ontario. This amount is roughly equivalent to the range of reductions in ozone obtained over the trajectory simulations in this study (with 3\% being representative and up to $7 \%$ or larger was reported).

Using a Lagrangian version of ADOM (ALOM), along with MC2, an Environment Canada working group (1996) has studied the impacts of a number of emission reduction strategies (scenarios) on ozone air quality in the WQC. In one scenario, known as "Phase I Management Plan emission Reduction Scenario," reductions of 25\% were applied to NOx and VOCs emissions in the provinces of Ontario, Quebec, and New Brunswick. For this scenario, the modeling study suggested a reduction of a few ppb in mixing ratio. In the GTA, on 3 August 1988, the reduction in ozone mixing ratios was $2 \mathrm{ppb}$, which is similar to the reductions obtained with the photochemical trajectory simulations in this study. 
This 2 ppb reduction can also be achieved by reducing either Canadian VOCs emissions by $50 \%$ or Canadian $\mathrm{NO}_{\mathrm{X}}$ emissions by $75 \%$. Again, it should be stressed that these comparisons are very qualitative. In addition, there is a risk in drawing such equivalencies because the results come from very different assumptions and models. However, the purpose here is to "assign" some "value" to the changes reported in this study.

\subsection{Episodic Extrapolations (for Energy Modeling)}

One additional purpose for performing the mesoscale meteorological simulations in this study is to develop an entire year of modified hourly air temperatures, e.g., modified Typical Meteorological Year (TMY) data. The annual hourly data thus generated can then be used in building energy-use modeling, such as the building energy model (DOE2). The data generated and discussed in this section are then transferred to another modeling component of this TAF-sponsored study, as described in Konopacki and Akbari (2001).

This section is kept very brief and the reader is directed to consult Taha (1998) and Taha et al. (1999) for additional information. Here, it suffices to explain that the basis of the above-mentioned hourly weather modifications is the development of correlation between incoming solar radiation and change in air temperature (in this case, the change in air temperature as a result of cool-city strategies). Figures 4.106 and 4.107 show the MM5 simulated urban-averaged changes in air temperature, as a result of cool-city scenarios, along with the MM5 simulated incoming solar radiation at ground level. One can qualitatively note that the urban-averaged change air temperature is larger as solar radiation increases.

From this analysis (Taha, 1998; Taha et al., 1999), a correlation was obtained for the January and July episodes in Toronto. The correlation has the form:

$$
\Delta \mathrm{T}=-0.0018 \mathrm{I},
$$

where $\Delta \mathrm{T}$ is in either Kelvin or Celsius and I is solar intensity in $\mathrm{W} / \mathrm{m}^{2}$. This assumes that the nighttime increase in air temperatures is negligible and may be ignored. To account for snow effect, the correlation is not applied during the months of October through March when snow is present. 


\section{Conclusion}

In this study, a short, preliminary analysis was conducted to assess the potential meteorological and ozone air-quality implications of implementing cool-city strategies in the Greater Toronto Area (GTA), Canada. A mesoscale meteorological model (PSU/NCAR MM5 v3.4) was used to simulate the various meteorological aspects related to changes in urban surface albedo and vegetative cover. In addition, a Lagrangian photochemical trajectory model (CIT) was used to obtain an initial insight into the possible impacts on air quality in the region. The modeling was performed for 10-17 July 1995 . This time interval was split into two sub-episodes: July 10-14 and July 15-17, inclusive.

The surface modifications, an increase of 0.13 in urban surface albedo and an increase of $10 \%$ in vegetative cover, were assumed to apply to an area of about $420 \mathrm{~km}^{2}$ in the GTA and about $40 \mathrm{~km}^{2}$ in the Hamilton area. Because the "modified" area was actually smaller than the total area of the Hamilton-Toronto-Oshawa urbanized corridor, this scenario could alternatively be interpreted as smaller increases in albedo or vegetation fraction but spread out over a larger area.

The meteorological simulations suggested an urban heat-island effect (UHI) in the GTA throughout the episode. While the UHI was observed during both day and night, the daytime UHI was relatively more persistent than that of the nighttime. The results suggested that even though the UHI can be positive or negative, the effect of cool-city implementation, in general, was to reduce the UHI during daytime without affecting it much at night. Averaged over the entire Toronto urban area, a typical daytime reduction in the UHI (cooling) was 0.5 to almost $1{ }^{\circ} \mathrm{C}$ and the typical nighttime increase in UHI (warming) was smaller than $0.25{ }^{\circ} \mathrm{C}$. However, in specific grids, the decrease in air temperature was larger than these averages. In randomly selected urban grids, the change in absolute air temperature at $2 \mathrm{~m}$ above ground could reach up to $2.7^{\circ} \mathrm{C}$, and the warming could reach up to $0.7^{\circ} \mathrm{C}$. The simulations indicated more frequent cooling than warming, even at night. The meteorological simulations also produced some larger cooling, for example up to $6{ }^{\circ} \mathrm{C}$, which was considered questionable and was not included in the analysis.

The photochemical trajectory simulations of the July 10-14 sub-episode suggested that the effects of cool city-strategies were to decrease ozone concentrations by $1-4 \mathrm{ppb}$ in and immediately downwind of the GTA. However, ozone concentrations could also be increased by $2-3 \mathrm{ppb}$ in some areas upwind of the GTA. The model also predicted a decrease as large as $8 \mathrm{ppb}$ in ozone concentration. The changes in ozone concentration translated into a mixing ratio decrease of 3 to $7.5 \%$ in and immediately downwind of the urban area. In one simulation, after a flow reversal, the mixing ratio decrease in north of Toronto reached $15 \%$, which had to be discarded as too large a decrease. For the July 1517 sub-episode, the trajectory model suggested that the effects of cool city-strategies decreased mixing ratios by 1 to $2 \mathrm{ppb}$ in the urban area and its surround. The decreases could reach up to $2.4 \mathrm{ppb}$. Percentage-wise, the decrease in mixing ratios for this episode could reach up to $3 \%$.

This study was very preliminary. Its purpose was to qualitatively answer the question of whether it would be worth pursuing heat-island mitigation studies for GTA further. Based 
on the preliminary results reported here, further study of UHI control in Toronto would be worth pursuing. This study could serve as an initial step toward more comprehensive and detailed studies in the future.

\section{Recommendations}

As mentioned throughout this report, this study was intended to serve as an initial assessment of the potential meteorological and air quality impacts of cool-city strategies in the GTA. The scope of the study and the resources allocated permitted only a modest modeling and analysis effort. This study, however, could serve as an initial step toward more comprehensive future studies for which the following recommendations might prove helpful:

- Because a trajectory air quality model was used in this study, the simulations did not capture the character of the episode or the range of possible impacts from cool-city strategies. There was also a need to simulate conditions to account for local, non-transport ozone production in the area. Therefore, it is recommended that the follow-up studies use the same meteorological model (MM5), but that it use a better air quality model, such as fine-resolution 3-D photochemical grid models.

- Rigorous model performance evaluation (meteorological or photochemical) was not attempted during the short time frame of this study. This should be done in the future, especially if this work is to become a basis for regulatory or planning purposes.

- Fine resolution land-use and land-cover data needed for this type of modeling work were not available to us. As a result, simplified assumptions were made. The entire Hamilton-Toronto-Oshawa "corridor" should be well characterized. Therefore, there is a need to repeat the simulations with a fine-resolution land-use classification that allows for sub-urban classifications as well. For example, use of aerial photography or fine-resolution surface observations is recommended.

- The resolution of emissions data obtained in this study was not fine enough to match that of the meteorological or the trajectory models. In the future, emissions data at resolutions of $4 \mathrm{~km}$ or better should be used, especially near the urban areas of interest.

- This study carried out a single-episodic assessment. In the future, additional episodes need to be identified and multi-episodic modeling should be performed. The purpose should be to assess the impacts and effectiveness of cool-city strategies under various flow regimes and synoptic conditions. 


\section{References}

Akbari, H., Rose, S. and Taha, H., 2002. "Analyzing the land cover of an urban environment using high-resolution orthophotos." Landscape and Urban Planning, accepted for publication.

Anthes, R.A. and Warner, T.T., 1978. "Development of hydrodynamic models suitable for air pollution and other meteorological studies." Monthly Weather Review 106: $1045-1047$.

Anthes, R.A., Hsie, E.Y., and Kuo, Y.H., 1987. "Description of the Penn State/NCAR Mesoscale Model Version 4 (MM4)." NCAR/TN-282+STR, National Center for atmospheric Research, Boulder, CO.

Berdahl, P. and Bretz, S.E., 1997. "Preliminary survey of the solar reflectance of cool roofing materials." Energy \& Buildings - Special Issue on Urban Heat Islands, Vol. 25(2): 149-158.

Bergin, M.S., Noblet, G.S., Petrini, K., Dhieux, J.R., Milford, J.B., and Harley, R.A., 1999. "Formal Uncertainty Analysis of a Lagrangian Photochemical Air Pollution Model." Environmental Science \& Technology 33: 1116-1126.

Burrows, W.R., Benjamin, M., Beauchamp, S., Lord, E.R., McCollor, D., and Thompson, B., 1995. "CART decision-tree statistical analysis and prediction of summer season maximum surface ozone for the Vancouver, Montreal, and Atlantic regions of Canada." Journal of Applied Meteorology 34: 1848-1862.

Byun, D.W. and Ching, J.K.S., 1999. "Science algorithms of the EPA MODELS-3 Community Multiscale Air Quality (CMAQ) Modeling System.” EPA/600/R99/030, March.

Carter W. P. L., Luo D. and Malkina I. L., 1997. "Environmental Chamber Studies for Development of an Updated Photochemical Mechanism for Reactivity Assessment." Final Report for California Air Resources Board Contract No. 92-345, Coordinating Research Council, Inc., Project M-9 and National Renewable Energy Laboratory, Contract ZF-2-12252-07.

Dudhia, J., 1993. "A non-hydrostatic version of the Penn State/NCAR mesoscale model: Validation tests and simulation of an Atlantic cyclone and cold front". Monthly Weather Review 121: 1493-1513.

Environment Canada, 1996. Data Analysis Working Group Report, Canadian 1996 Nox/VOC Science Assessment (October 1997), Ottawa, Canada.

Goodridge, J., 1989. "Population and temperature trends in California." Proceedings of the Pacific Climate Workshop, Pacific Grove, California, March 22-26. 
Grell, G.A., Dudghia, J., and Stauffer, D.R., 1994. "A description of the fifth generation of the Penn State/NCAR Mesosca le Model (MM5)". NCAR Technical Note, NCAR TN-398-STR.

Guenther, A., Baugh, B., Brasseur, G., Greenberg, J., Harley, P., Klinger, L., Serca, D., and Vierleng, L., 1999. "Isoprene emission estimates and uncertainties for the Central African EXPRESSO study domain." Journal of Geophysical Research 104: 30625-30639.

Hastie, D.R., Shepson, P.B., Reid, N, Roussel, P.B. and Melo, O.T., 1996. "Summertime NOx, NOy, and Ozone at a Site in Rural Ontario." Atmospheric Environment 30(12): 2157-2167.

Konopacki, S., and Akbari, H., 2001. "Energy impacts of heat island reduction strategies in the greater Toronto area, Canada". Lawrence Berkeley National Laboratory Report No. 49172.

Martilli, A., 2001. Development of an urban turbulence parameterization for mesoscale atmospheric models. Doctoral dissertation, Federal Polytechnic School, Lausanne, Switzerland (186 pp).

McRae, G.J. and Russell, A.G., 1981. "Vertically resolved Lagrangian trajectory model." Environmental Quality Laboratory, California Instutute of technology, Pasadena, California.

McRae, G.J. and Seinfeld, J.H., 1982. "Development of a second-generation mathematical model for urban air pollution-I: Model formulation." Atmospheric Environment 16(4): 679-696.

McRae, G.J. and Seinfeld, J.H., 1983. "Development of a second-generation mathematical model for urban air pollution-I: Evaluation of model performance." Atmospheric Environment 17(3): 501-522.

Madronich, S., and Flocke, S., 1998. "The role of solar radiation in atmospheric chemistry," in Handbook of Environmental Chemistry, Springer-Verlag, Heidelberg, 126.

Mestayer, P.G. and Bornstein, R.D., 1998. "Workshop on the linkages of numerical urban canopy layer and PBL models". Bulletin of the American Meteorological Society, Submitted.

Oke, T.R., 1987. Boundary Layer Climates, $2^{\text {nd }}$ edition, Methuen, London.

Oke, T.R., 1988. “The urban energy balance.” Progress in Physical Geography 12: 471.

Peterson, J.T., 1976. "Calculated actinic fluxes $(290-700 \mathrm{~nm})$ for air pollution photochemistry applications." US EPA Report EPA-600/4-76-025, Research Triangle Park, North Carolina. 
Petterssen, S., 1940. Weather Analysis and Forecasting. McGraw-Hill Company, New York.

Reynolds, S.D., Roth, P.M., and Seinfeld, J.H., 1973. Mathematical modeling of photochemical air pollution: I-Formulation of the model. Atmospheric Environment 7: 1033-1061.

Rosenfeld, A.H., Akbari, H.A., Romm, J.J., and Pomerantz, M., 1998. "Cool communities: strategies for heat island mitigation and smog reduction." Energy \& Buildings 28: 51-62.

Seaman, N.L., Stauffer, D.R., and Mario, L.M., 1995. “A multiscale four-dimensional data assimilation system applied to the San Joaquin Valley during SARMAP. Part I: Modeling design and basic performance characteristics." Journal of Applied Meteorology, No. 34, pp. 1739-1761.

Seinfeld, J.H. and Pandis, S.N., 1998. Atmospheric chemistry and physics. John Wiley and Sons, New York (1326 pp).

Stockwell, W.R., Middleton, P., Chang, J.S., and Tang, X., 1990. "The second generation regional acid deposition model chemical mechanism for regional air quality modeling," Journal of Geophysical Research 95: 16343-16367.

Stockwell, W.R and Kley, D., 1994. The Euro-RADM Mechanism: A Gas-Phase Chemical Mechanism for European Air Quality Studies. Forschungszentrum Julich $\mathrm{GmbH}$ (KFA) Julich, Germany.

Stohl, A., 1999. The FLEXTRA Trajectory Model. University of Munich, Germany.

Stohl, A., Baumann, K., Wotawa, G., Langer, M., Neininger, B., Piringer, M., and Formayer, H., (1997). "Diagnostic downsacling of large scale wind fields to compute local scale trajectories.” Journal of Applied Meteorology 36: 931-942.

Taha, H., Chang, S.C., and Akbari, H., 2001. "Meteorological and air quality implications of heat island reduction in Houston TX." Status Report to the USEPA and EPA/OAQPS, February 28.

Taha, H., Chang, S.C., and Akbari, H., 2001. "Sensitivity of the Houston-Galveston meteorology and ozone air quality to local perturbations in surface albedo, vegetation fraction, and soil moisture: Initial modeling results." Report prepared for the Global Environment and Technology Foundation, Center for Energy and Climate Solutions, March 31, 2001. LBNL Draft Report No. LBNL-47663.

Taha, H., Chang, S.C., and Akbari, H., 2000. "Meteorological and air quality impacts of heat island mitigation in three U.S. cities." Lawrence Berkeley National Laboratory Report No. 44222 (135 pp). 
Taha H. and Bornstein, R., 1999. "Urbanization of meteorological models: Implications on simulated heat islands and air quality." Invited paper, Proceedings of the International Congress on Biometeorology and International Conference on Urban Climatology, November 8-12, Sydney, Australia. Lawrence Berkeley National Laboratory Report No. LBNL-43706.

Taha, H., Konopacki, S., and Gabersek, S., 1999. "Impacts of large-scale surface modifications on meteorological conditions and energy use: A 10-region modeling study." Theoretical and Applied Climatology 62: 175-185.

Taha, H., 1998. "Modifying a mesoscale meteorological model to better incorporate urban heat storage: A bulk-parameterization approach." Journal of Applied Meteorology 38: 466-473.

Taha, H., 1997a. "Urban climates and heat islands, albedo, evapotranspiration, and anthropogenic heat". Energy \& Buildings, Special Issue on Urban Heat Islands, 25(2): 99-103.

Taha, H., 1997b. "Modeling the impacts of large-scale albedo changes on ozone air quality in the South Coast Air Basin." Atmospheric Environment 31(11): 1667-1676.

Taha, H., 1996. "Modeling the impacts of increased urban vegetation on ozone air quality in the South Coast Air Basin." Atmospheric Environment 30(20): 3423-3430.

Wotawa, G. and Stohl, A., 2000. "A tracer dispersion model driven by global-scale analyses and mesoscale (MM5) model output and its validation with tracer experiment data." Proceedings of the American Meteorological Society's $11^{\text {th }}$ Joint Conference on the Applications of Air Pollution Meteorology, 446.

Xu, D., Yap, D., and Taylor, P.A., 1995. "Meteorologically-adjusted ground-level ozone trends in Ontario," Atmospheric Environment 30(7): 117-1124.

Yap, D., Ning, D.T., and Dong, W., 1988. "An assessment of source contributions to the ozone mixing ratios in southern Ontario," Amtospheric Environment 22: 11611168.

Young, T.R. and Boris, J.P., 1977. "A numerical technique for solving stiff ordinary differential equations associated with the chemical kinetics of reactive flow problems," Journal of Physical Chemistry. 

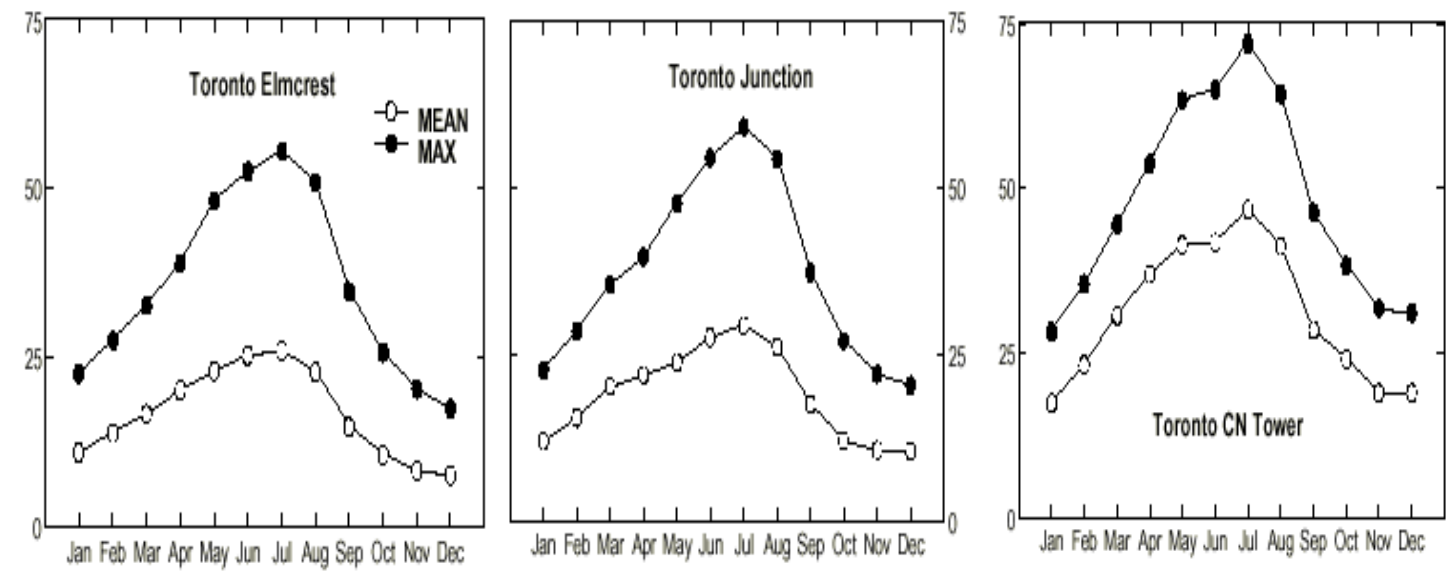

Figure 2.1: Monthly averages of mean and mean daily maximum ozone, ppb, (1986-1993) in Toronto. Source: Environment Canada, 1996.
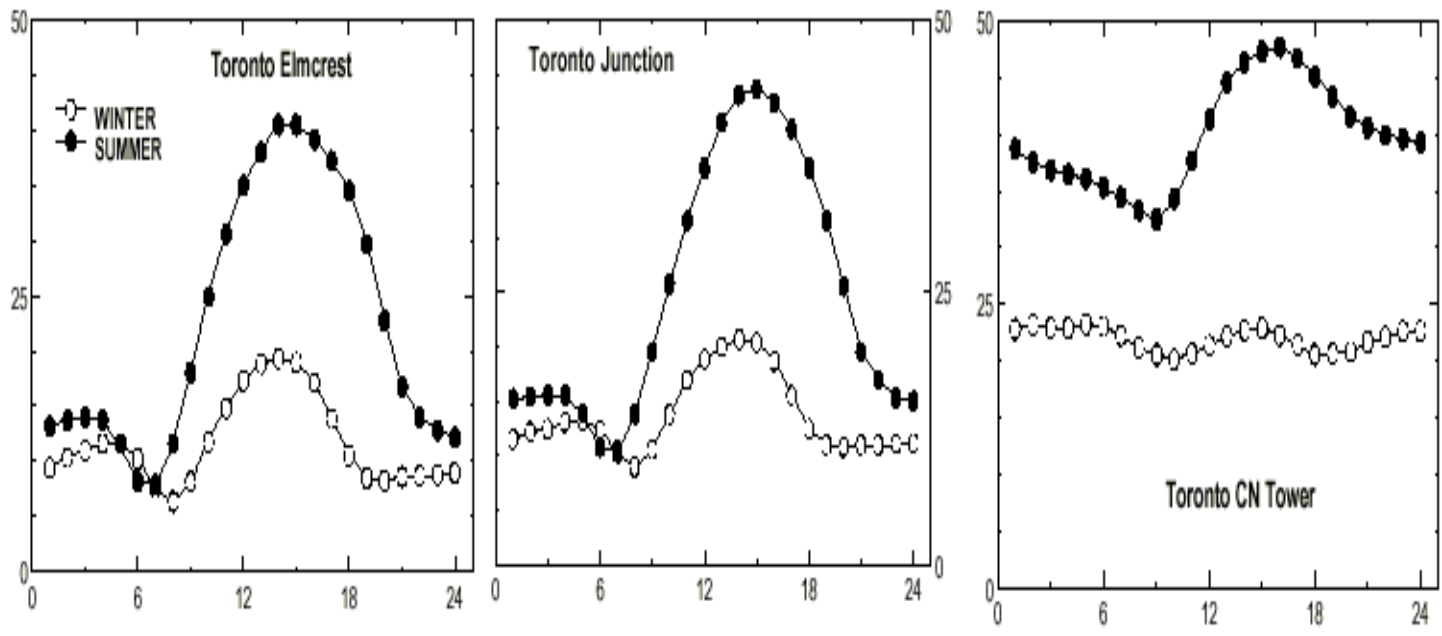

Figure 2.2: Hourly average ozone mixing ratios, ppb, for summer and winter (1986-1993) in Toronto. Source: Environment Canada, 1996. (Horizontal axis is time, LST). 

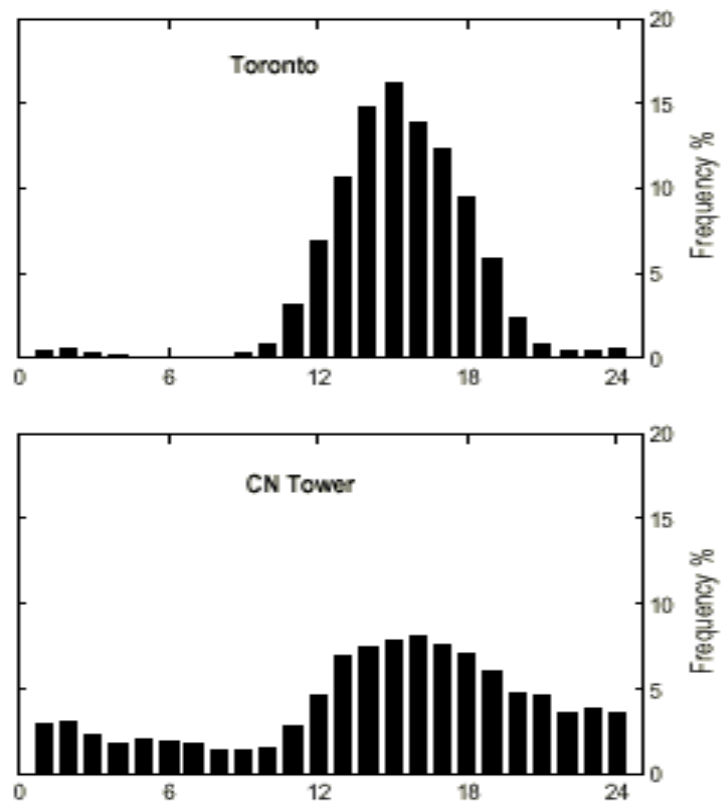

Figure 2.3: Percentage occurrence of hours with ozone mixing ratios greater than $82 \mathrm{ppb}$ by time of day (1986-1993) Toronto. Source: Environment Canada, 1996.

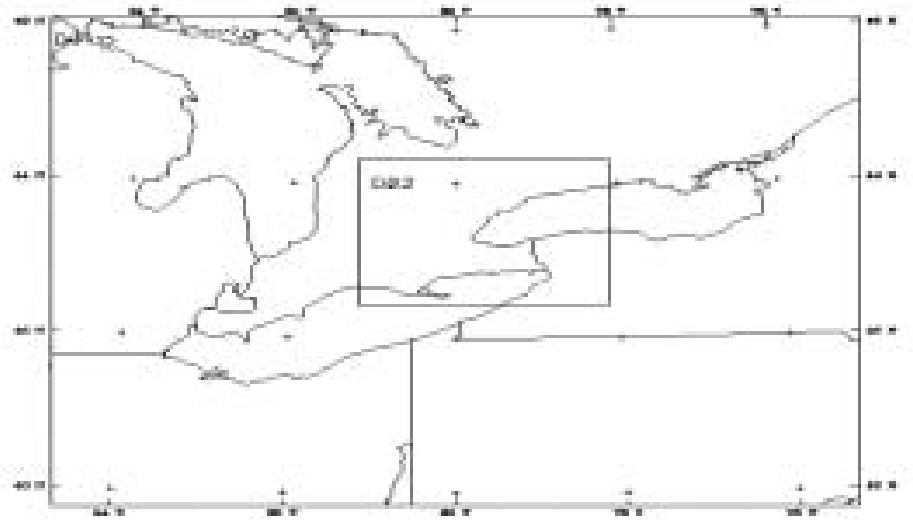

Figure 3.1. Modeling domains for the MM5 simulations. D01 has a resolution of $8 \mathrm{~km}$ and D02 a resolution of $2 \mathrm{~km}$. 


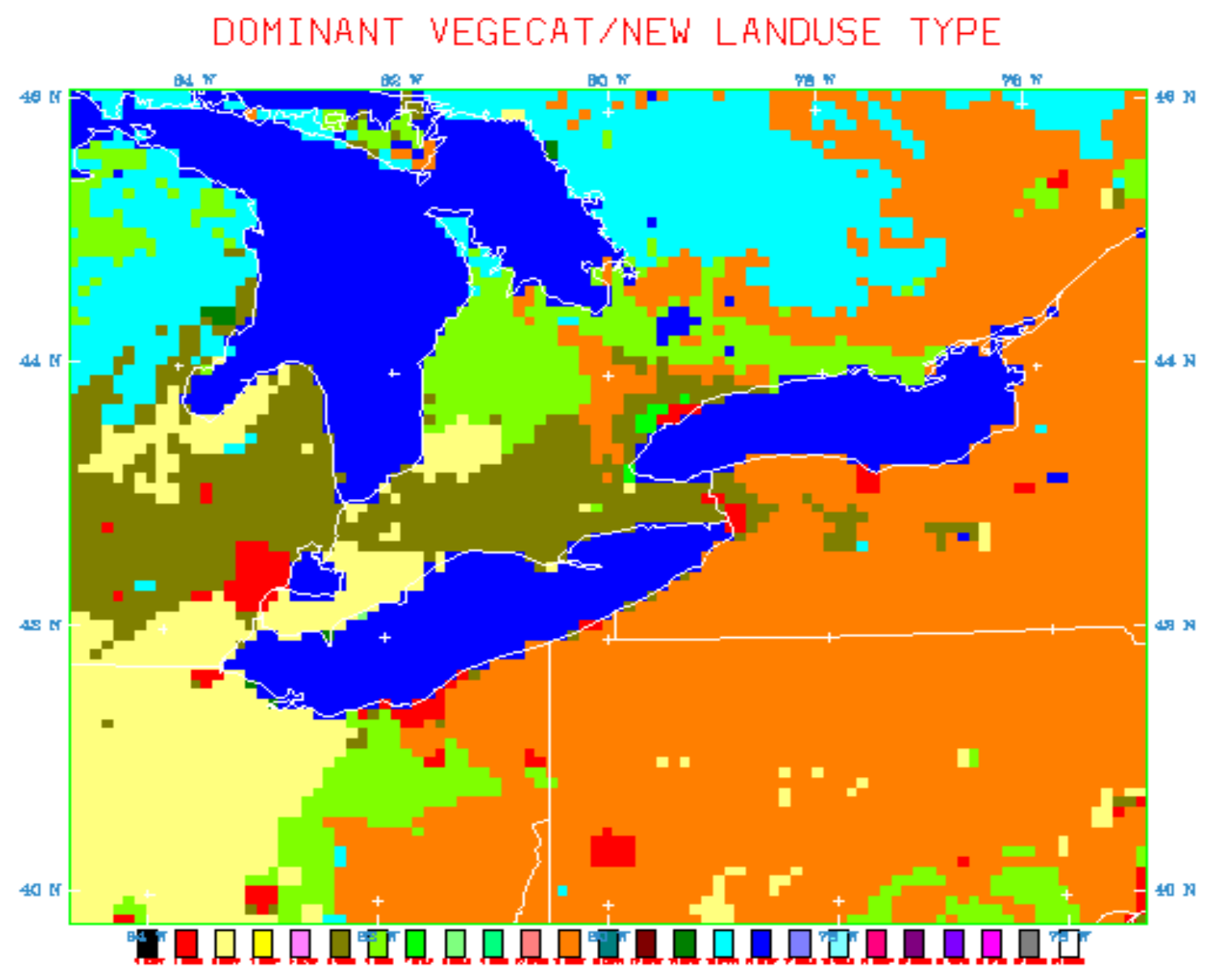

Figure 3.2. Land-use and land-cover categories in the coarse domain. Red color denotes urban areas. 


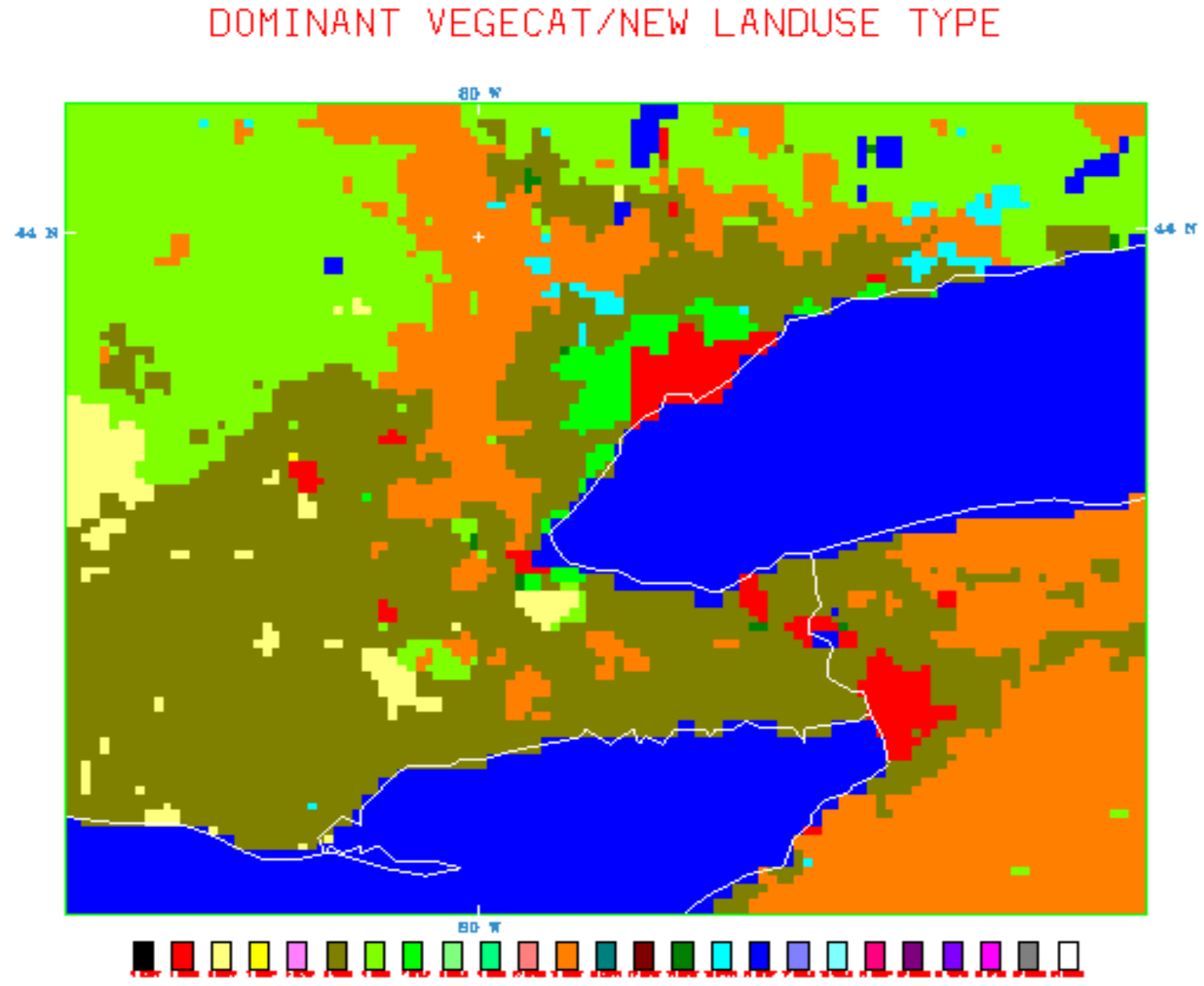

Figure 3.3. Land-use and land-cover distribution in the fine domain. Red color denotes urban areas. 


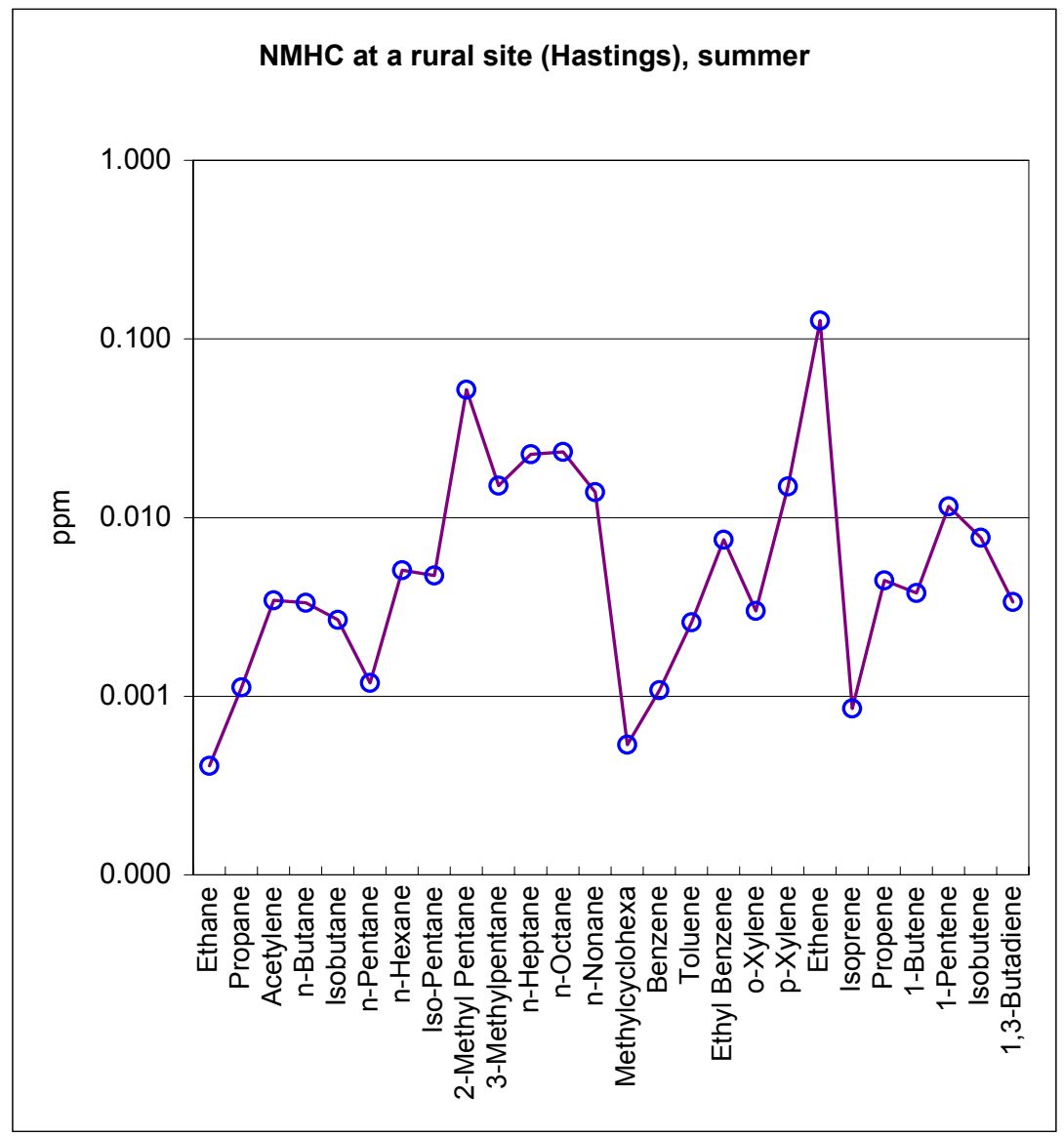

Figure 3.4. Initial conditions (doubled initial mixing ratios) for NMHC at Hastings, Canada in the summer. 

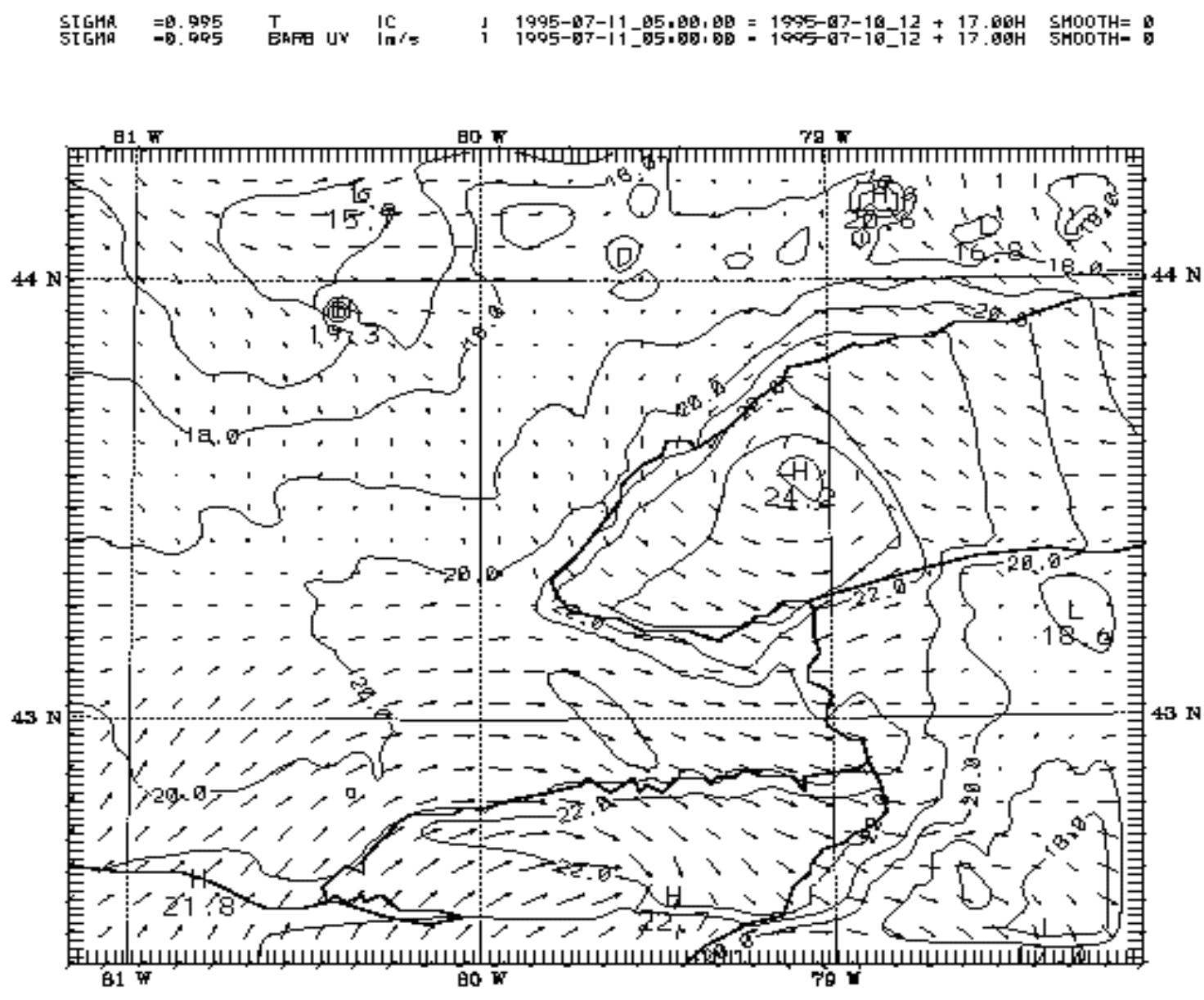

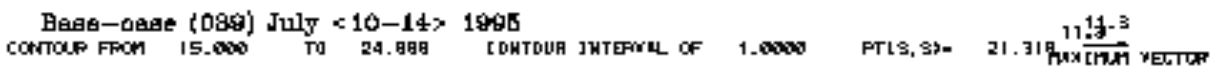

Figure 4.1. July 11, 1995 at 0000 LST base case scenario: Simulated temperature and wind-vector field, for the inner, fine-resolution $(2-\mathrm{km})$ domain. 


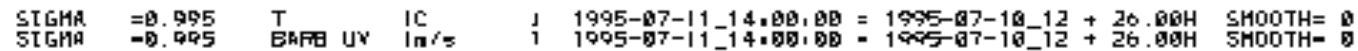

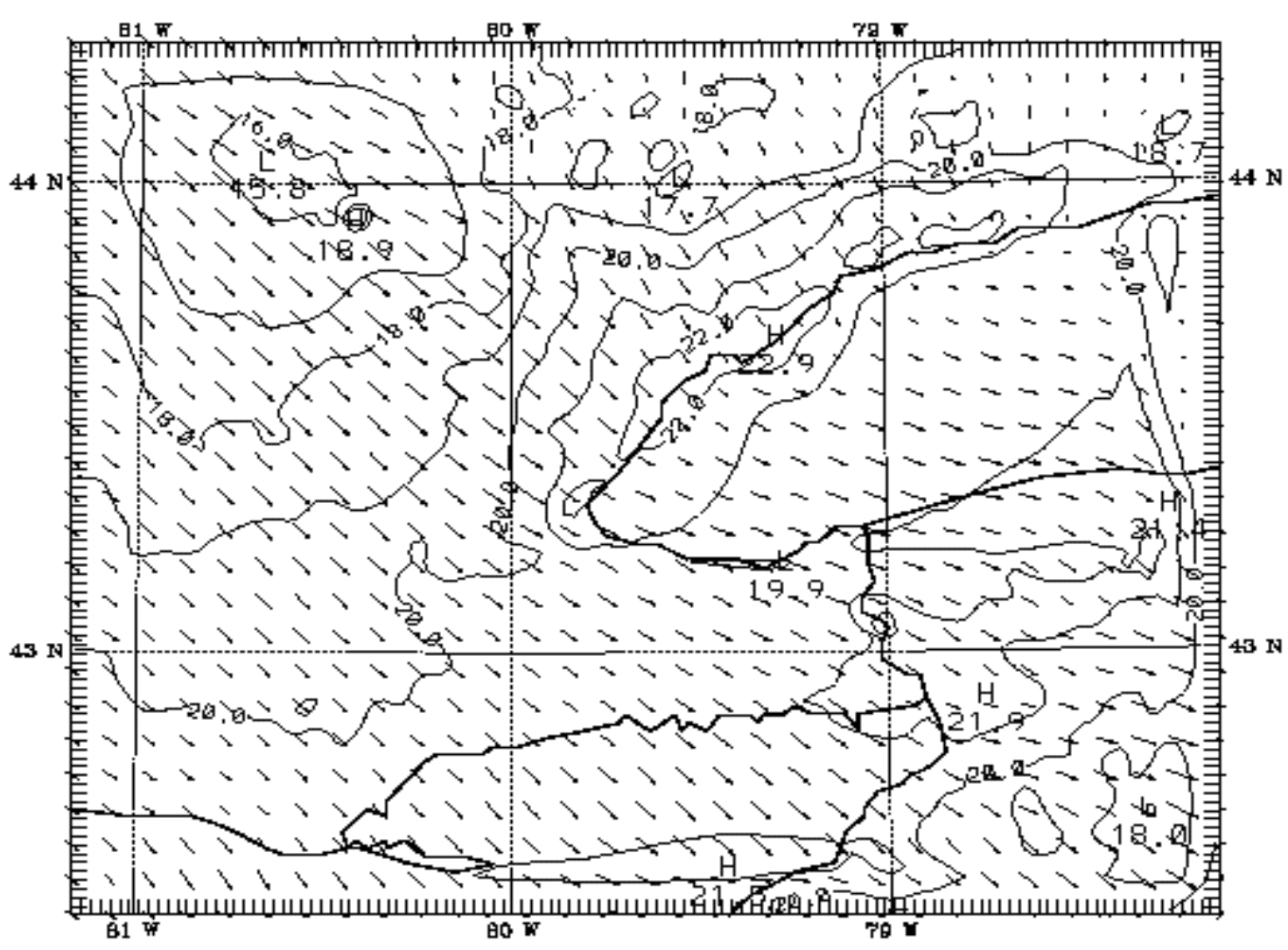

Beag-0age (089) July $<10-14>1965$
contop FFom 15.000

Figure 4.2. July 11, 1995 at 0900 LST base case scenario: Simulated temperature and wind-vector field, for the inner, fine-resolution $(2-\mathrm{km})$ domain. 


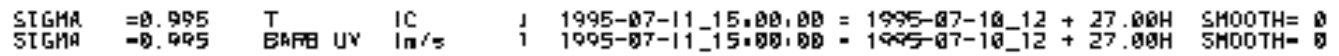

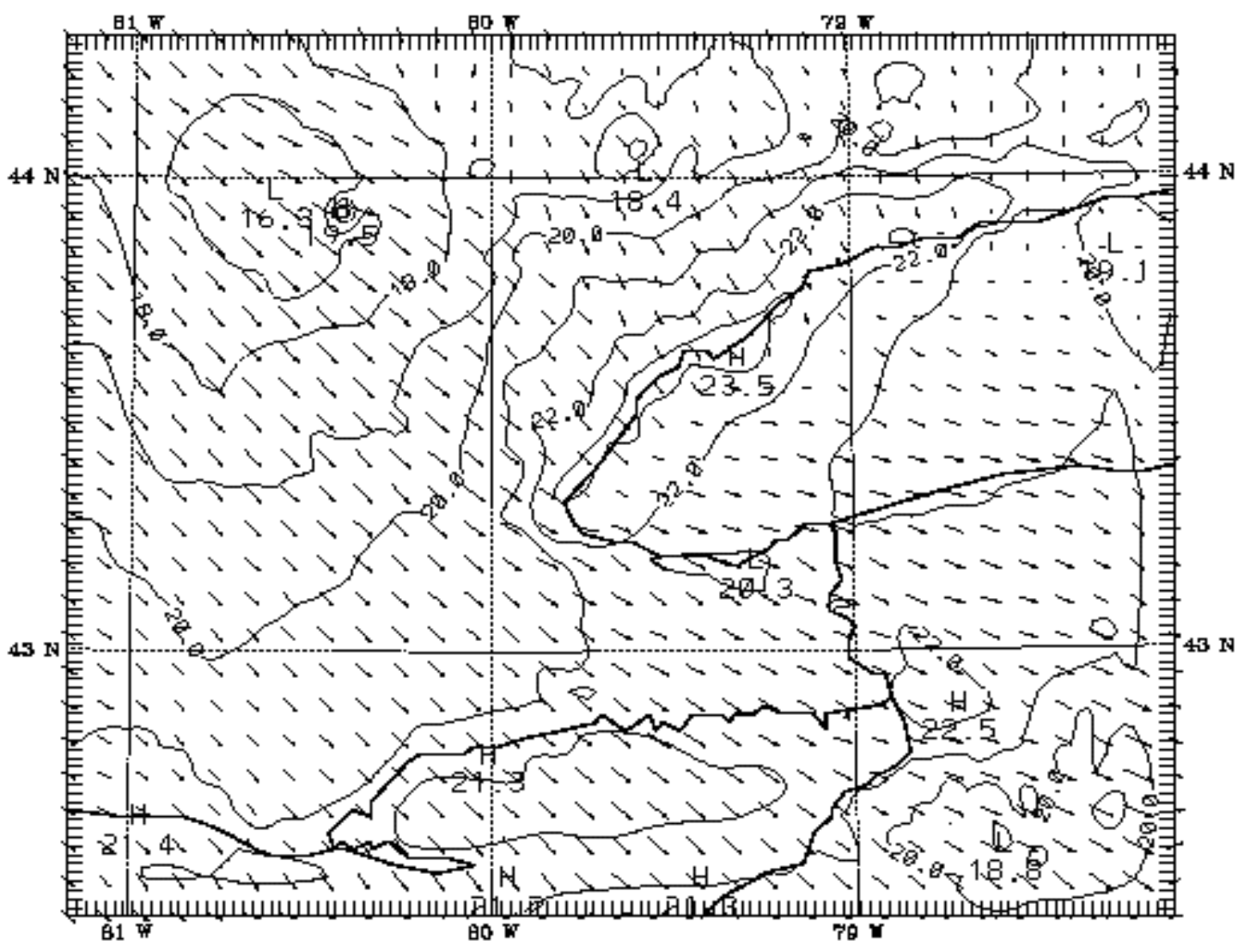

Beag-0age (009) July $<10-14>1995$
cotrop Fon 16.000

Figure 4.3. July 11, 1995 at 1000 LST base case scenario: Simulated temperature and wind-vector field, for the inner, fine-resolution $(2-\mathrm{km})$ domain. 


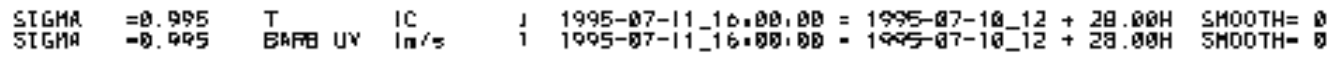

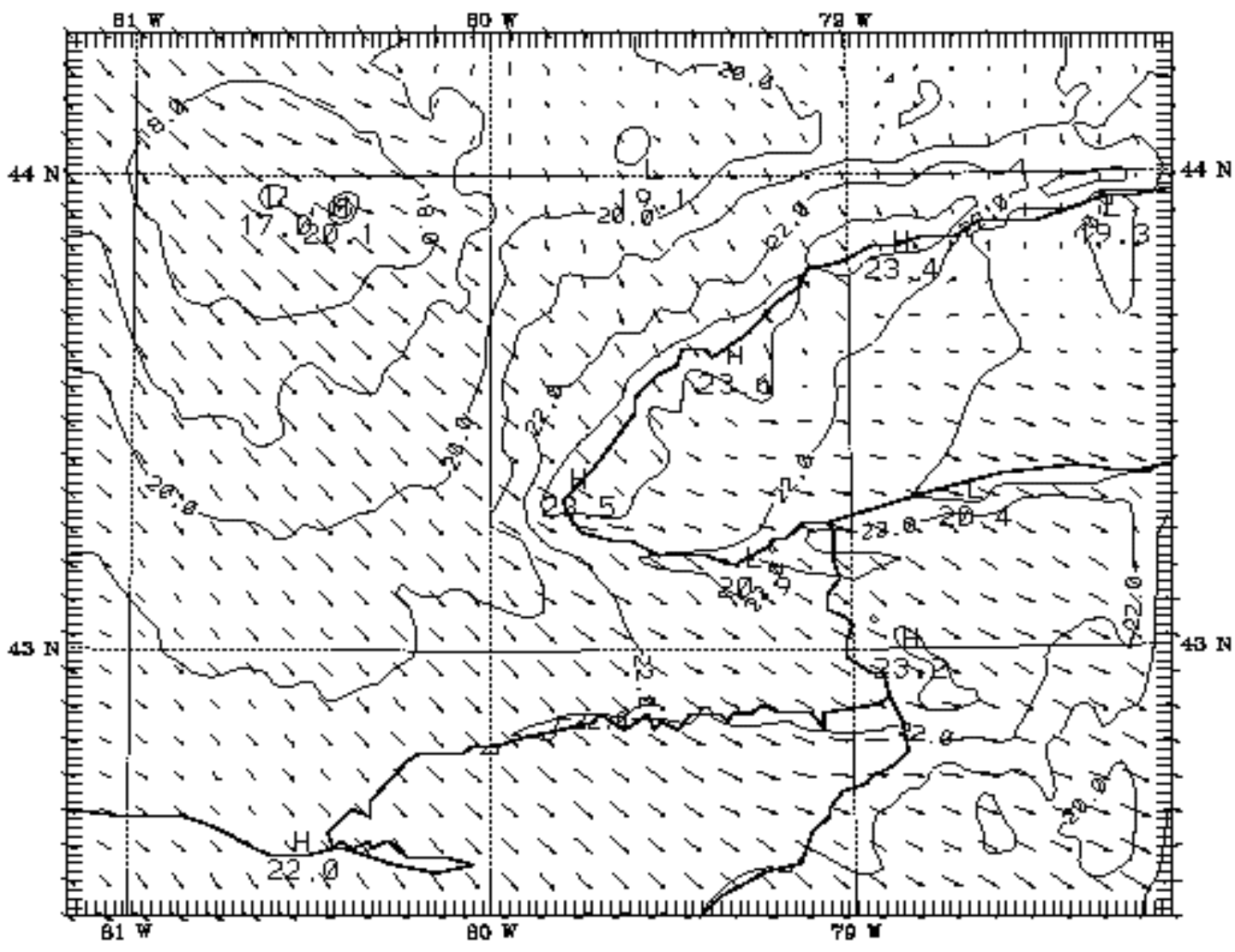

Beas-0age (089) July $<10-14>1995$
cortop FFon 16.000

Figure 4.4. July 11, 1995 at 1100 LST base case scenario: Simulated temperature and wind-vector field, for the inner, fine-resolution $(2-\mathrm{km})$ domain. 


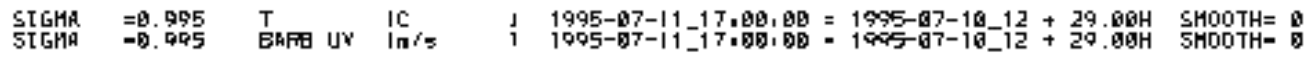

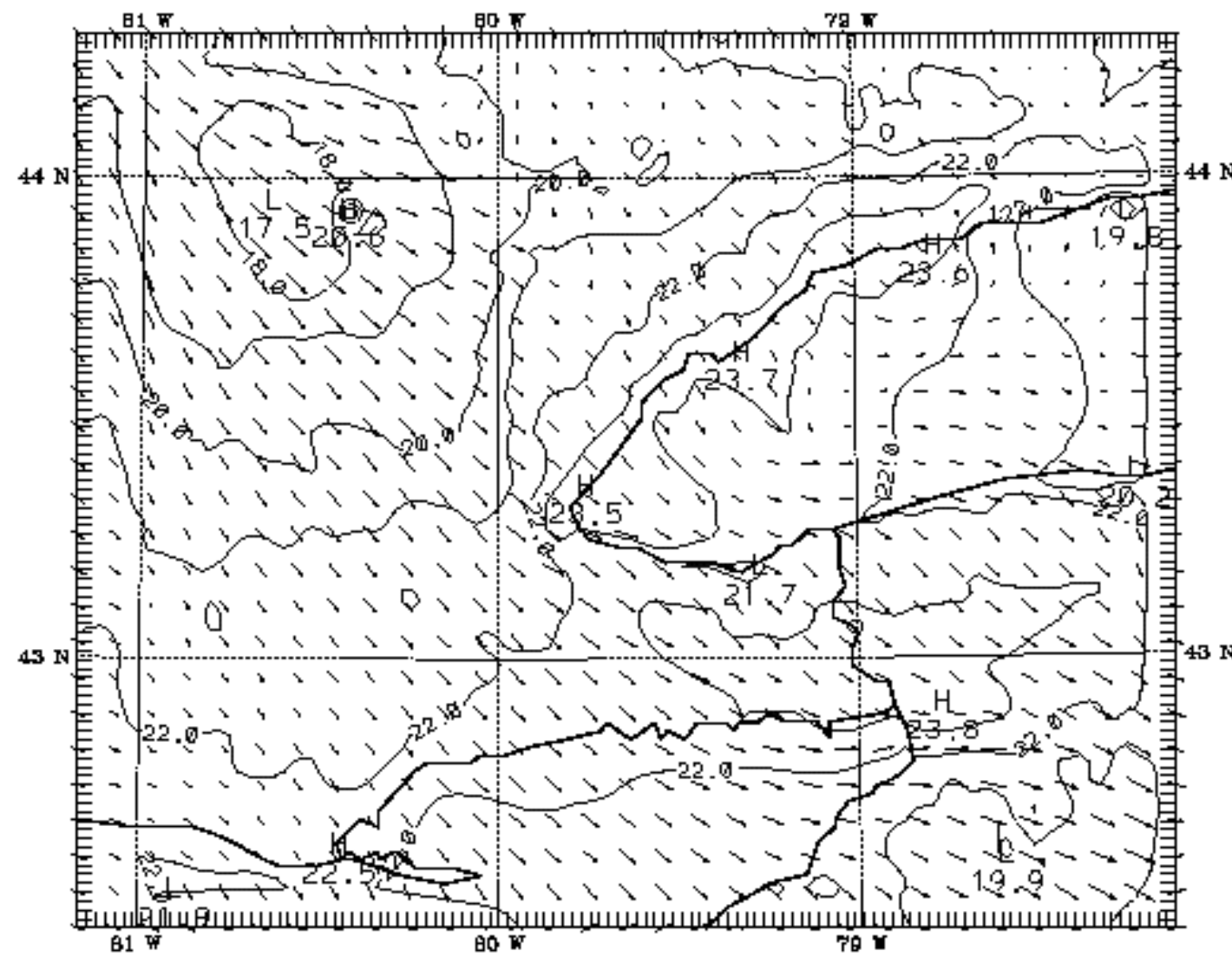

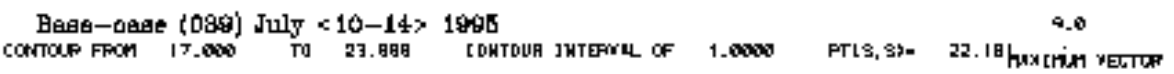

Figure 4.5. July 11, 1995 at 1200 LST base case scenario: Simulated temperature and wind-vector field, for the inner, fine-resolution $(2-\mathrm{km})$ domain. 


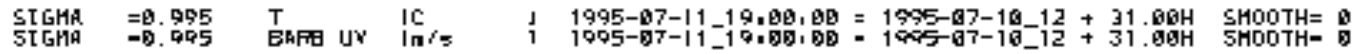

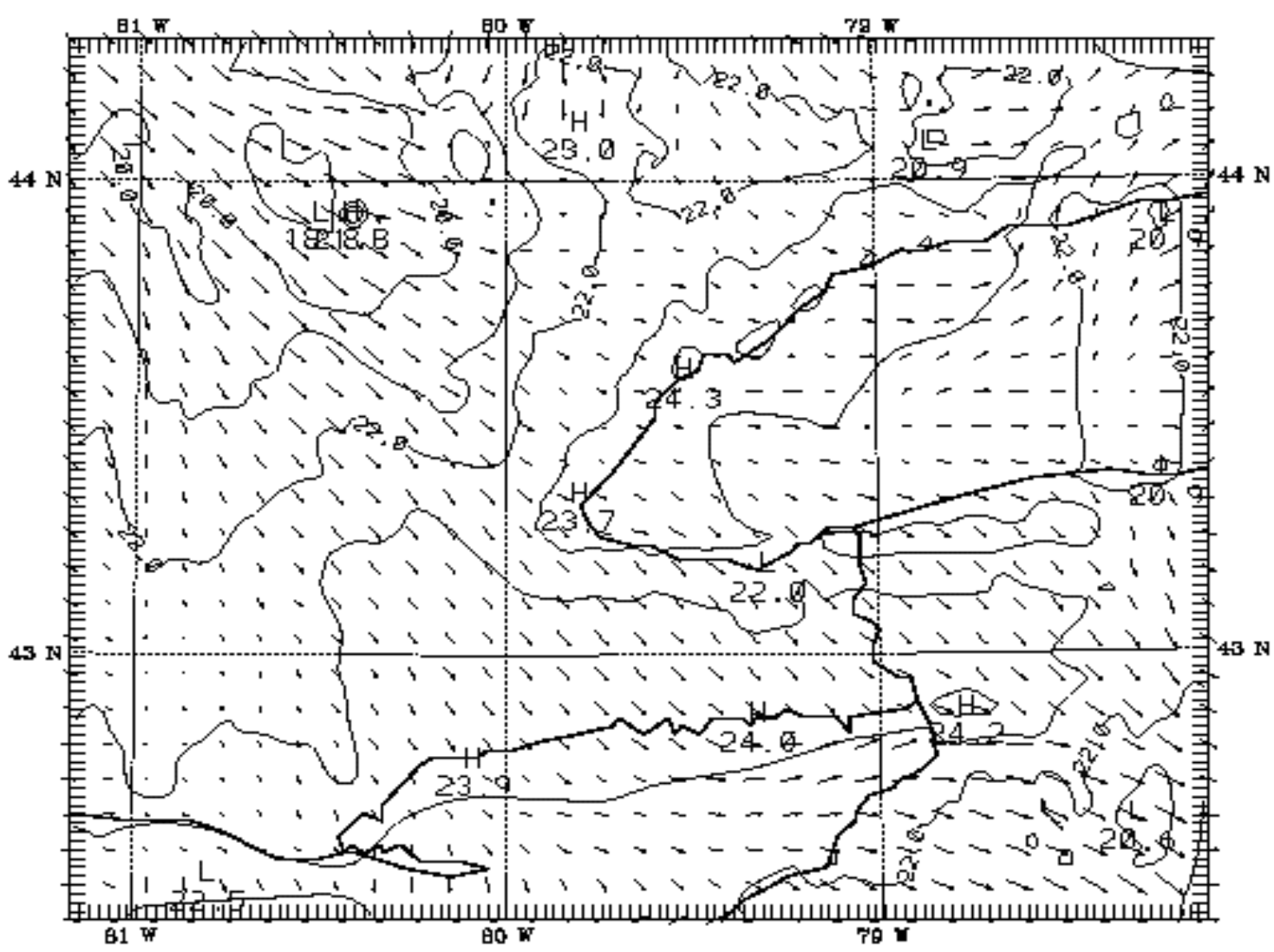

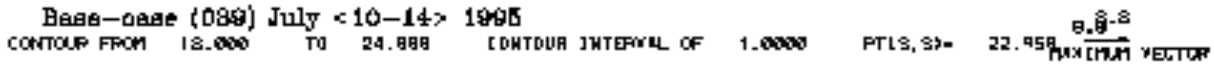

Figure 4.6. July 11, 1995 at 1400 LST base case scenario: Simulated temperature and wind-vector field, for the inner, fine-resolution (2-km) domain. 


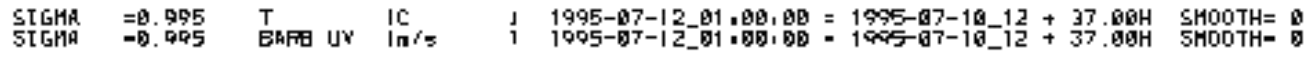

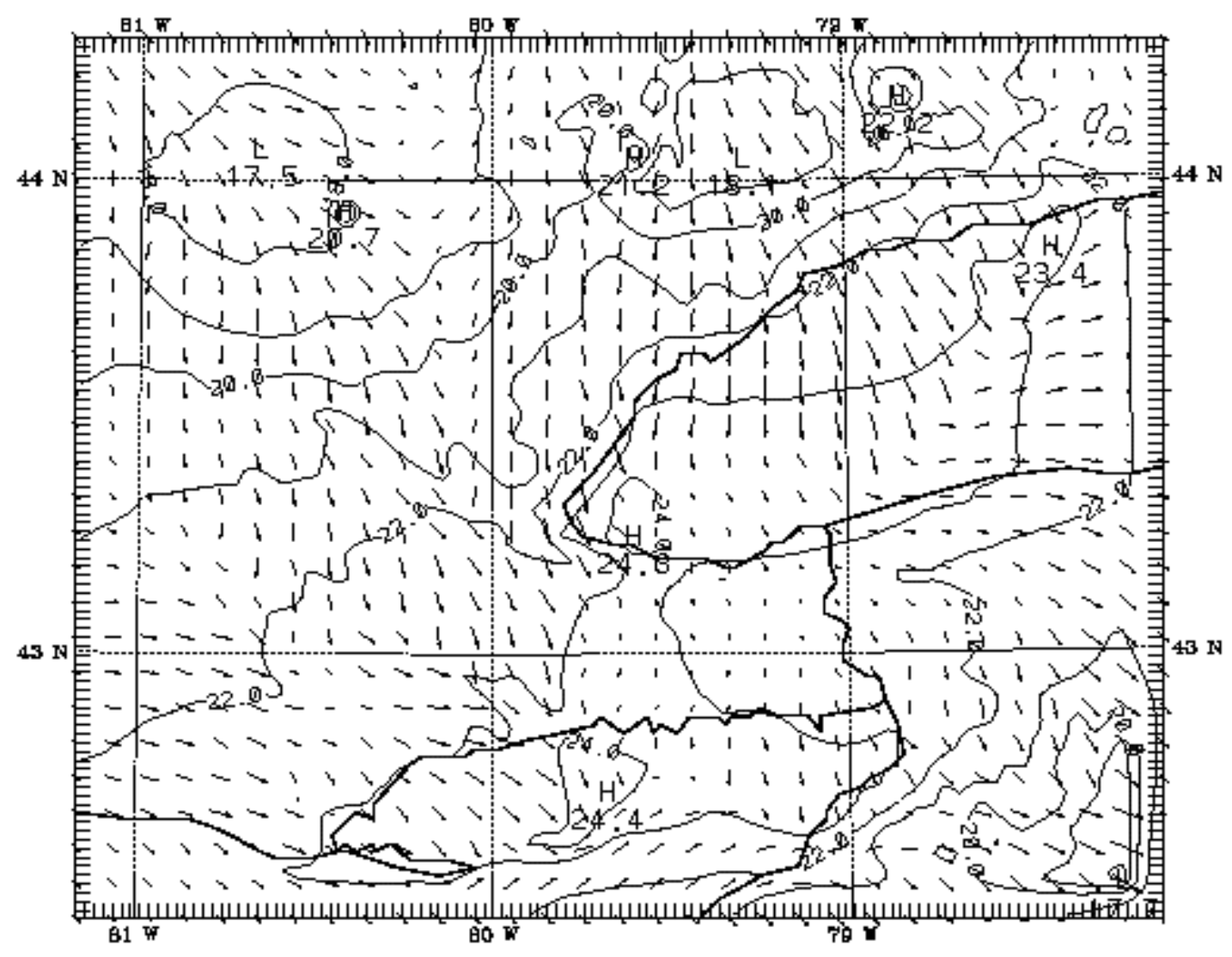

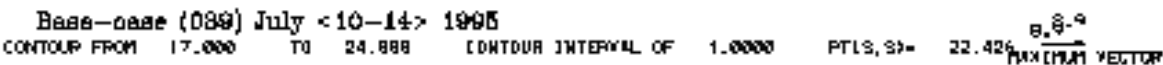

Figure 4.7. July 11, 1995 at 2000 LST base case scenario: Simulated temperature and wind-vector field, for the inner, fine-resolution $(2-\mathrm{km})$ domain. 


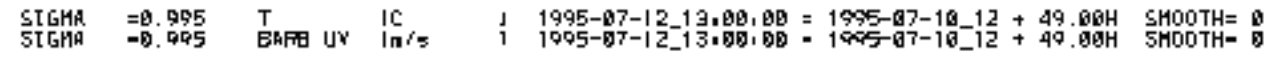

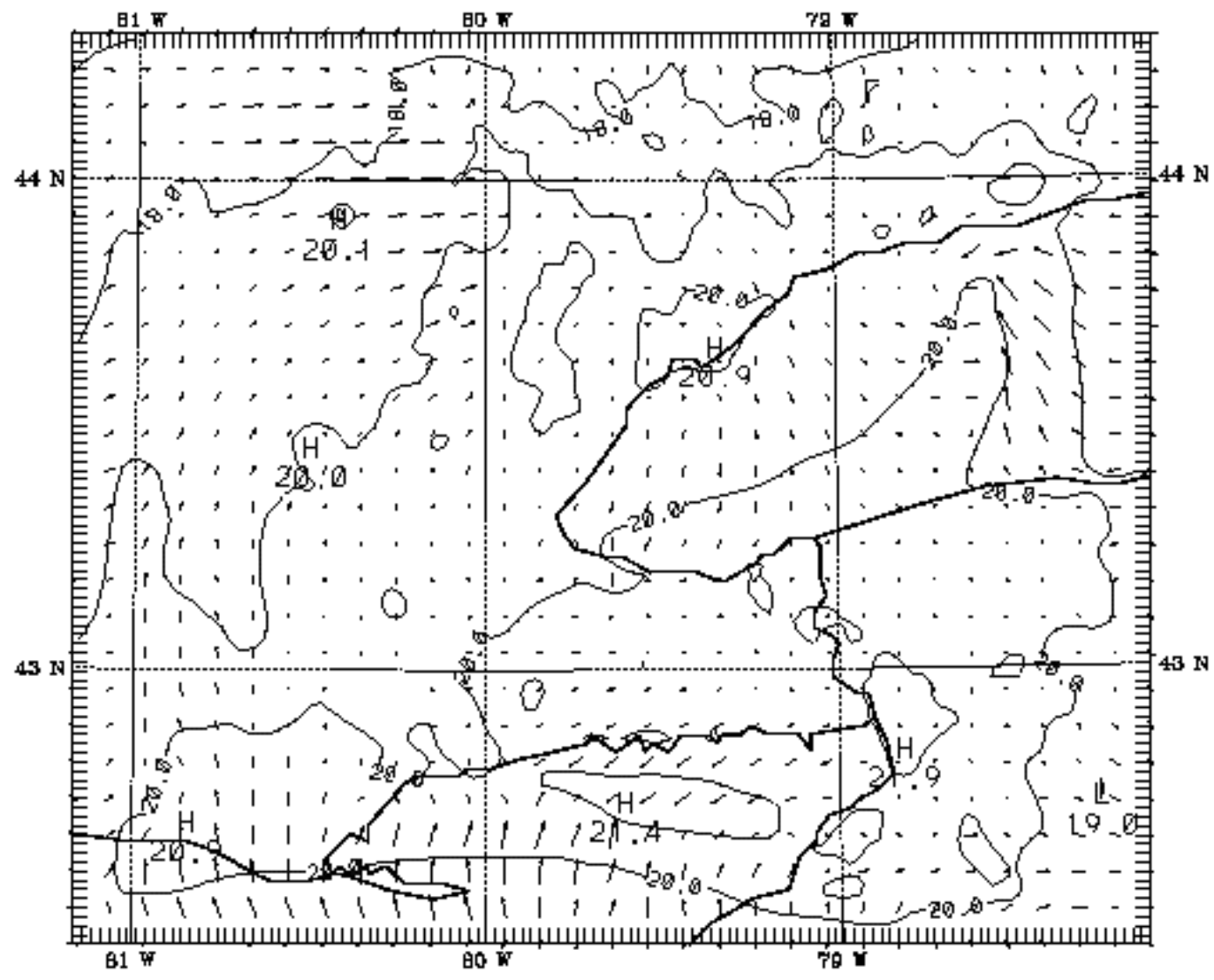

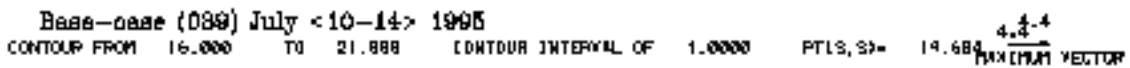

Figure 4.8. July 12, 1995 at 0800 LST base case scenario: Simulated temperature and wind-vector field, for the inner, fine-resolution $(2-\mathrm{km})$ domain. 


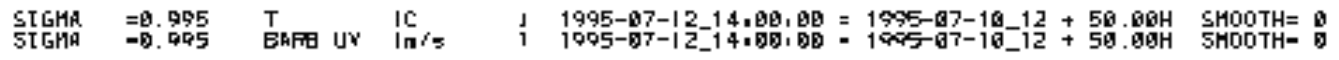

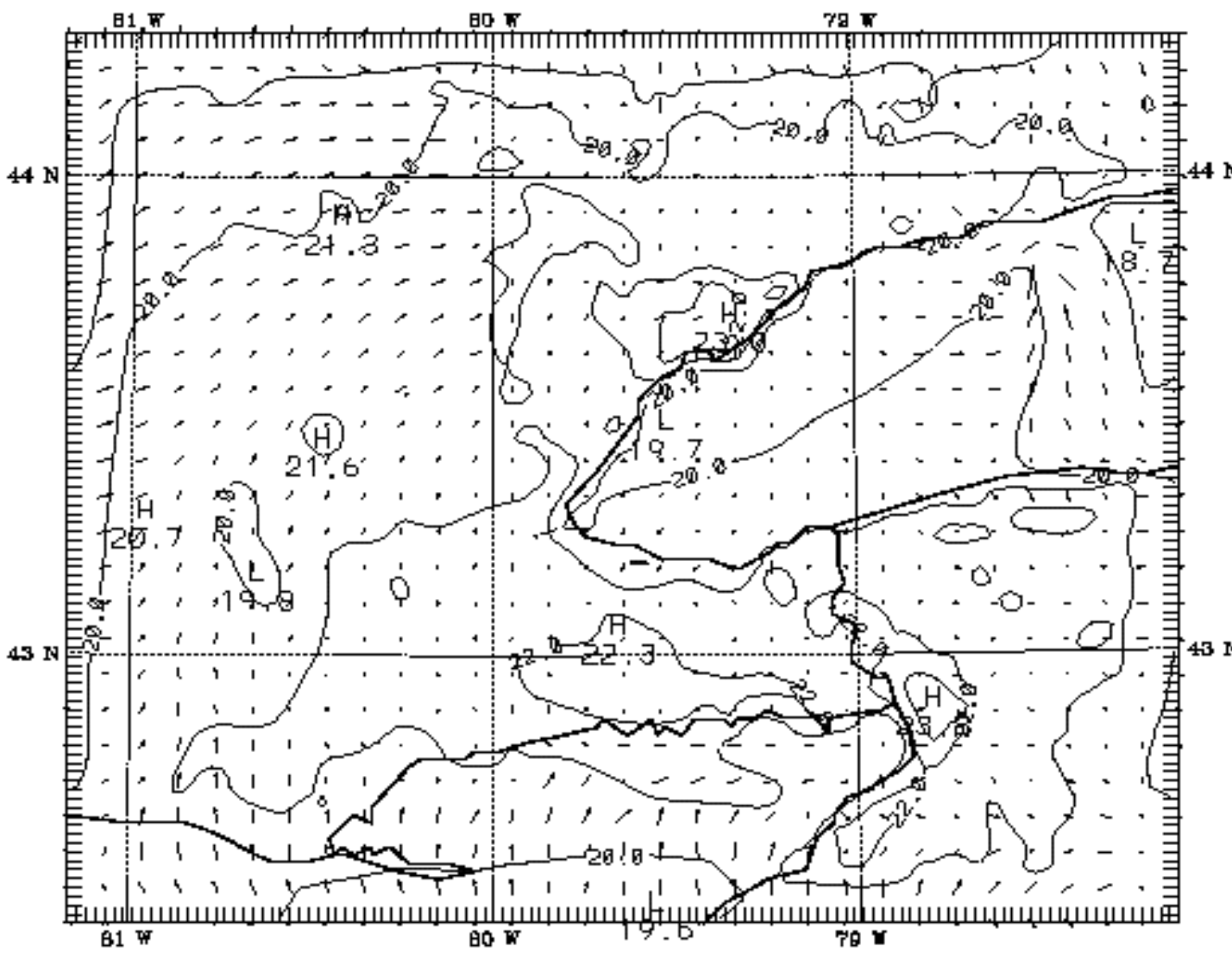

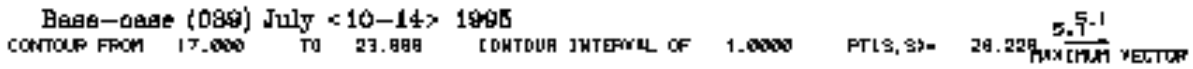

Figure 4.9. July 12, 1995 at 0900 LST base case scenario: Simulated temperature and wind-vector field, for the inner, fine-resolution $(2-\mathrm{km})$ domain. 

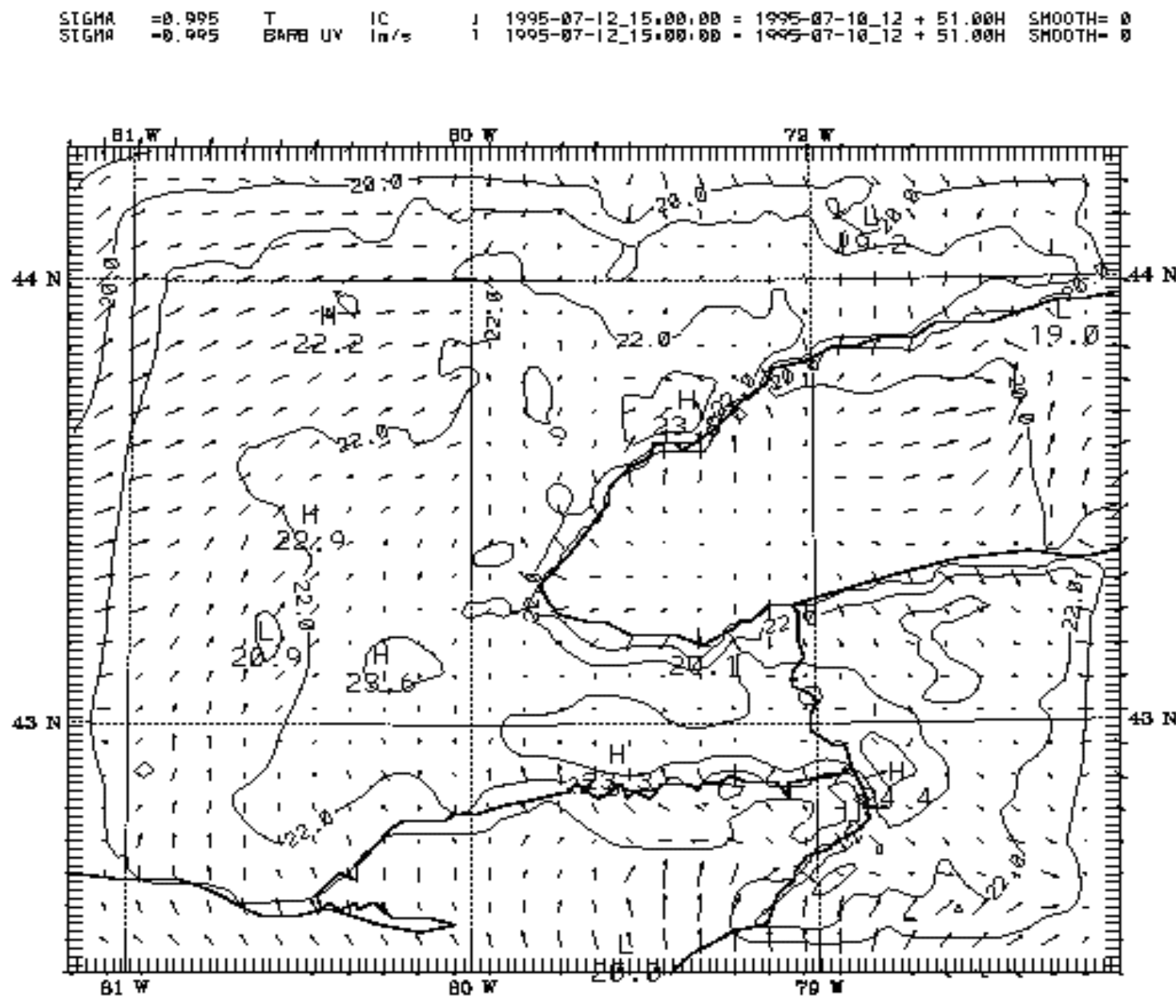

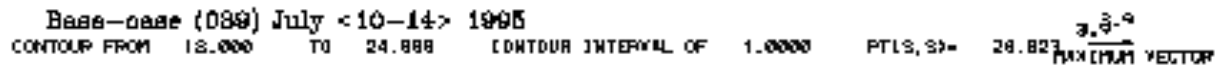

Figure 4.10. July 12, 1995 at 1000 LST base case scenario: Simulated temperature and wind-vector field, for the inner, fine-resolution $(2-\mathrm{km})$ domain. 


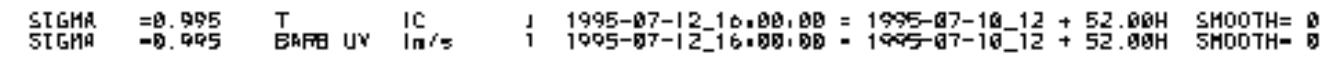

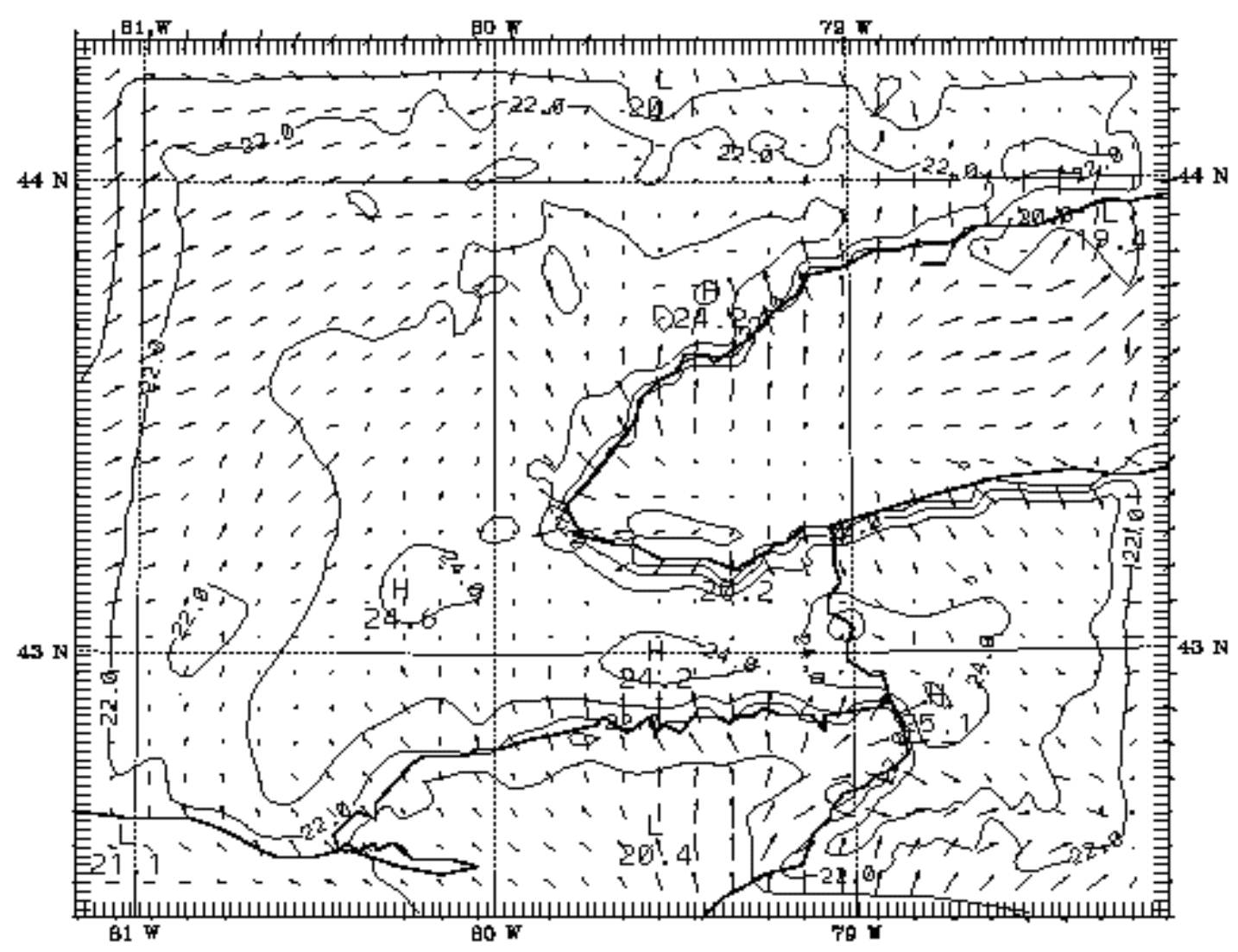

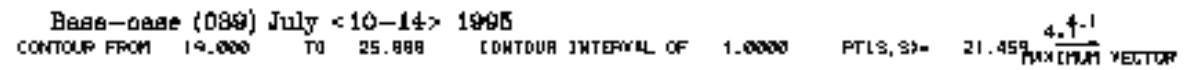

Figure 4.11. July 12, 1995 at 1100 LST base case scenario: Simulated temperature and wind-vector field, for the inner, fine-resolution $(2-\mathrm{km})$ domain. 


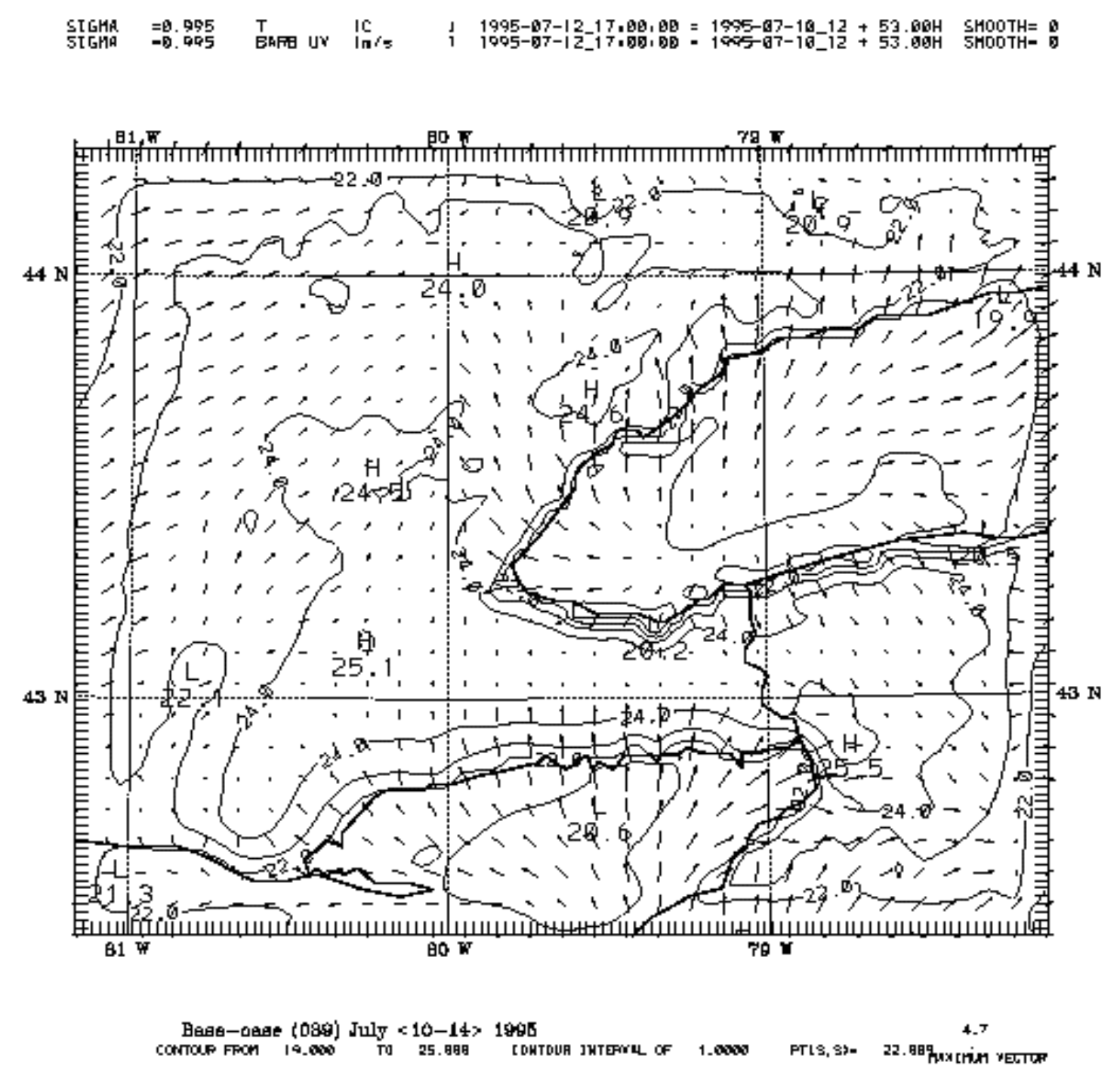

Figure 4.12. July 12, 1995 at 1200 LST base case scenario: Simulated temperature and wind-vector field, for the inner, fine-resolution $(2-\mathrm{km})$ domain. 


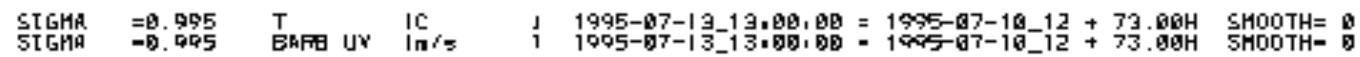

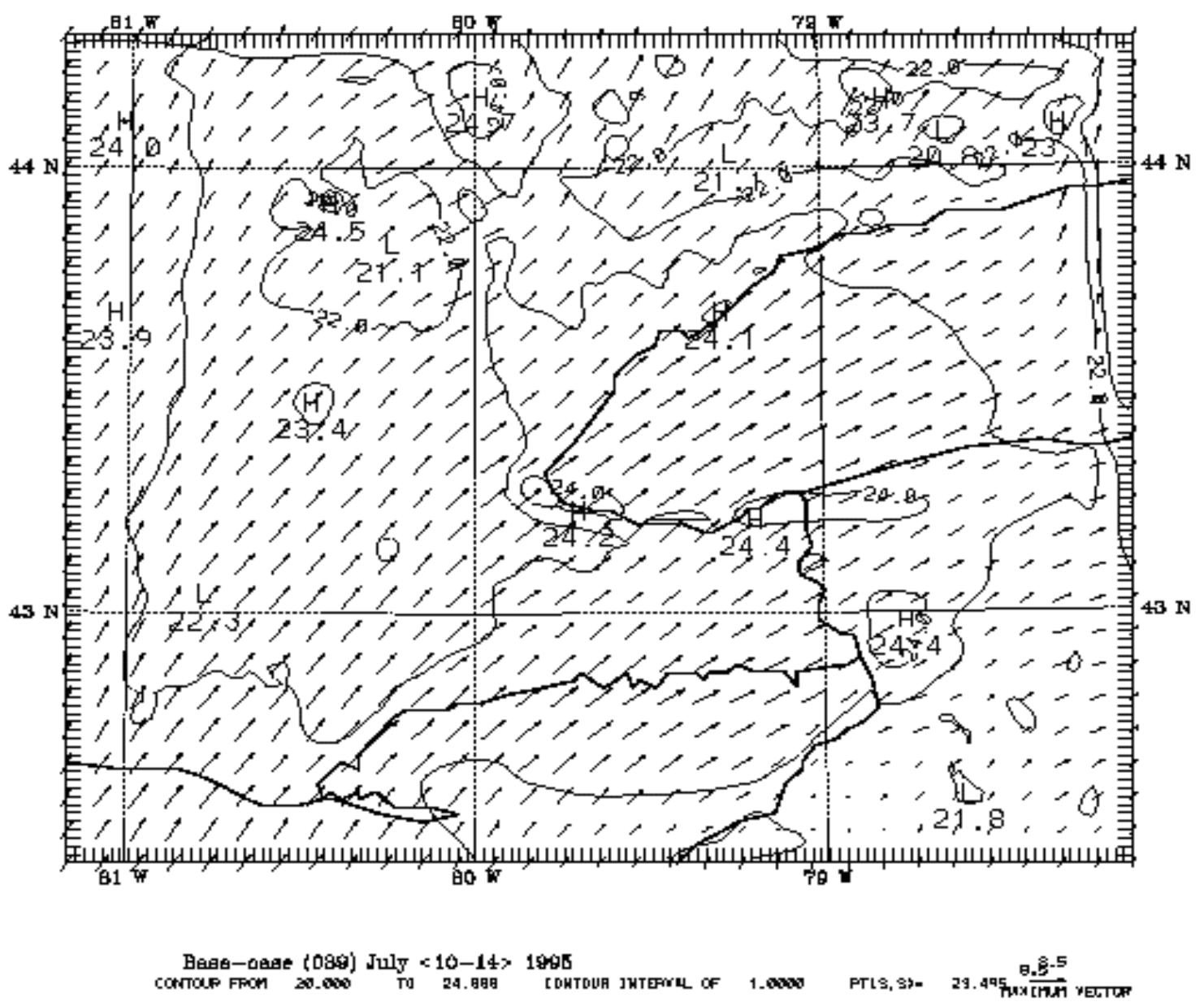

Figure 4.13. July 13, 1995 at 0800 LST base case scenario: Simulated temperature and wind-vector field, for the inner, fine-resolution $(2-\mathrm{km})$ domain. 


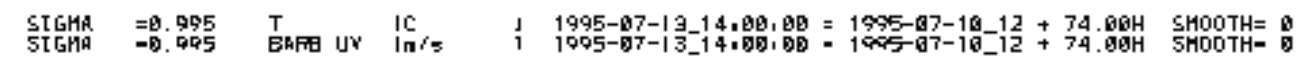

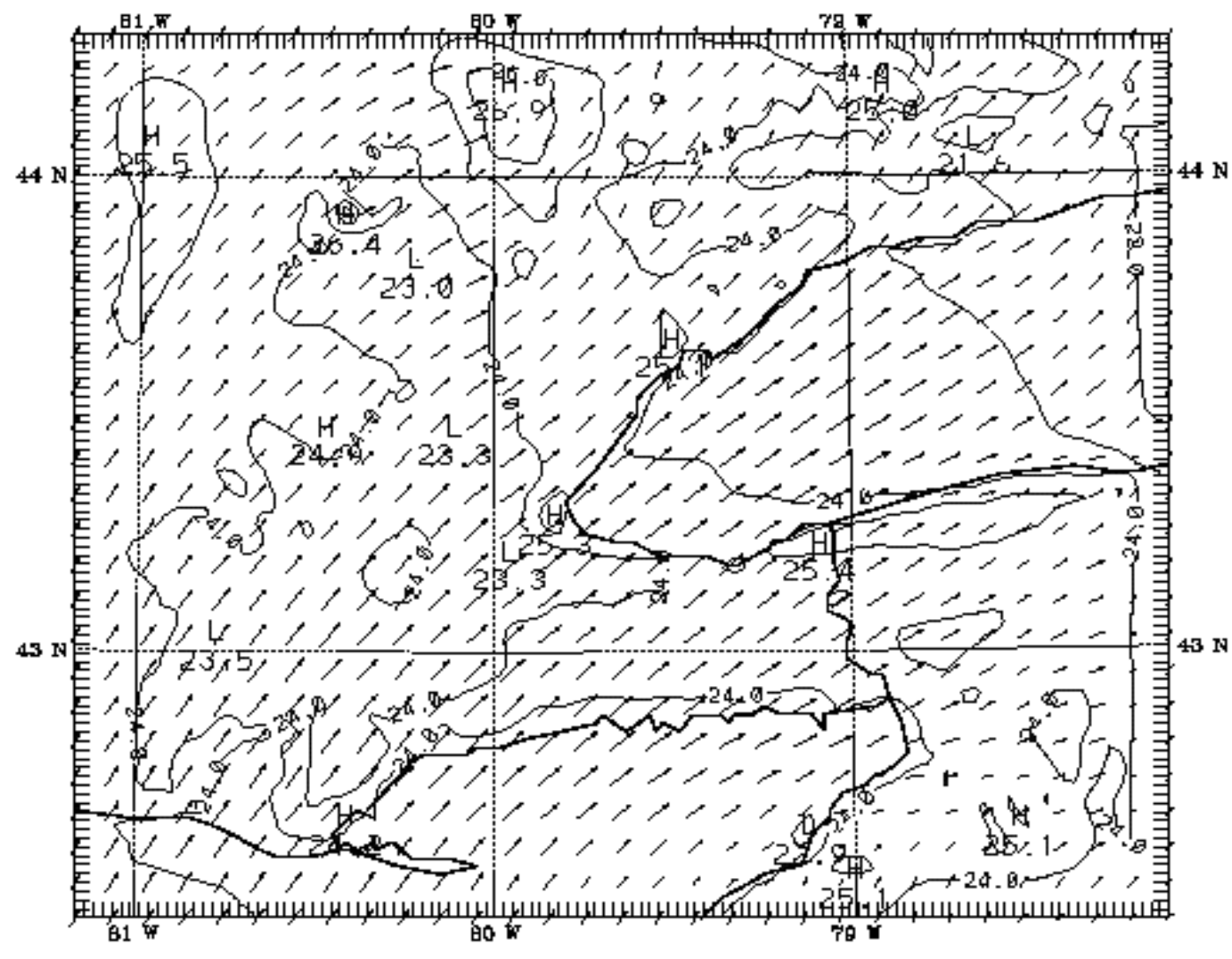

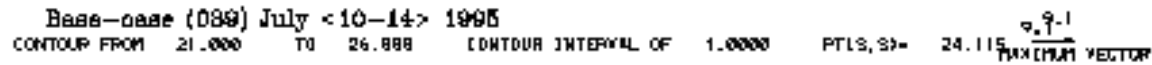

Figure 4.14. July 13, 1995 at 0900 LST base case scenario: Simulated temperature and wind-vector field, for the inner, fine-resolution $(2-\mathrm{km})$ domain. 

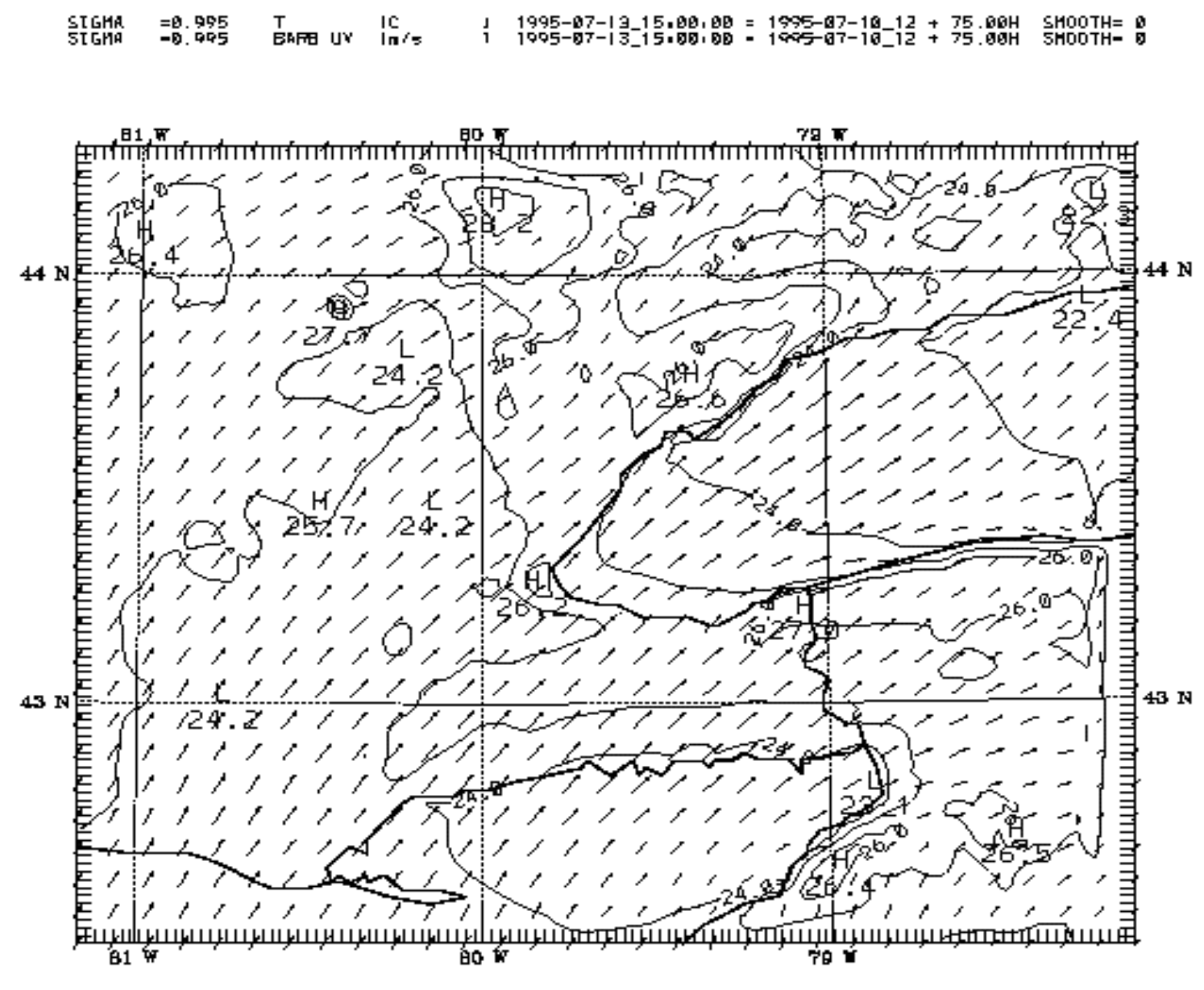

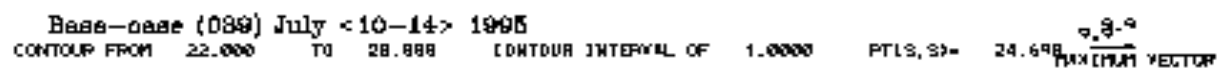

Figure 4.15. July 13, 1995 at 1000 LST base case scenario: Simulated temperature and wind-vector field, for the inner, fine-resolution (2-km) domain. 


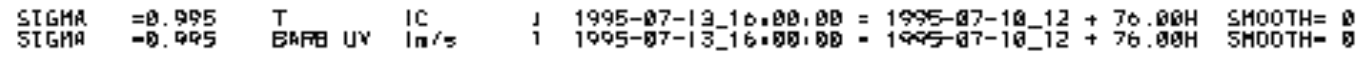

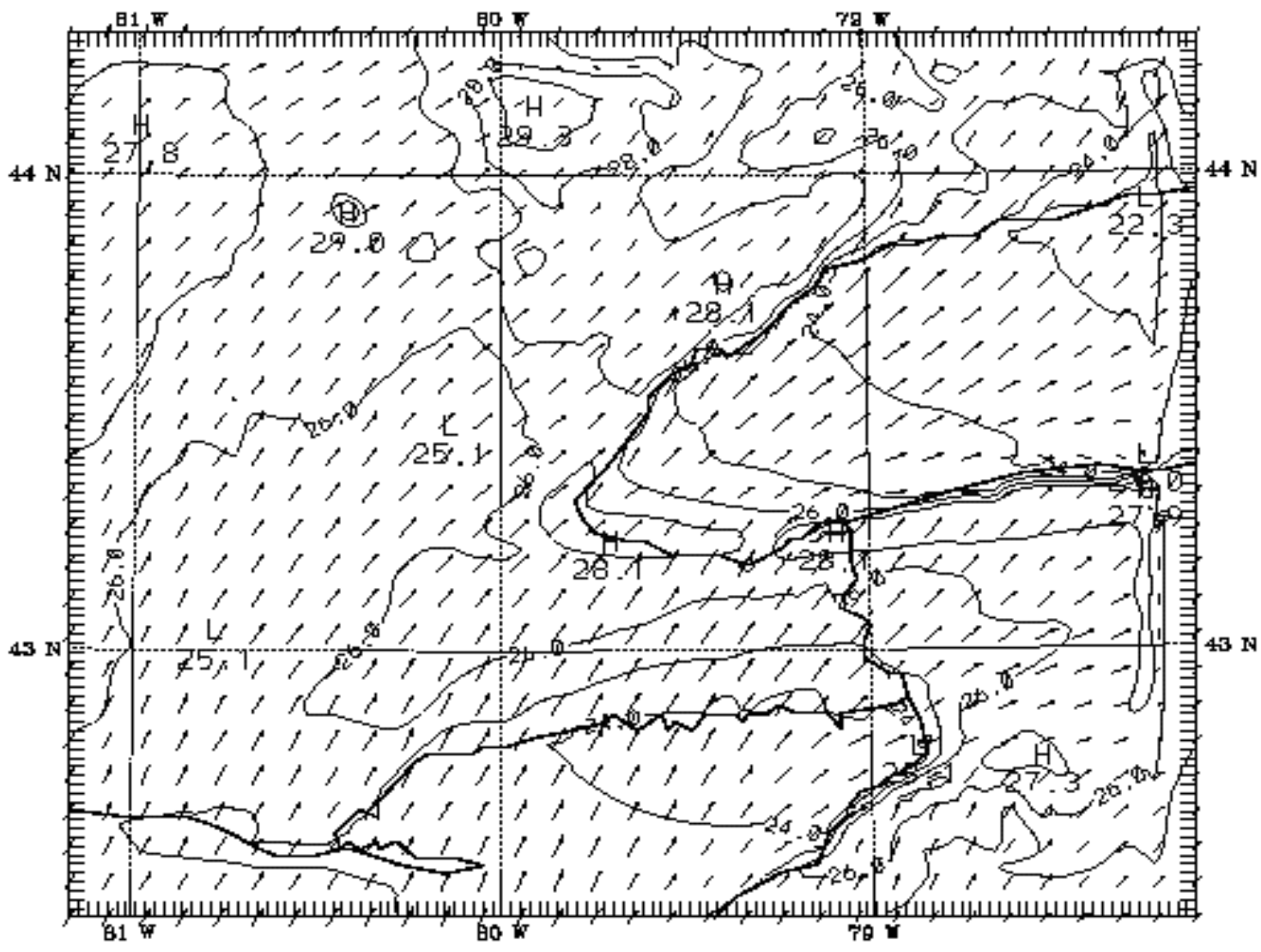

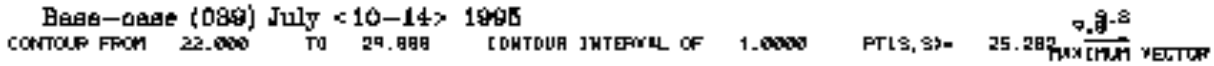

Figure 4.16. July 13, 1995 at 1100 LST base case scenario: Simulated temperature and wind-vector field, for the inner, fine-resolution $(2-\mathrm{km})$ domain. 

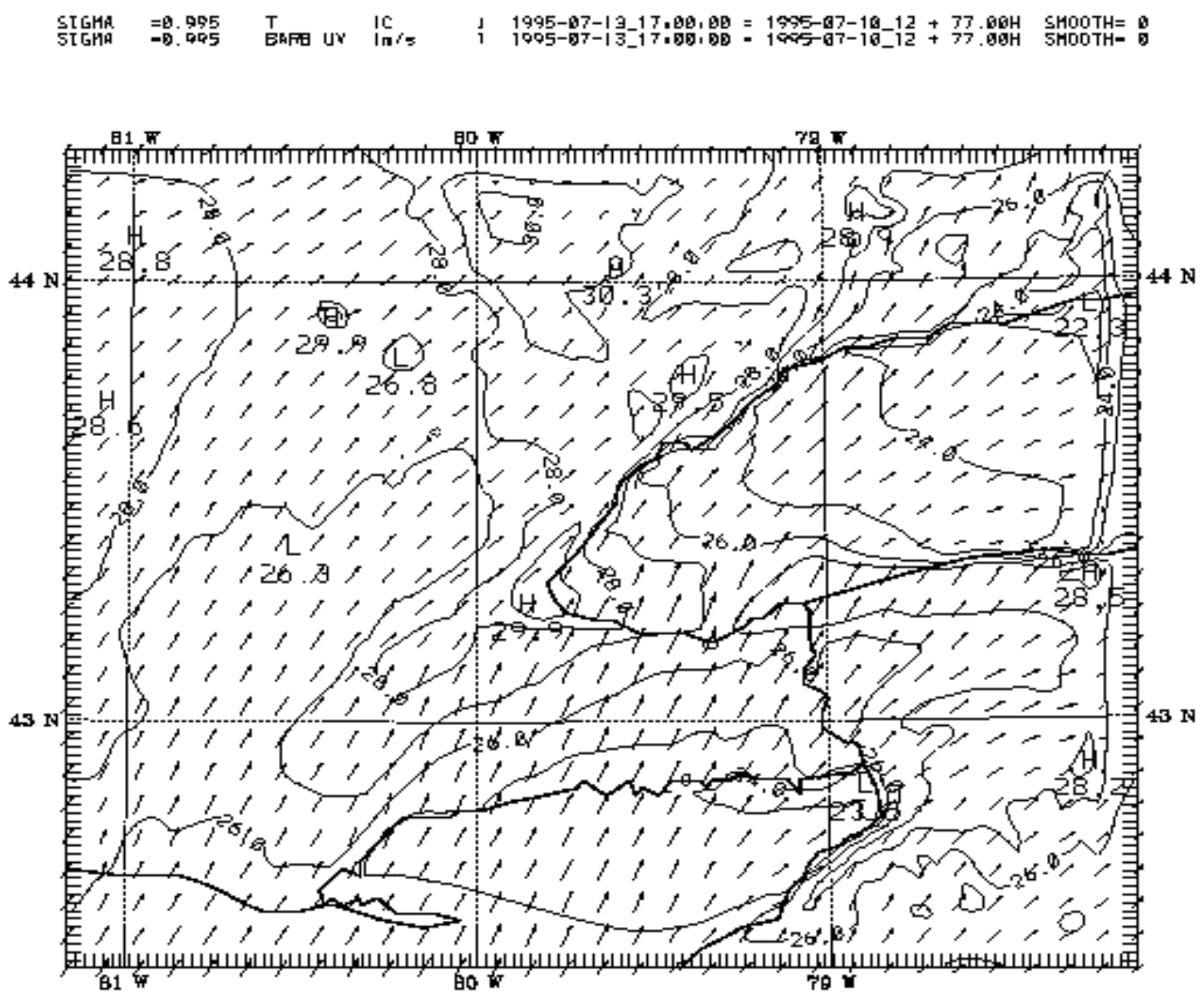

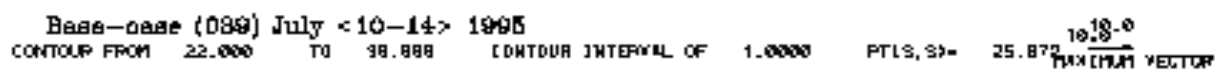

Figure 4.17. July 13, 1995 at 1200 LST base case scenario: Simulated temperature and wind-vector field, for the inner, fine-resolution (2-km) domain. 


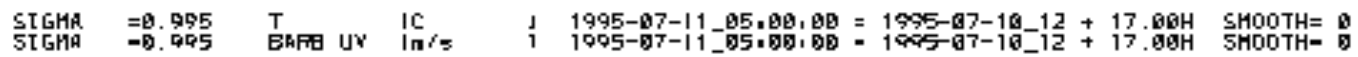

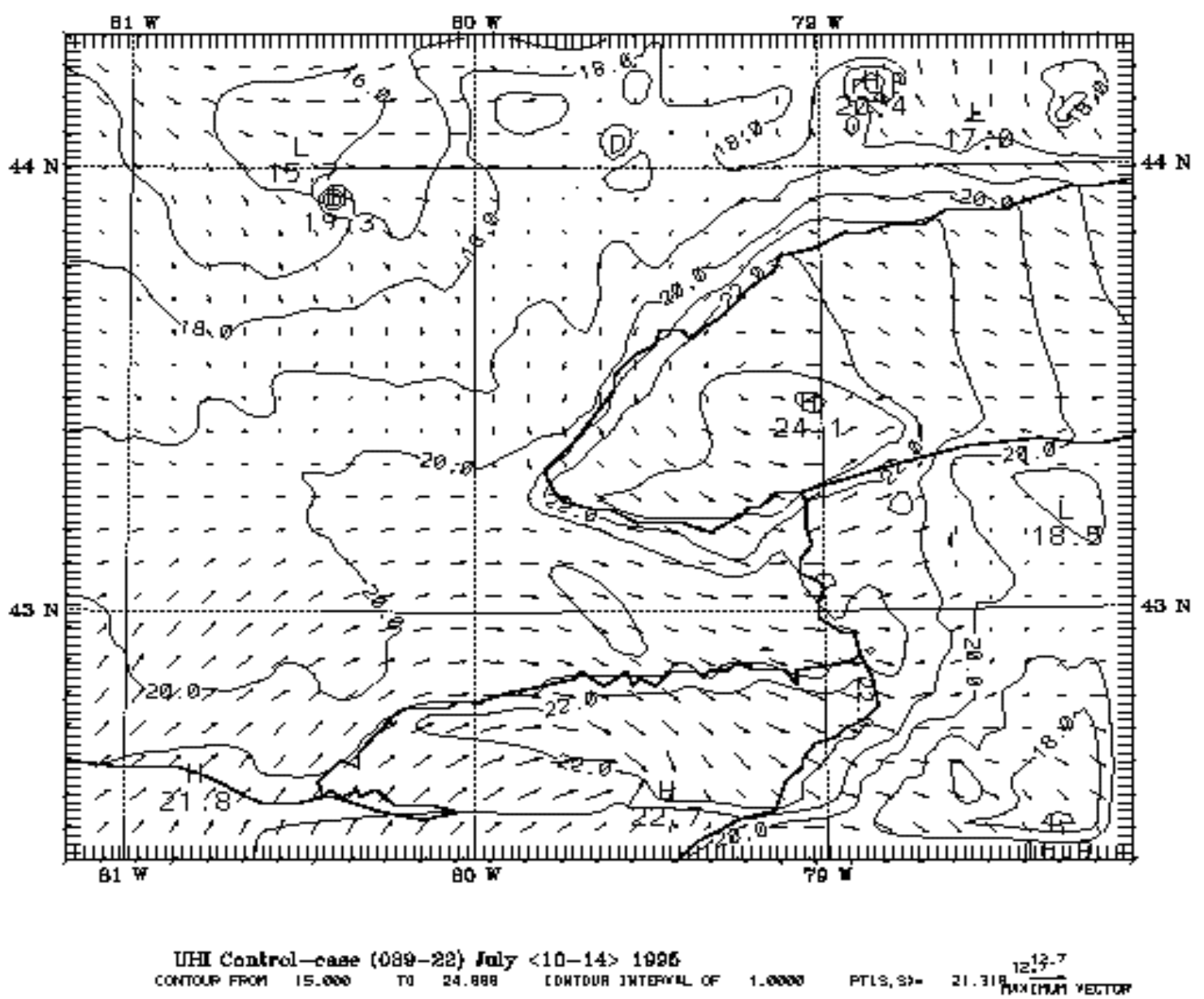

Figure 4.18. July 11, 1995 at 0000 LST cool-city scenario: Simulated temperature and wind-vector field, for the inner, fine-resolution (2-km) domain. 


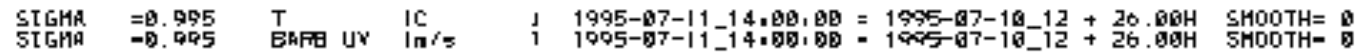

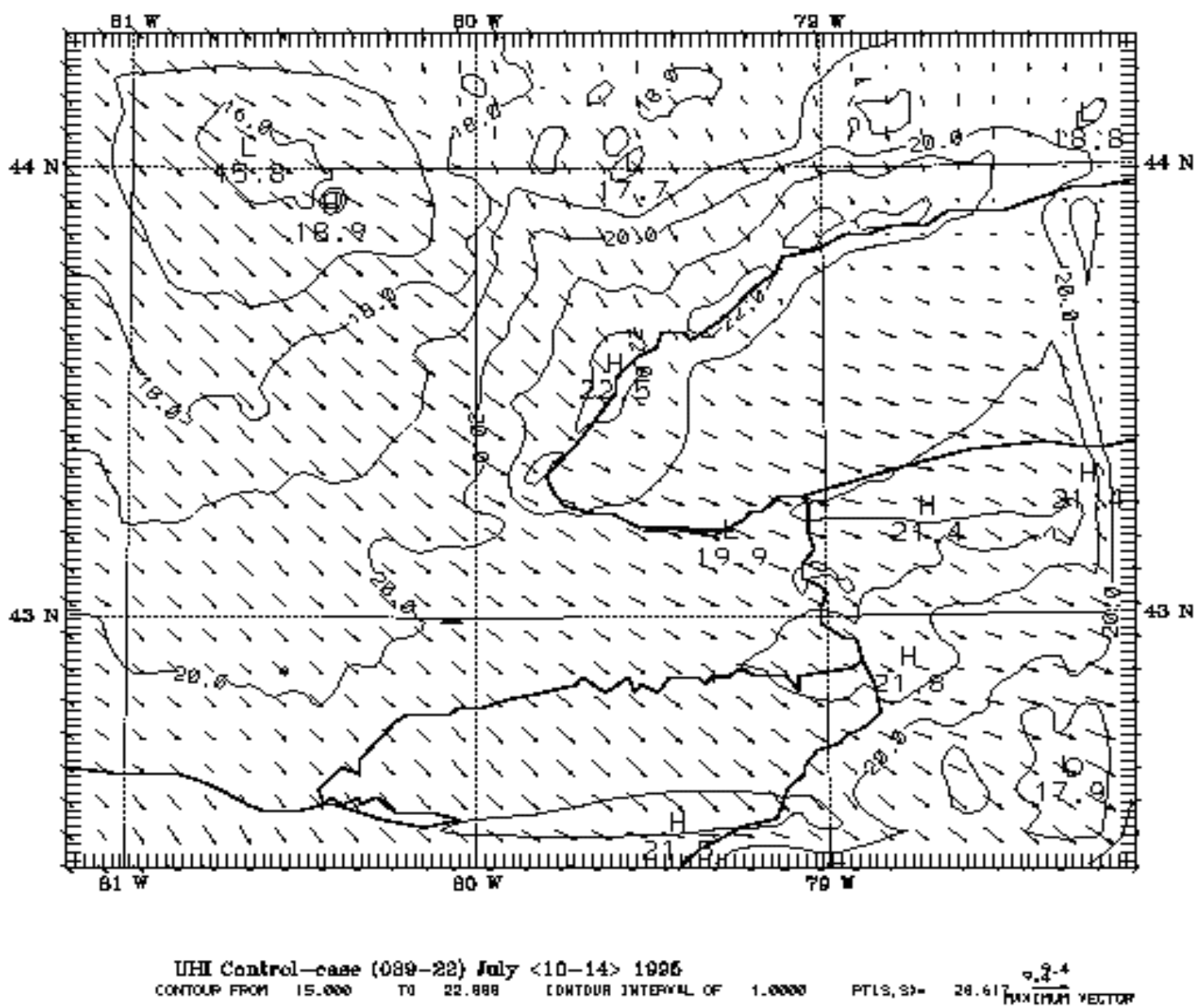

Figure 4.19. July 11, 1995 at 0900 LST cool-city scenario: Simulated temperature and wind-vector field, for the inner, fine-resolution $(2-\mathrm{km})$ domain. 


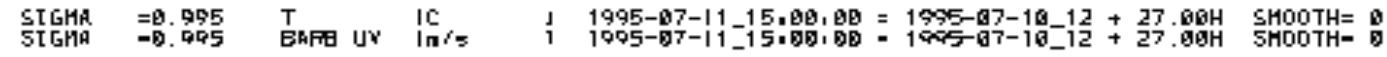

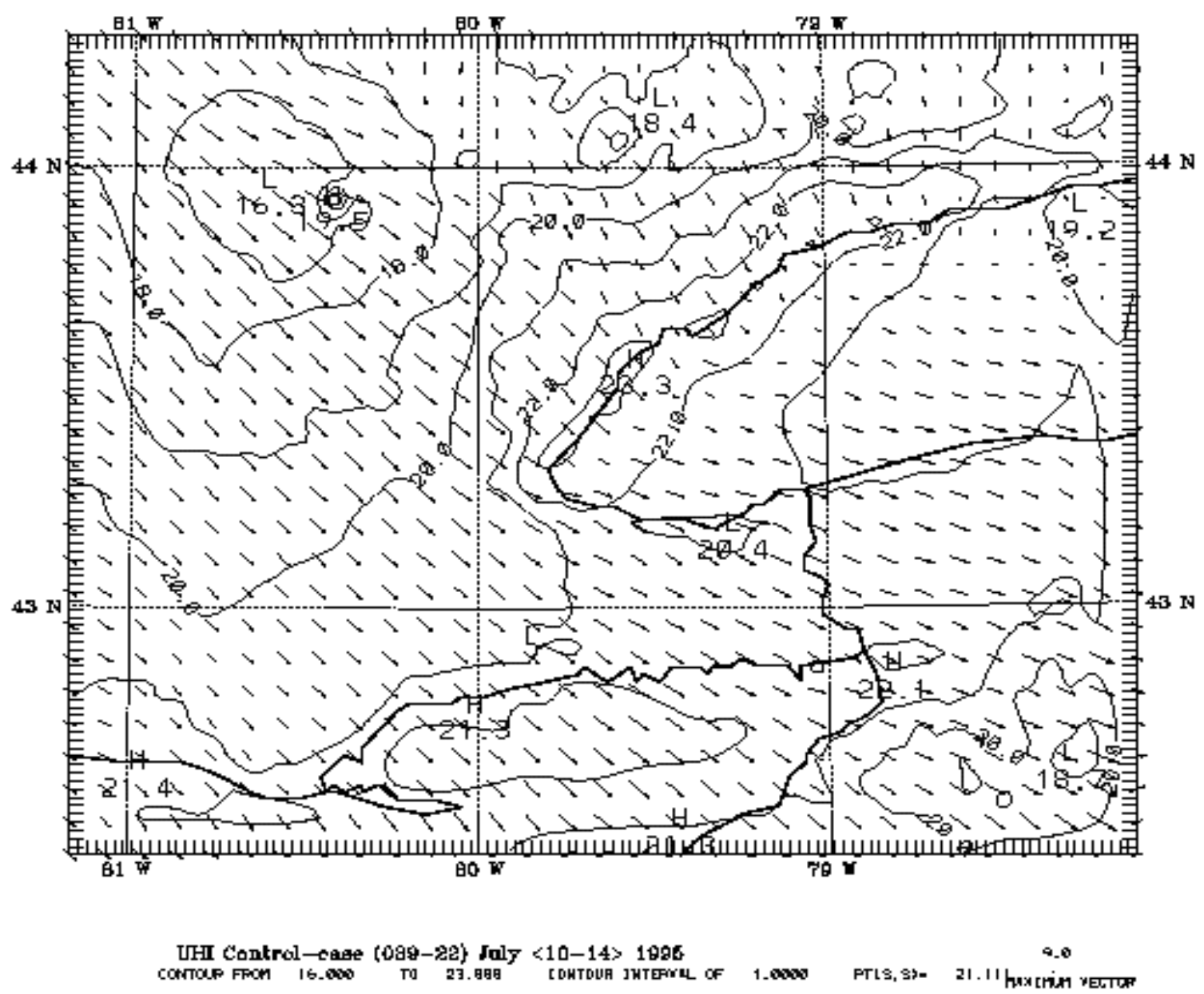

Figure 4.20. July 11, 1995 at 1000 LST cool-city scenario: Simulated temperature and wind-vector field, for the inner, fine-resolution $(2-\mathrm{km})$ domain. 
SIGHA $=9.995$
StGHa

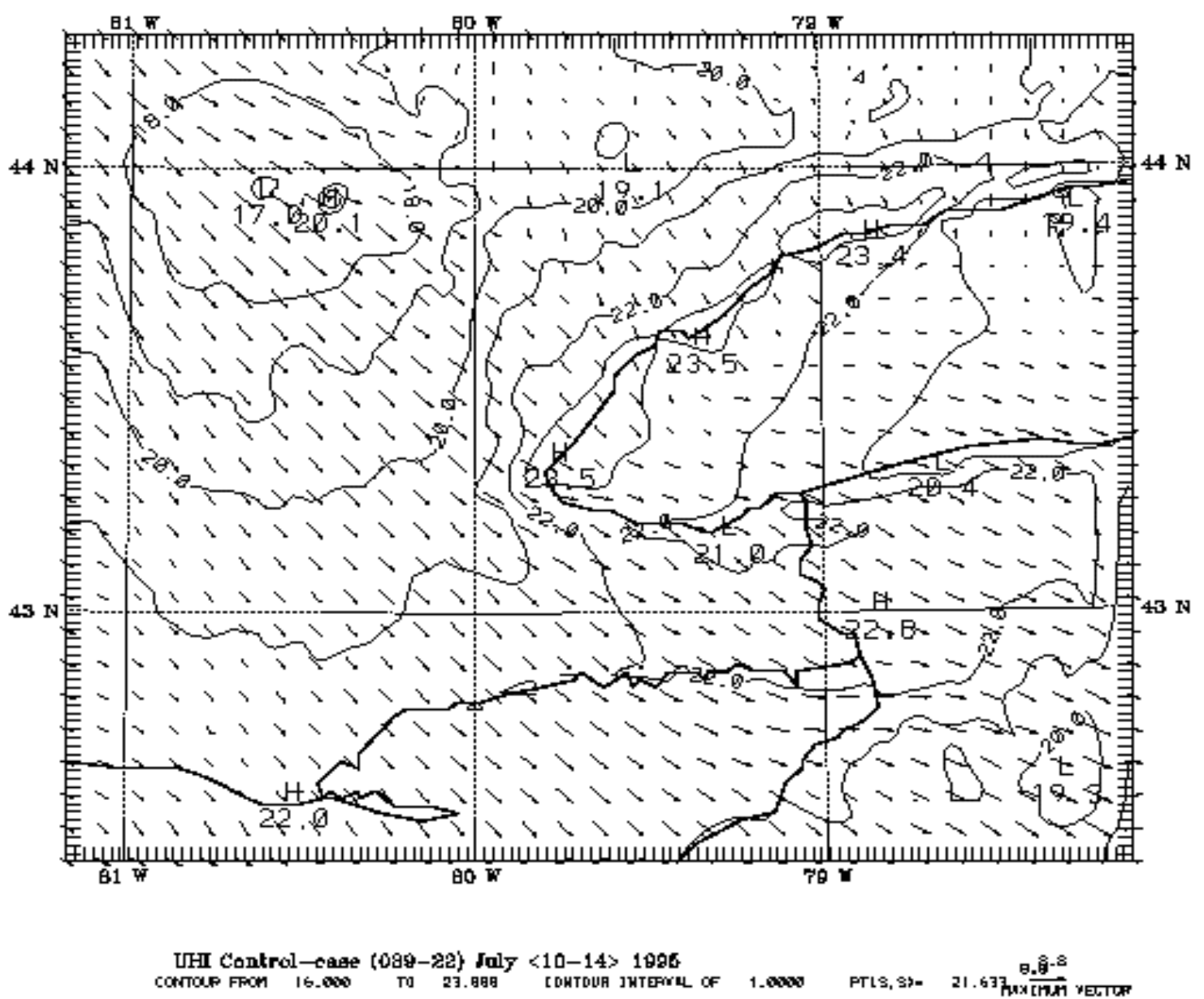

Figure 4.21. July 11, 1995 at 1100 LST cool-city scenario: Simulated temperature and wind-vector field, for the inner, fine-resolution $(2-\mathrm{km})$ domain. 
SIGHA $=9.995$
StGHa

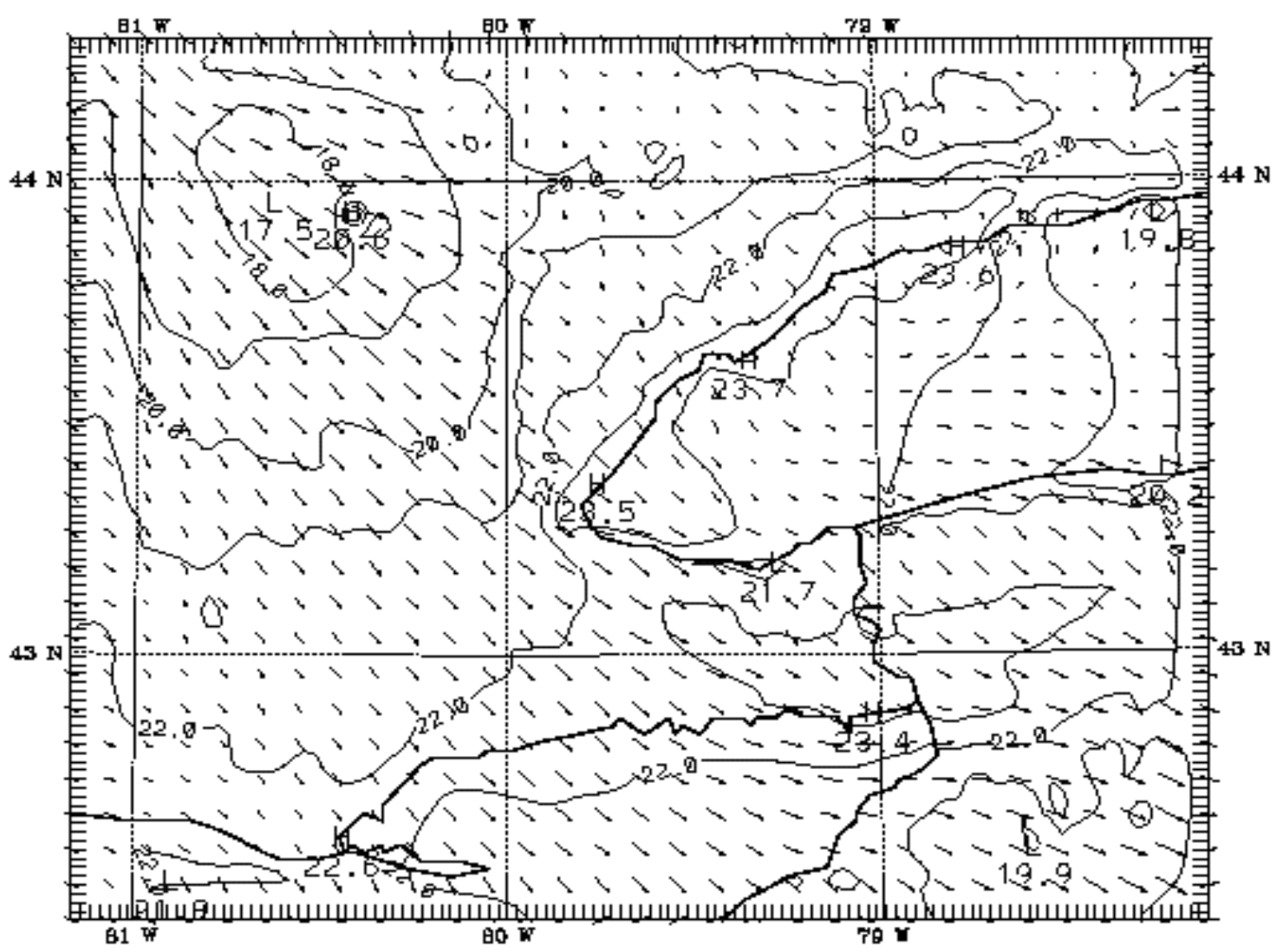

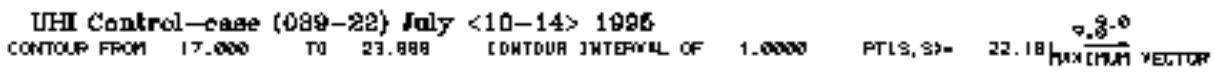

Figure 4.22. July 11, 1995 at 1200 LST cool-city scenario: Simulated temperature and wind-vector field, for the inner, fine-resolution $(2-\mathrm{km})$ domain. 
SIGHR =8.995 T

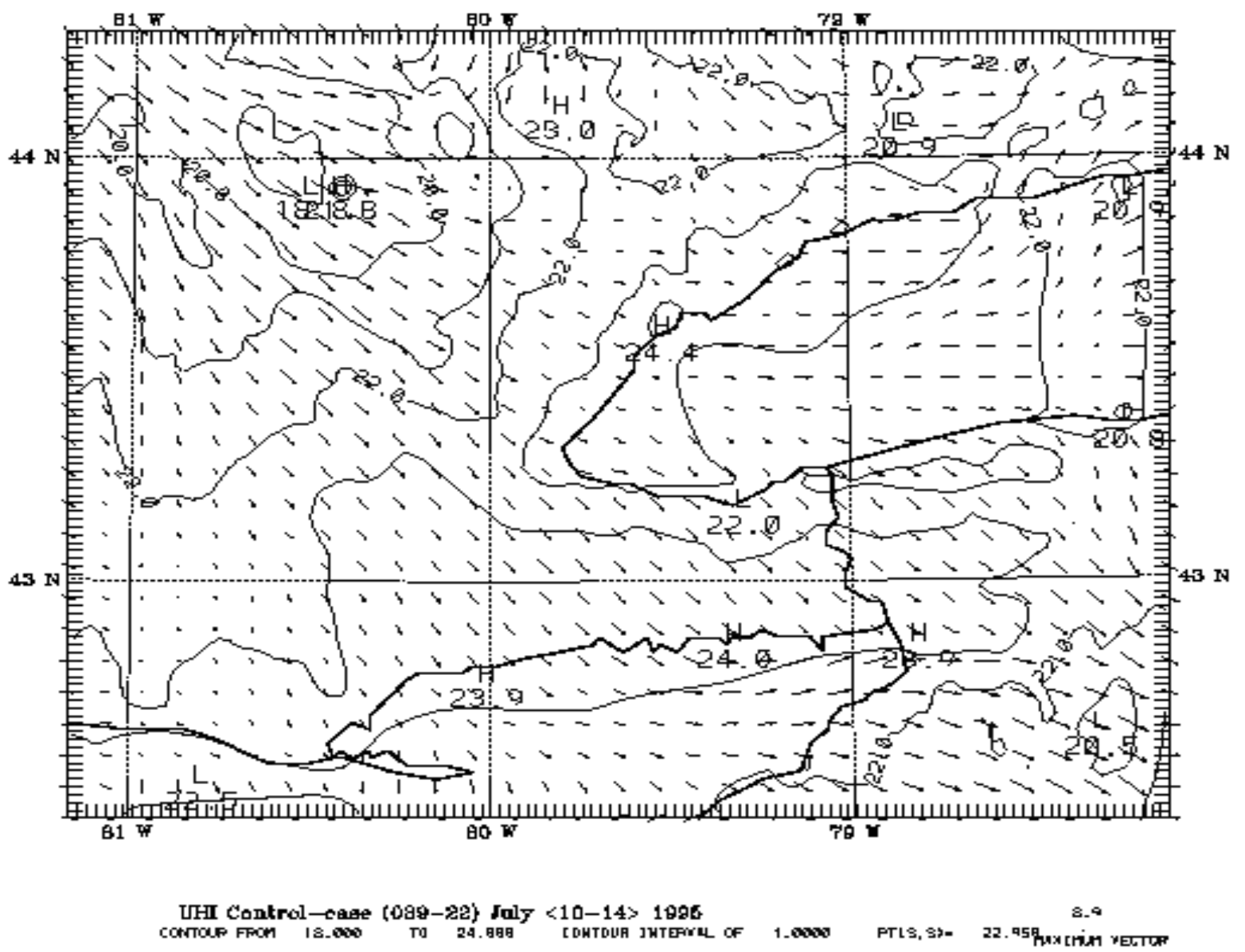

Figure 4.23. July 11, 1995 at 1400 LST cool-city scenario: Simulated temperature and wind-vector field, for the inner, fine-resolution $(2-\mathrm{km})$ domain. 


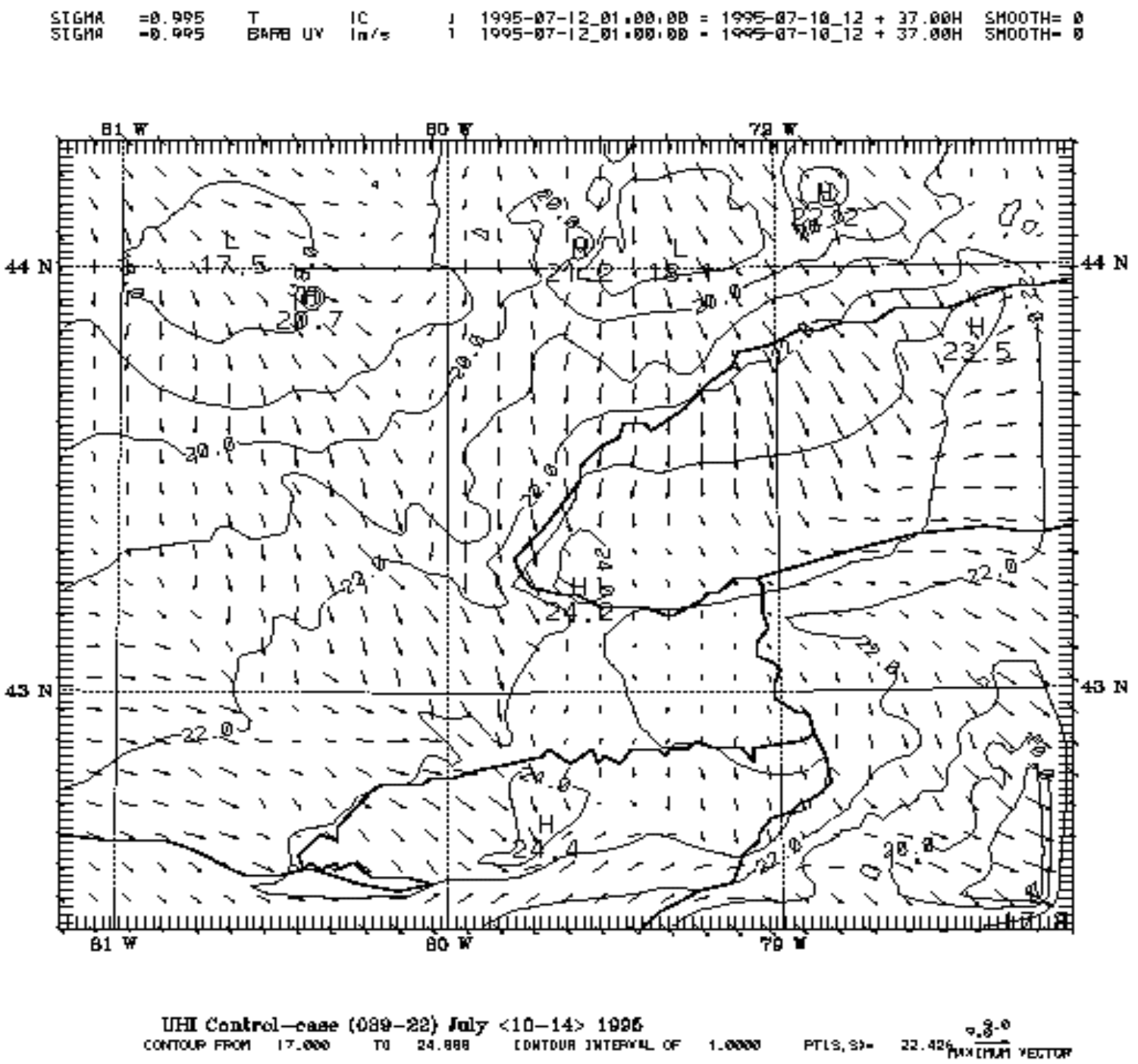

Figure 4.24. July 11, 1995 at 2000 LST cool-city scenario: Simulated temperature and wind-vector field, for the inner, fine-resolution $(2-\mathrm{km})$ domain. 


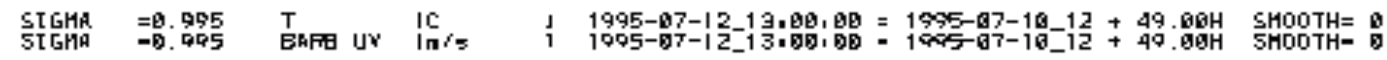

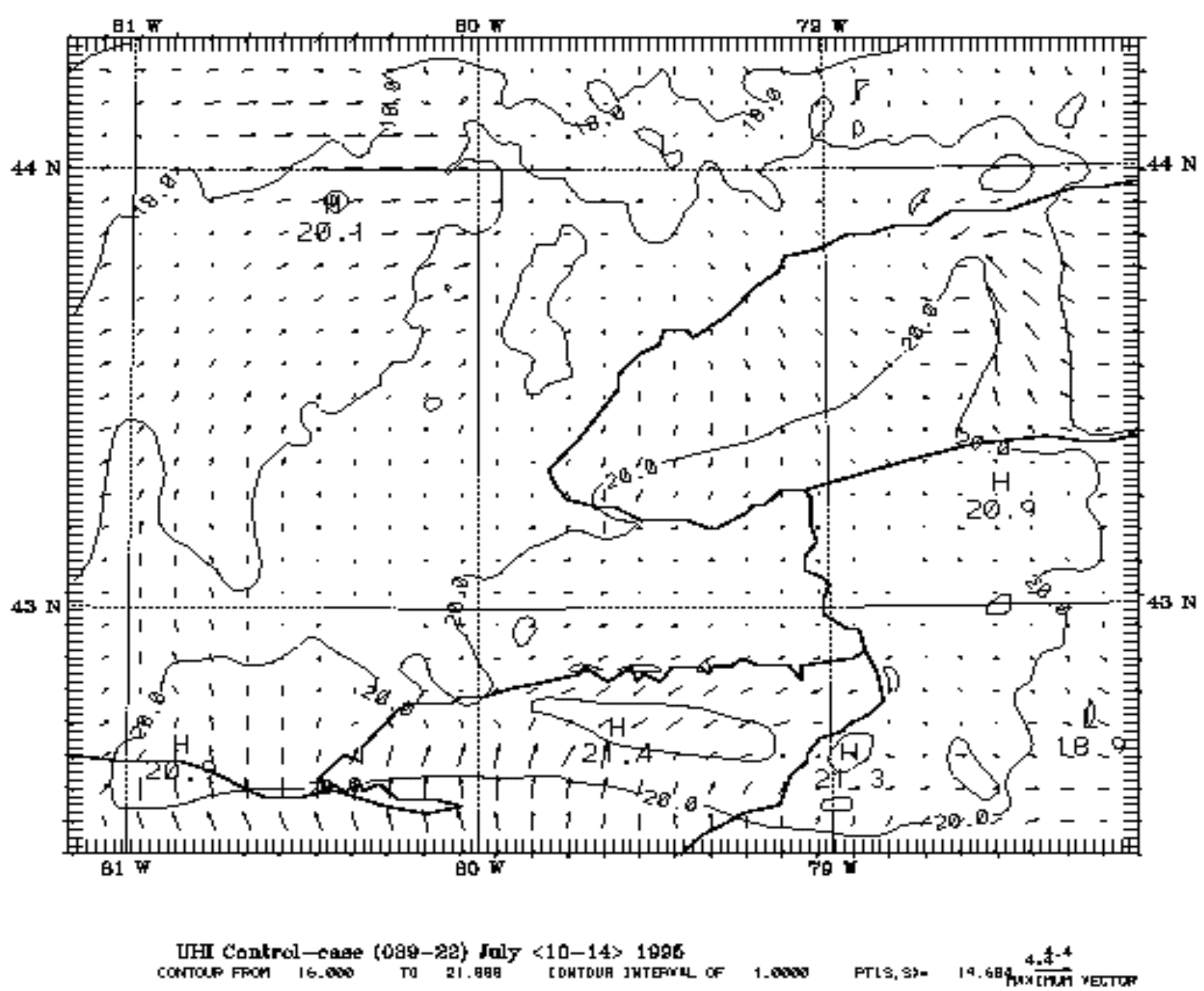

Figure 4.25. July 12, 1995 at 0800 LST cool-city scenario: Simulated temperature and wind-vector field, for the inner, fine-resolution $(2-\mathrm{km})$ domain. 


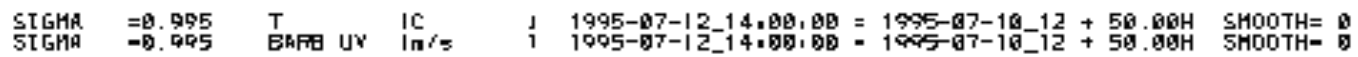

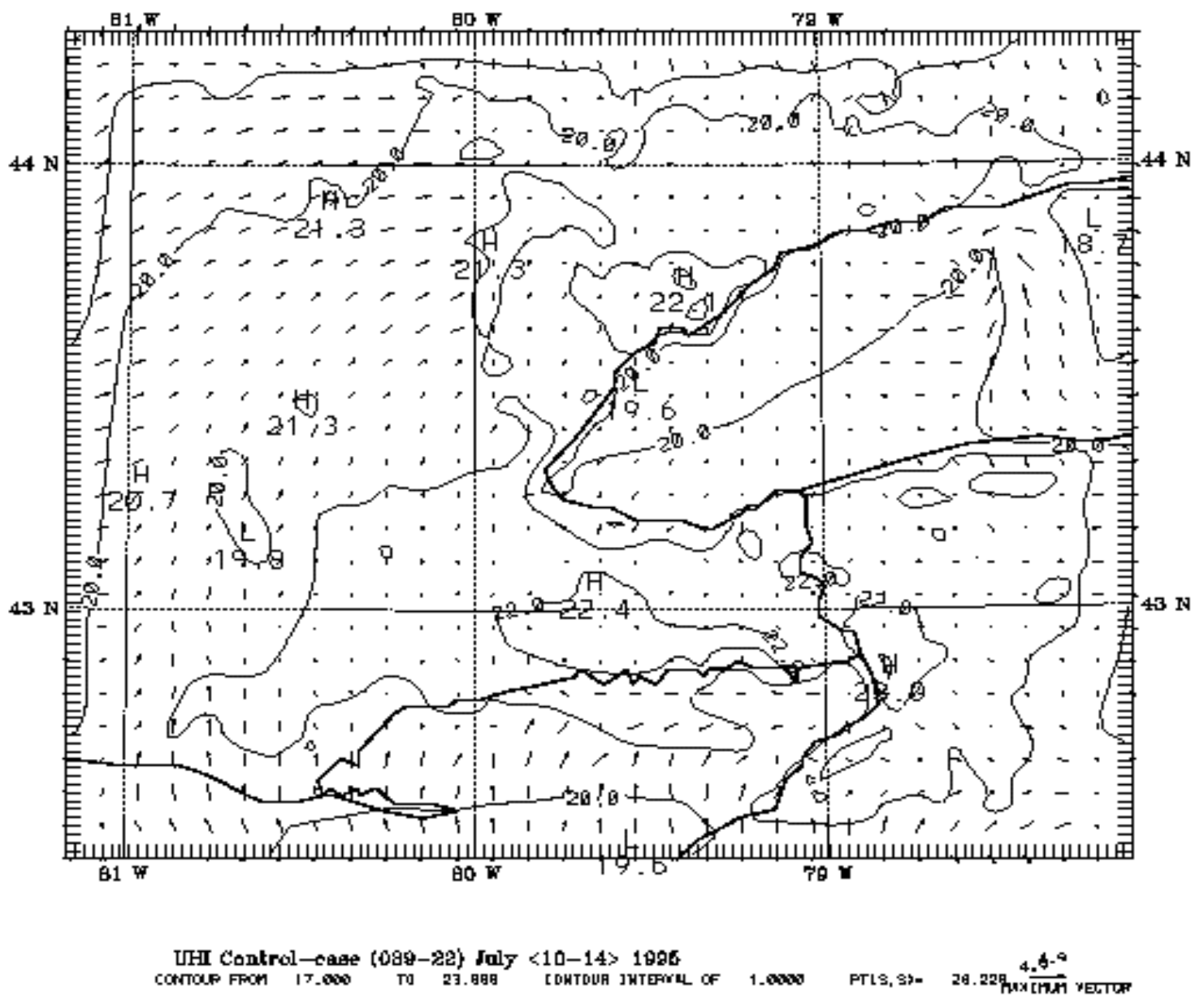

Figure 4.26. July 12, 1995 at 0900 LST cool-city scenario: Simulated temperature and wind-vector field, for the inner, fine-resolution $(2-\mathrm{km})$ domain. 
SIGHA
STG $=8.995$

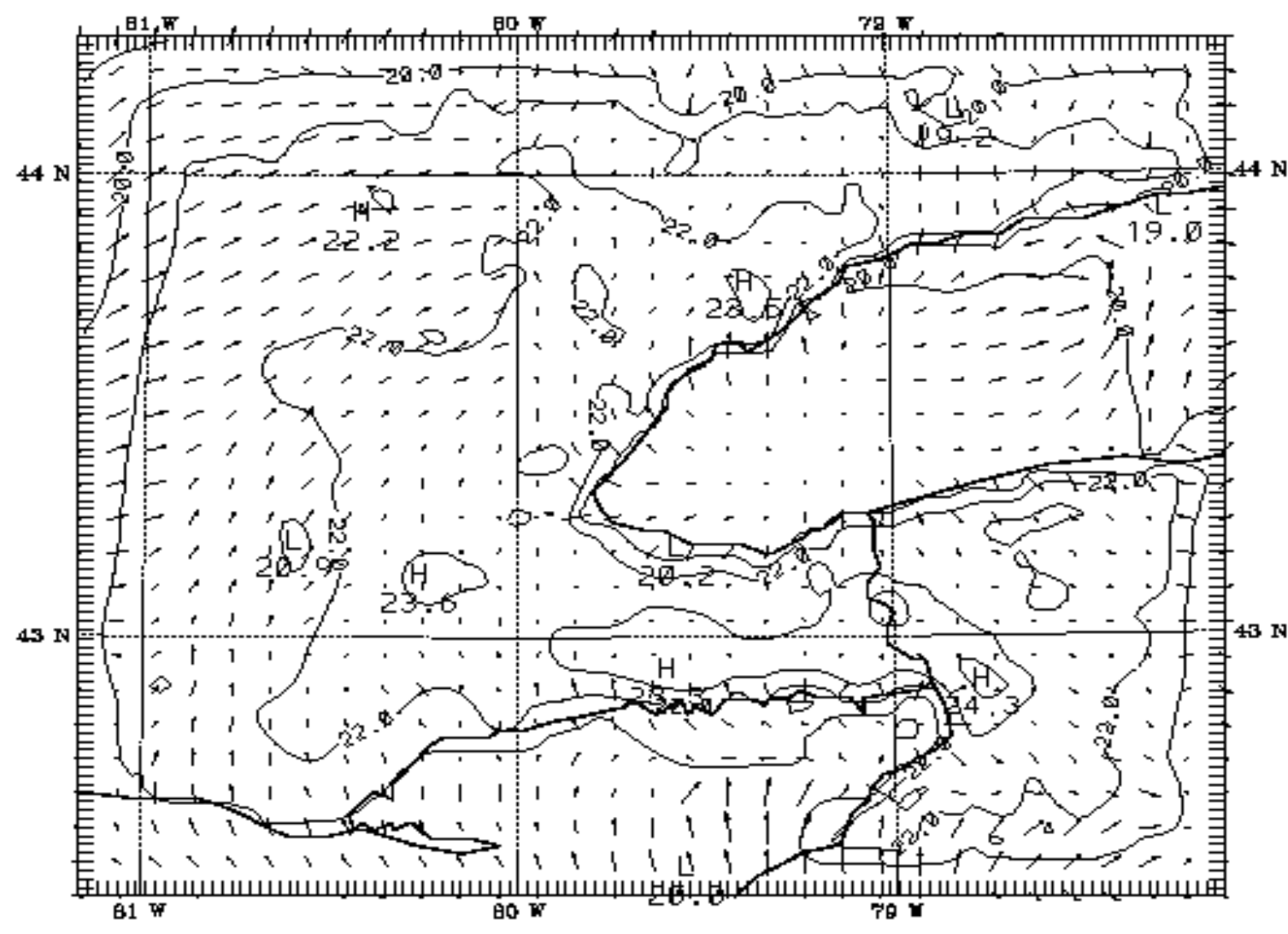

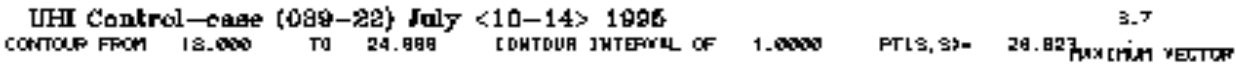

Figure 4.27. July 12, 1995 at 1000 LST cool-city scenario: Simulated temperature and wind-vector field, for the inner, fine-resolution $(2-\mathrm{km})$ domain. 

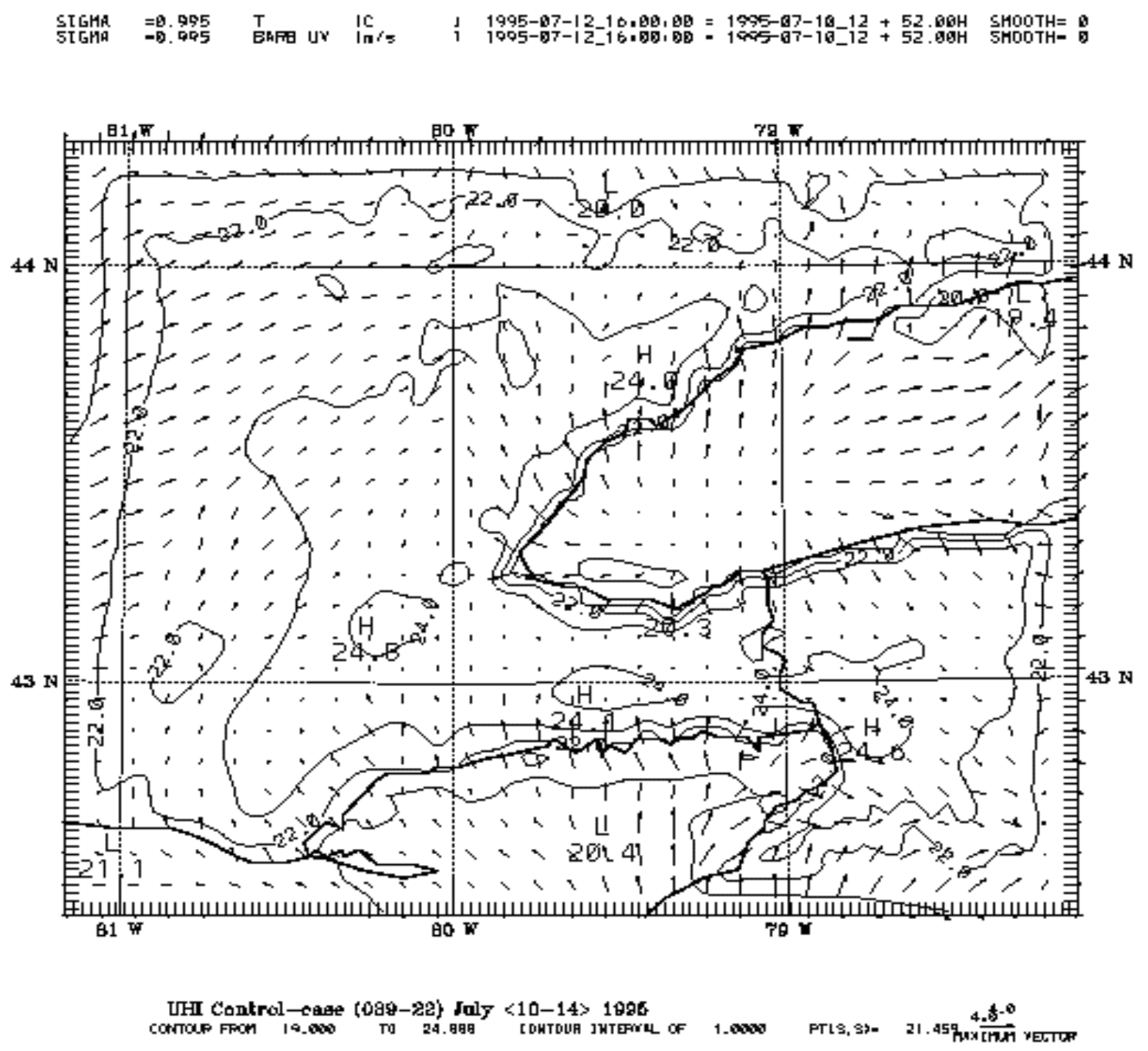

Figure 4.28. July 12, 1995 at 1100 LST cool-city scenario: Simulated temperature and wind-vector field, for the inner, fine-resolution $(2-\mathrm{km})$ domain. 

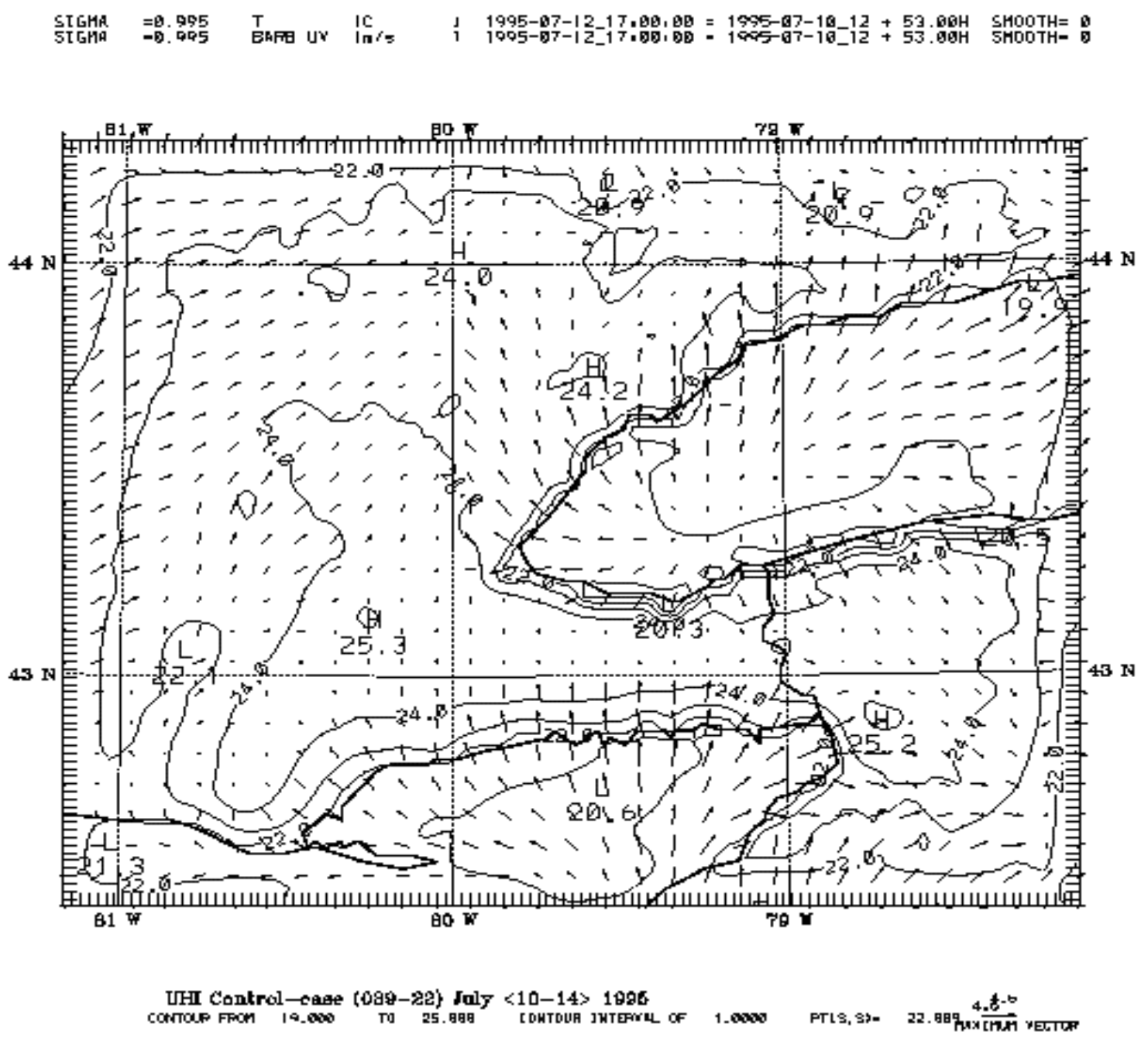

Figure 4.29. July 12, 1995 at 1200 LST cool-city scenario: Simulated temperature and wind-vector field, for the inner, fine-resolution (2-km) domain. 


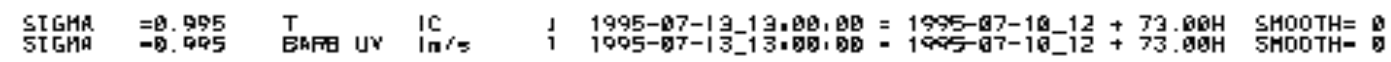

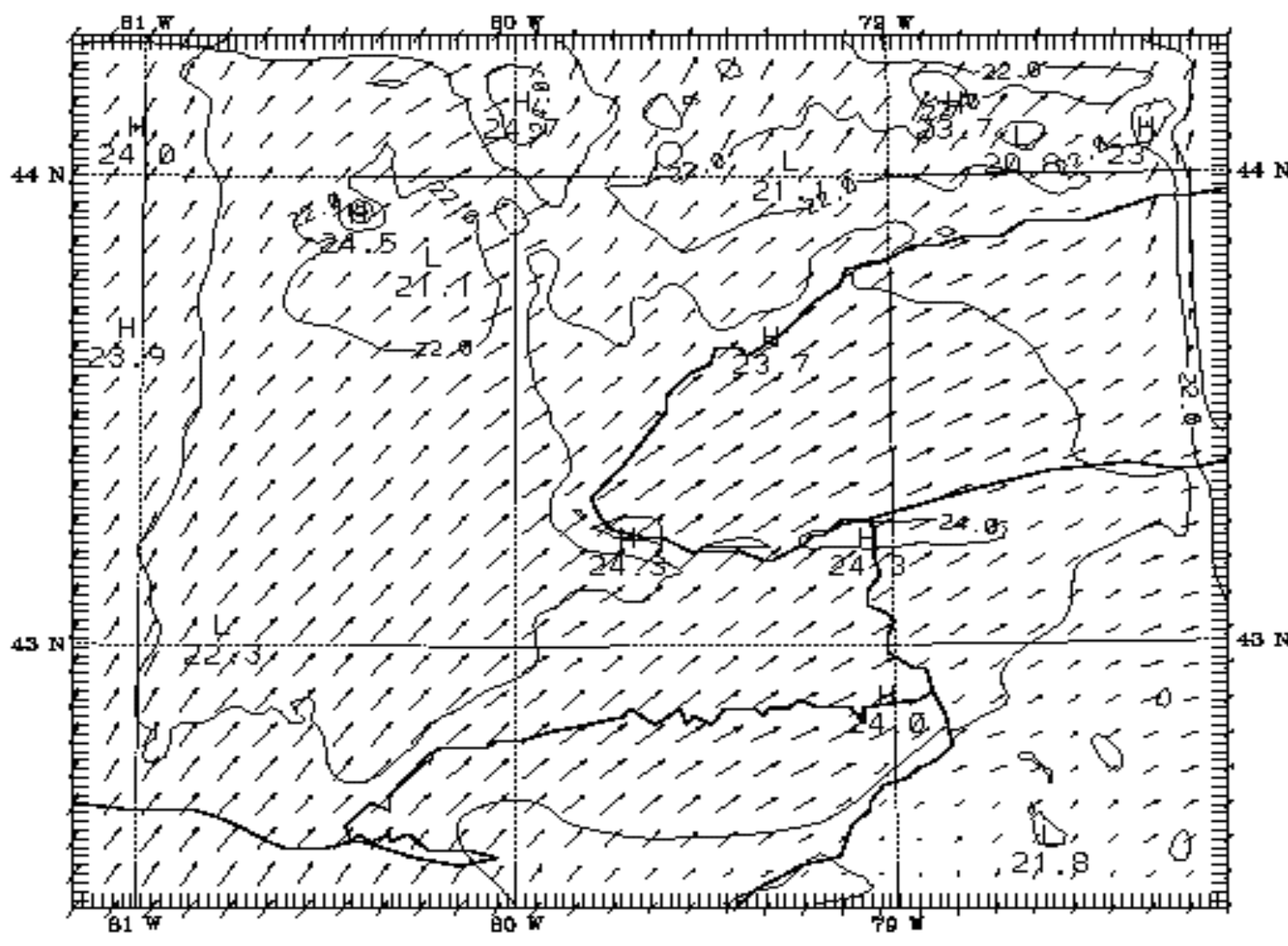

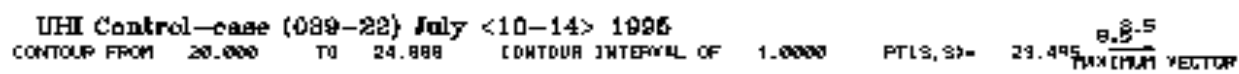

Figure 4.30. July 13, 1995 at 0800 LST cool-city scenario: Simulated temperature and wind-vector field, for the inner, fine-resolution $(2-\mathrm{km})$ domain. 


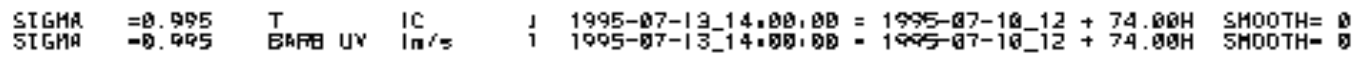

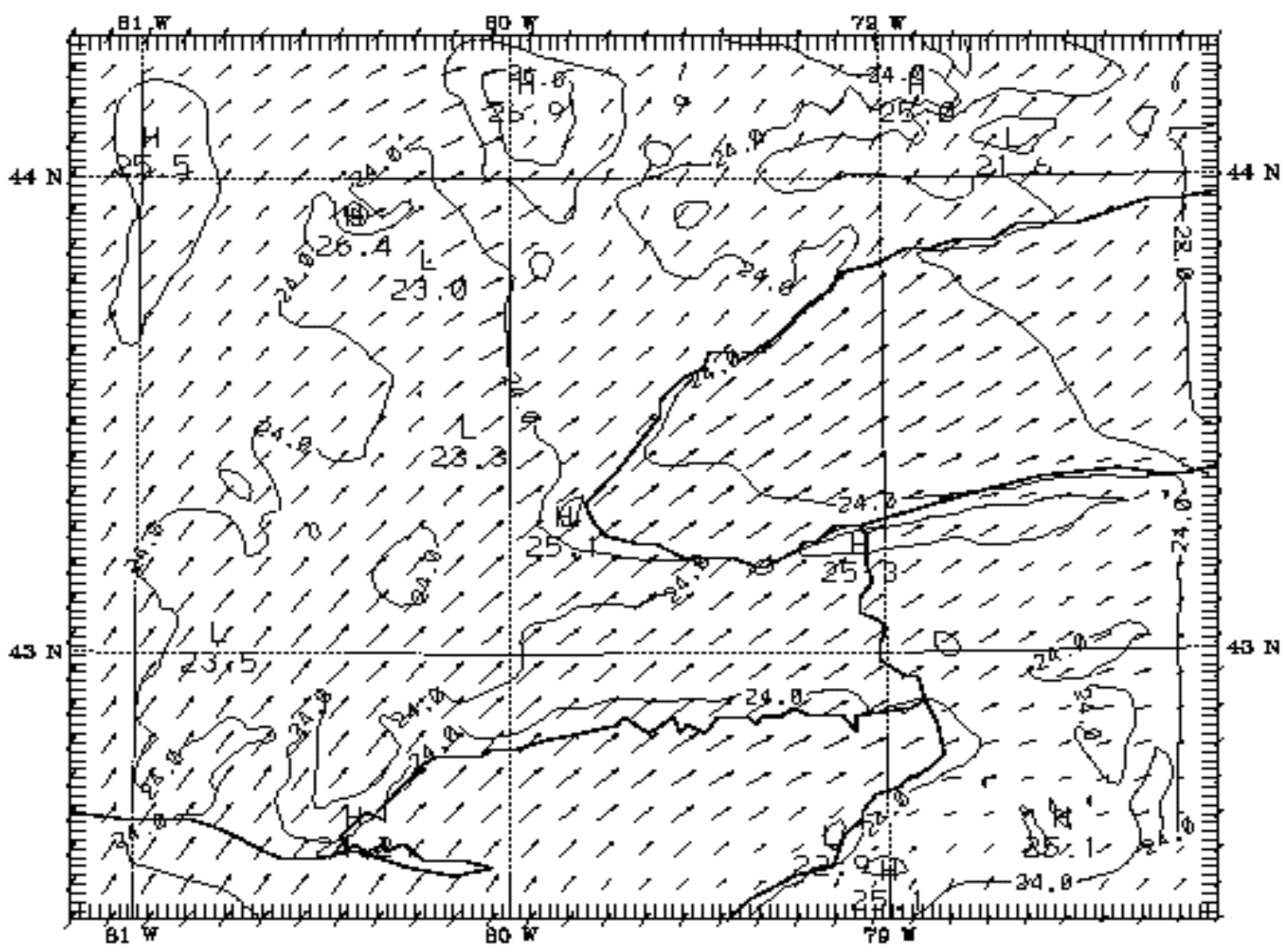

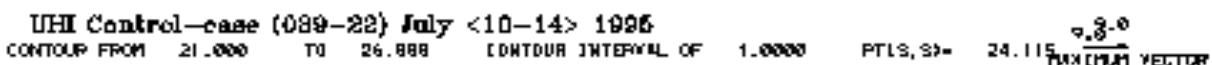

Figure 4.31. July 13, 1995 at 0900 LST cool-city scenario: Simulated temperature and wind-vector field, for the inner, fine-resolution $(2-\mathrm{km})$ domain. 


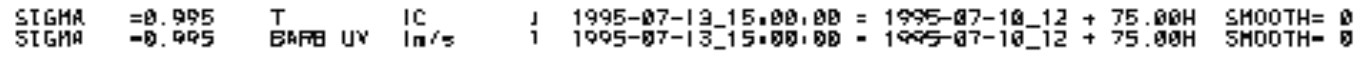

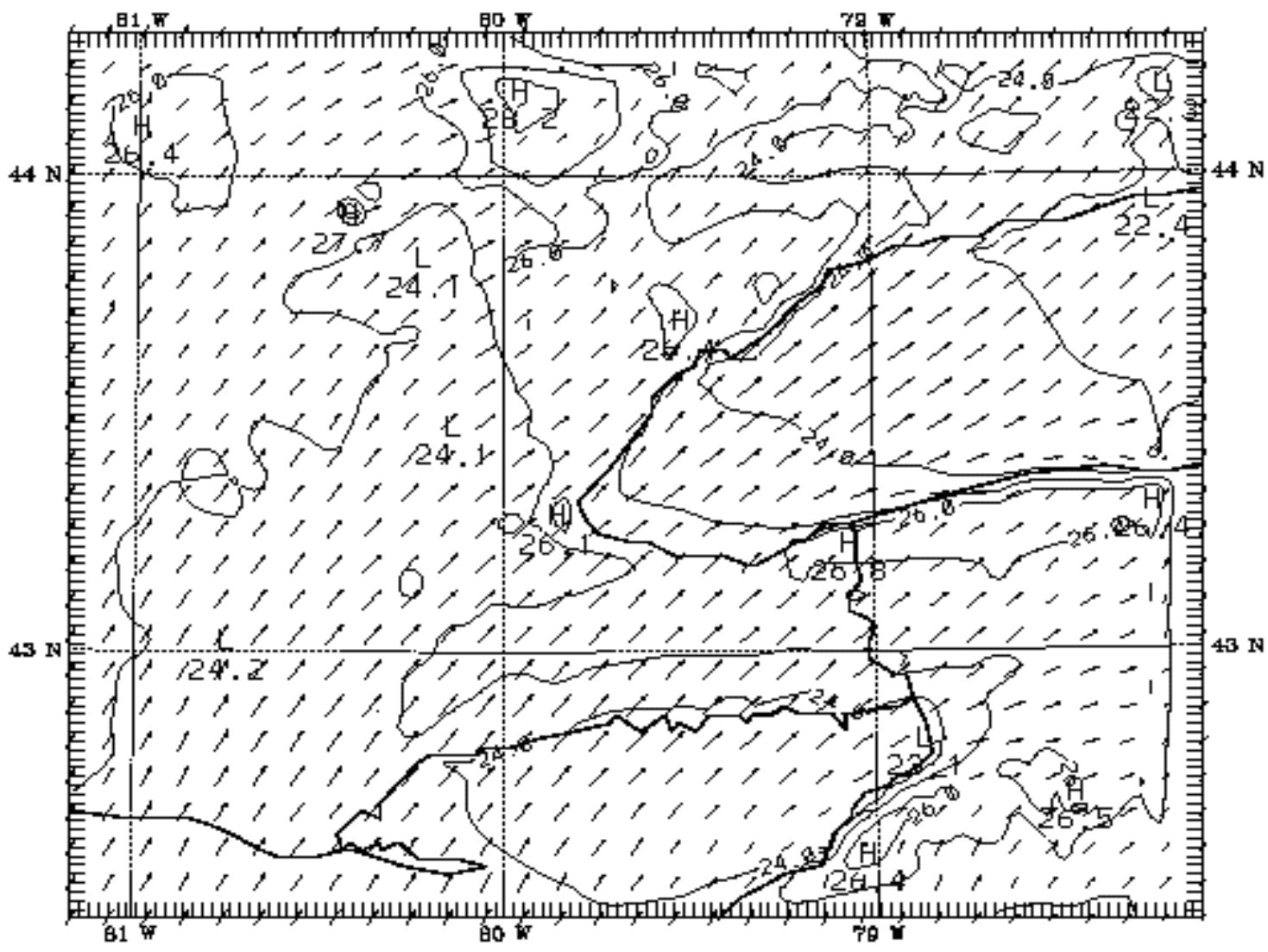

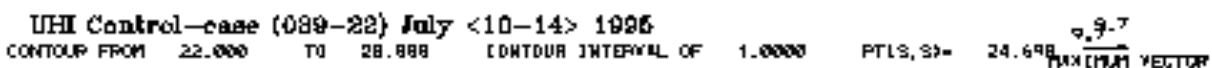

Figure 4.32. July 13, 1995 at 1000 LST cool-city scenario: Simulated temperature and wind-vector field, for the inner, fine-resolution $(2-\mathrm{km})$ domain. 


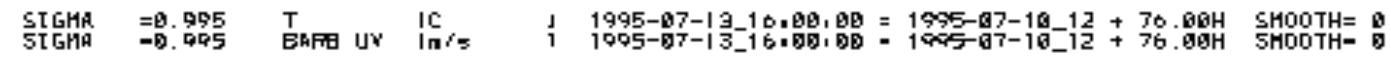

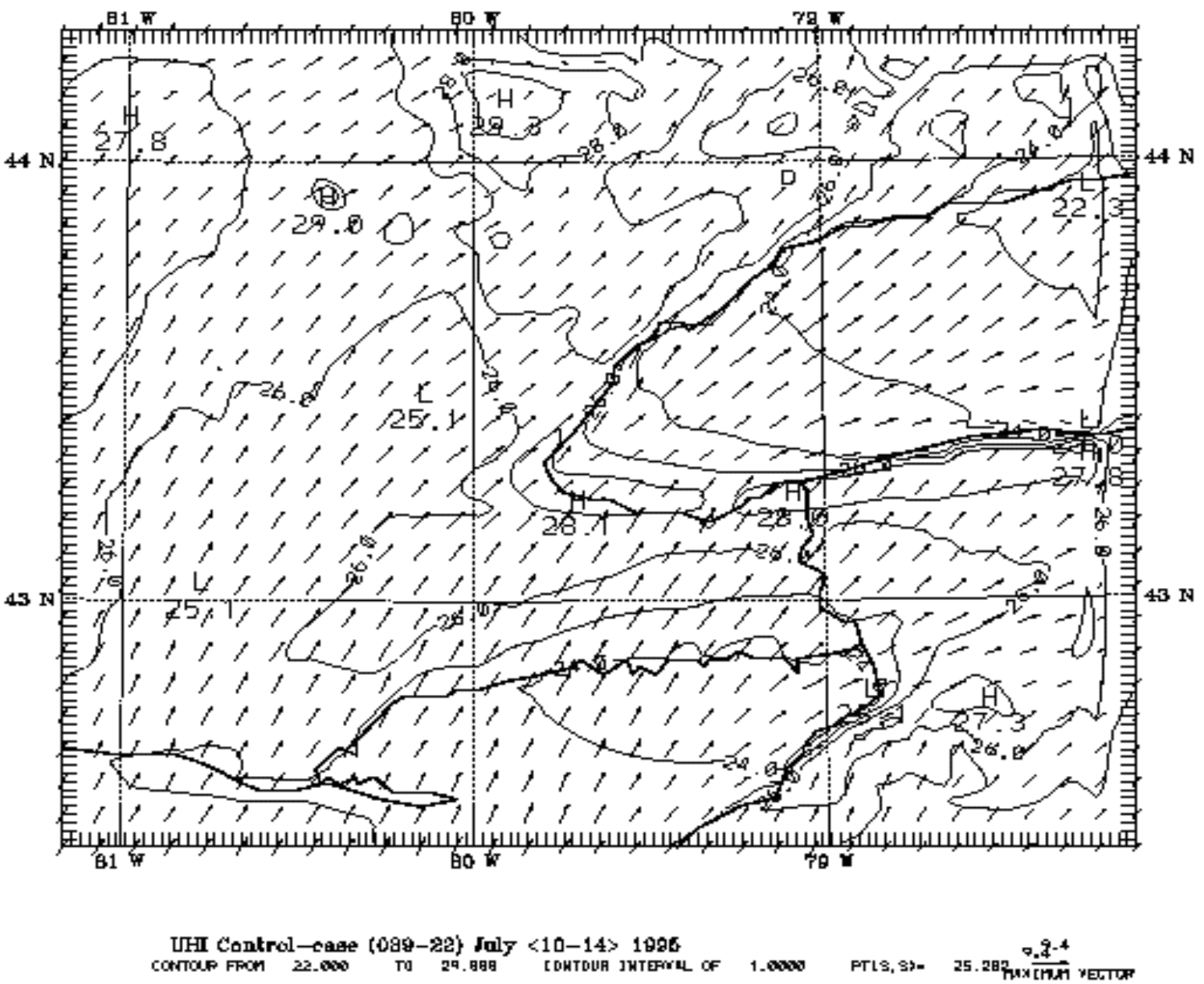

Figure 4.33. July 13, 1995 at 1100 LST cool-city scenario: Simulated temperature and wind-vector field, for the inner, fine-resolution $(2-\mathrm{km})$ domain. 


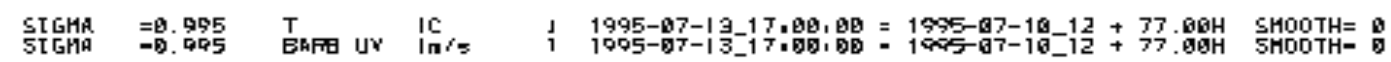

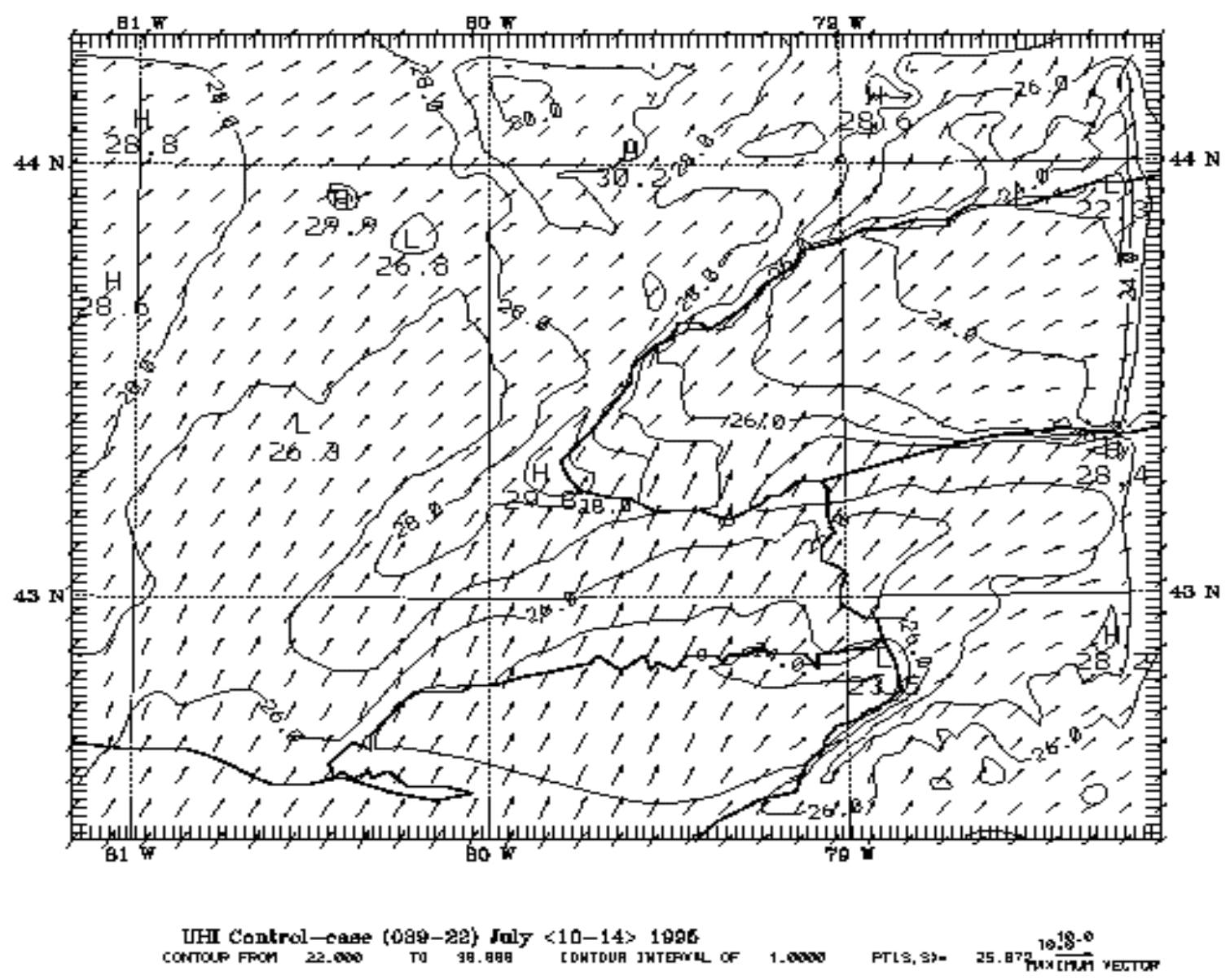

Figure 4.34. July 13, 1995 at 1200 LST cool-city scenario: Simulated temperature and wind-vector field, for the inner, fine-resolution $(2-\mathrm{km})$ domain. 


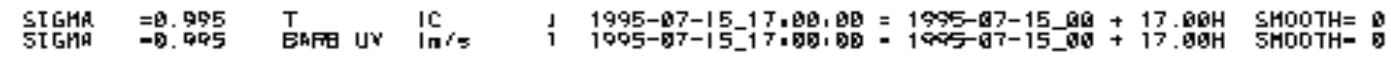

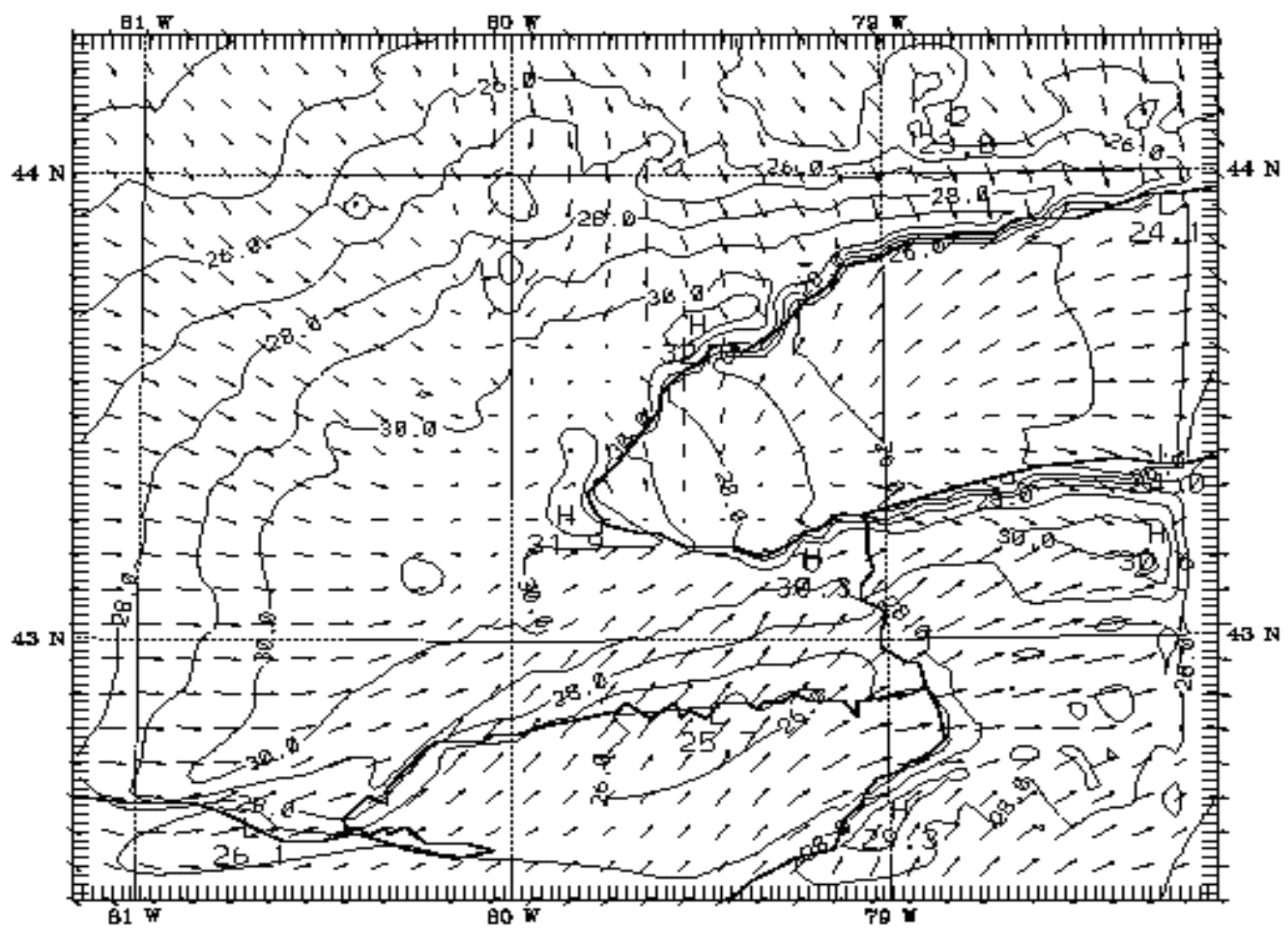

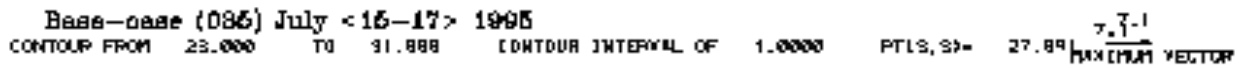

Figure 4.35. July 15, 1995 at 1200 LST base case scenario: Simulated temperature and wind-vector field, for the inner, fine-resolution $(2-\mathrm{km})$ domain. 


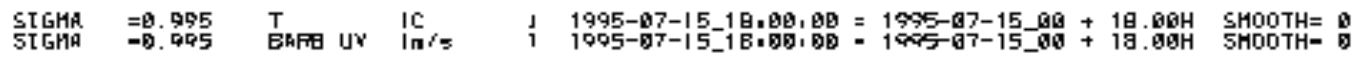

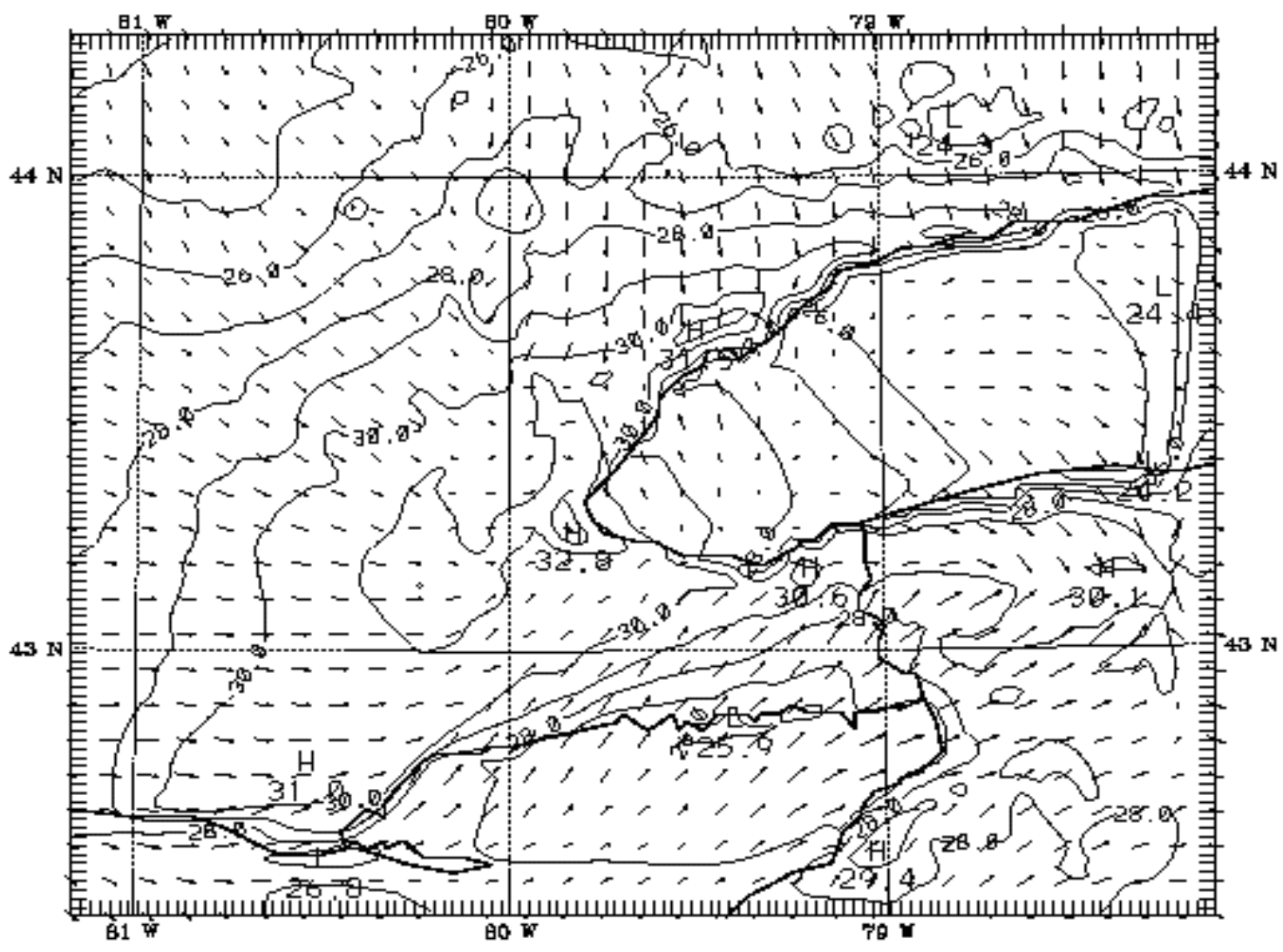

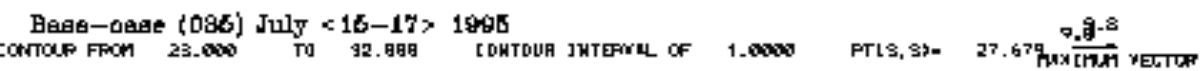

Figure 4.36. July 15, 1995 at 1300 LST base case scenario: Simulated temperature and wind-vector field, for the inner, fine-resolution $(2-\mathrm{km})$ domain. 


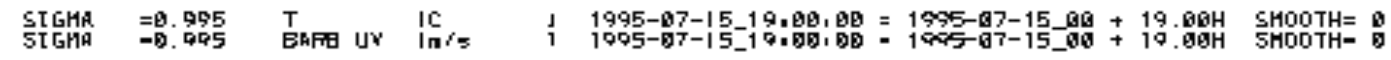

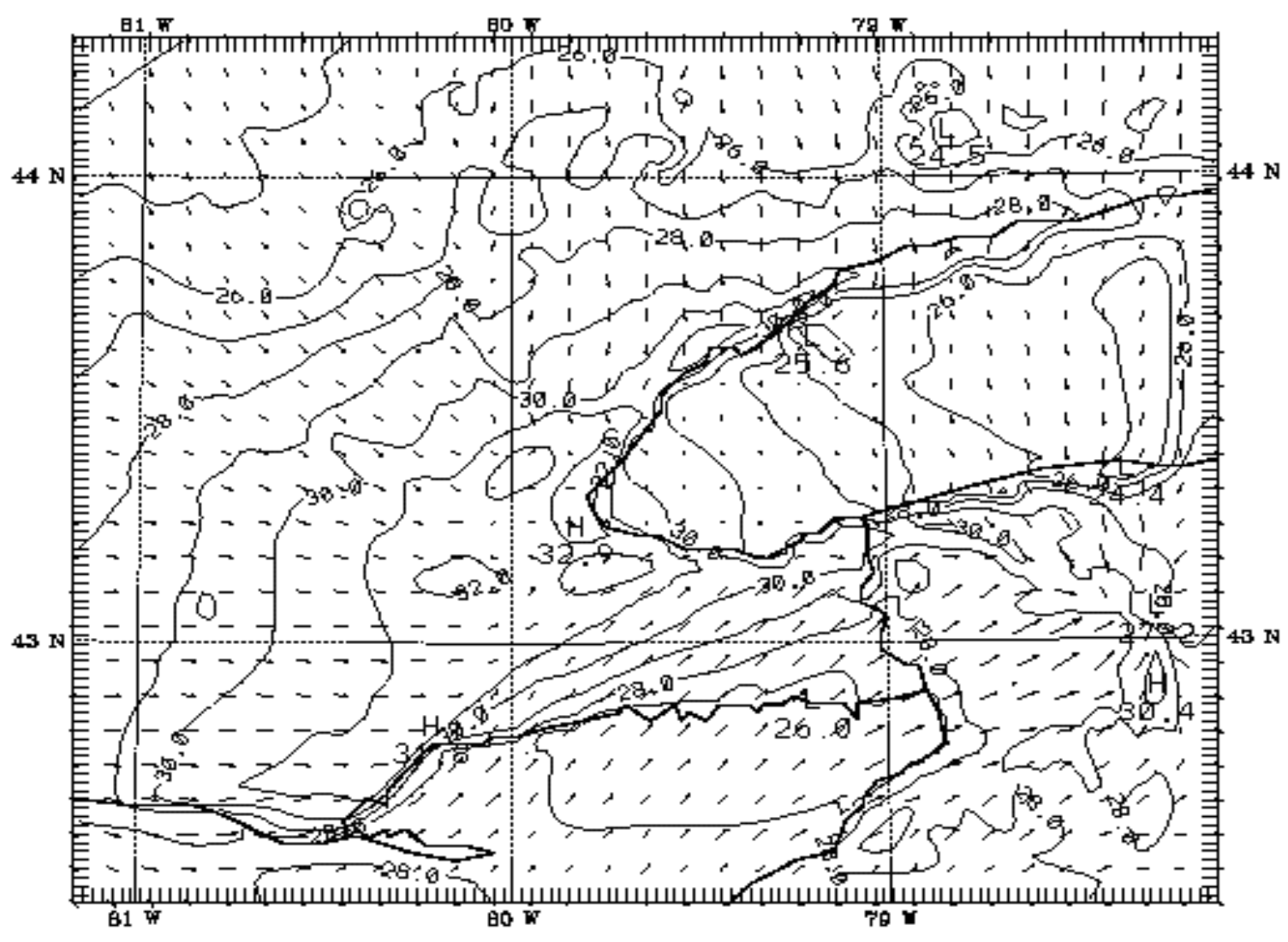

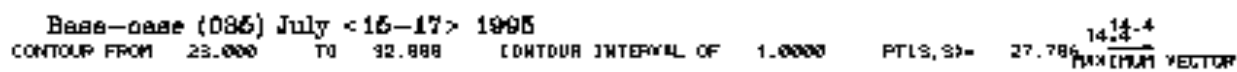

Figure 4.37. July 15, 1995 at 1400 LST base case scenario: Simulated temperature and wind-vector field, for the inner, fine-resolution $(2-\mathrm{km})$ domain. 


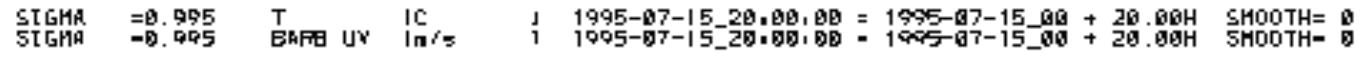

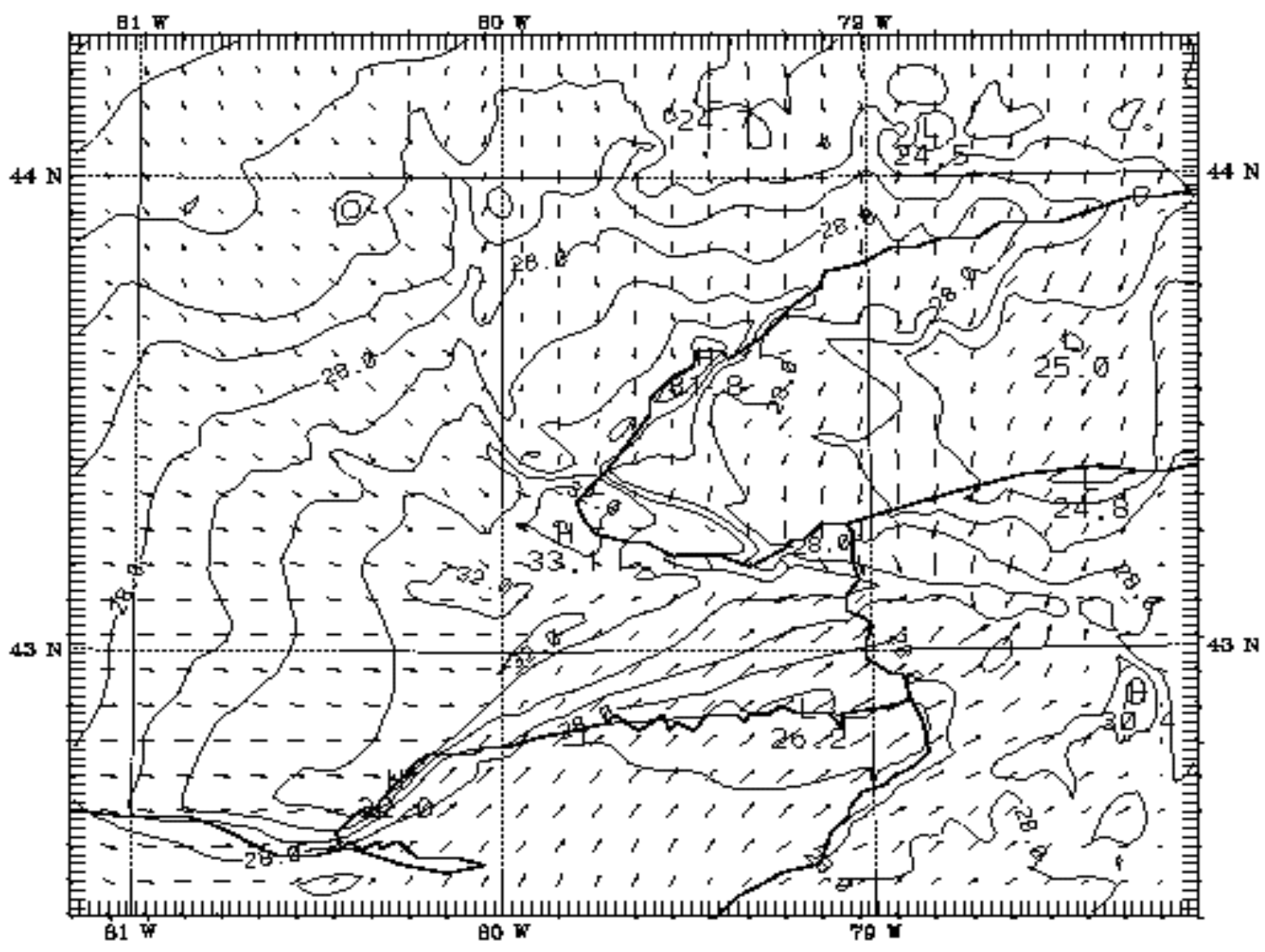

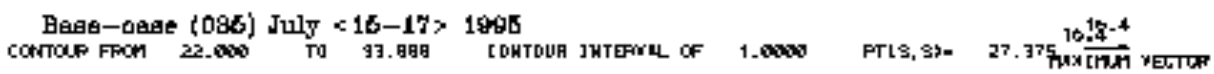

Figure 4.38. July 15, 1995 at 1500 LST base case scenario: Simulated temperature and wind-vector field, for the inner, fine-resolution $(2-\mathrm{km})$ domain. 


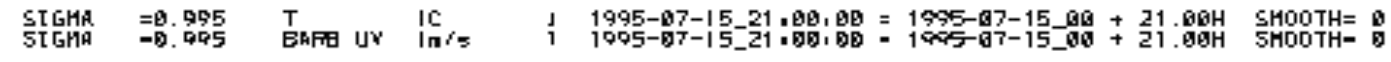

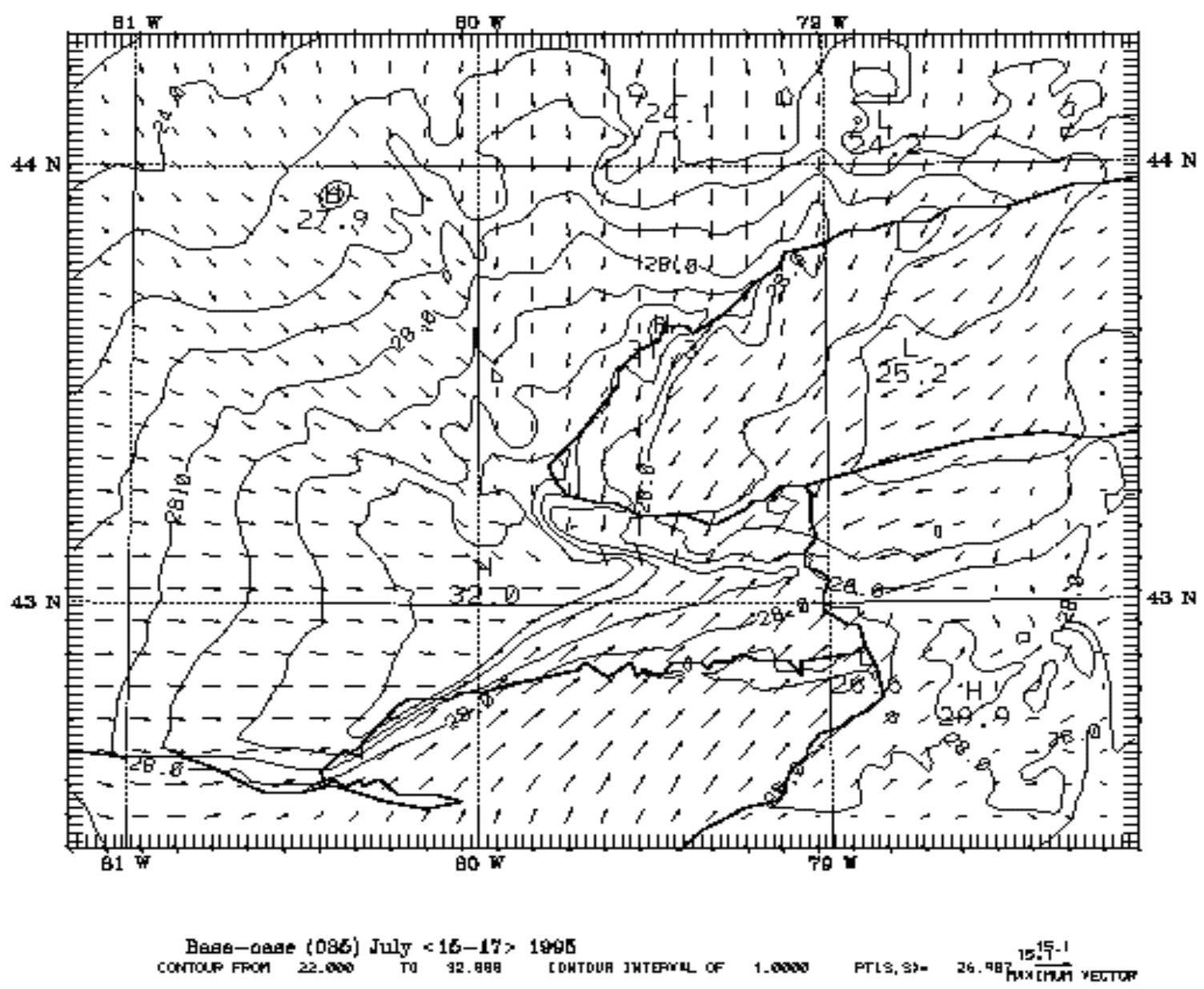

Figure 4.39. July 15, 1995 at 1600 LST base case scenario: Simulated temperature and wind-vector field, for the inner, fine-resolution $(2-\mathrm{km})$ domain. 


\section{SIGMA $=9.995$
5tGHa}

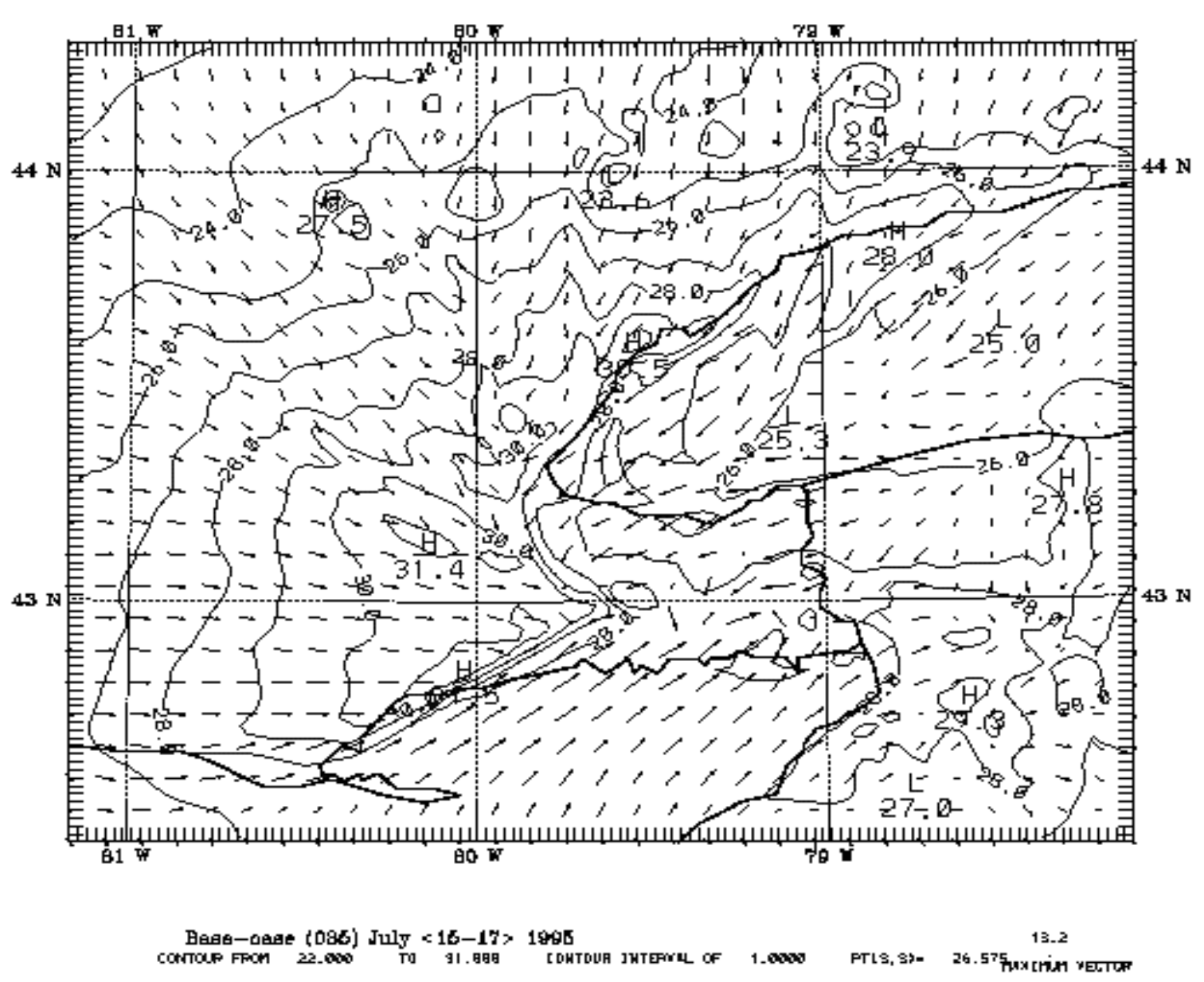

Figure 4.40. July 15, 1995 at 1700 LST base case scenario: Simulated temperature and wind-vector field, for the inner, fine-resolution $(2-\mathrm{km})$ domain. 


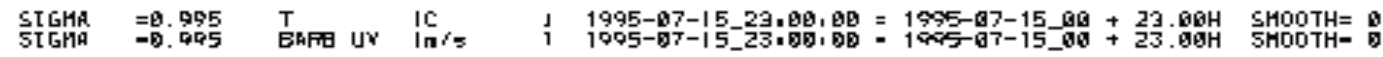

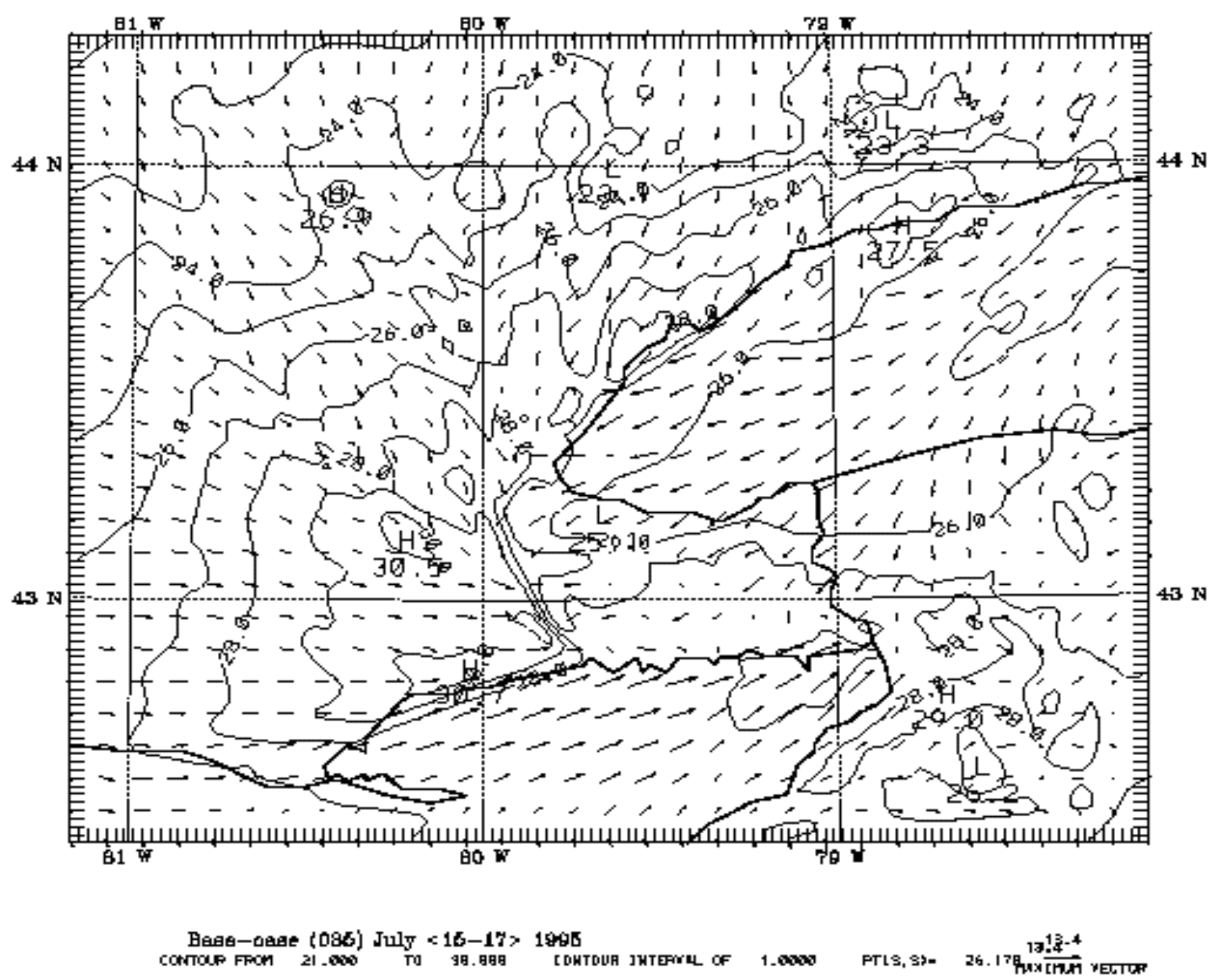

Figure 4.41. July 15, 1995 at 1800 LST base case scenario: Simulated temperature and wind-vector field, for the inner, fine-resolution $(2-\mathrm{km})$ domain. 


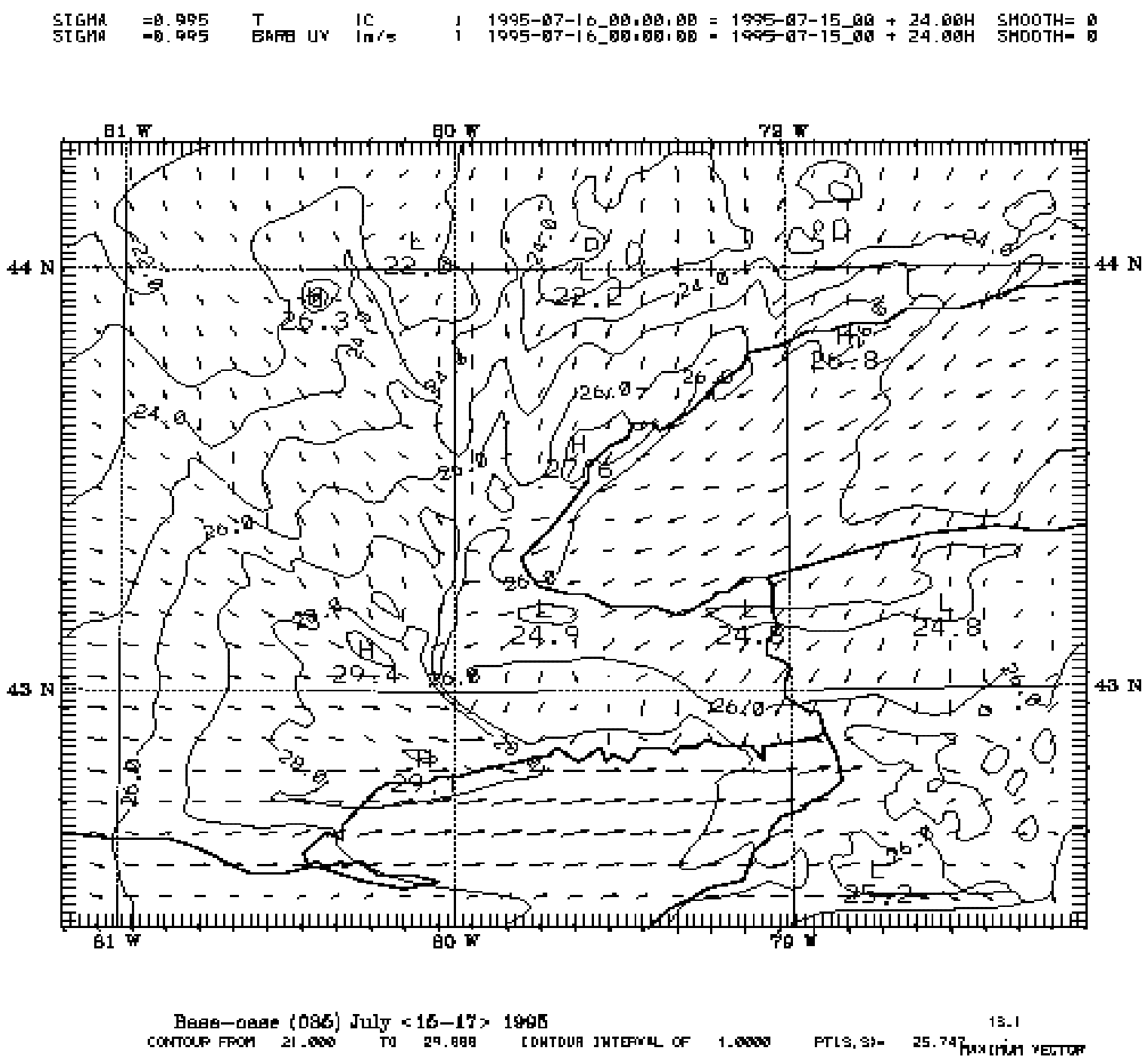

Figure 4.42. July 15, 1995 at 1900 LST base case scenario: Simulated temperature and wind-vector field, for the inner, fine-resolution (2-km) domain. 


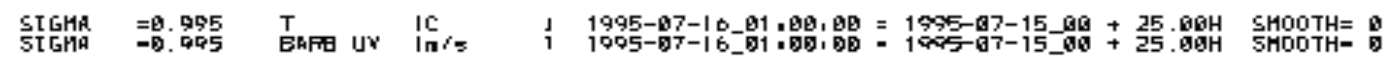

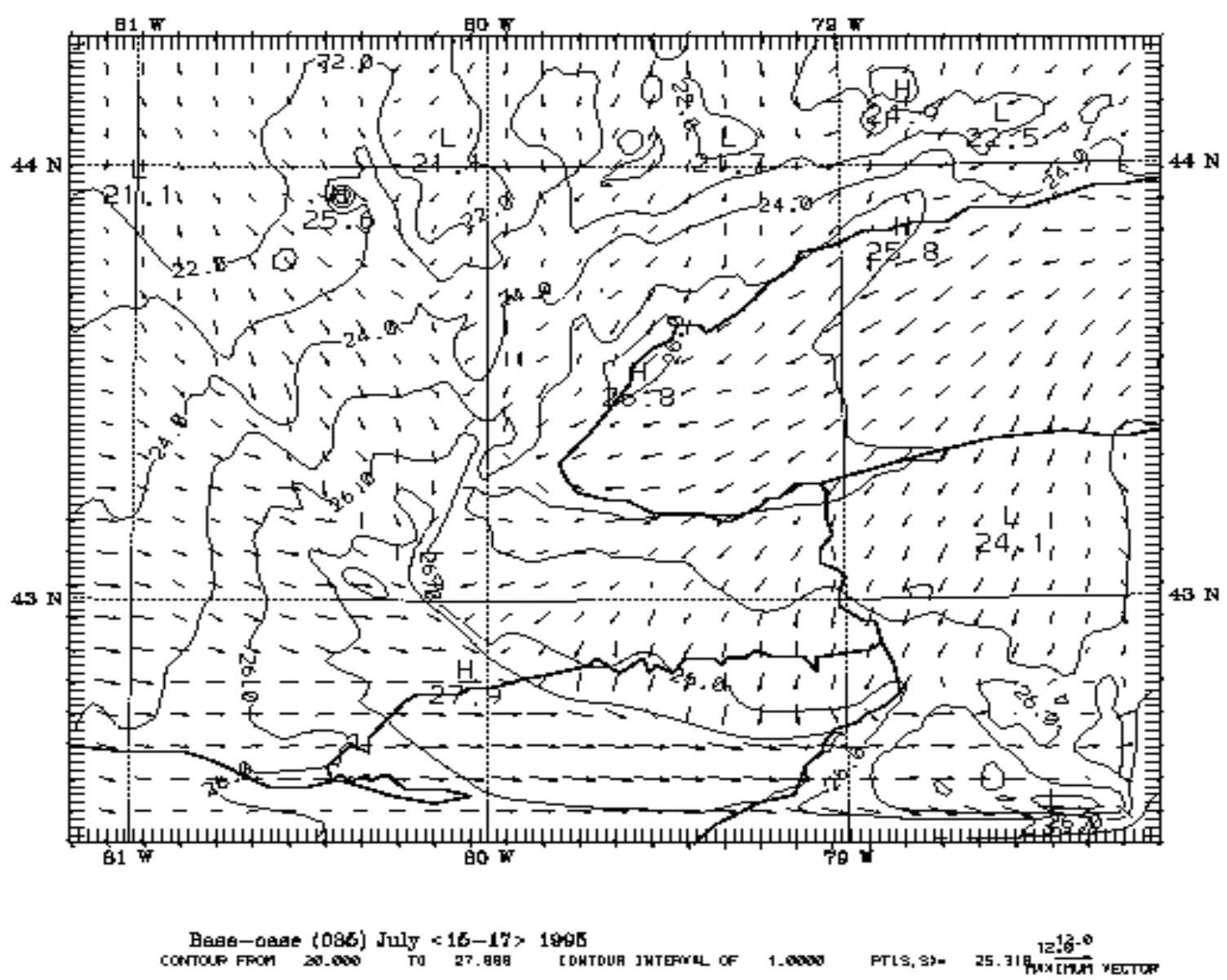

Figure 4.43. July 15, 1995 at 2000 LST base case scenario: Simulated temperature and wind-vector field, for the inner, fine-resolution $(2-\mathrm{km})$ domain. 

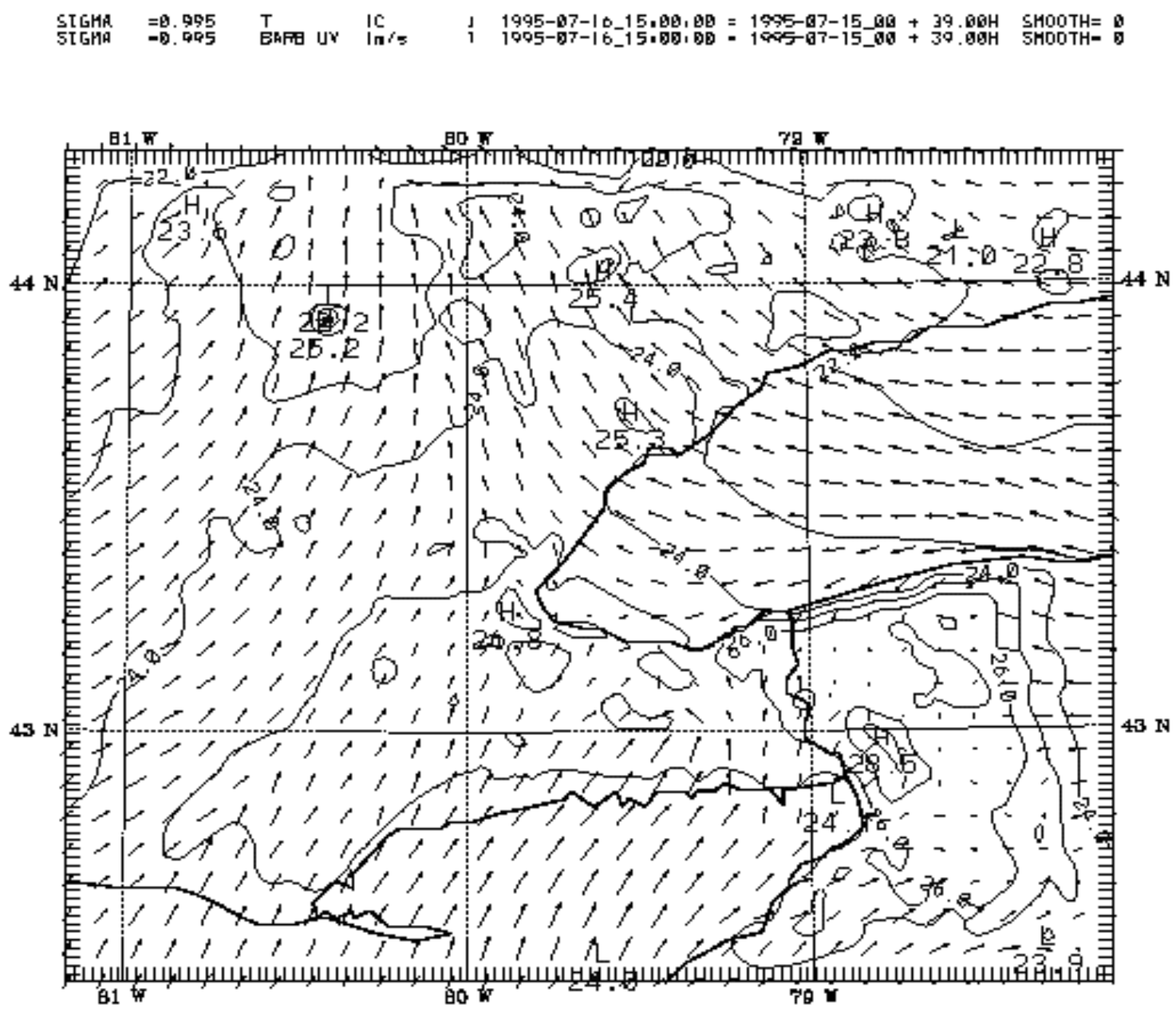

Beag-0age $(086) \mathrm{July}<16-17>1965$
cotroup From 20.000

Figure 4.44. July 16, 1995 at 1000 LST base case scenario: Simulated temperature and wind-vector field, for the inner, fine-resolution $(2-\mathrm{km})$ domain. 


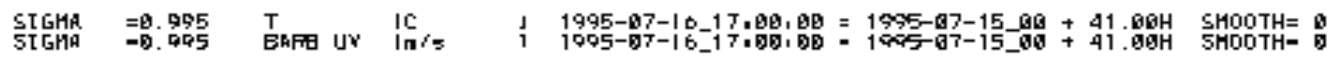

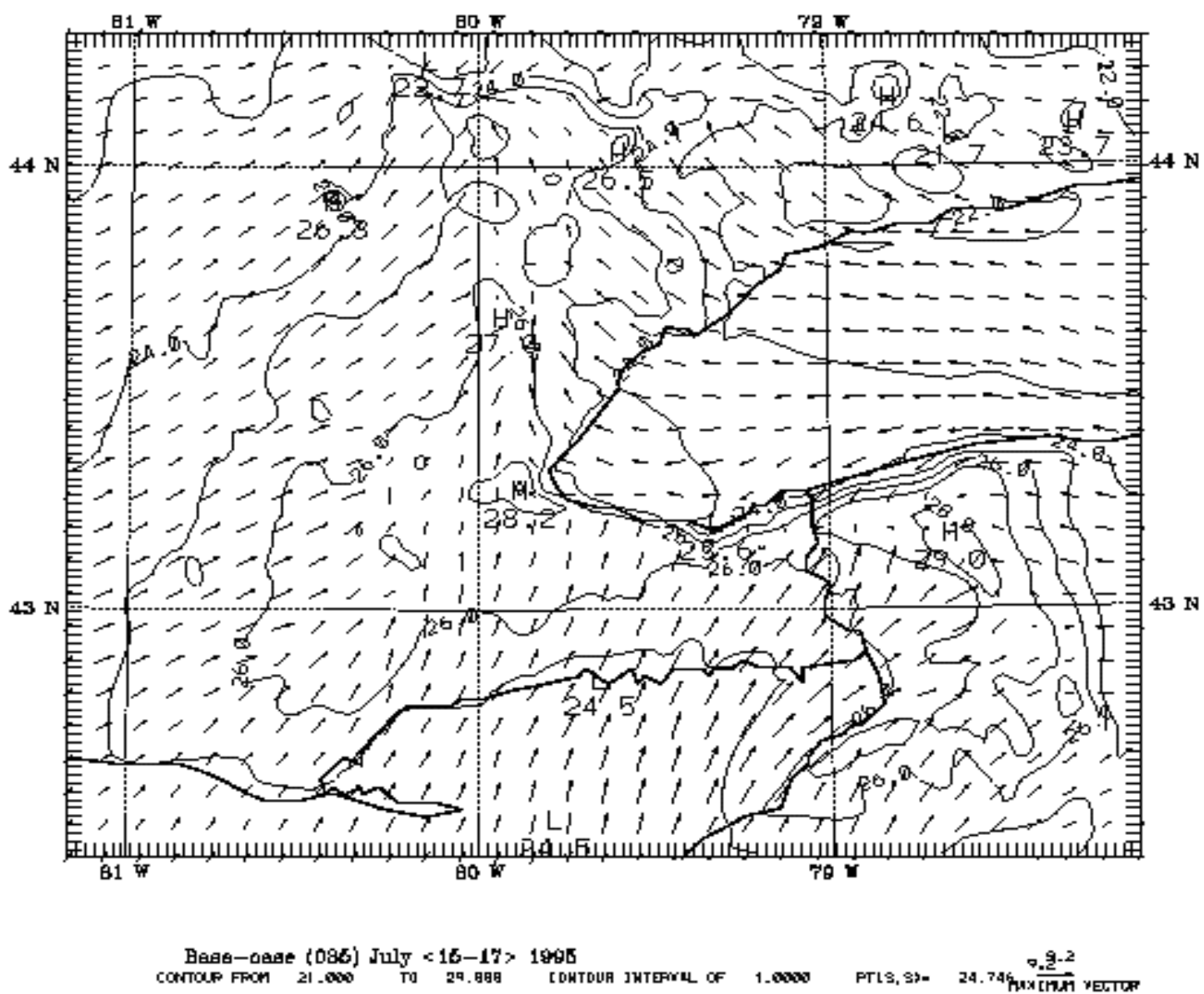

Figure 4.45. July 16, 1995 at 1200 LST base case scenario: Simulated temperature and wind-vector field, for the inner, fine-resolution $(2-\mathrm{km})$ domain. 


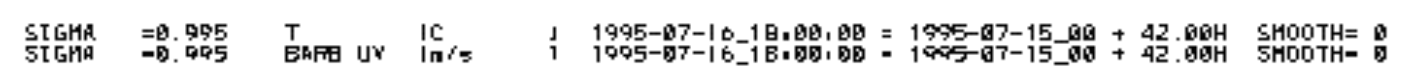

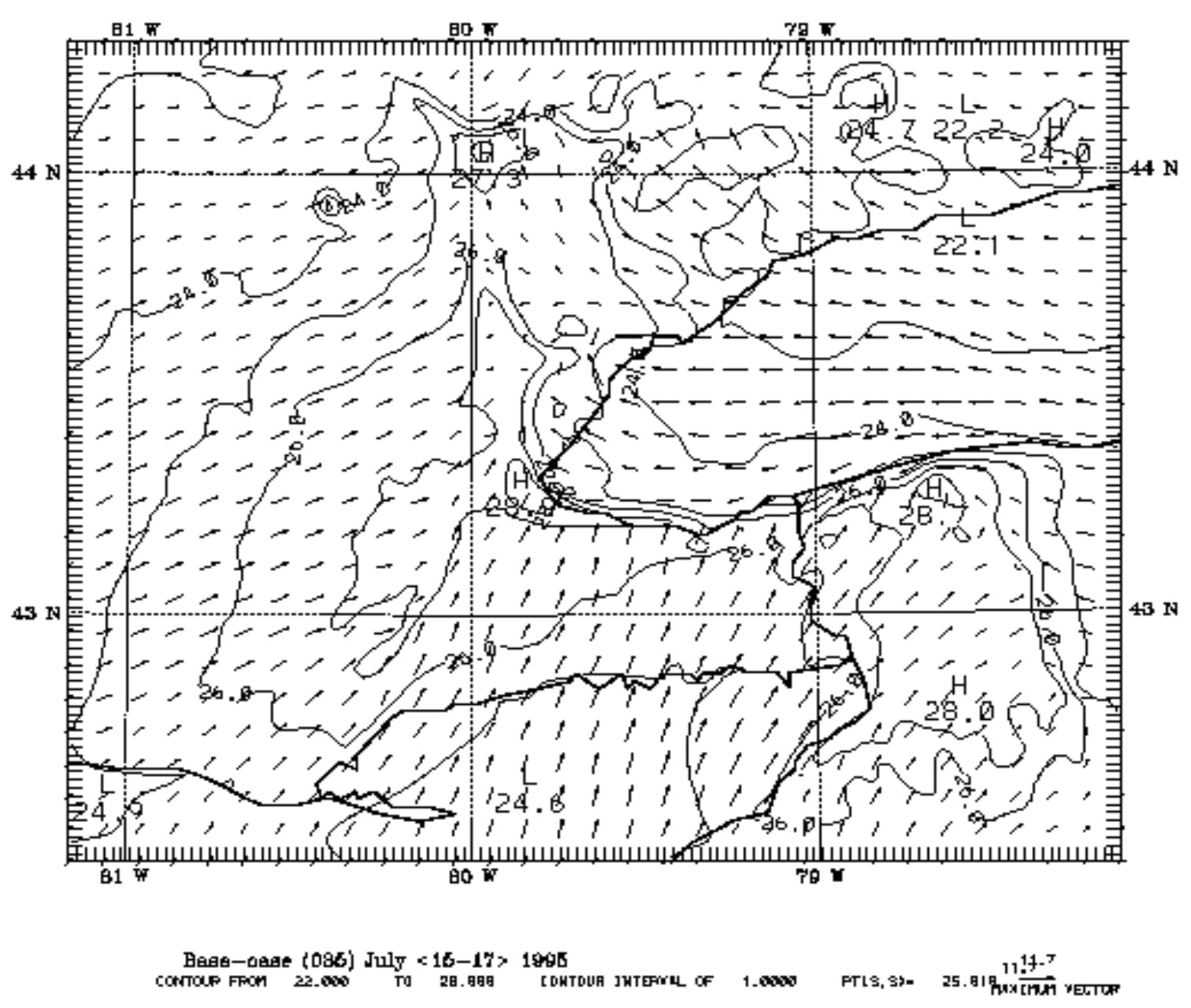

Figure 4.46. July 16, 1995 at 1300 LST base case scenario: Simulated temperature and wind-vector field, for the inner, fine-resolution $(2-\mathrm{km})$ domain. 


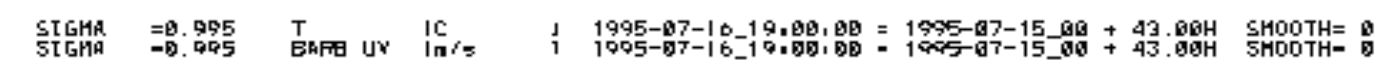

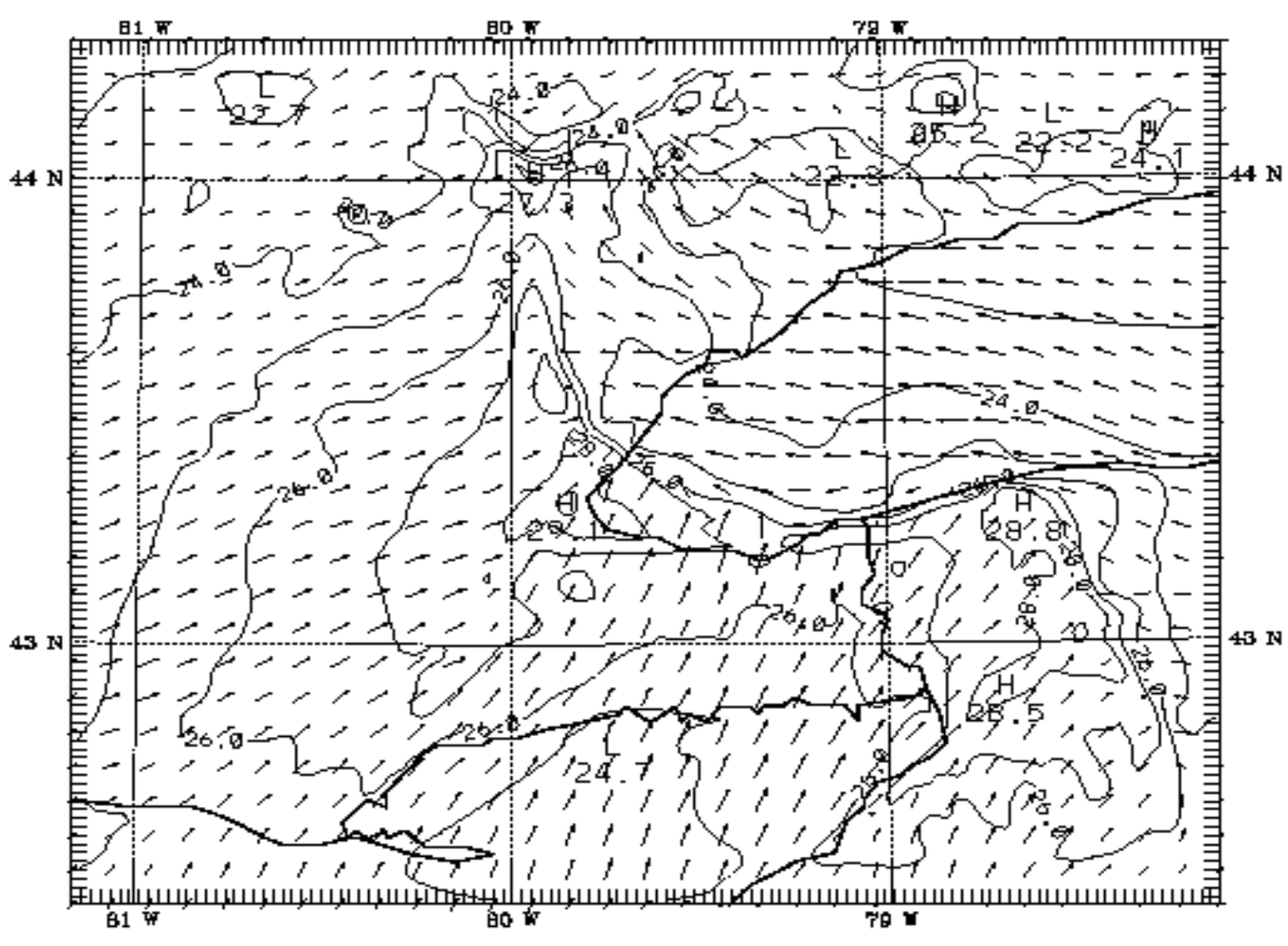

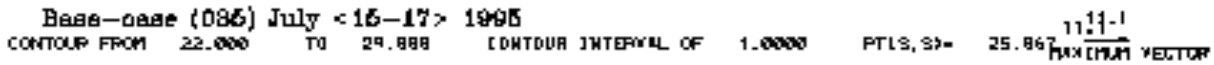

Figure 4.47. July 16, 1995 at 1400 LST base case scenario: Simulated temperature and wind-vector field, for the inner, fine-resolution (2-km) domain. 


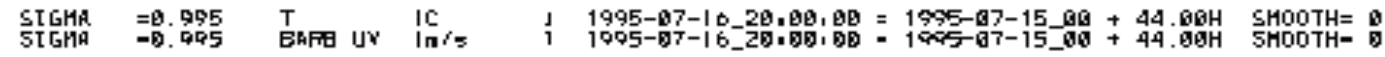

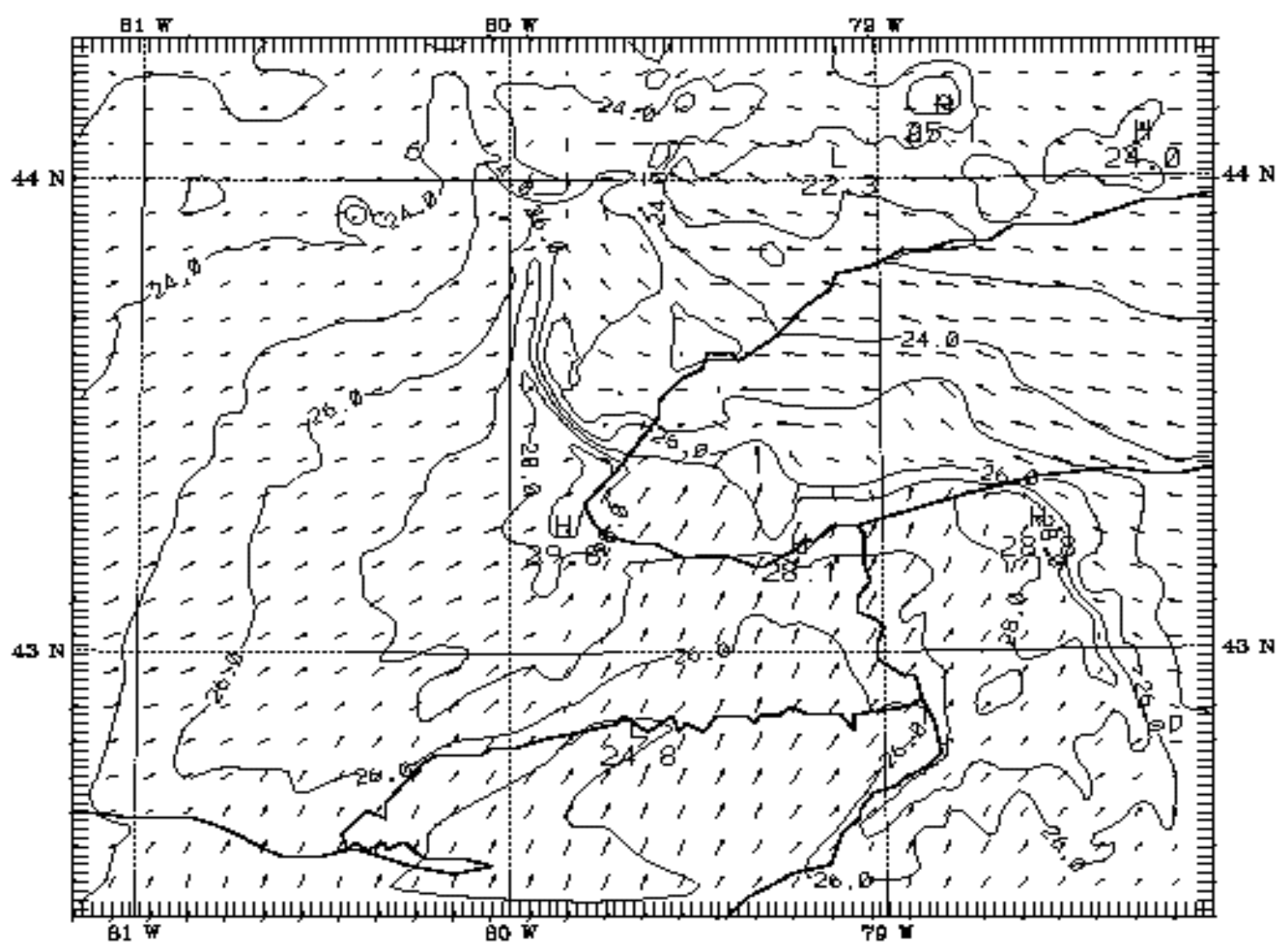

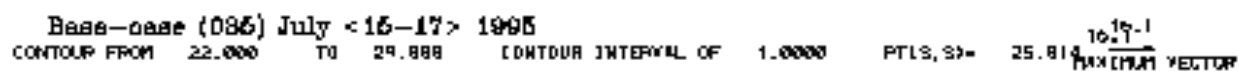

Figure 4.48. July 16, 1995 at 1500 LST base case scenario: Simulated temperature and wind-vector field, for the inner, fine-resolution $(2-\mathrm{km})$ domain. 


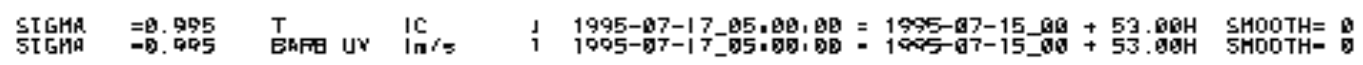

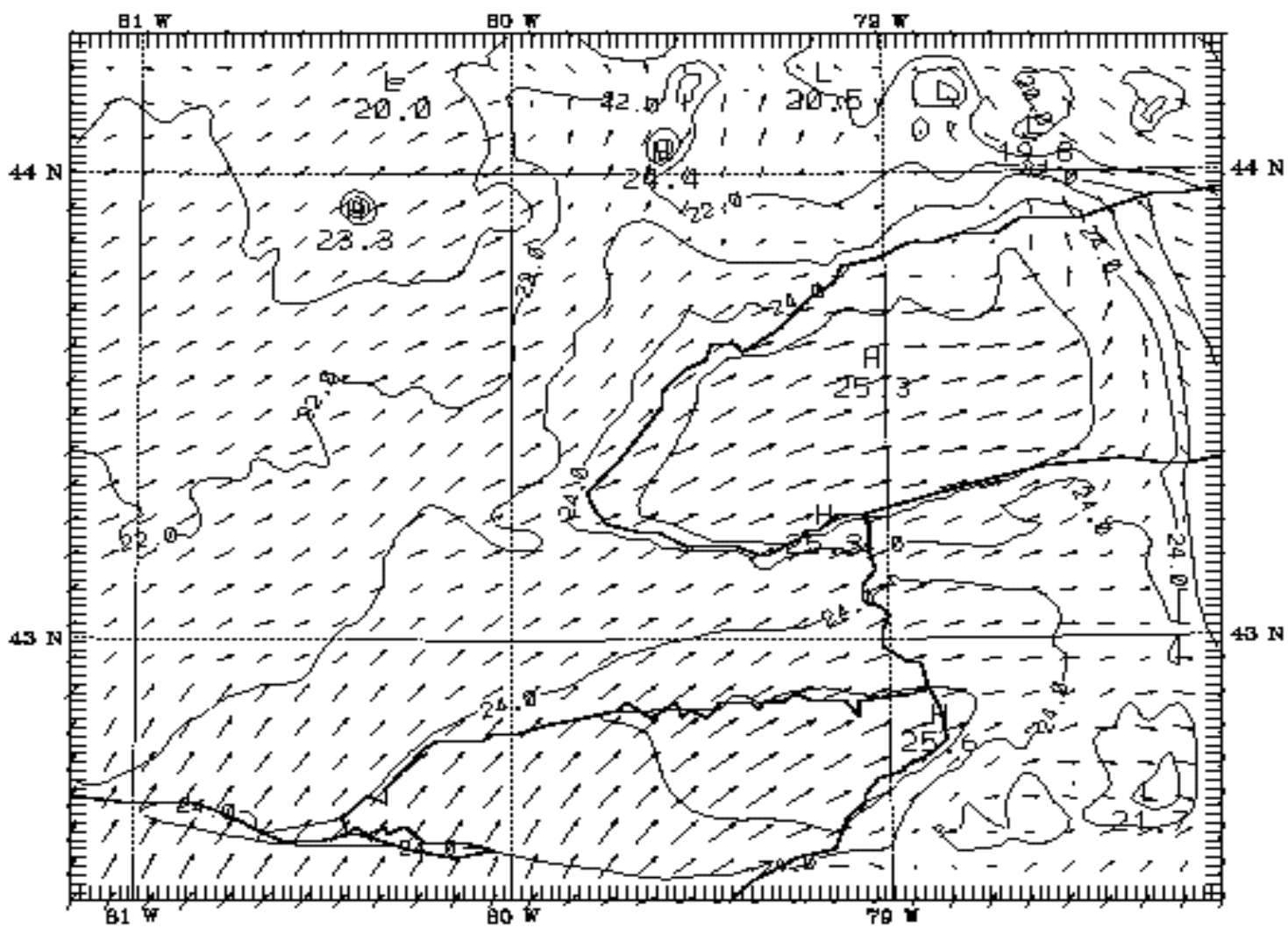

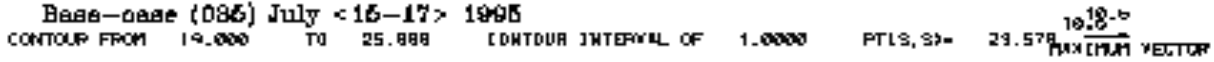

Figure 4.49. July 17, 1995 at 0000 LST base case scenario: Simulated temperature and wind-vector field, for the inner, fine-resolution $(2-\mathrm{km})$ domain. 
SIGHa $=9.995$
STGKa

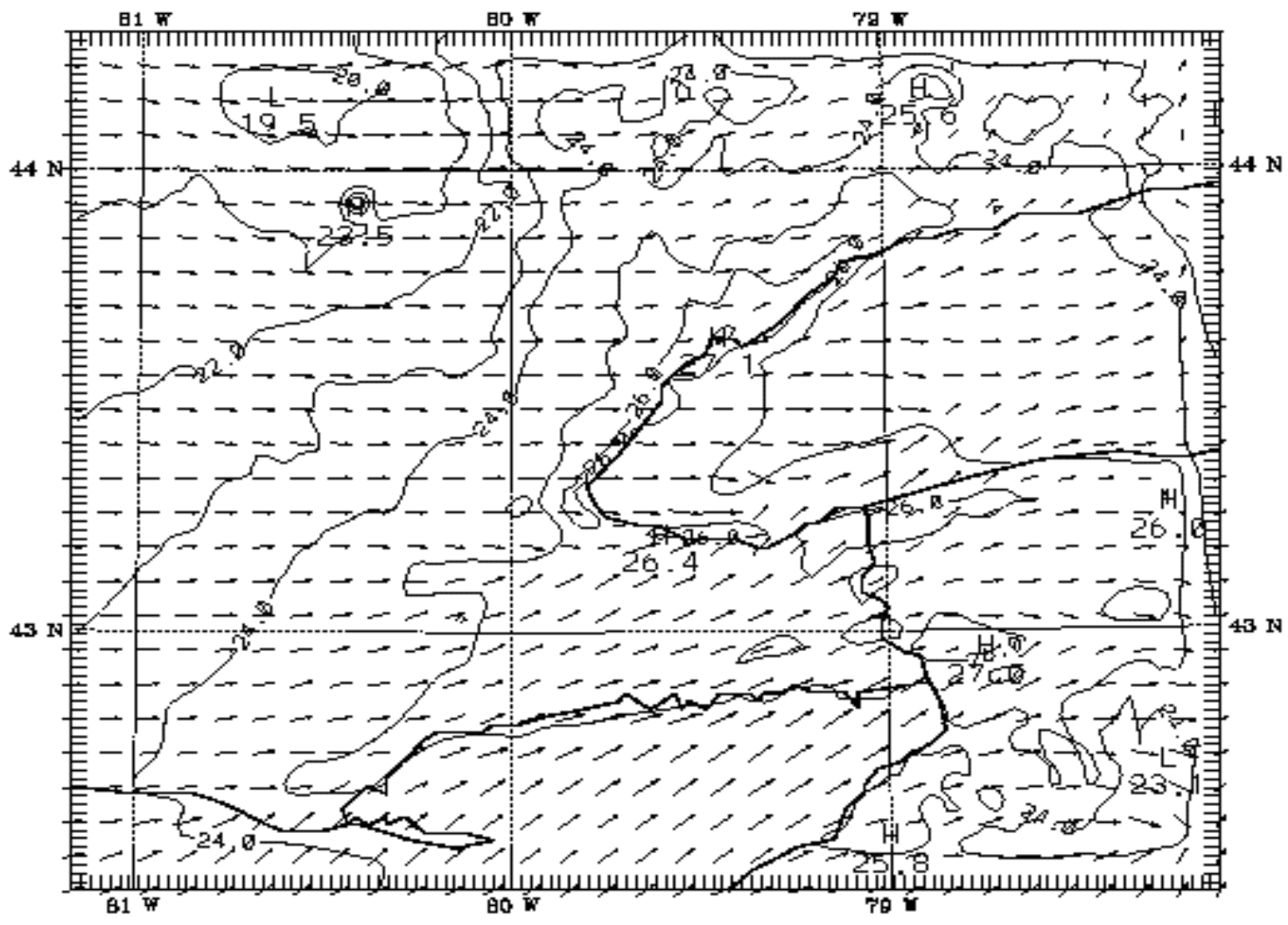

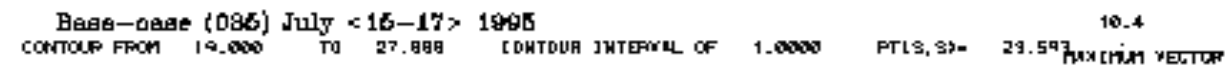

Figure 4.50. July 17, 1995 at 1000 LST base case scenario: Simulated temperature and wind-vector field, for the inner, fine-resolution $(2-\mathrm{km})$ domain. 


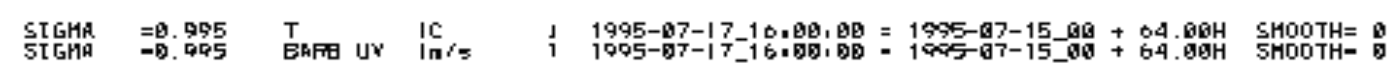

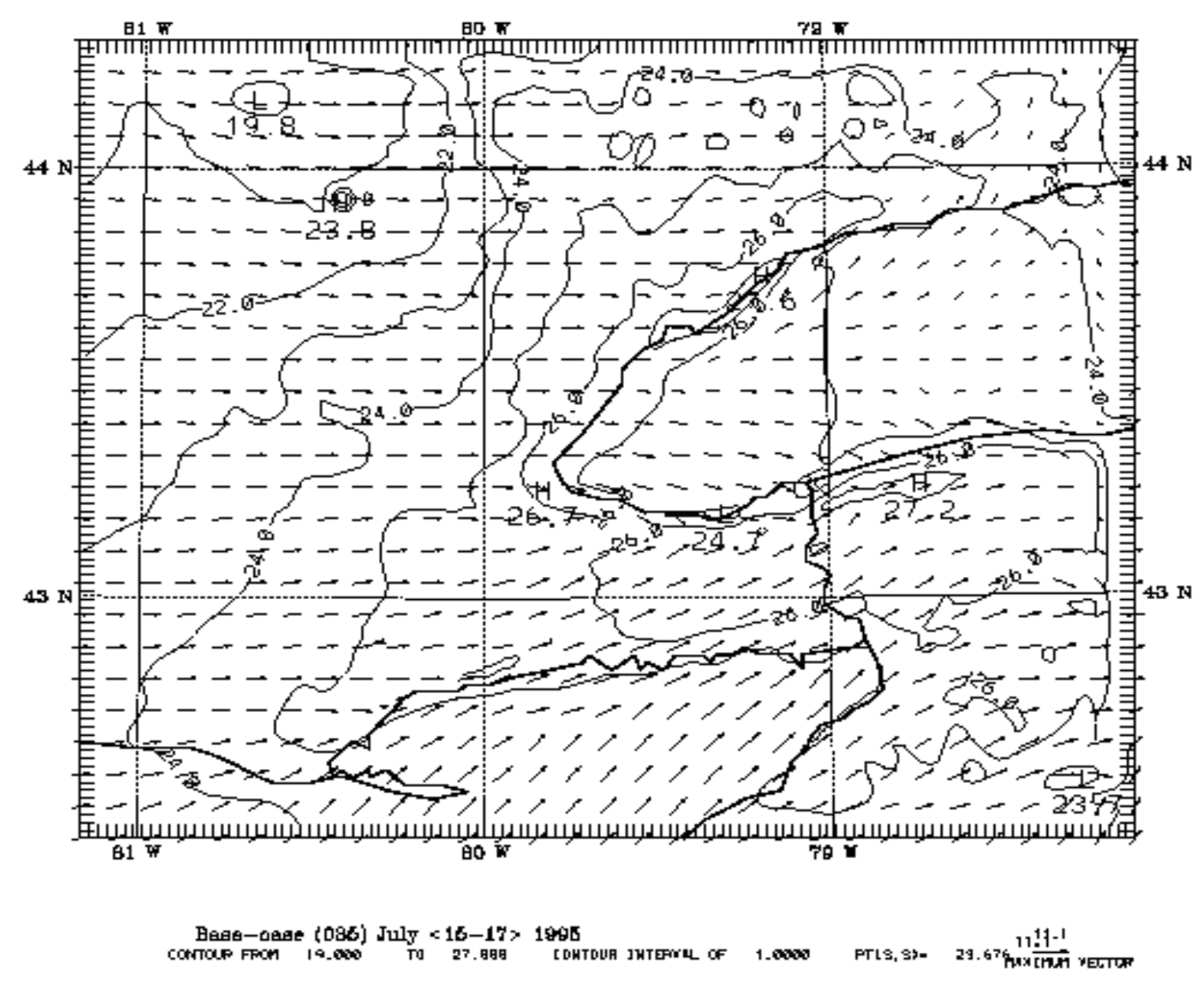

Figure 4.51. July 17, 1995 at 1100 LST base case scenario: Simulated temperature and wind-vector field, for the inner, fine-resolution $(2-\mathrm{km})$ domain. 


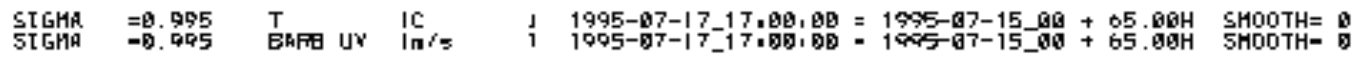

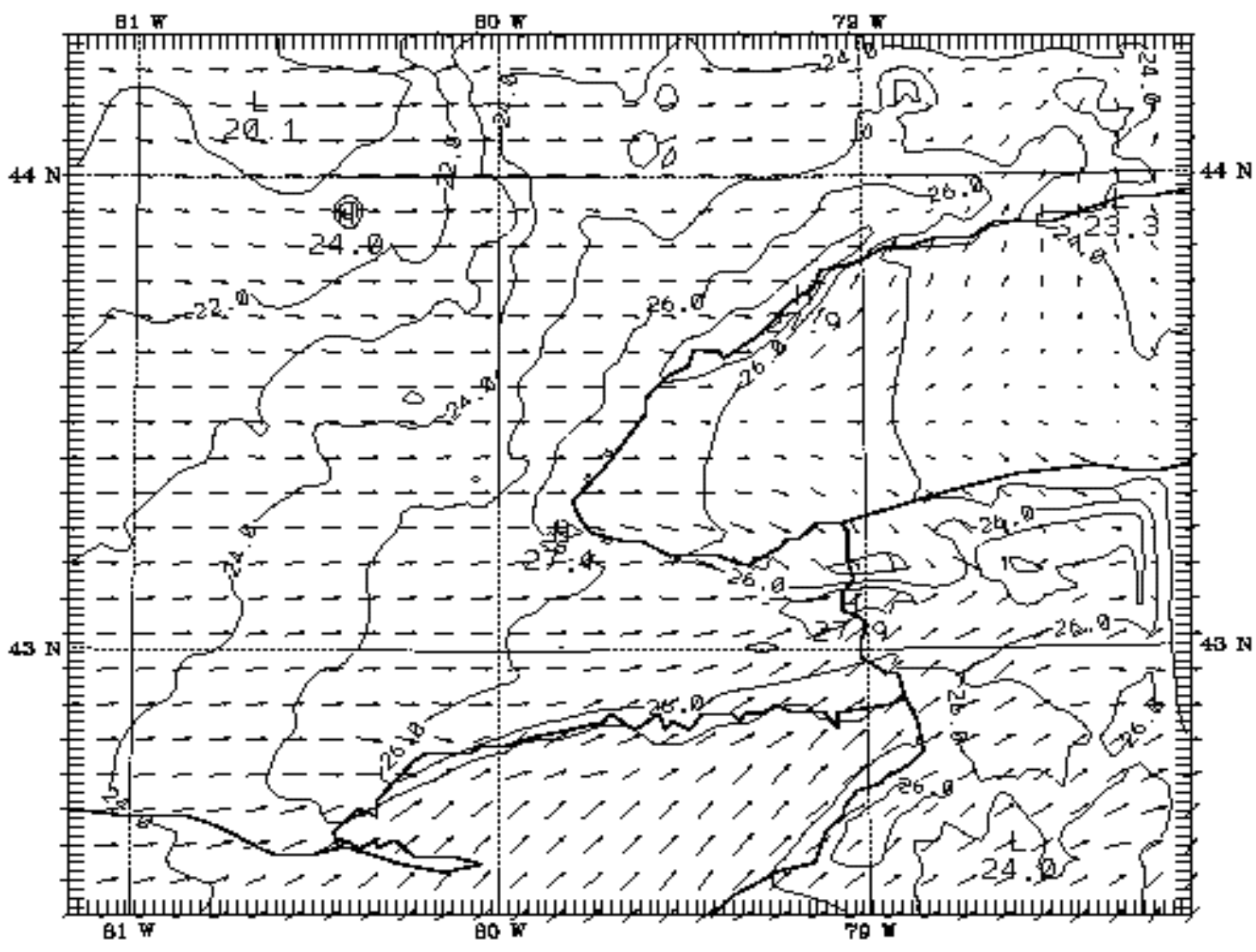

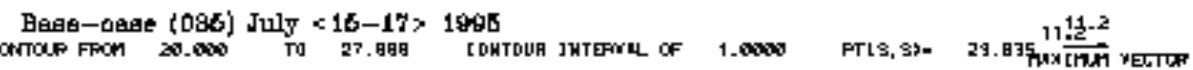

Figure 4.52. July 17, 1995 at 1200 LST base case scenario: Simulated temperature and wind-vector field, for the inner, fine-resolution $(2-\mathrm{km})$ domain. 


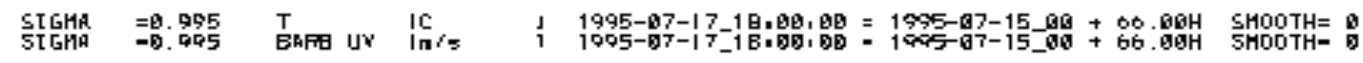

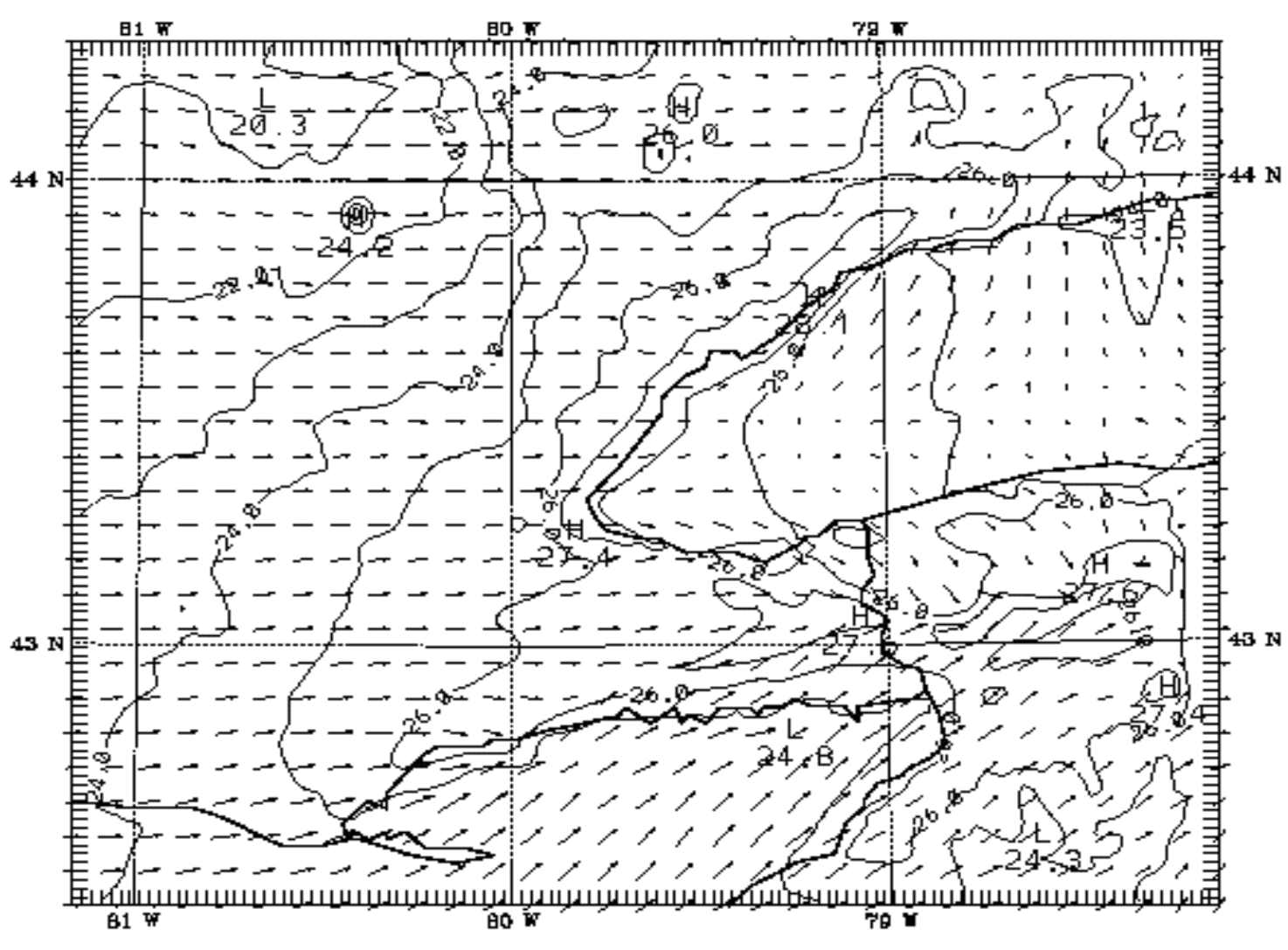

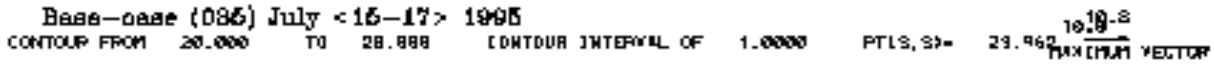

Figure 4.53. July 17, 1995 at 1300 LST base case scenario: Simulated temperature and wind-vector field, for the inner, fine-resolution $(2-\mathrm{km})$ domain. 


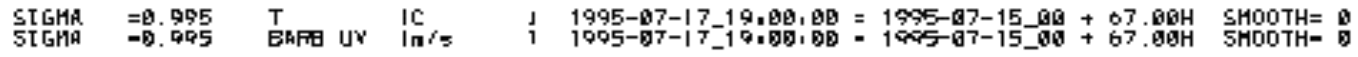

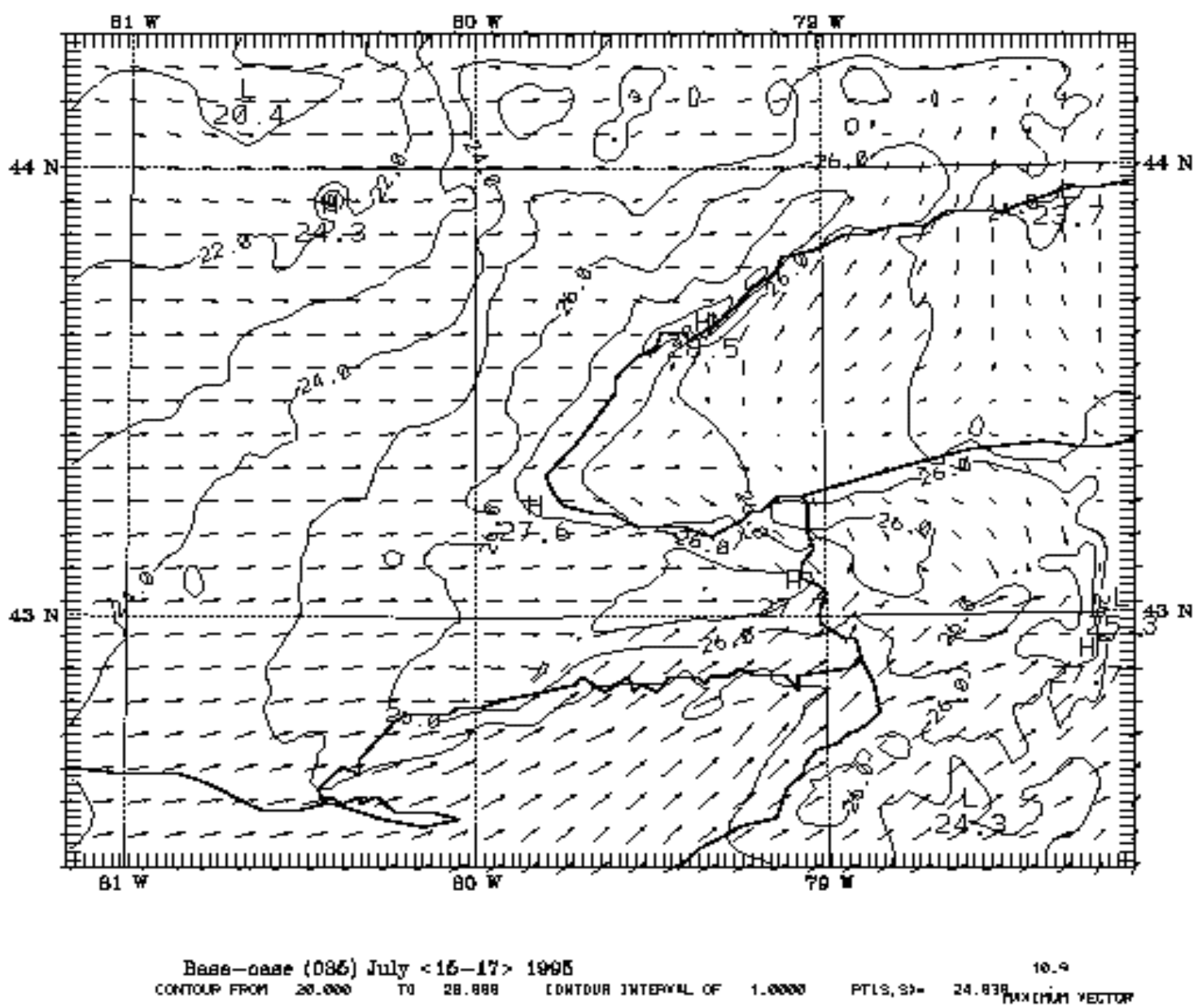

Figure 4.54. July 17, 1995 at 1400 LST base case scenario: Simulated temperature and wind-vector field, for the inner, fine-resolution $(2-\mathrm{km})$ domain. 


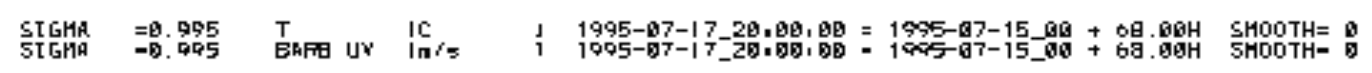

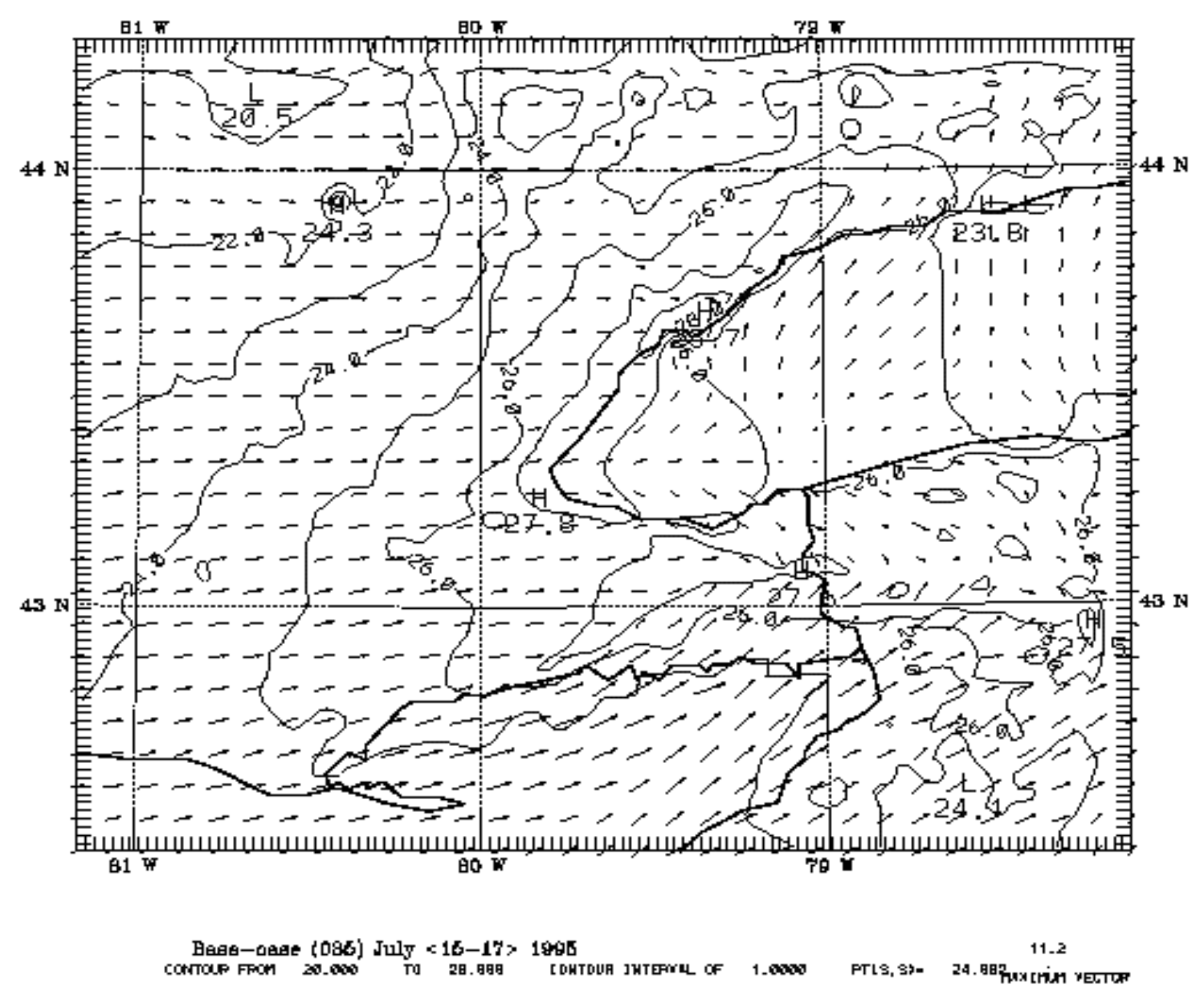

Figure 4.55. July 17, 1995 at 1500 LST base case scenario: Simulated temperature and wind-vector field, for the inner, fine-resolution $(2-\mathrm{km})$ domain. 
SIGHA $=9.995$
StGHa

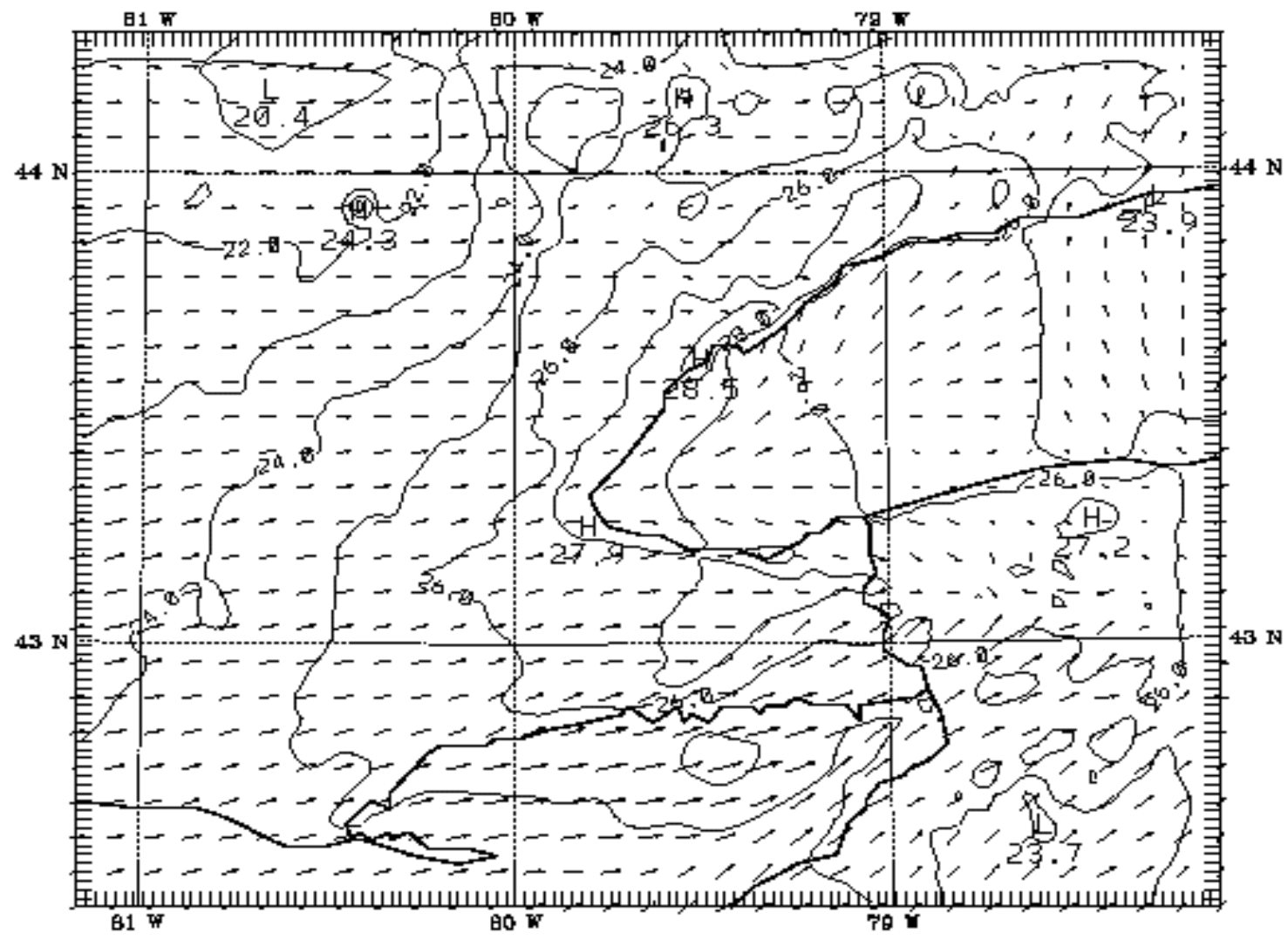

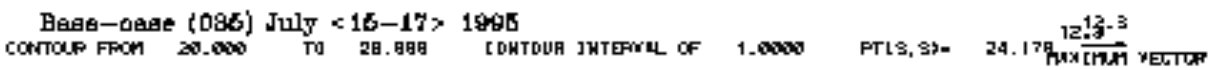

Figure 4.56. July 17, 1995 at 1600 LST base case scenario: Simulated temperature and wind-vector field, for the inner, fine-resolution $(2-\mathrm{km})$ domain. 
SIGHA =9. $595 \quad T$ T

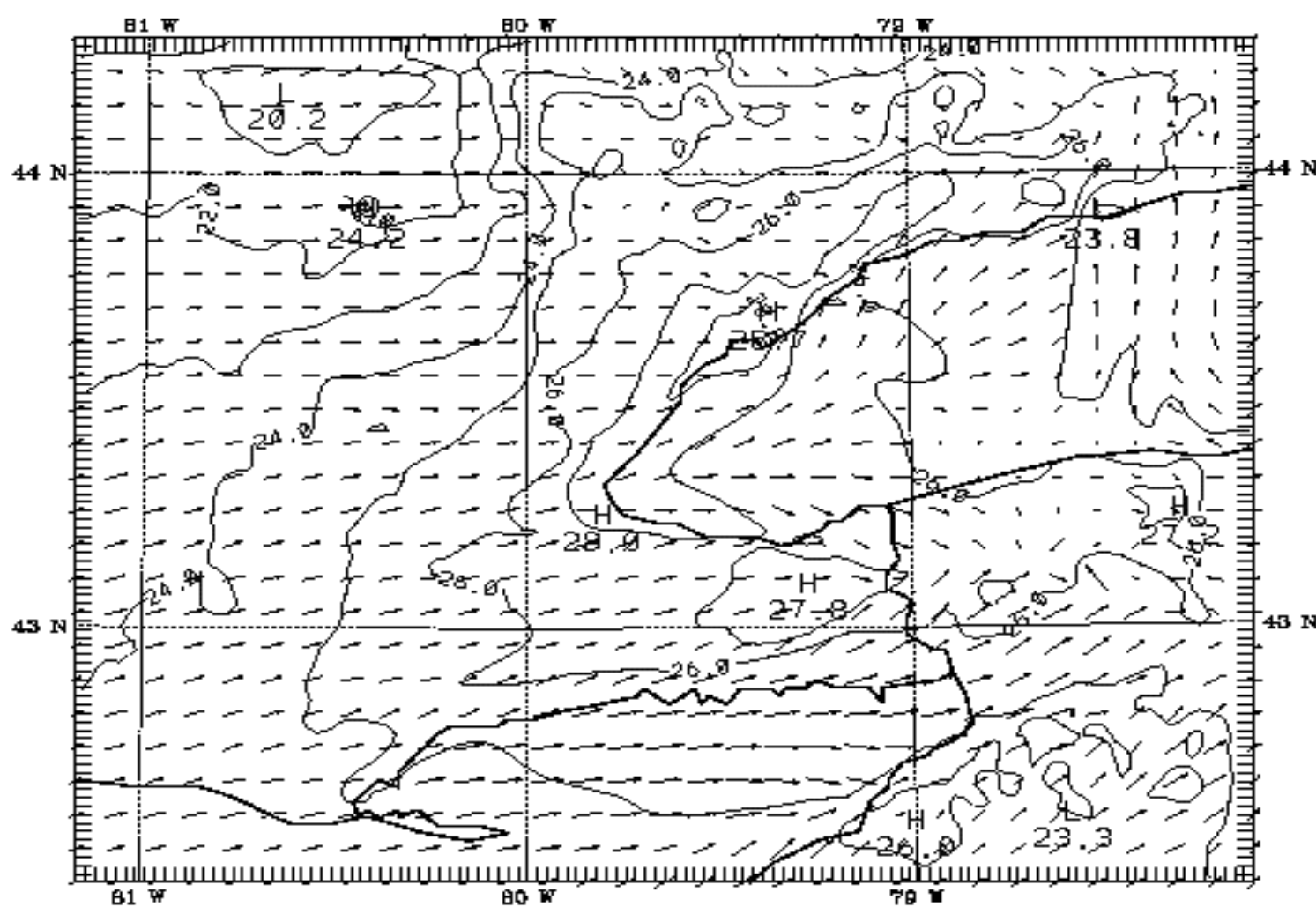

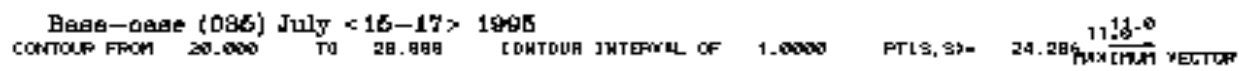

Figure 4.57. July 17, 1995 at 1700 LST base case scenario: Simulated temperature and wind-vector field, for the inner, fine-resolution $(2-\mathrm{km})$ domain. 


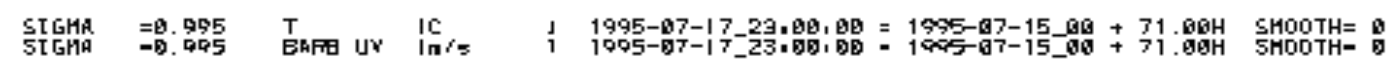

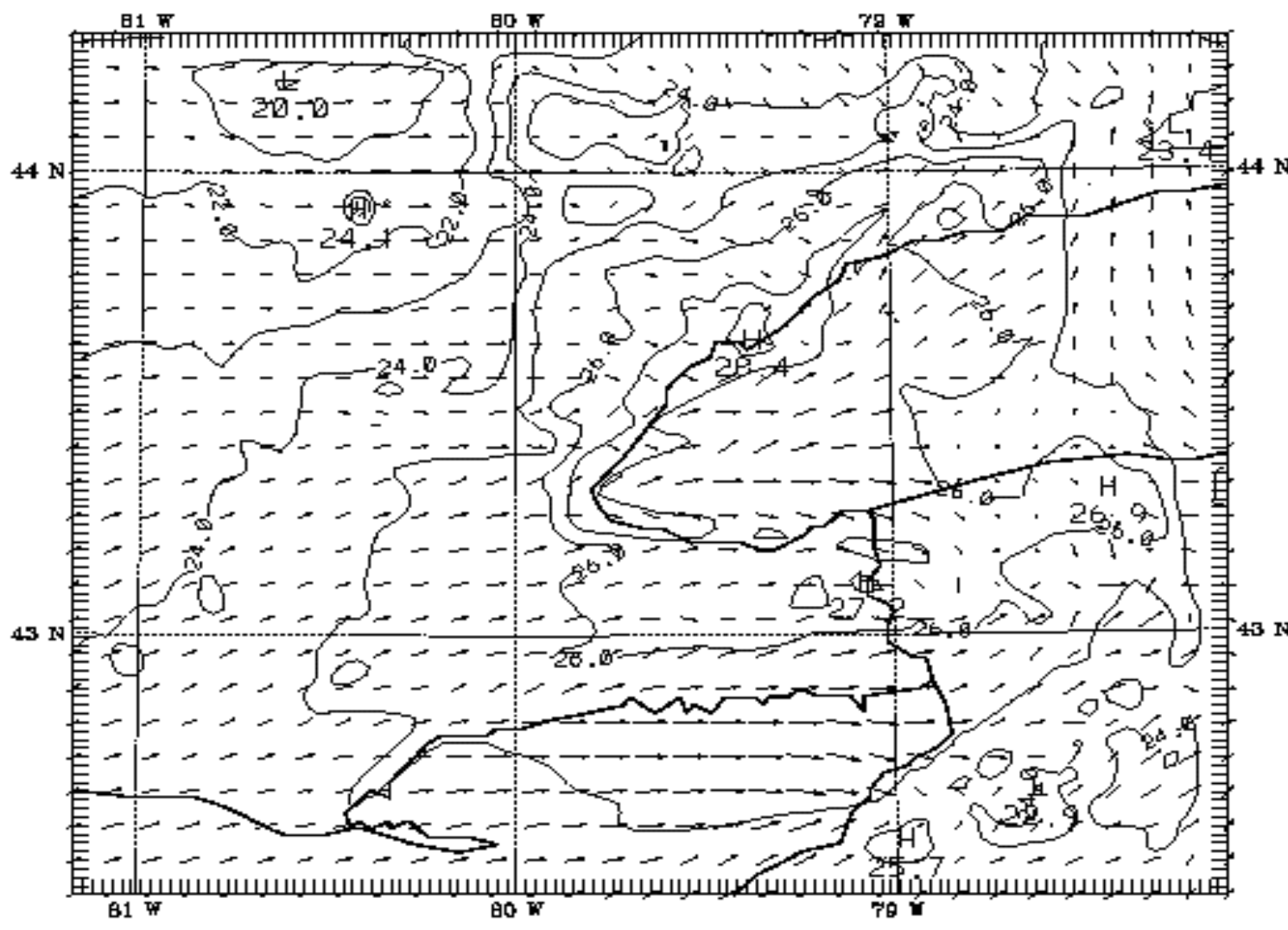

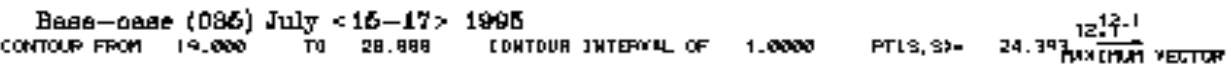

Figure 4.58. July 17, 1995 at 1800 LST base case scenario: Simulated temperature and wind-vector field, for the inner, fine-resolution $(2-\mathrm{km})$ domain. 

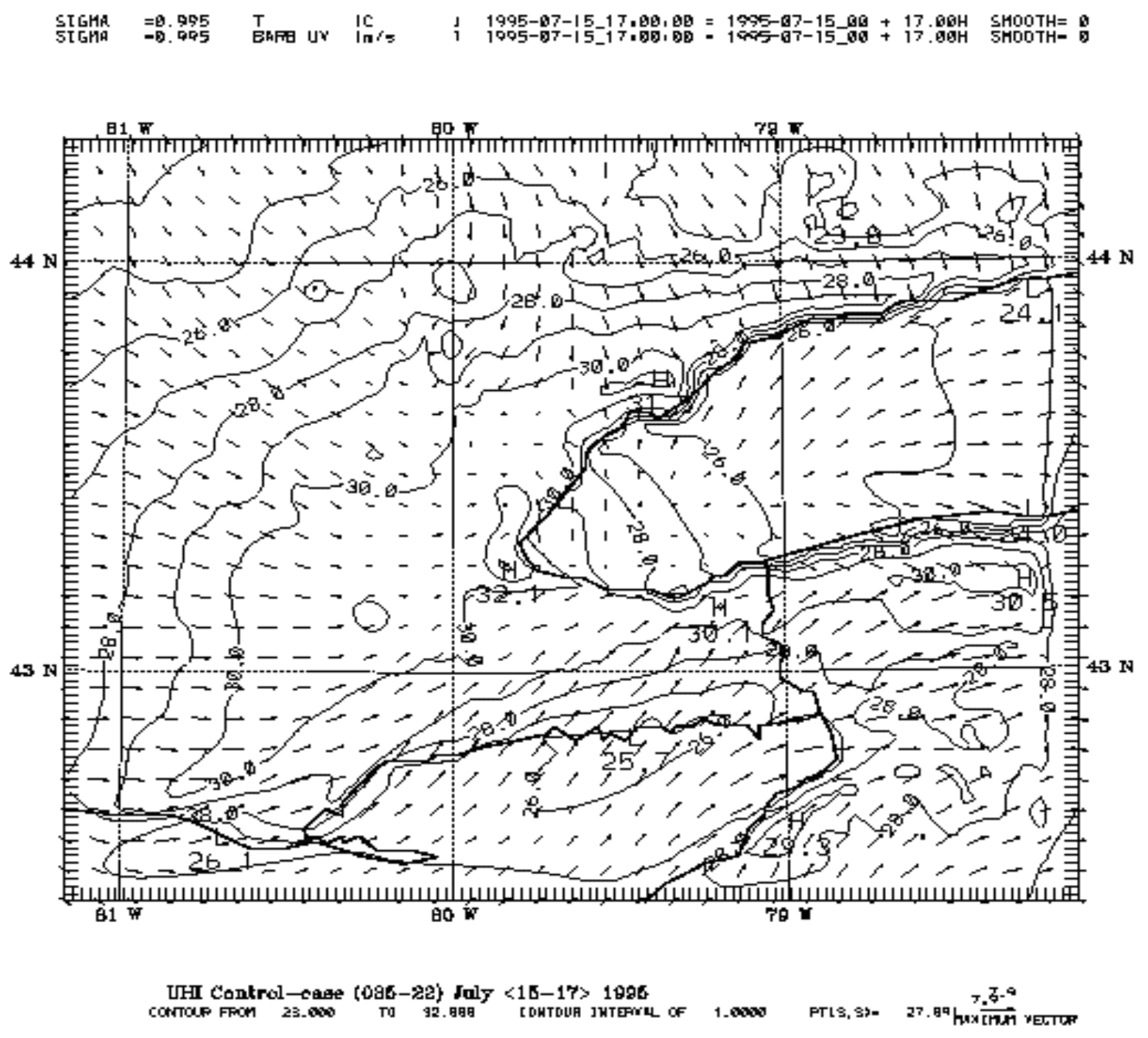

Figure 4.59. July 15, 1995 at 1200 LST cool-city scenario: Simulated temperature and wind-vector field, for the inner, fine-resolution $(2-\mathrm{km})$ domain. 


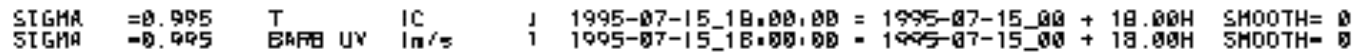

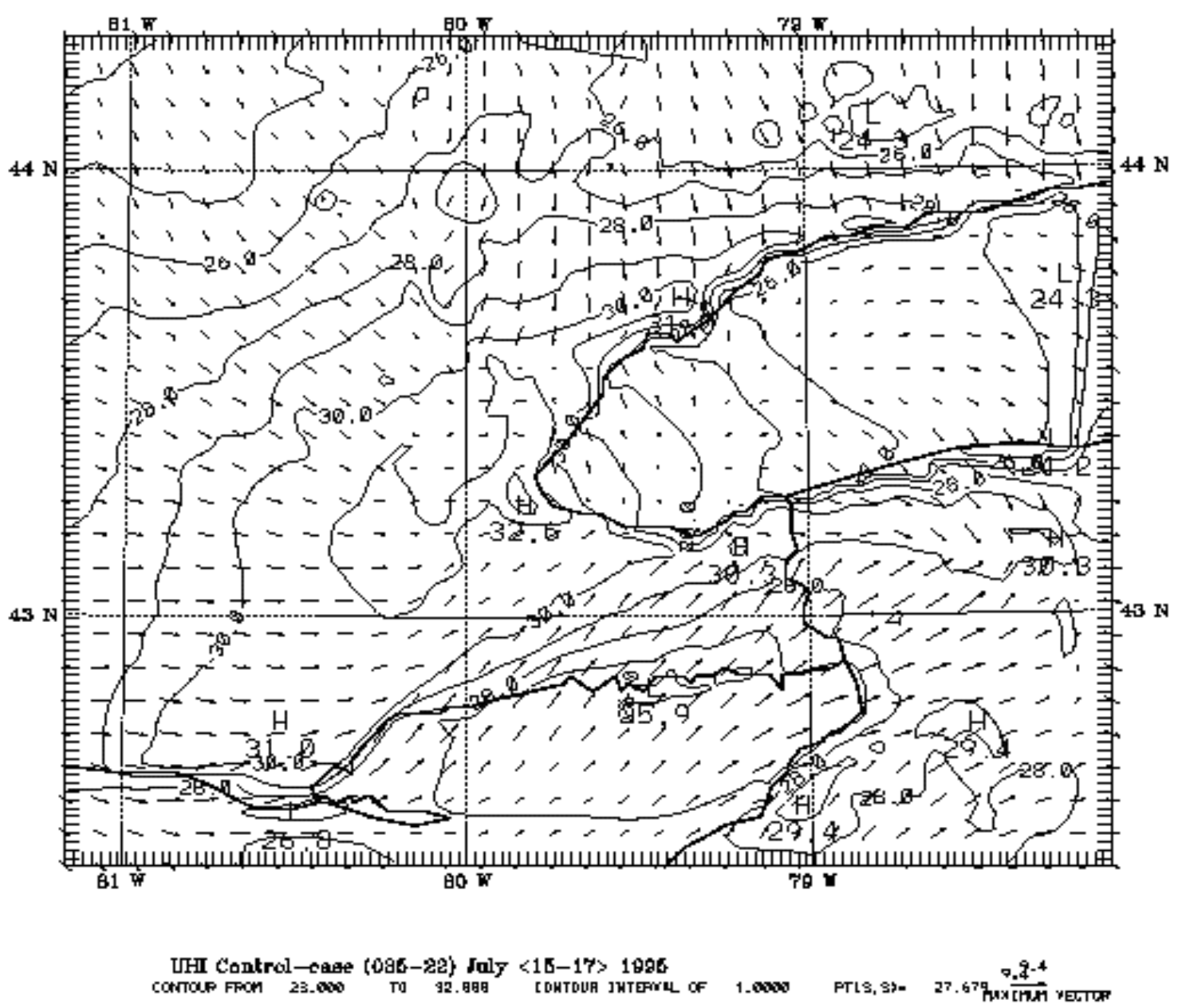

Figure 4.60. July 15, 1995 at 1300 LST cool-city scenario: Simulated temperature and wind-vector field, for the inner, fine-resolution $(2-\mathrm{km})$ domain. 


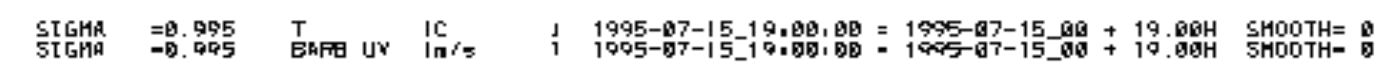

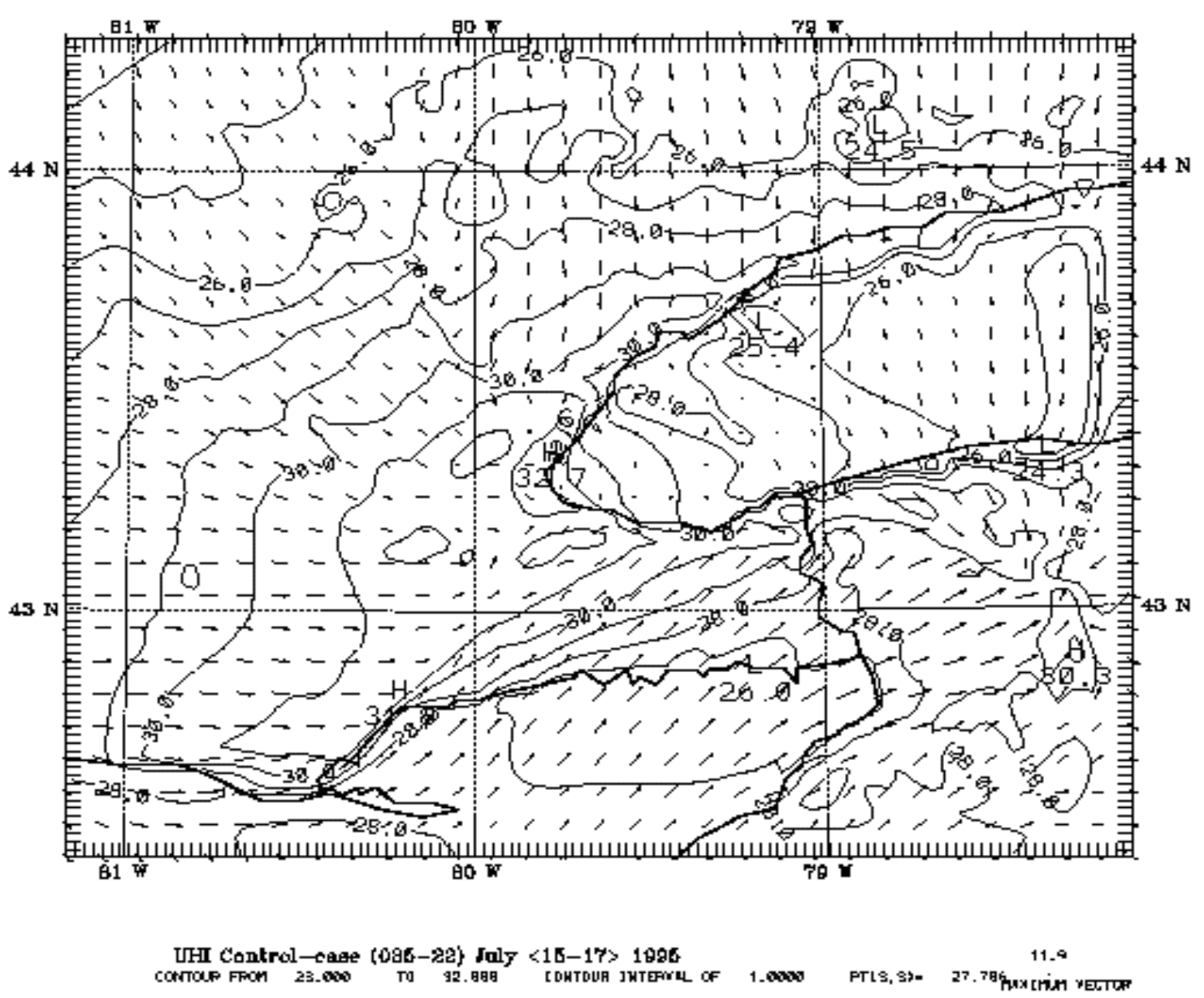

Figure 4.61. July 15, 1995 at 1400 LST cool-city scenario: Simulated temperature and wind-vector field, for the inner, fine-resolution (2-km) domain. 


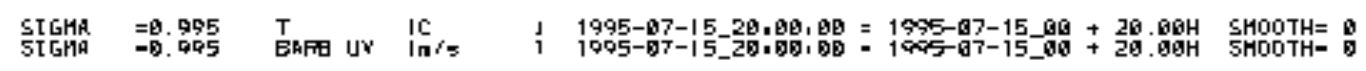

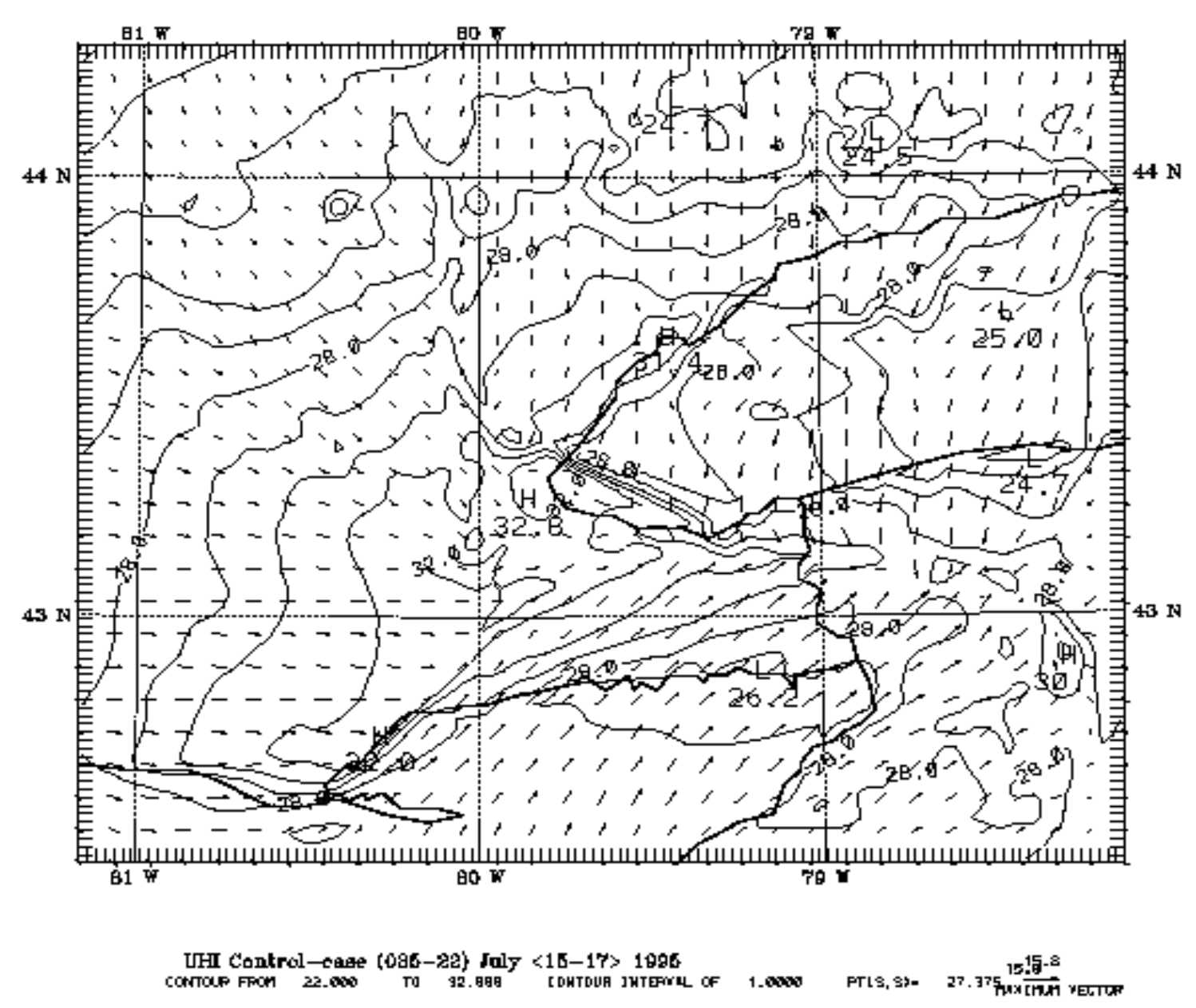

Figure 4.62. July 15, 1995 at 1500 LST cool-city scenario: Simulated temperature and wind-vector field, for the inner, fine-resolution $(2-\mathrm{km})$ domain. 


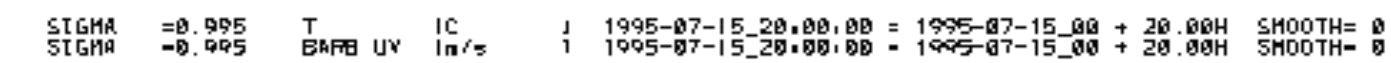

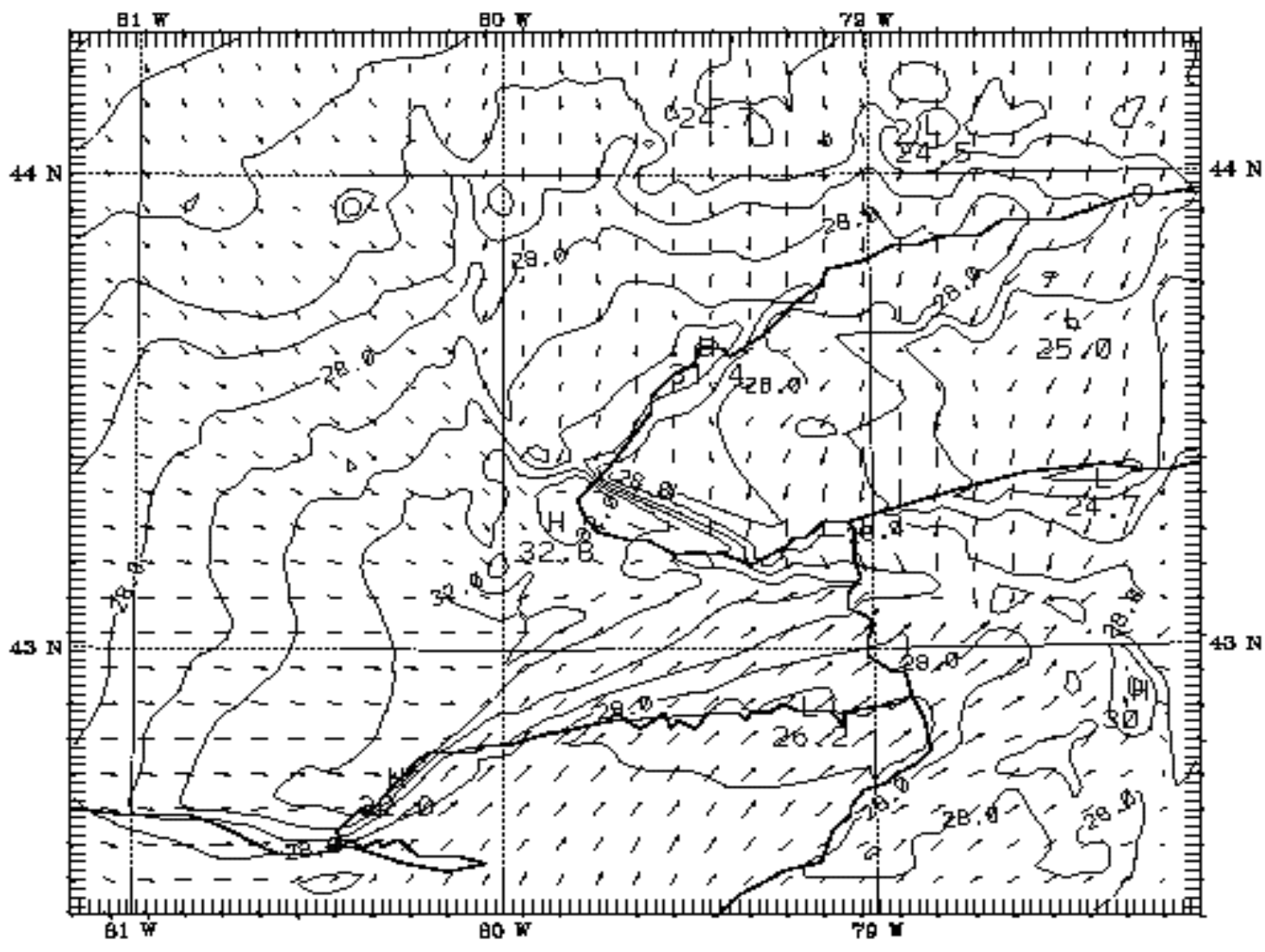

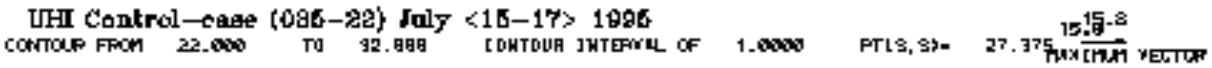

Figure 4.63. July 15, 1995 at 1600 LST cool-city scenario: Simulated temperature and wind-vector field, for the inner, fine-resolution $(2-\mathrm{km})$ domain. 


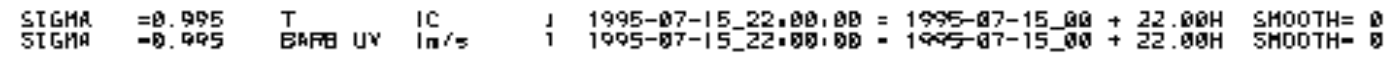

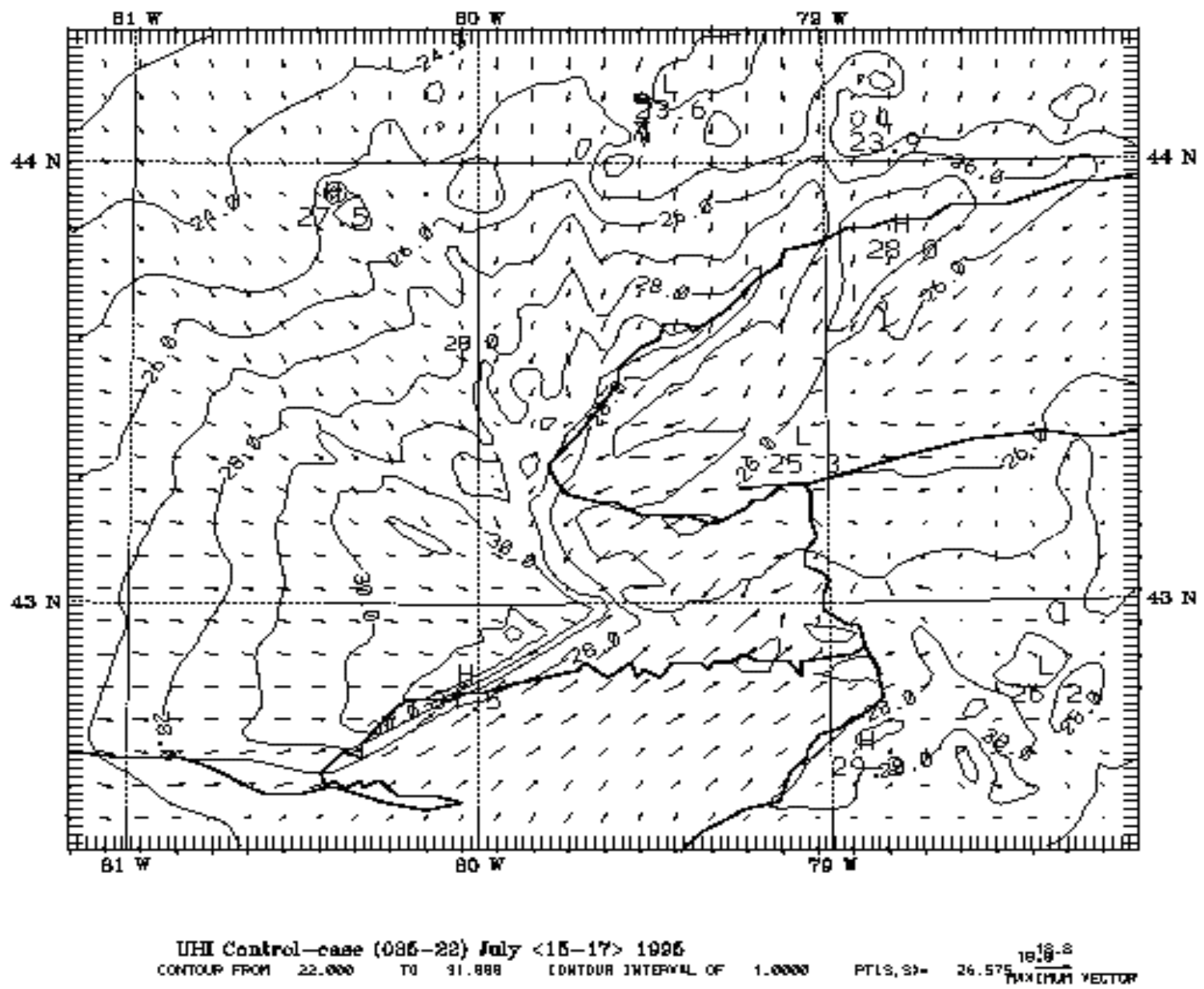

Figure 4.64. July 15, 1995 at 1700 LST cool-city scenario: Simulated temperature and wind-vector field, for the inner, fine-resolution $(2-\mathrm{km})$ domain. 


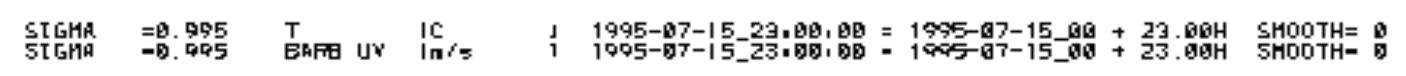

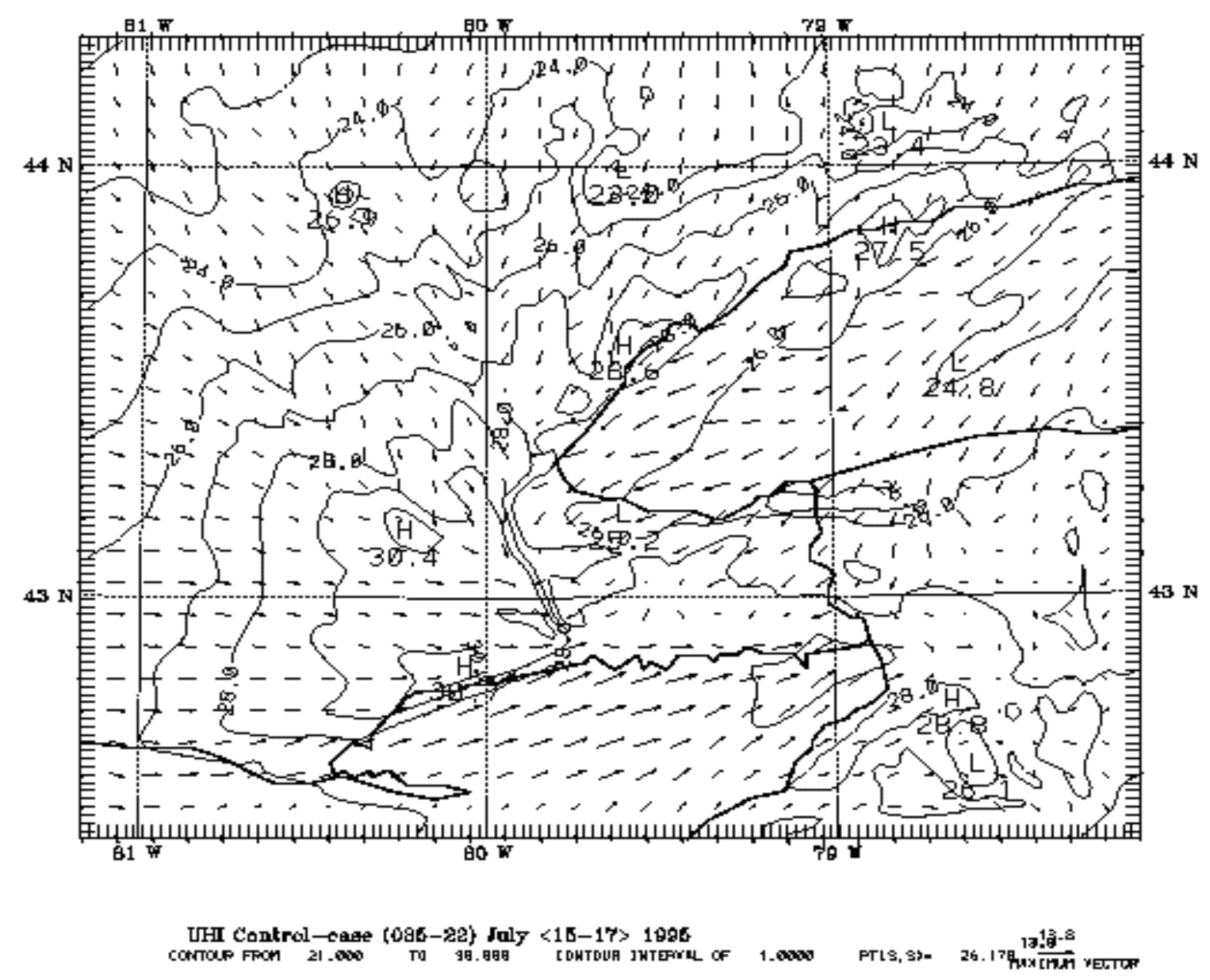

Figure 4.65. July 15, 1995 at 1800 LST cool-city scenario: Simulated temperature and wind-vector field, for the inner, fine-resolution $(2-\mathrm{km})$ domain. 


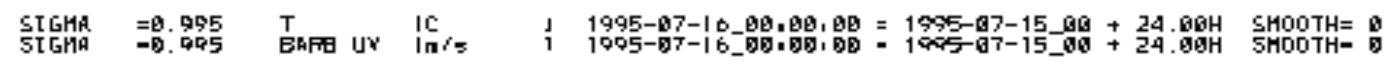

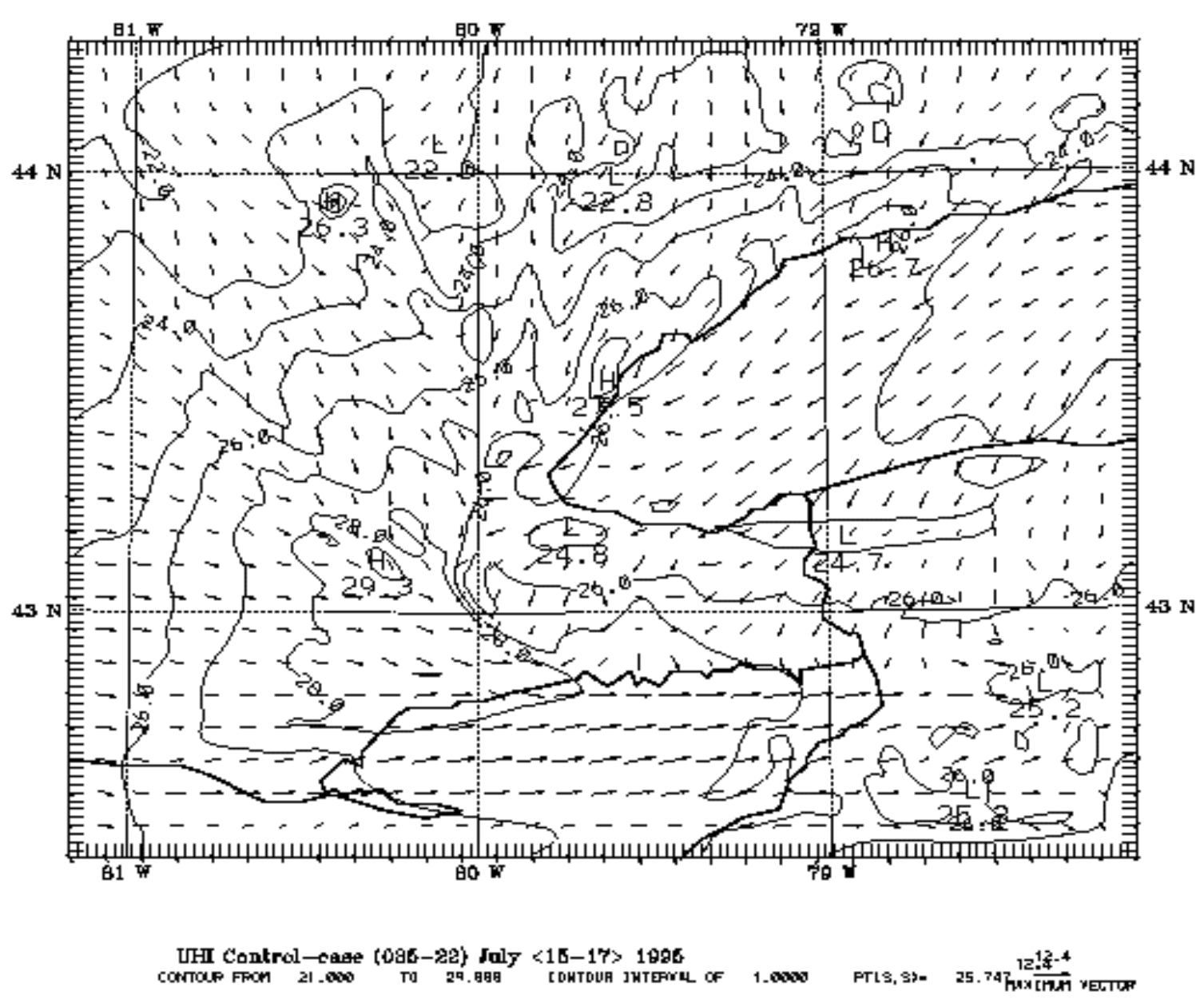

Figure 4.66. July 15, 1995 at 1900 LST cool-city scenario: Simulated temperature and wind-vector field, for the inner, fine-resolution $(2-\mathrm{km})$ domain. 


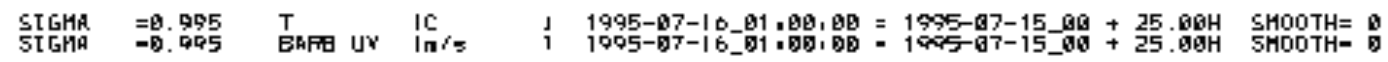

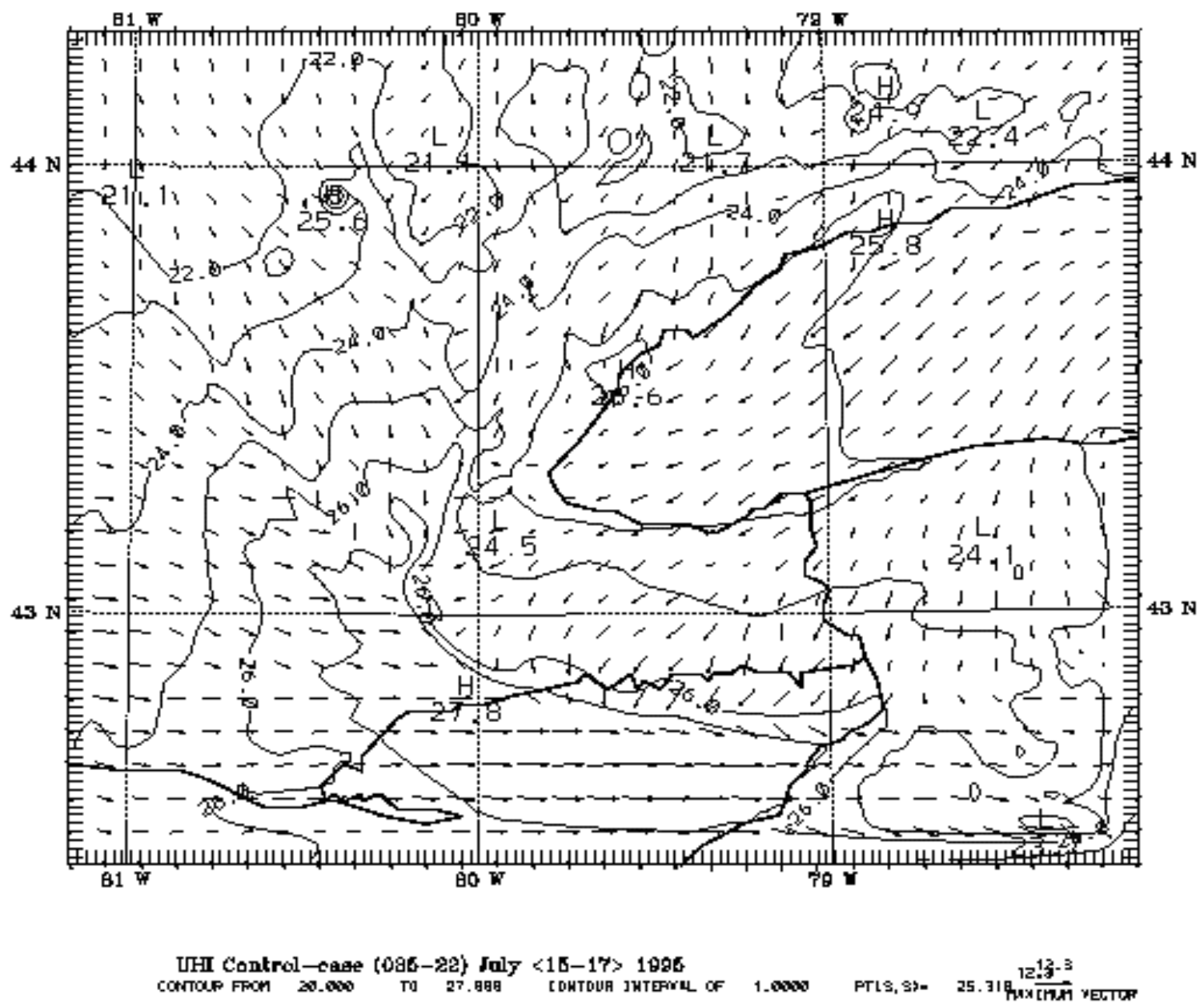

Figure 4.67. July 15, 1995 at 2000 LST cool-city scenario: Simulated temperature and wind-vector field, for the inner, fine-resolution $(2-\mathrm{km})$ domain. 


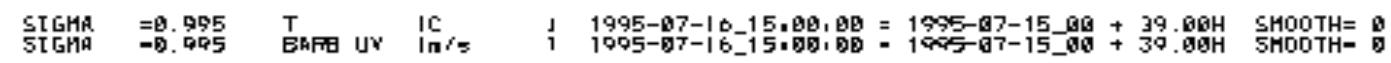

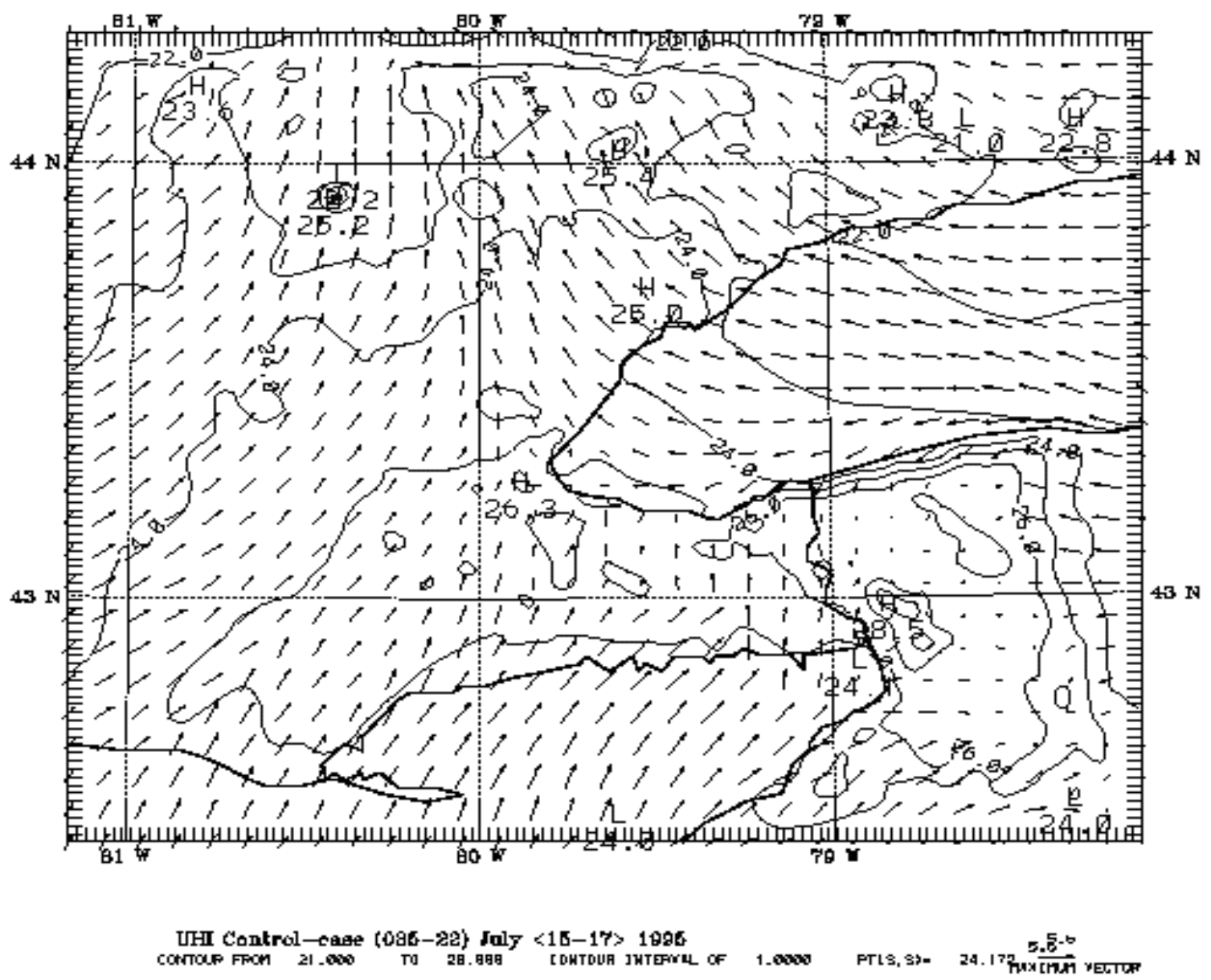

Figure 4.68. July 16, 1995 at 1000 LST cool-city scenario: Simulated temperature and wind-vector field, for the inner, fine-resolution $(2-\mathrm{km})$ domain. 


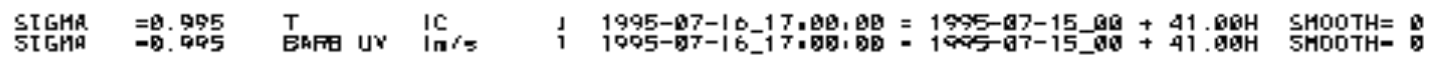

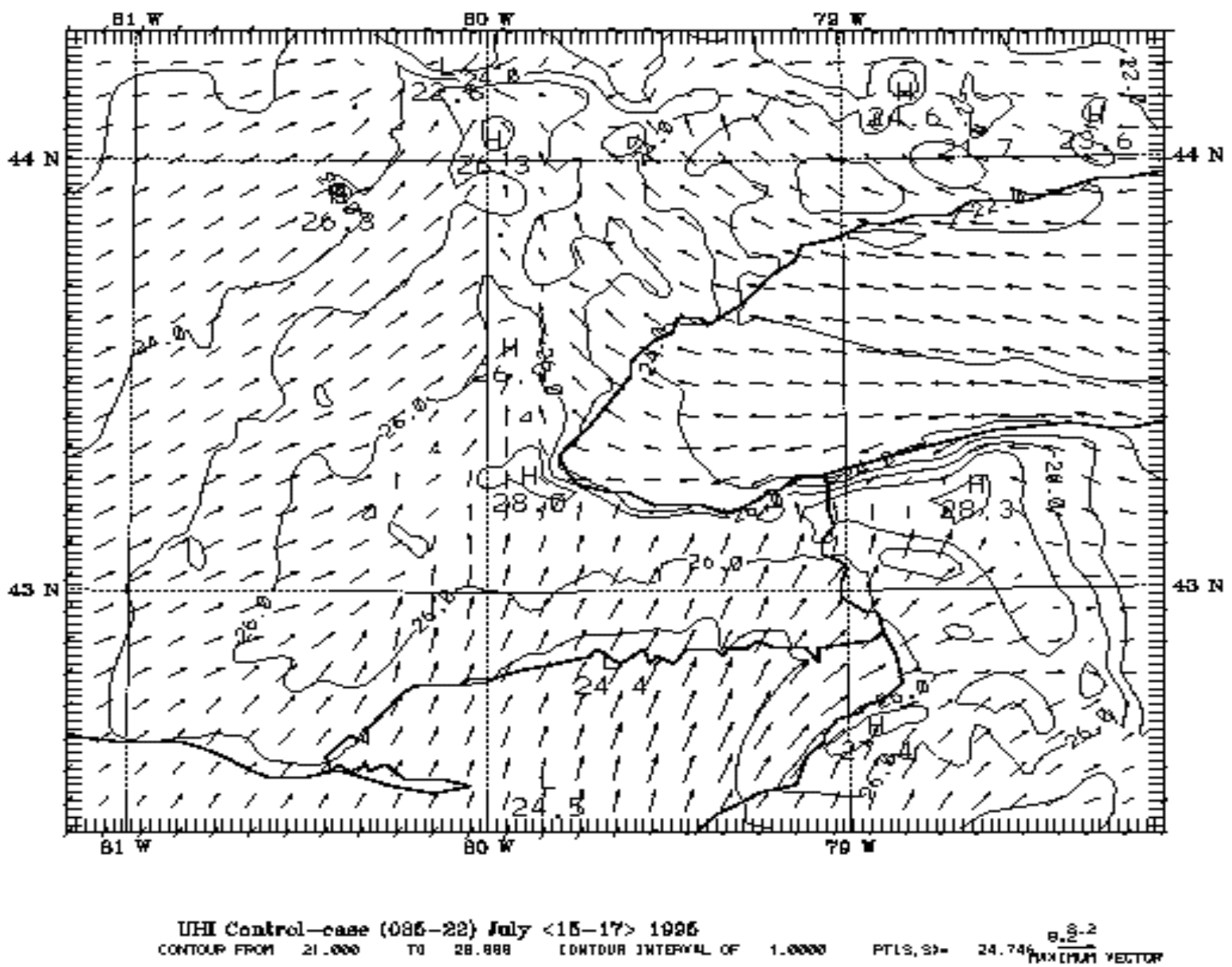

Figure 4.69. July 16, 1995 at 1200 LST cool-city scenario: Simulated temperature and wind-vector field, for the inner, fine-resolution $(2-\mathrm{km})$ domain. 


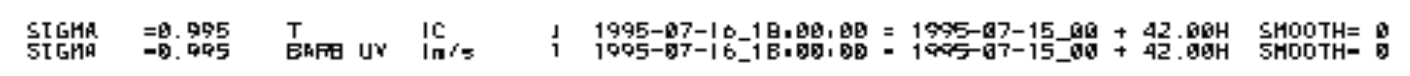

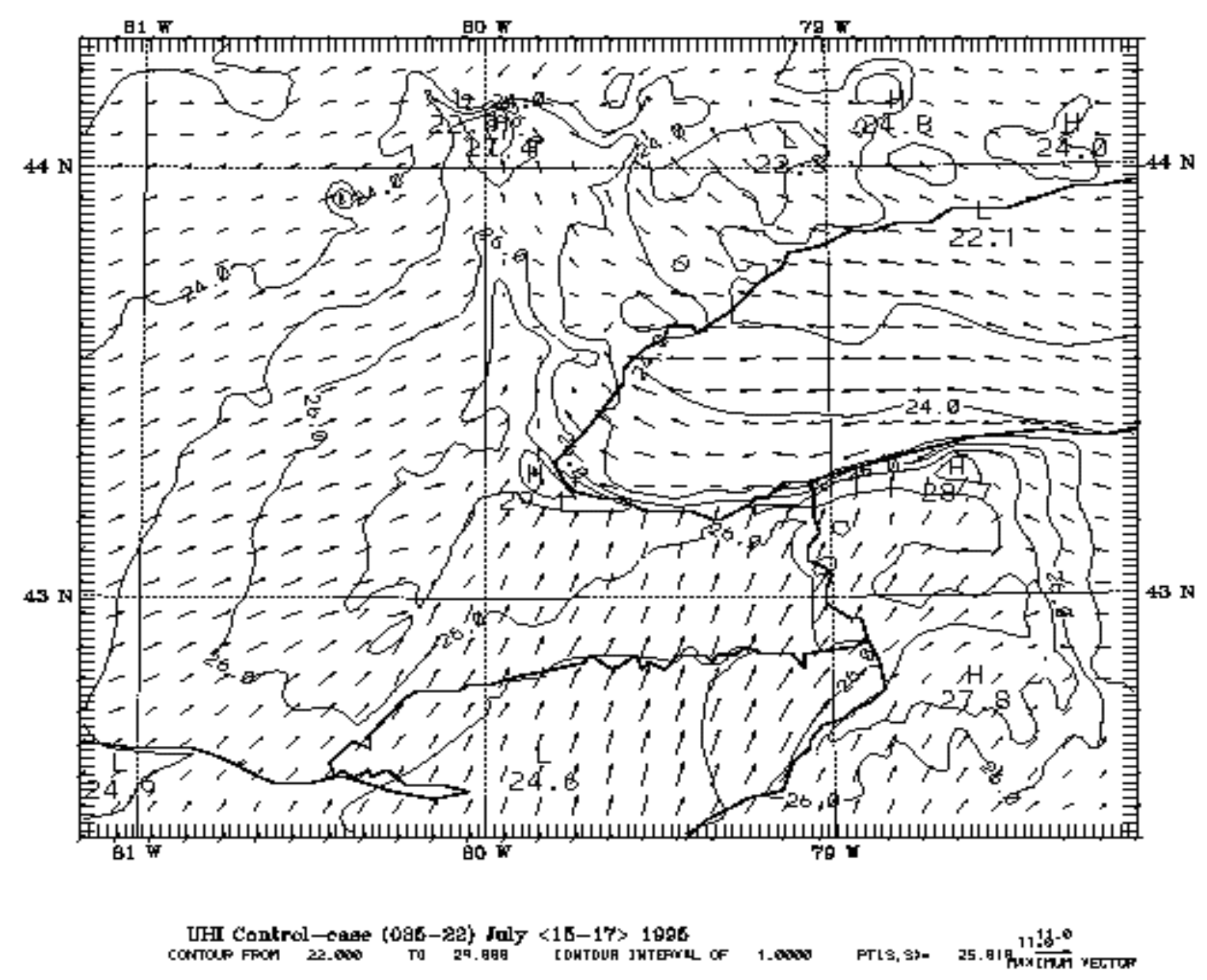

Figure 4.70. July 16, 1995 at 1300 LST cool-city scenario: Simulated temperature and wind-vector field, for the inner, fine-resolution $(2-\mathrm{km})$ domain. 


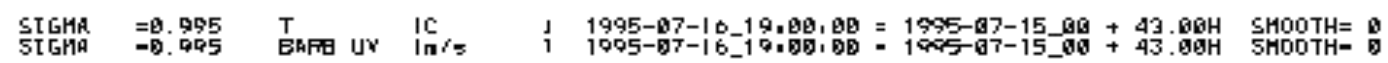

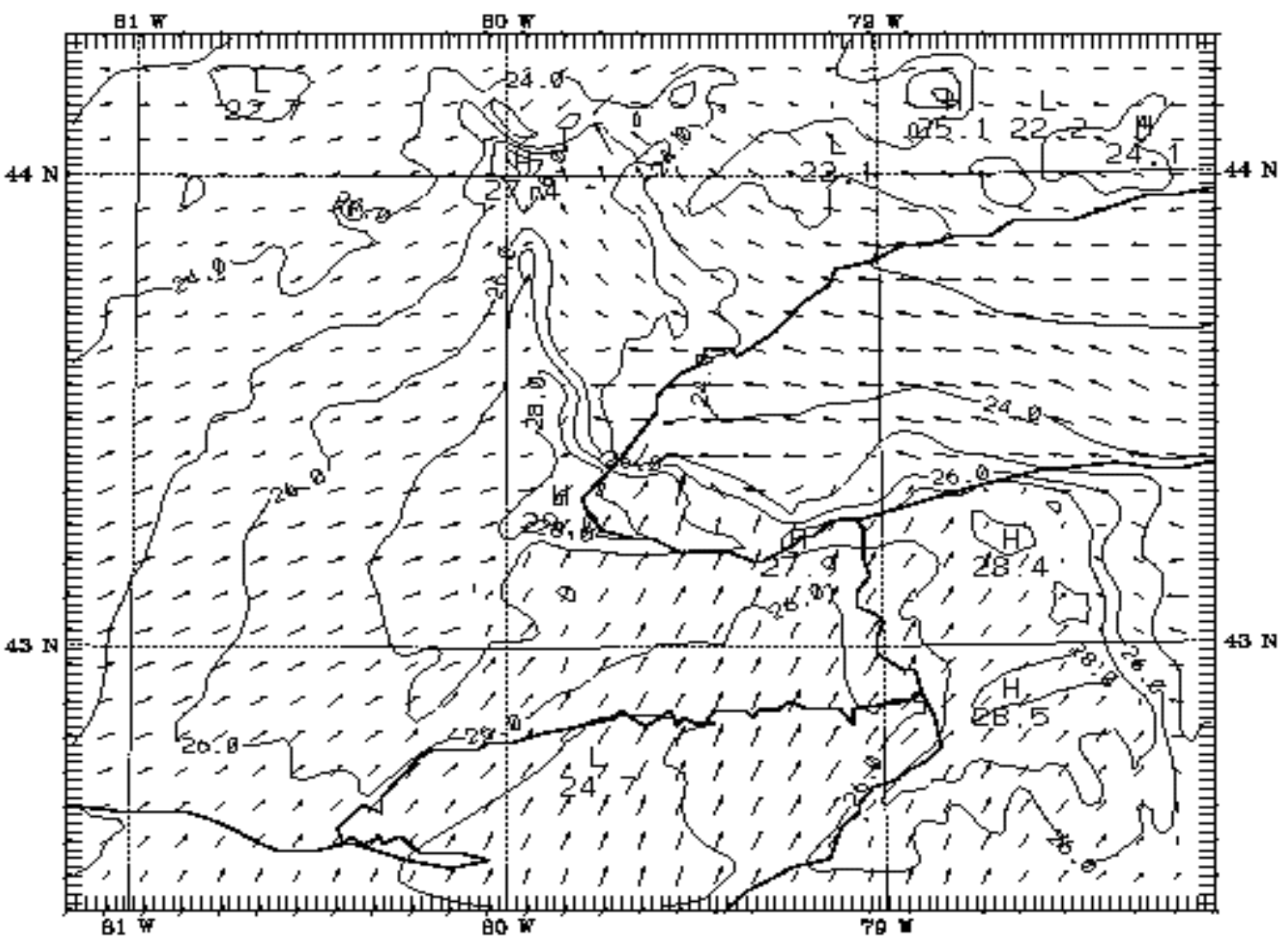

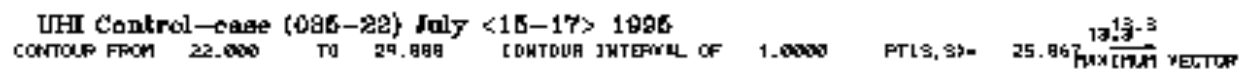

Figure 4.71. July 16, 1995 at 1400 LST cool-city scenario: Simulated temperature and wind-vector field, for the inner, fine-resolution $(2-\mathrm{km})$ domain. 


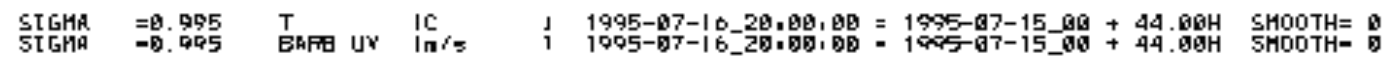

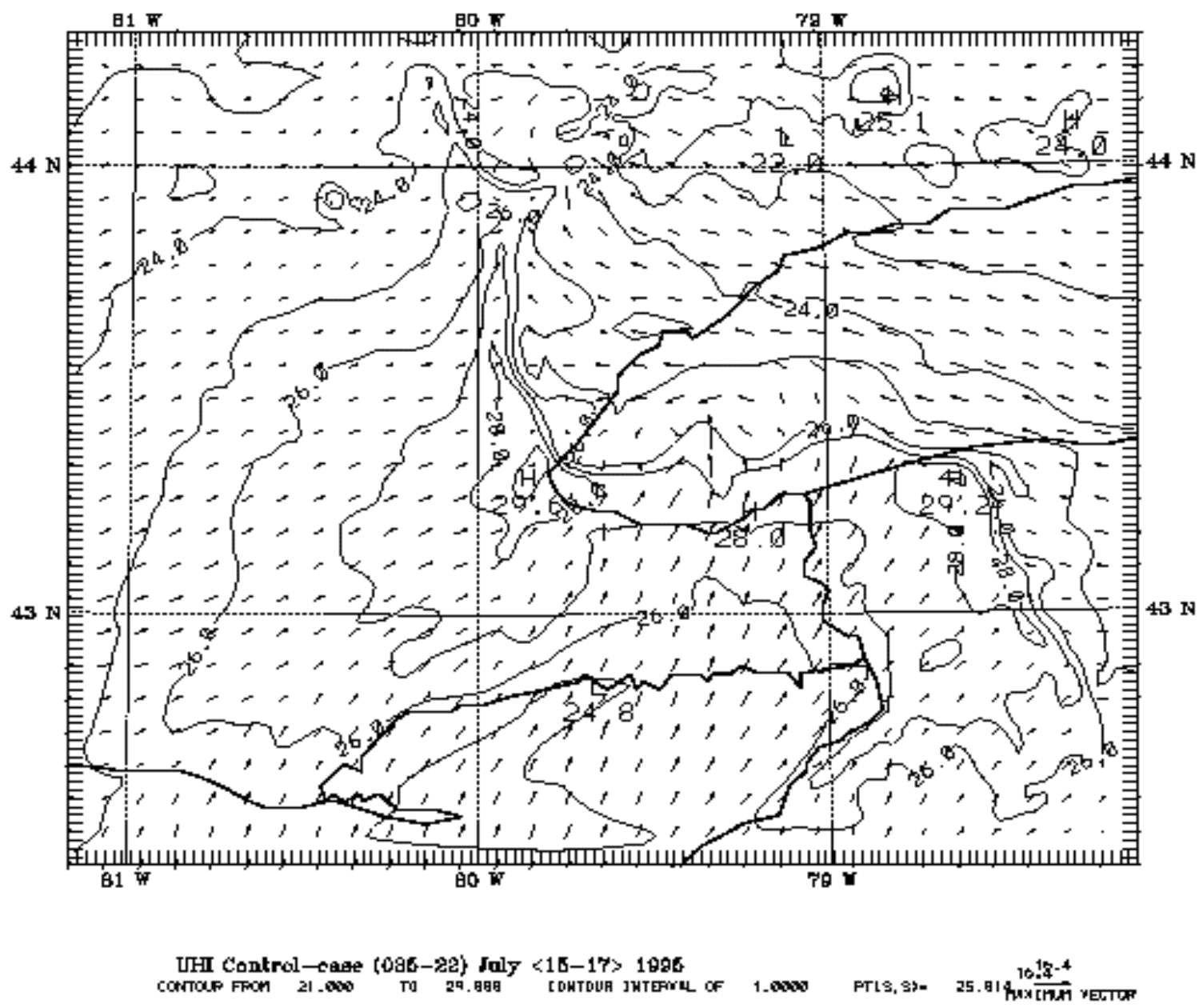

Figure 4.72. July 16, 1995 at 1500 LST cool-city scenario: Simulated temperature and wind-vector field, for the inner, fine-resolution $(2-\mathrm{km})$ domain. 


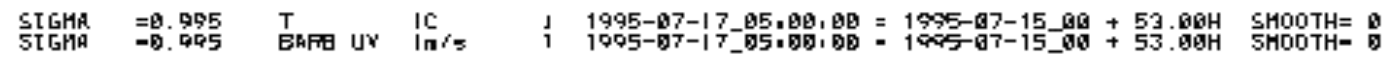

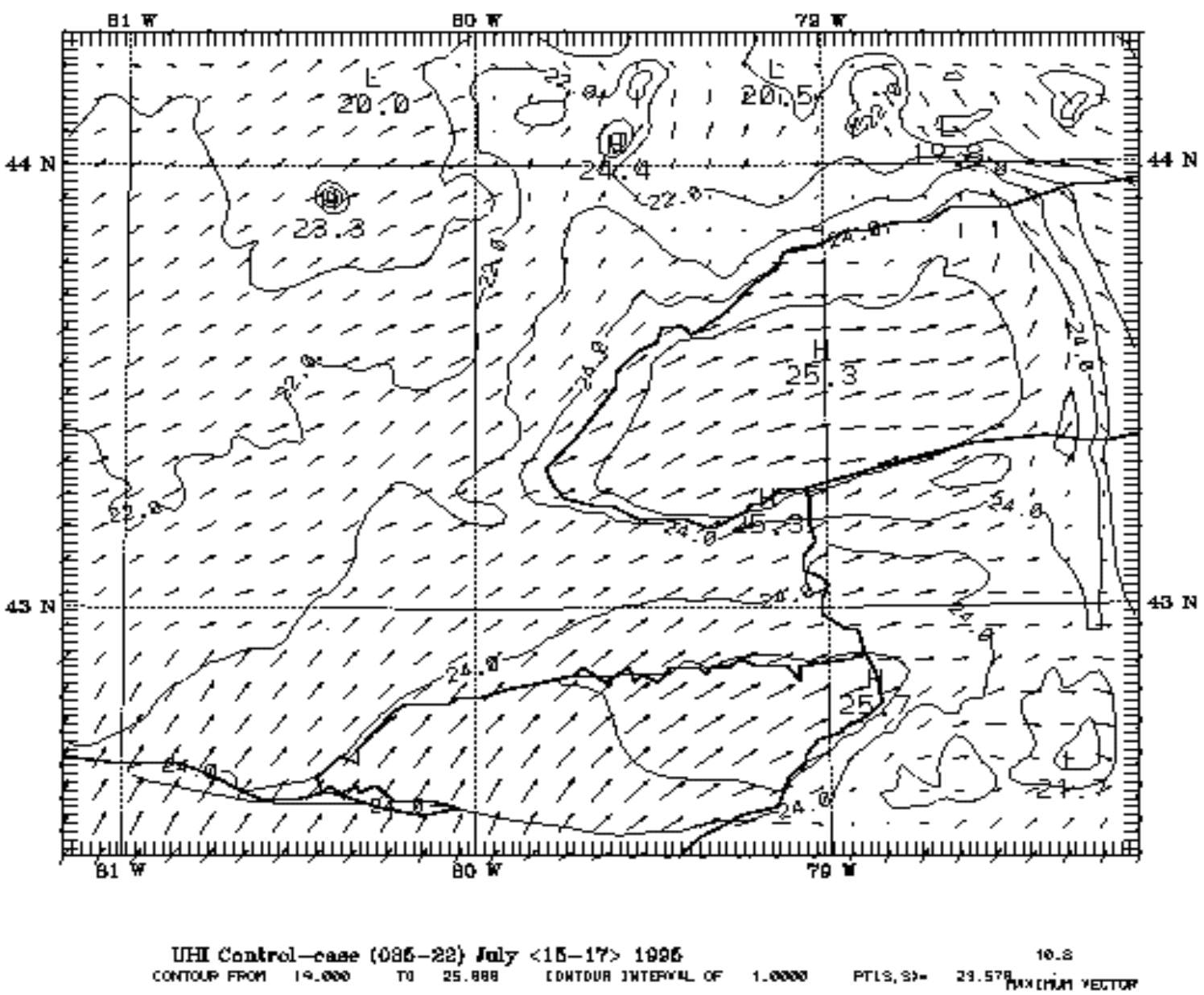

Figure 4.73. July 17, 1995 at 0000 LST cool-city scenario: Simulated temperature and wind-vector field, for the inner, fine-resolution $(2-\mathrm{km})$ domain. 


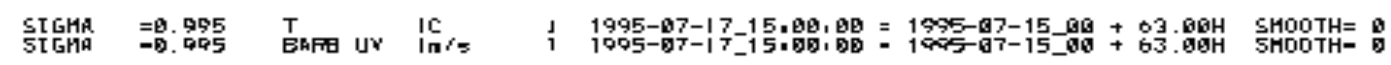

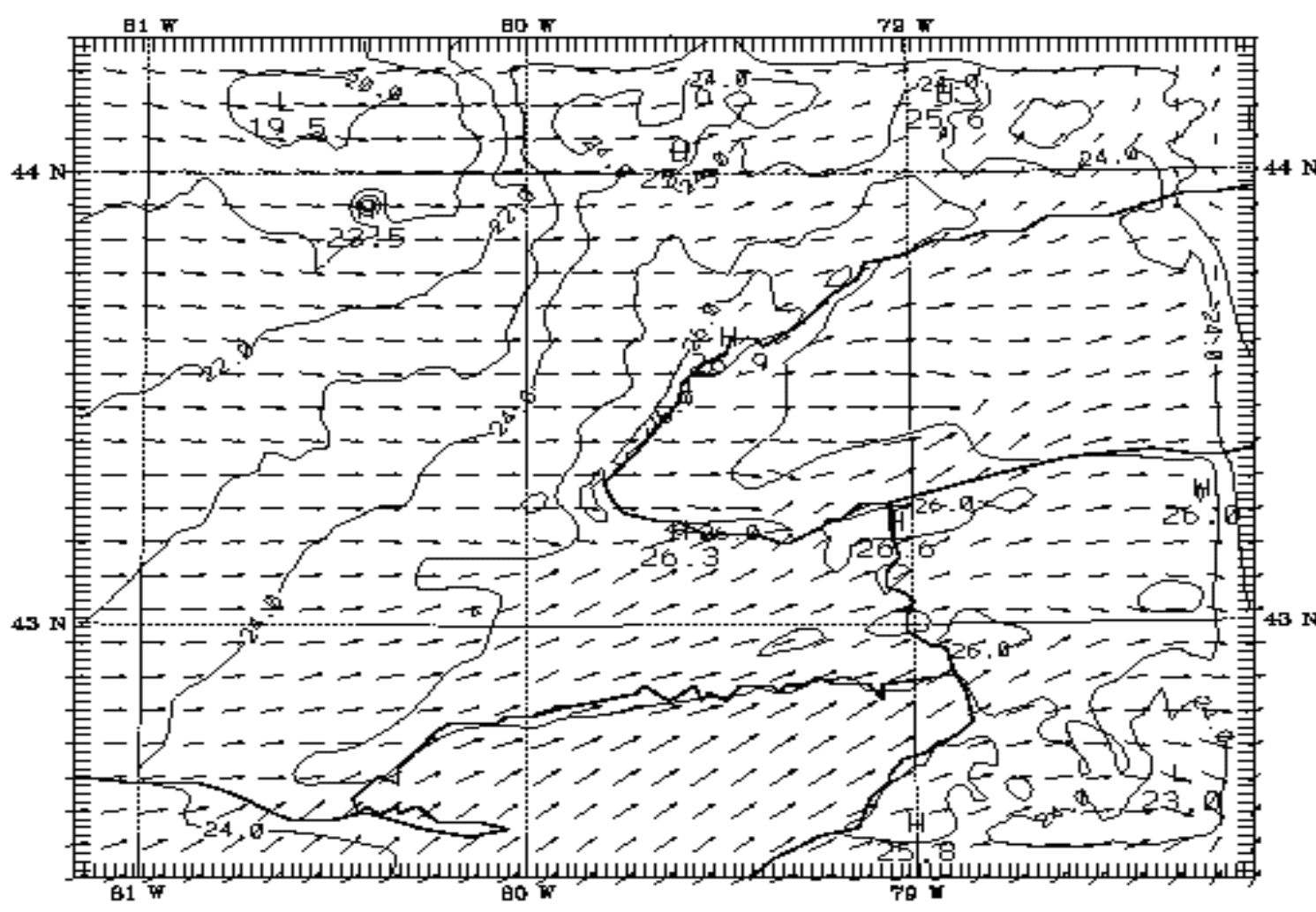

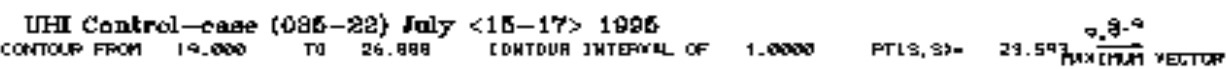

Figure 4.74. July 17, 1995 at 1000 LST cool-city scenario: Simulated temperature and wind-vector field, for the inner, fine-resolution $(2-\mathrm{km})$ domain. 


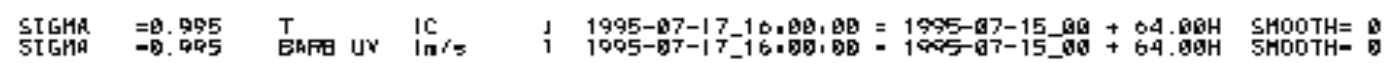

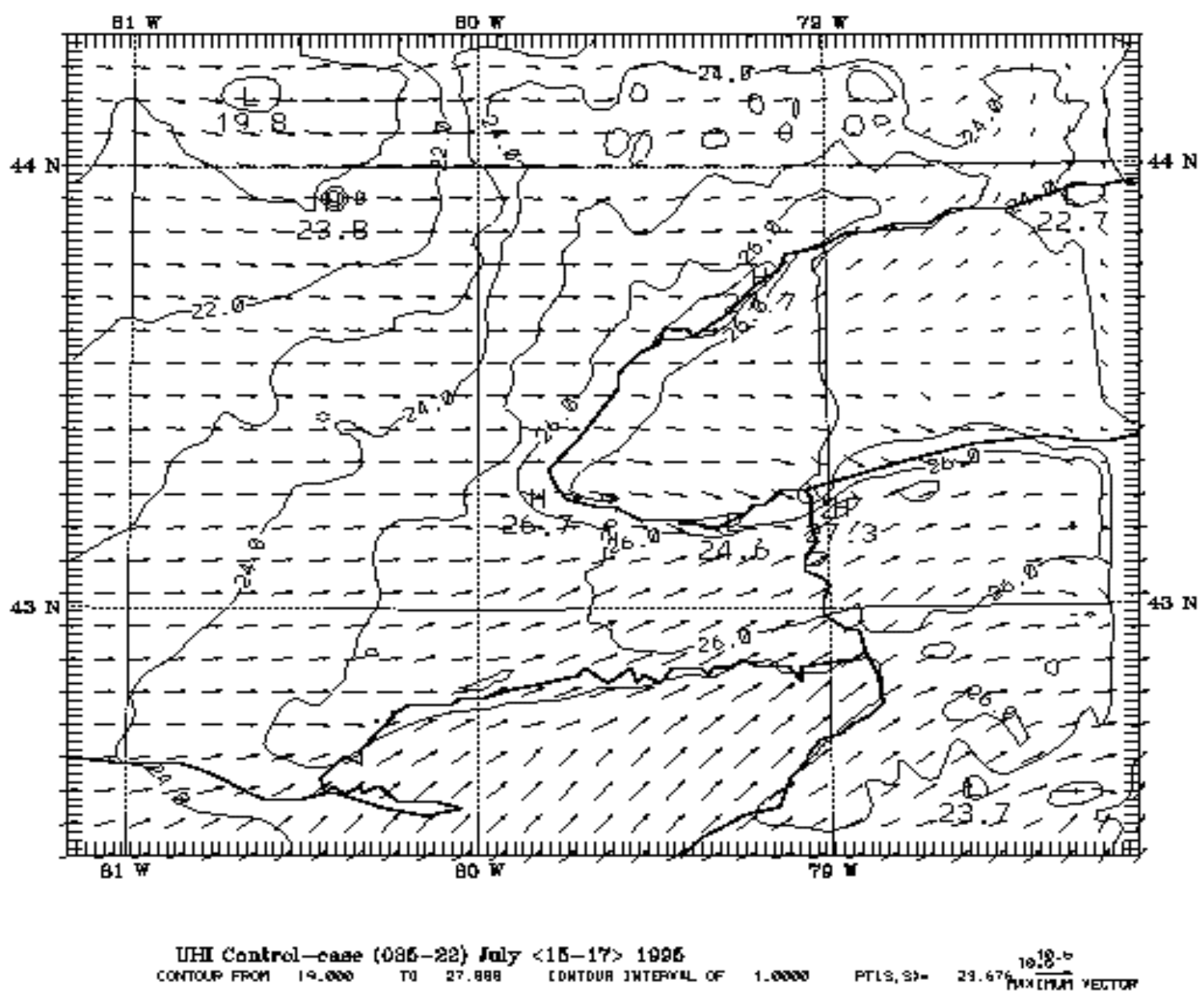

Figure 4.75. July 17, 1995 at 1100 LST cool-city scenario: Simulated temperature and wind-vector field, for the inner, fine-resolution $(2-\mathrm{km})$ domain. 
SIGMA $=9.995$
5tGHa

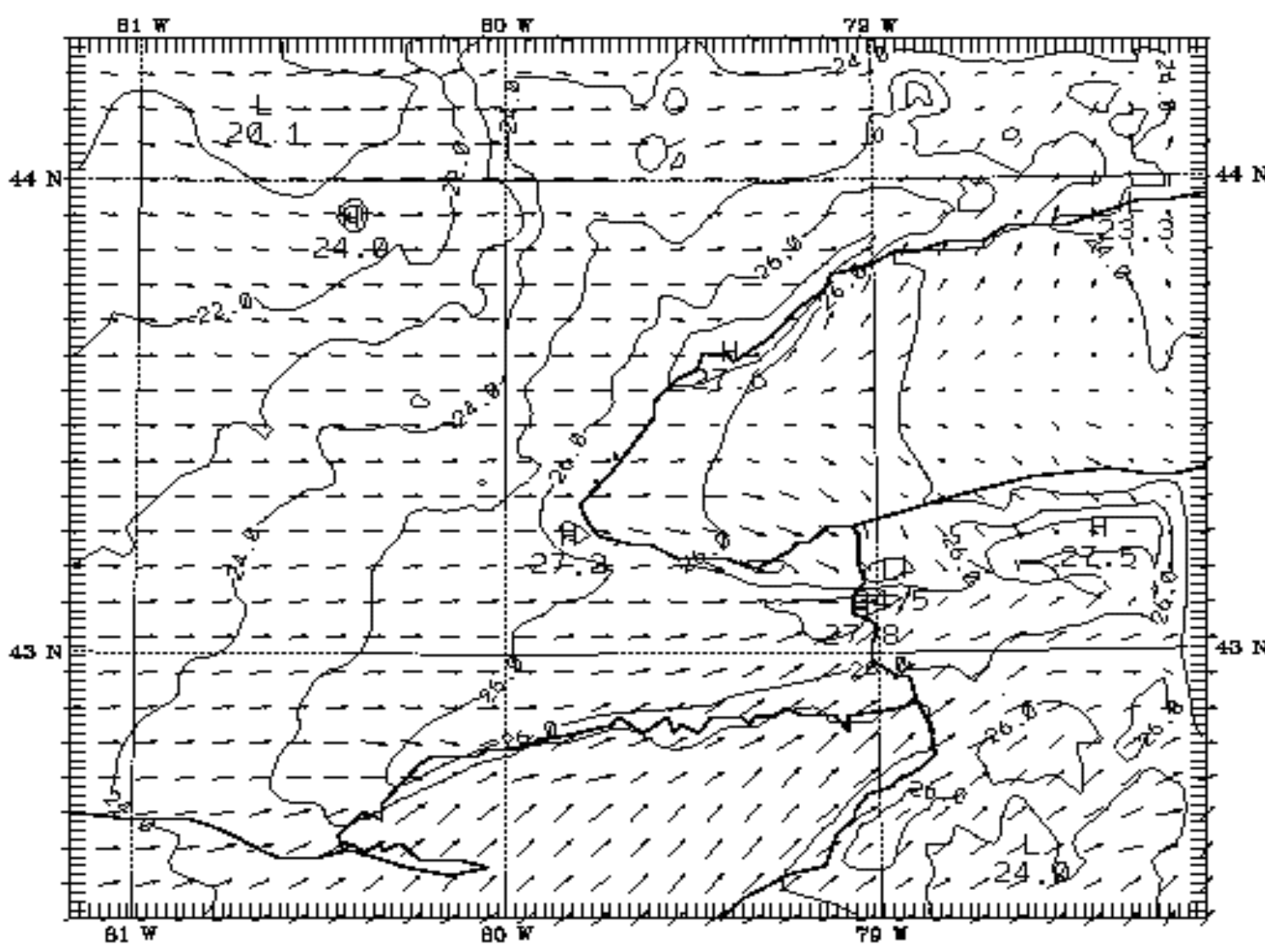

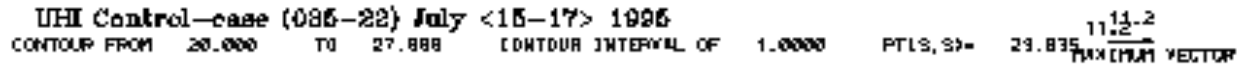

Figure 4.76. July 17, 1995 at 1200 LST cool-city scenario: Simulated temperature and wind-vector field, for the inner, fine-resolution $(2-\mathrm{km})$ domain. 


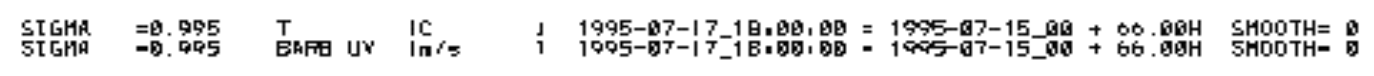

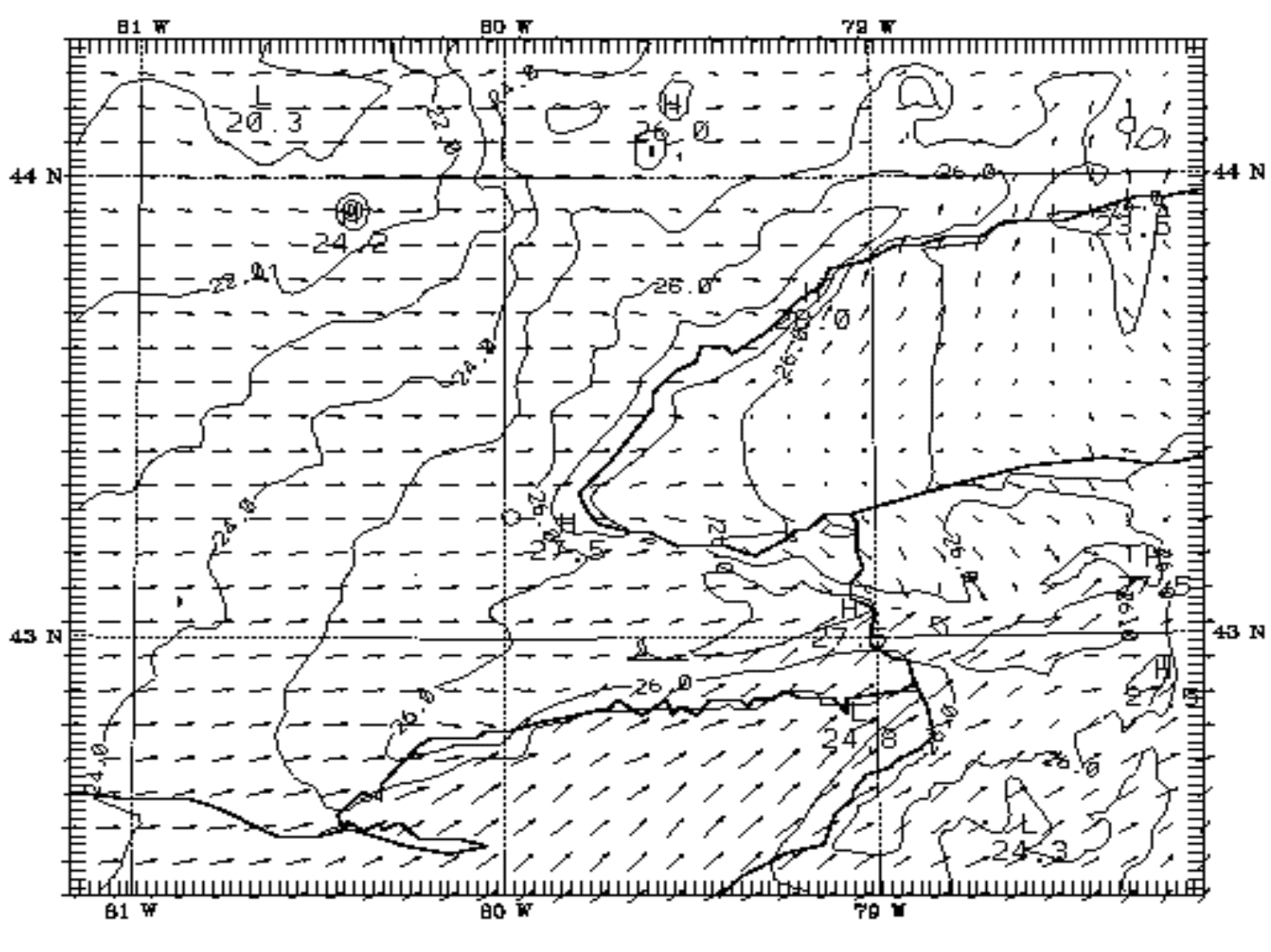

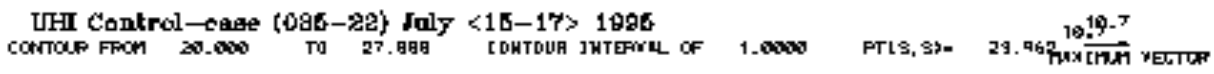

Figure 4.77. July 17, 1995 at 1300 LST cool-city scenario: Simulated temperature and wind-vector field, for the inner, fine-resolution (2-km) domain. 
SIGHA $=0.995$
StGHA

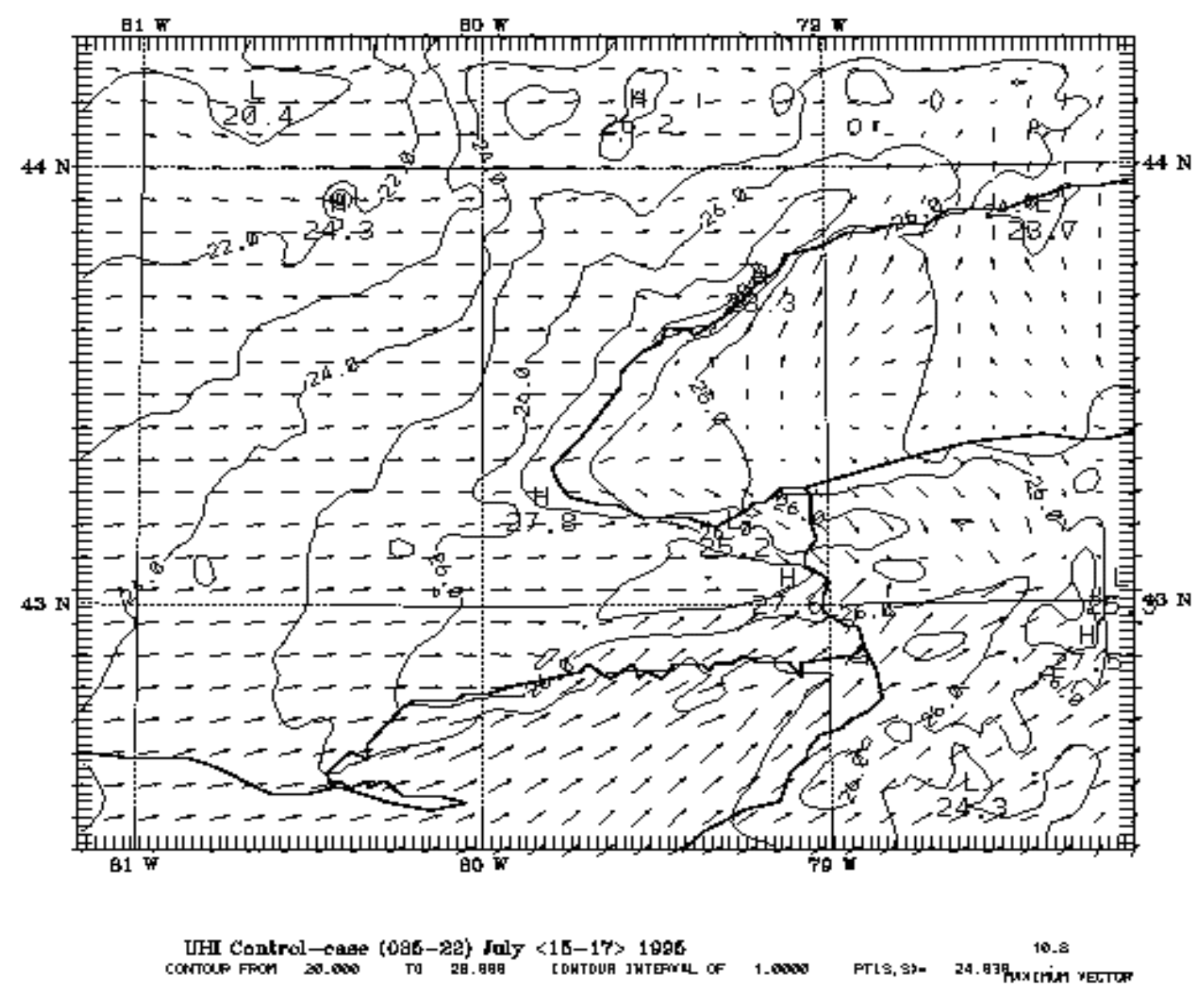

Figure 4.78. July 17, 1995 at 1400 LST cool-city scenario: Simulated temperature and wind-vector field, for the inner, fine-resolution $(2-\mathrm{km})$ domain. 


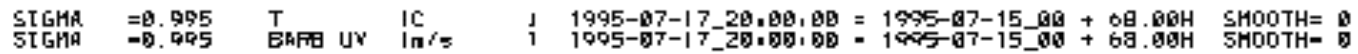

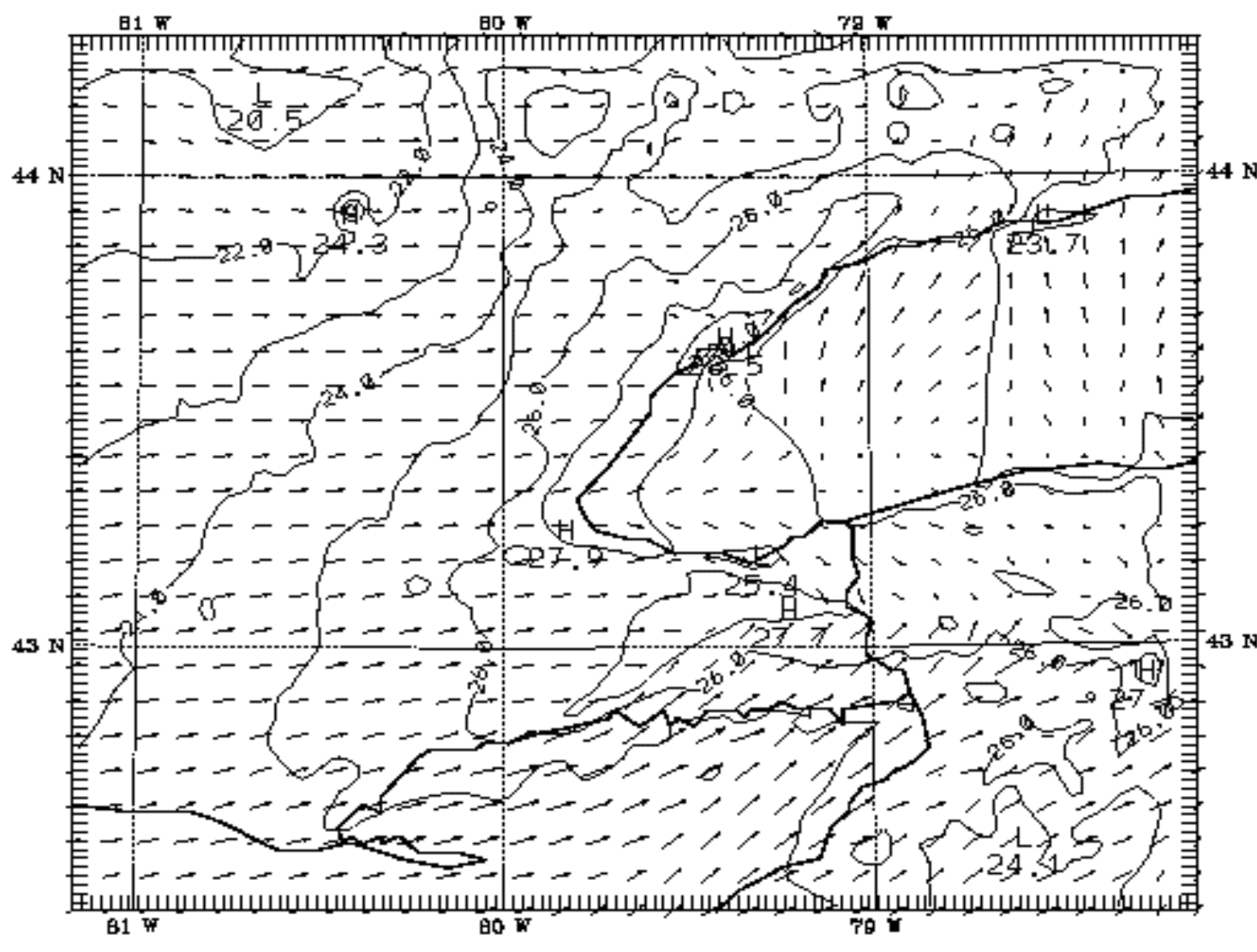

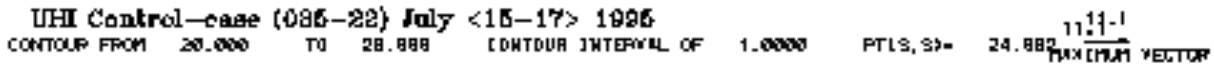

Figure 4.79. July 17, 1995 at 1500 LST cool-city scenario: Simulated temperature and wind-vector field, for the inner, fine-resolution $(2-\mathrm{km})$ domain. 
SIGHA $=9.995$
STGH

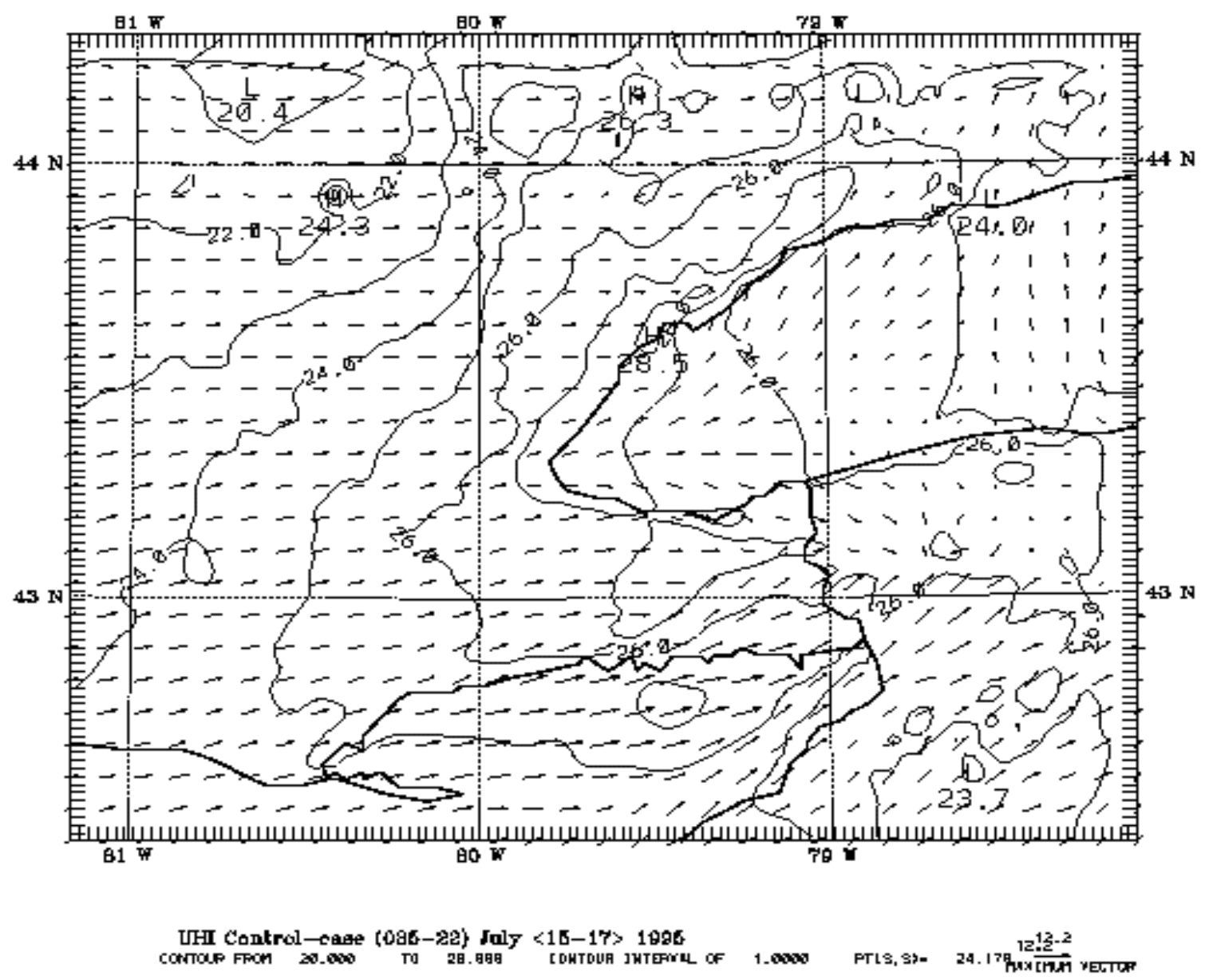

Figure 4.80. July 17, 1995 at 1600 LST cool-city scenario: Simulated temperature and wind-vector field, for the inner, fine-resolution $(2-\mathrm{km})$ domain. 


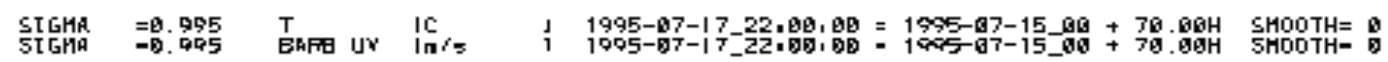

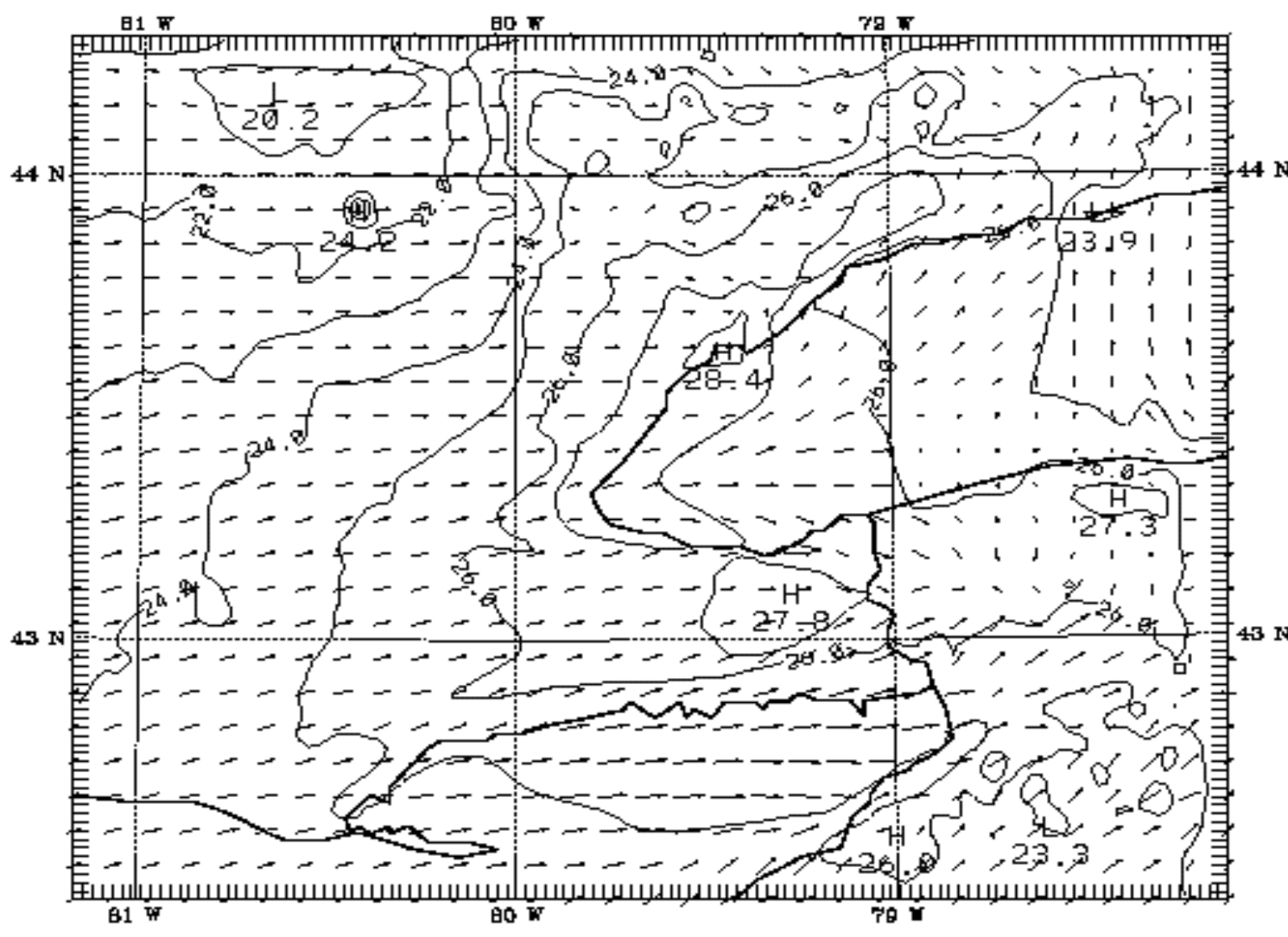

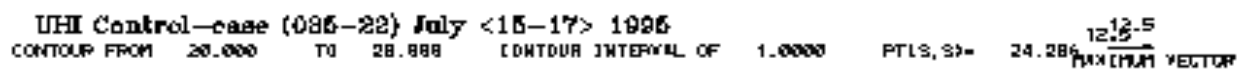

Figure 4.81. July 17, 1995 at 1700 LST cool-city scenario: Simulated temperature and wind-vector field, for the inner, fine-resolution $(2-\mathrm{km})$ domain. 


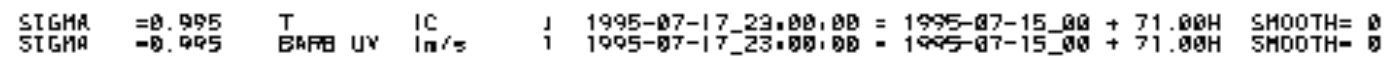

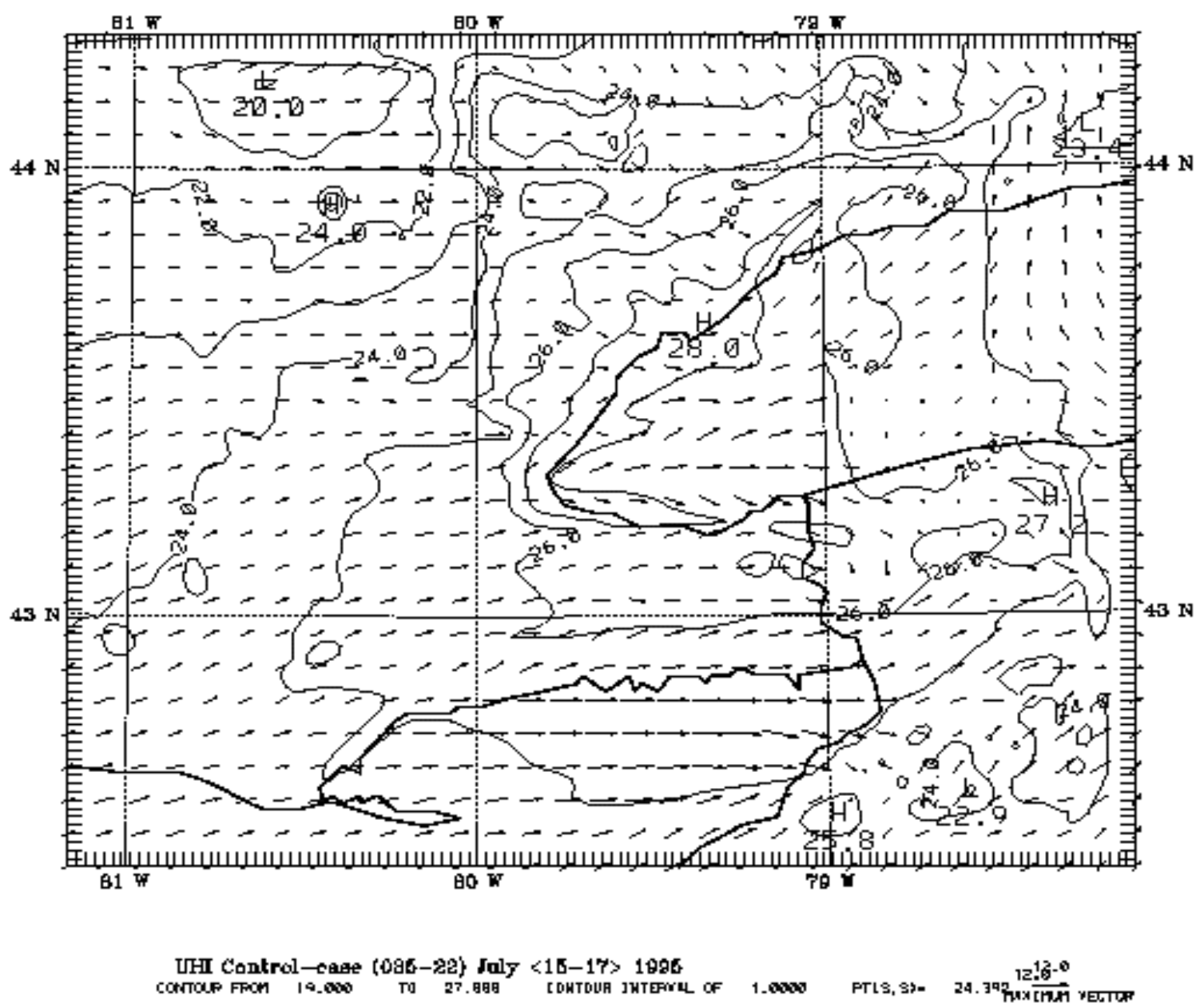

Figure 4.82. July 17, 1995 at 1800 LST cool-city scenario: Simulated temperature and wind-vector field, for the inner, fine-resolution $(2-\mathrm{km})$ domain. 


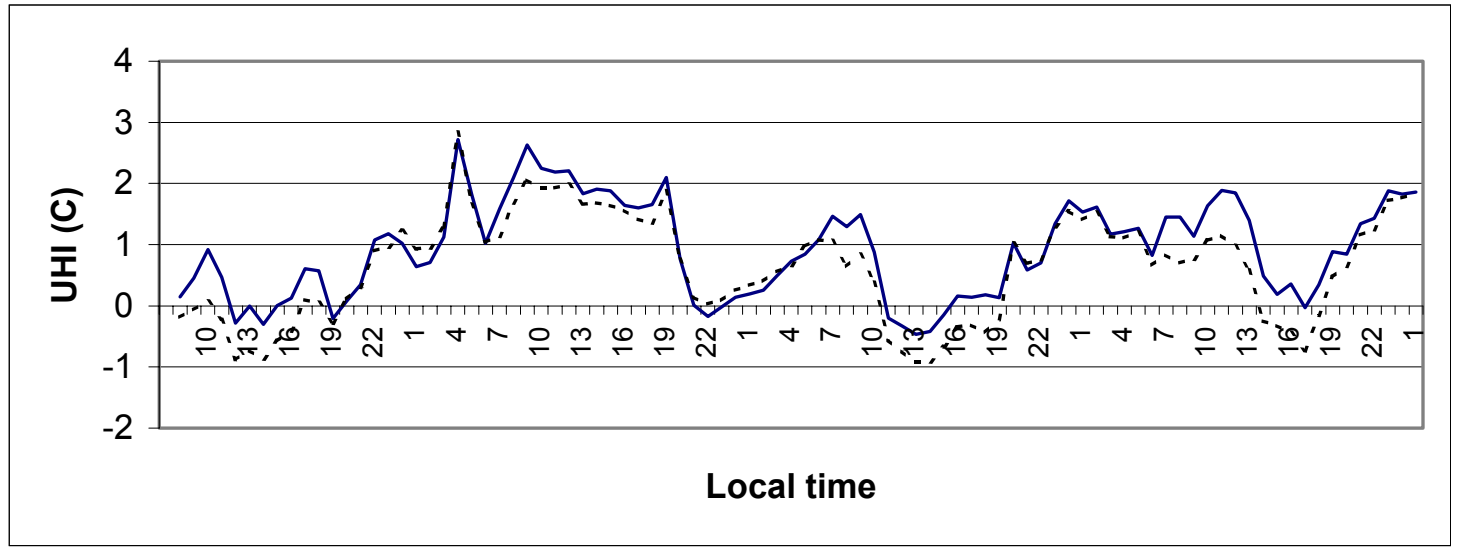

Figure 4.83: UHI time series for case 039 for base (solid) and cool-city (broken) scenarios. Time series are for averaged urban temperatures vs. averaged rural temperatures.

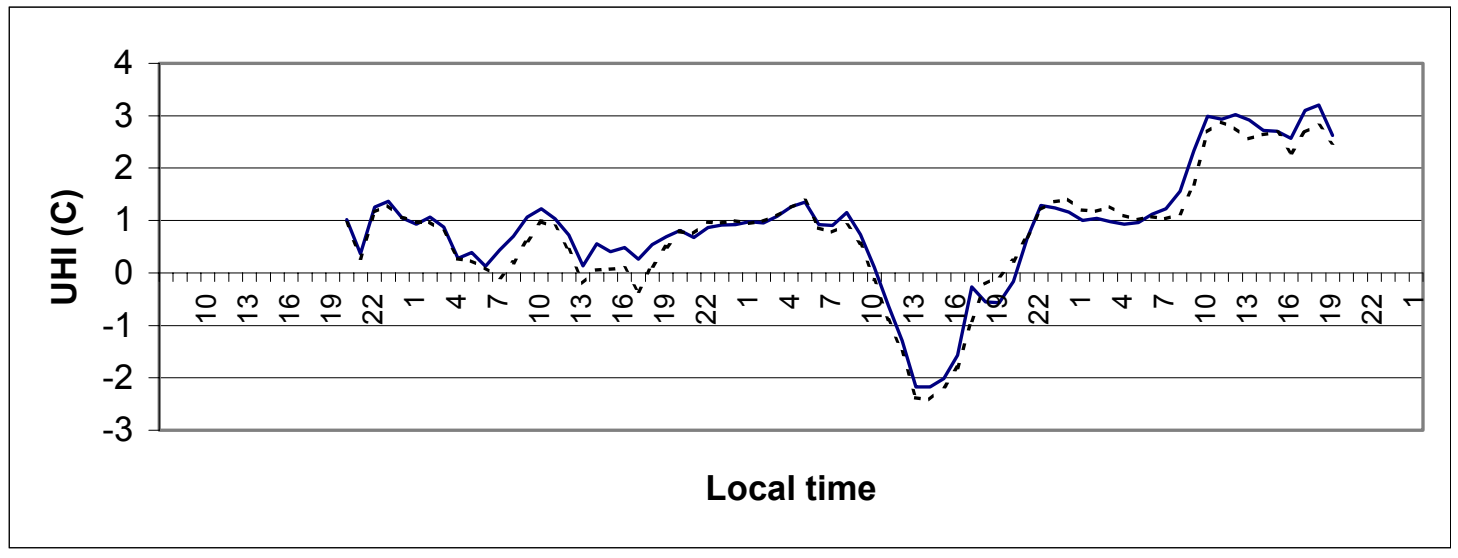

Figure 4.84: UHI time series for case 035 for base (solid) and cool-city (broken) scenarios. Time series are for averaged urban temperatures vs. Averaged rural temperatures.

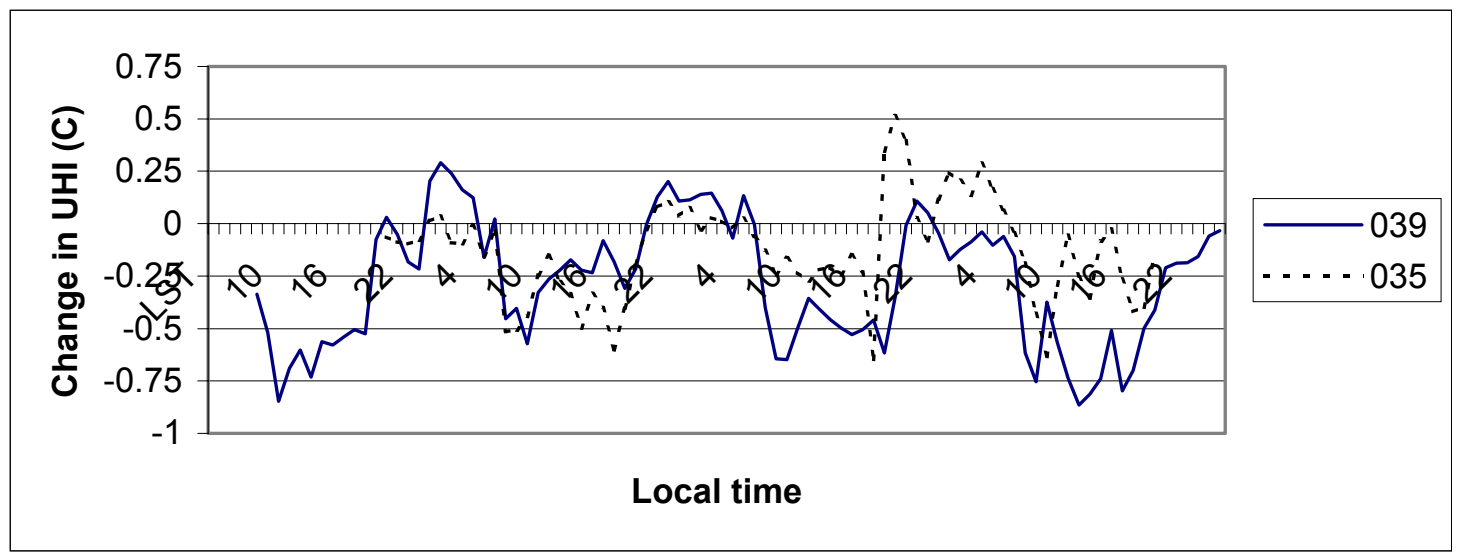

Figure 4.85: Change in UHI (with respect to base-case UHI) for cases 039 and 035 as a result of cool-city scenarios. 


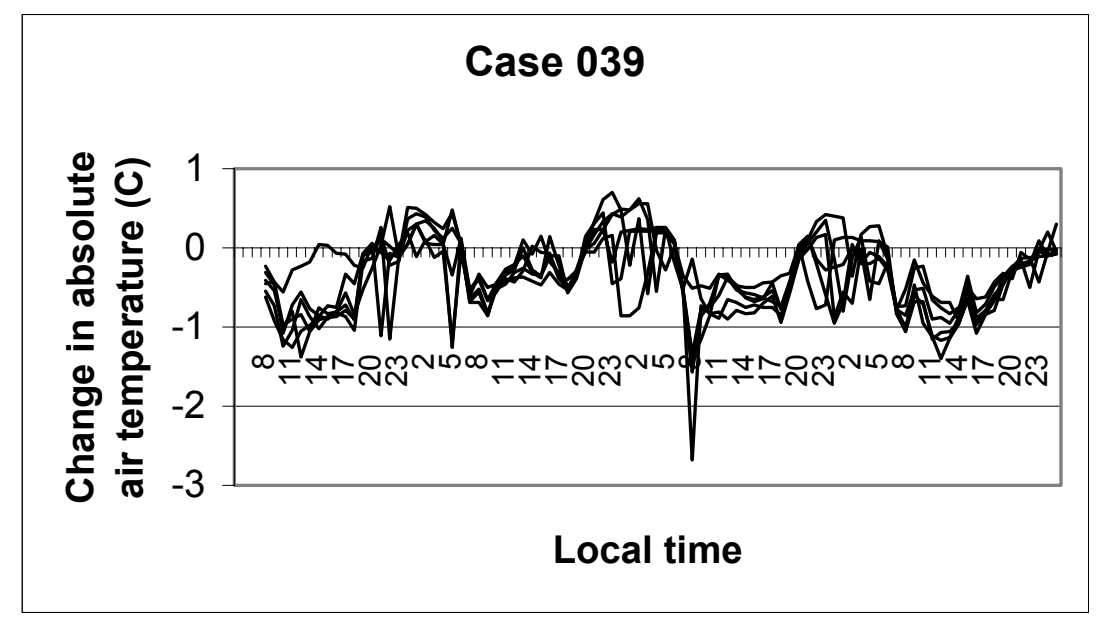

Figure 4.86: Change in absolute air temperature (not UHI) at six random urban locations.

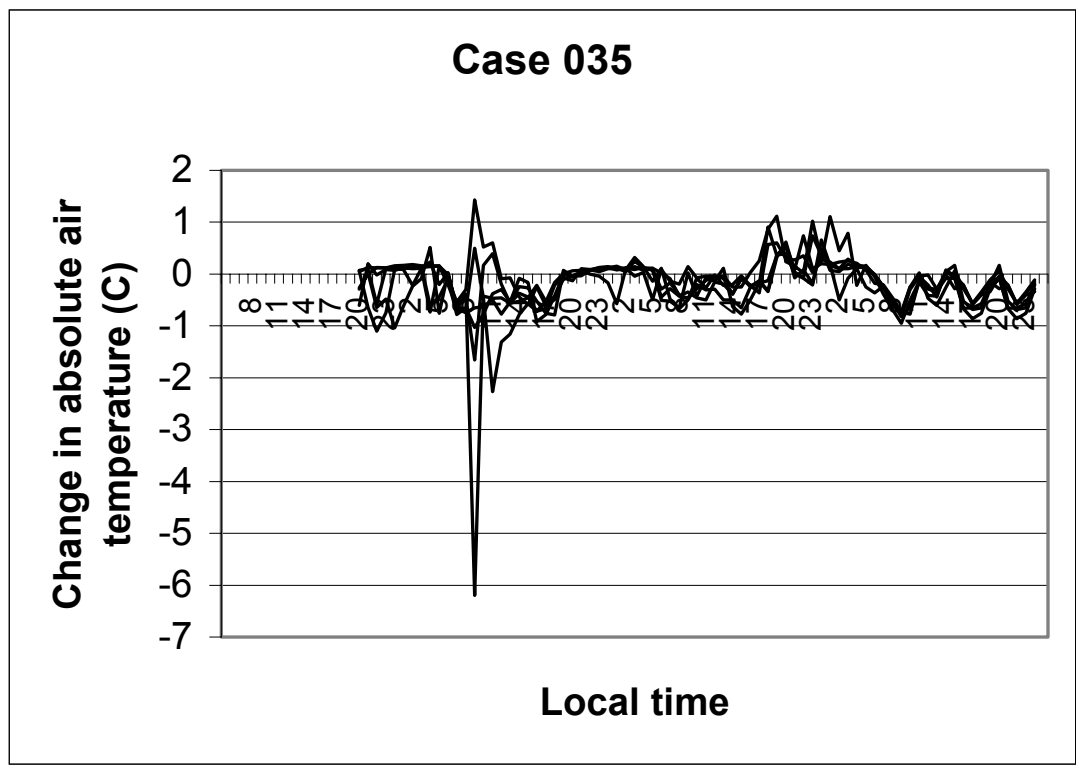

Figure 4.87: Change in absolute air temperature (not UHI) at six random urban locations. 


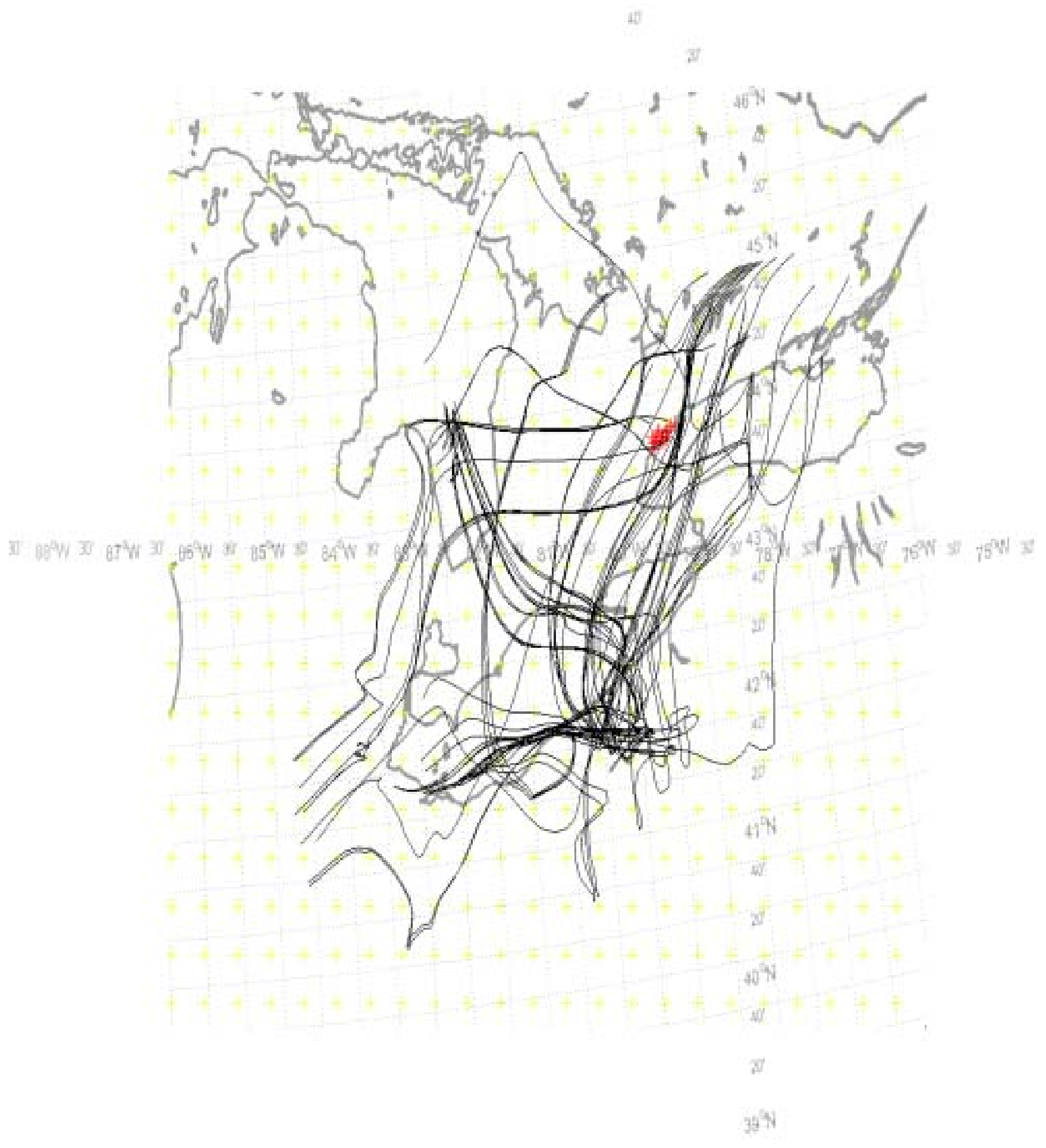

Figure 4.88: Selected meteorological trajectories (from ensemble generated in this study). These trajectories arrive urban Toronto (shown with red pluses) $48-72$ hours later. 


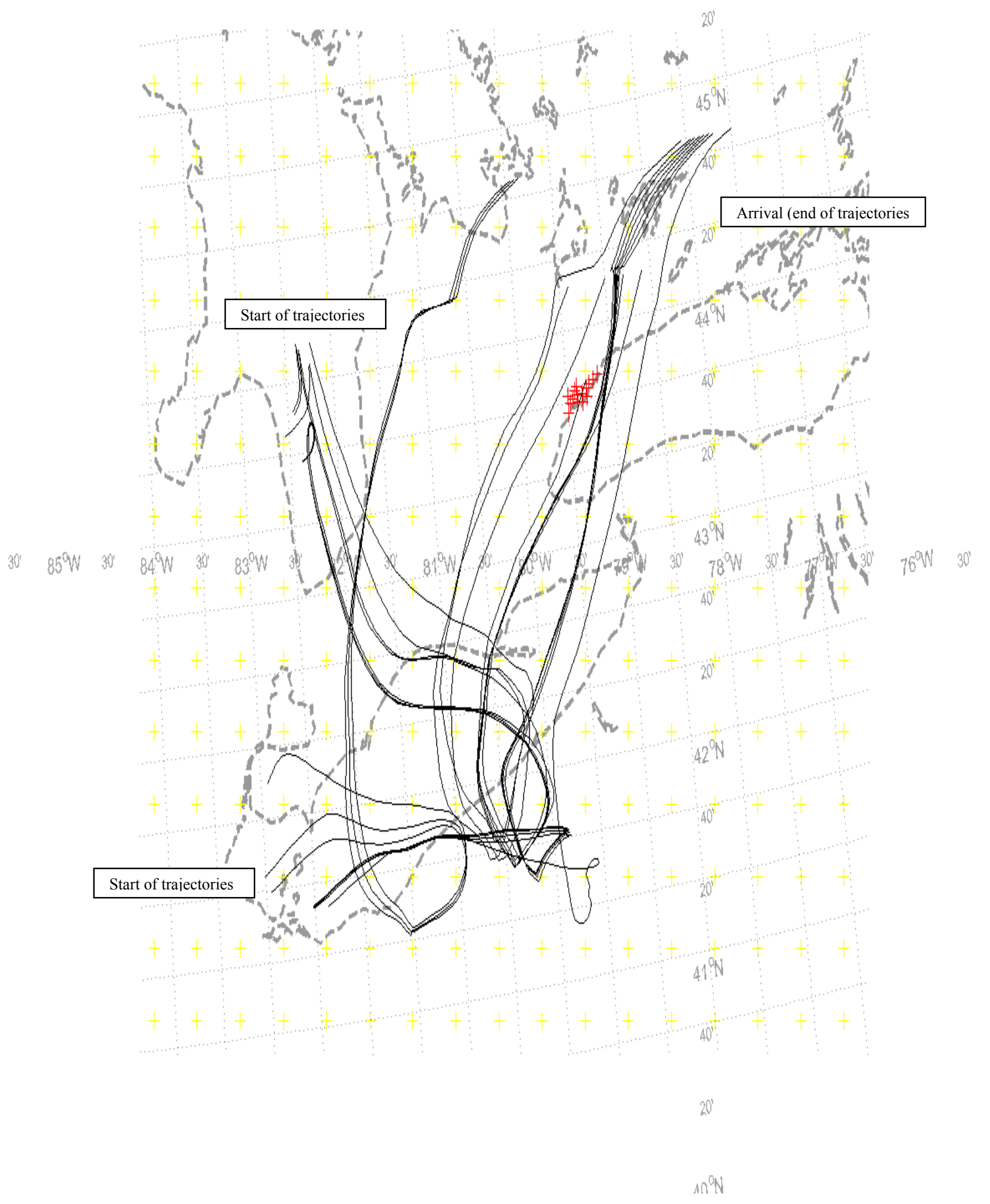

Figure 4.89: Trajectories for case 039 . 


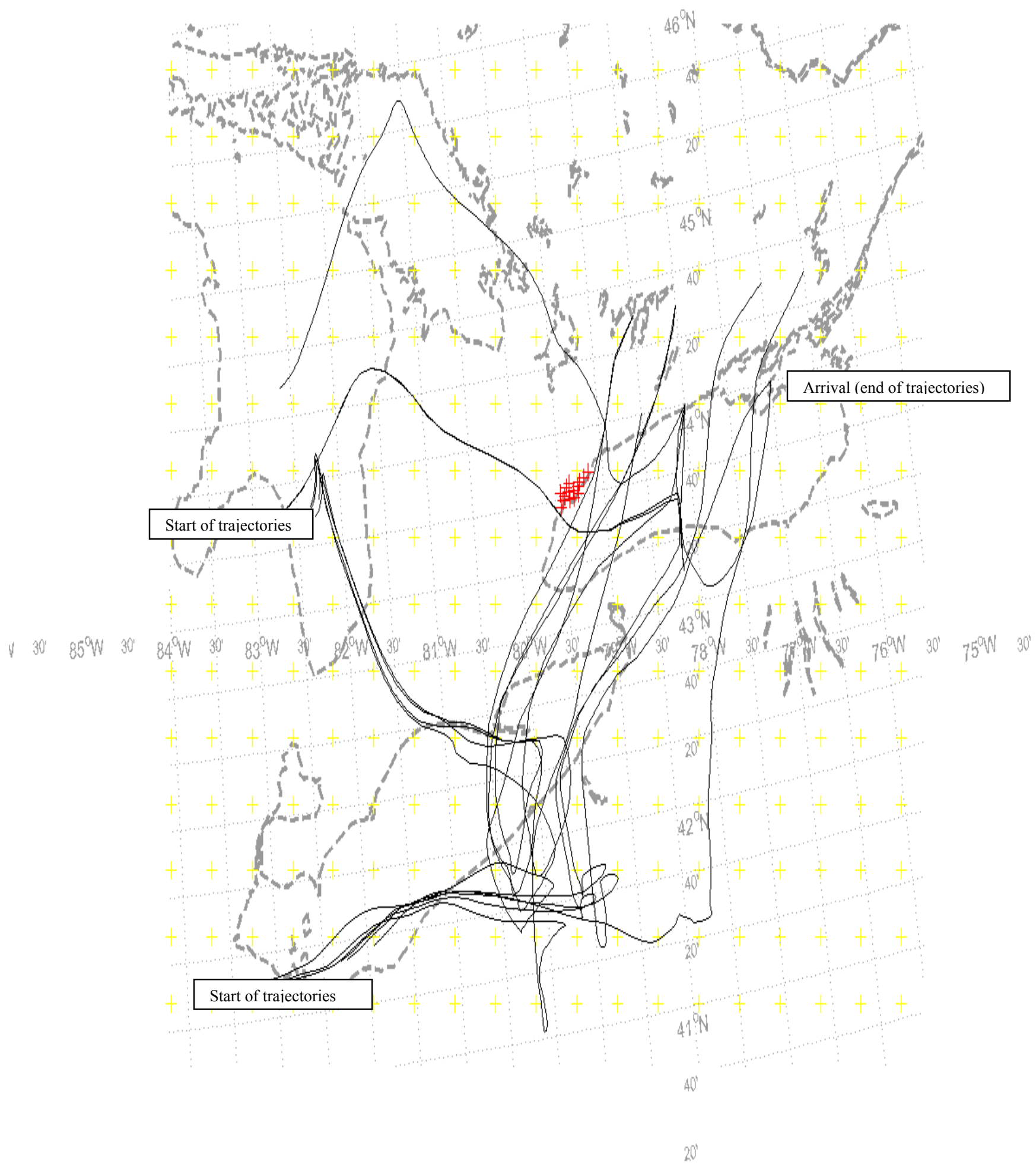

Figure 4.90: Selection of trajectories for case 039. 


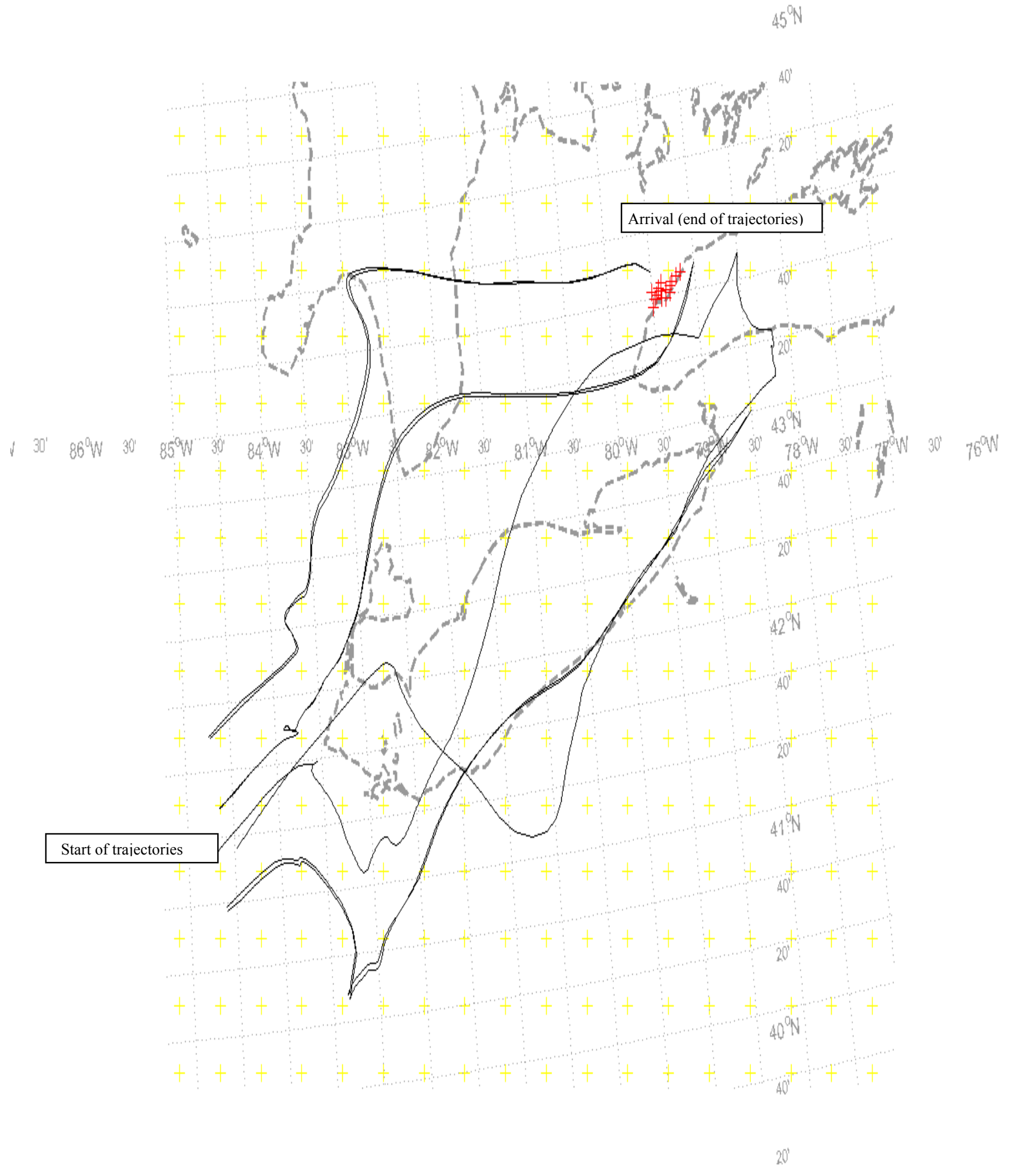

Figure 4.91: Trajectories for case 035. 


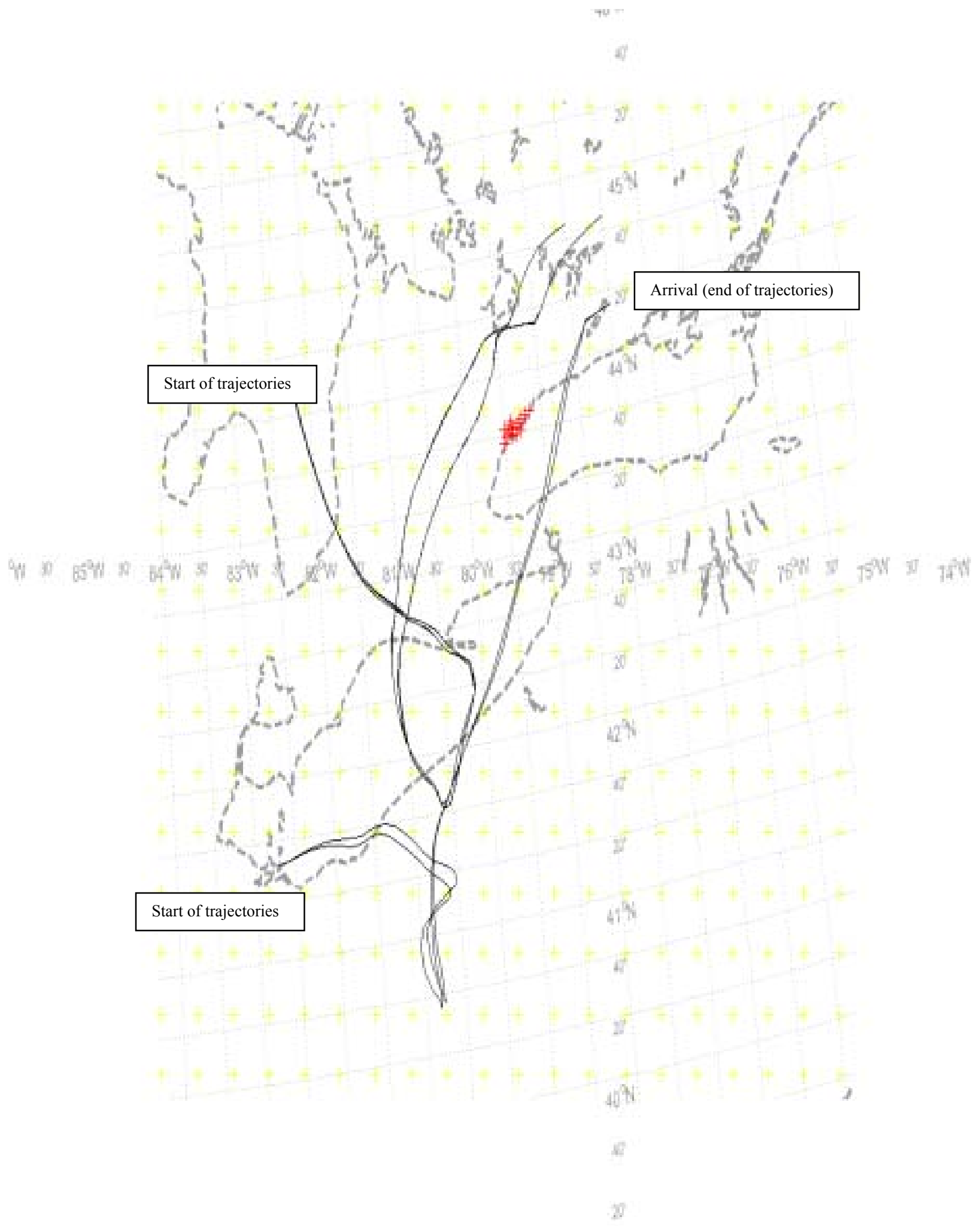

Figure 4.92. Case 039 trajectories. 


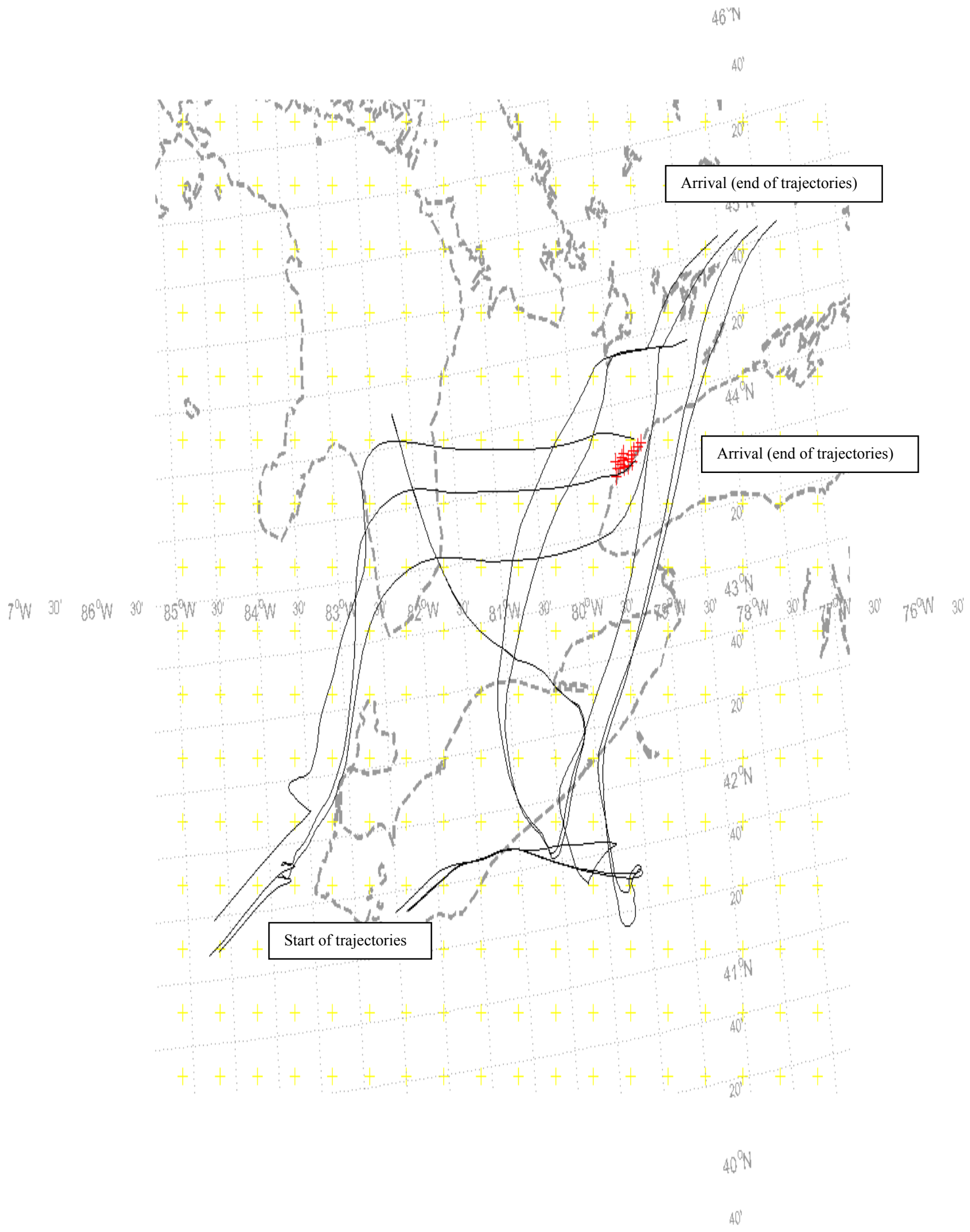

Figure 4.93: Selected trajectories for case 035 and 039. 


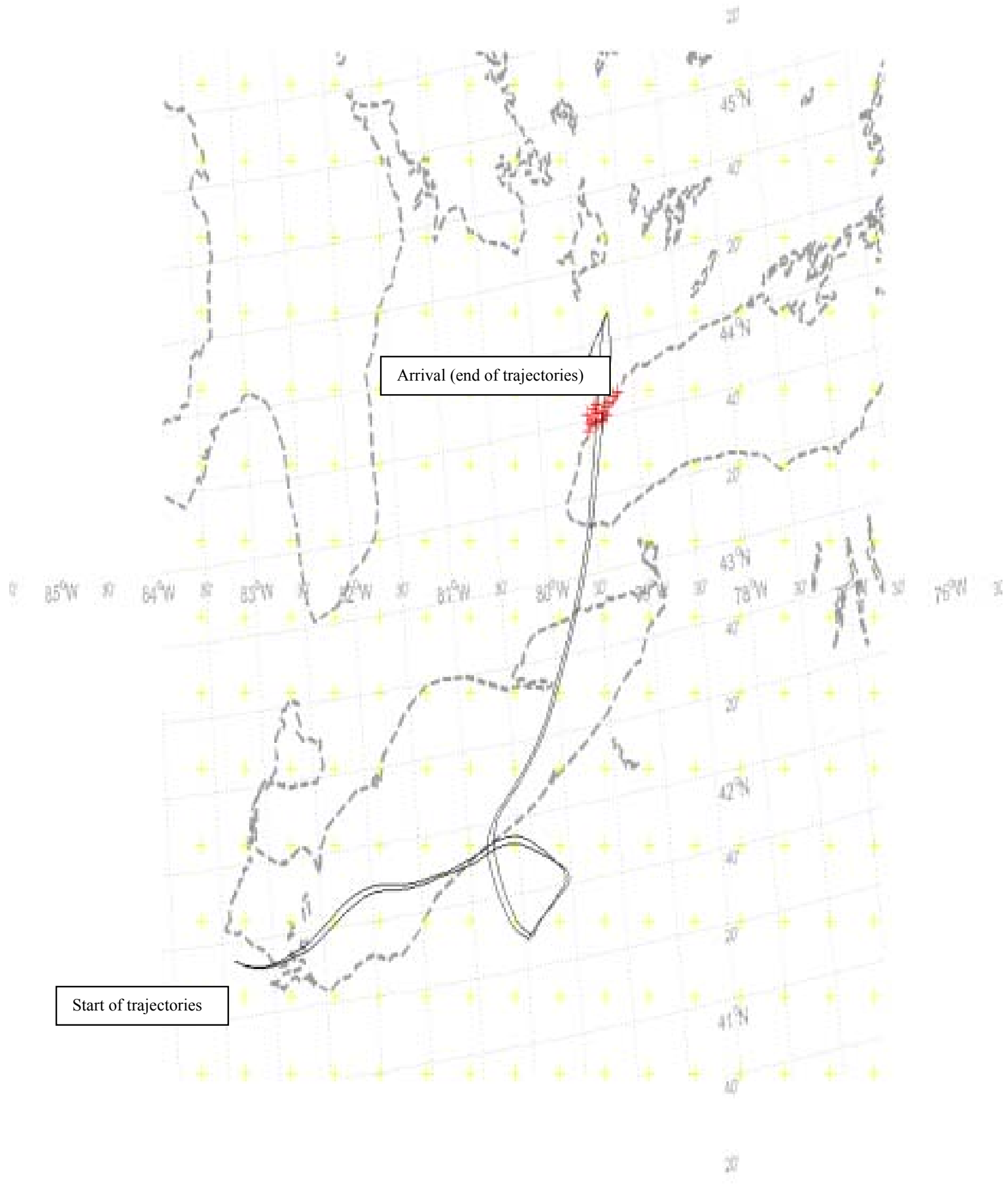

Figure 4.94: Selected trajectories for case 039. 


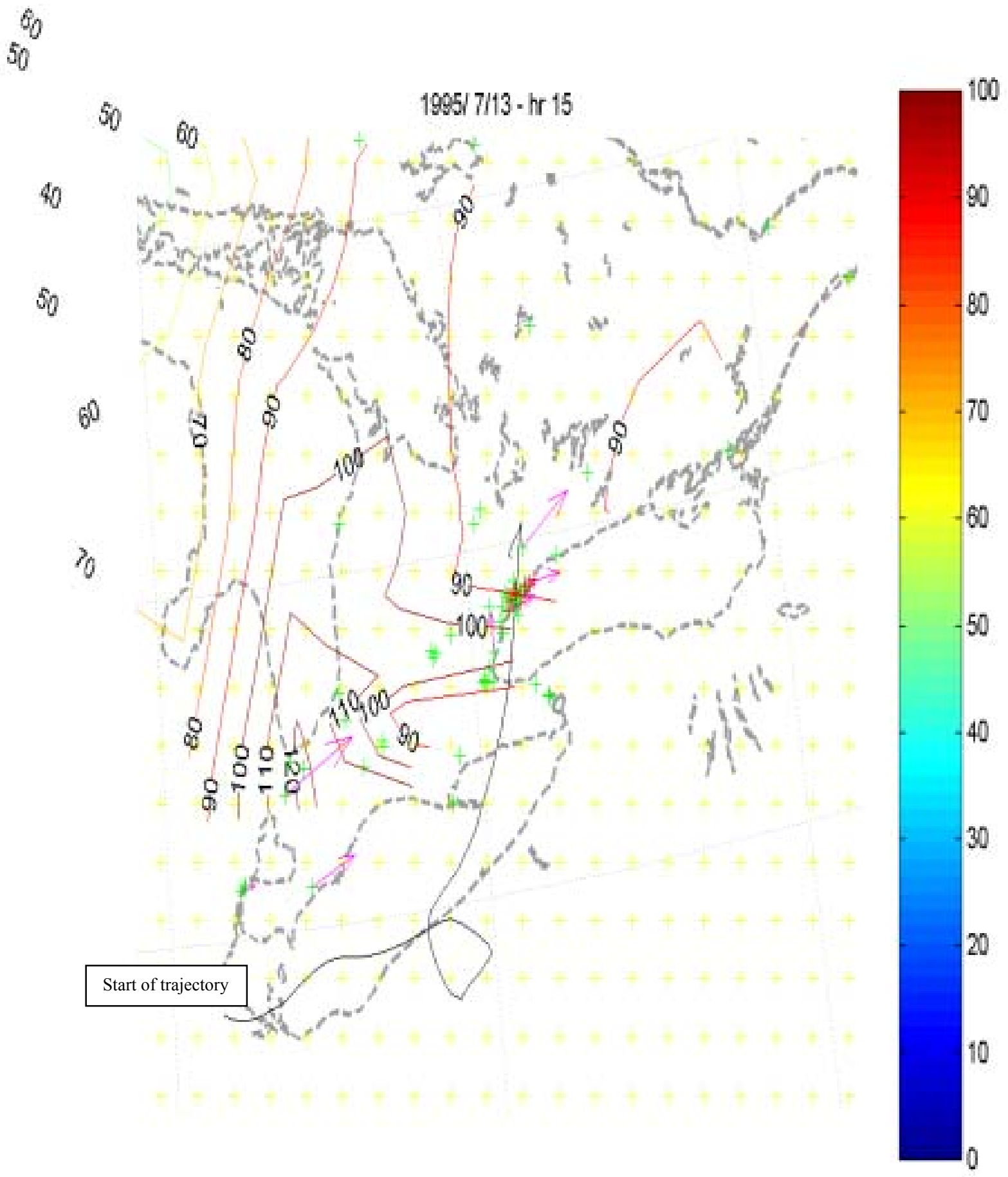

Figure 4.95: Photochemical trajectory for case 039. Observed ozone concentrations (contour values) are for 15 LST on July 13. 


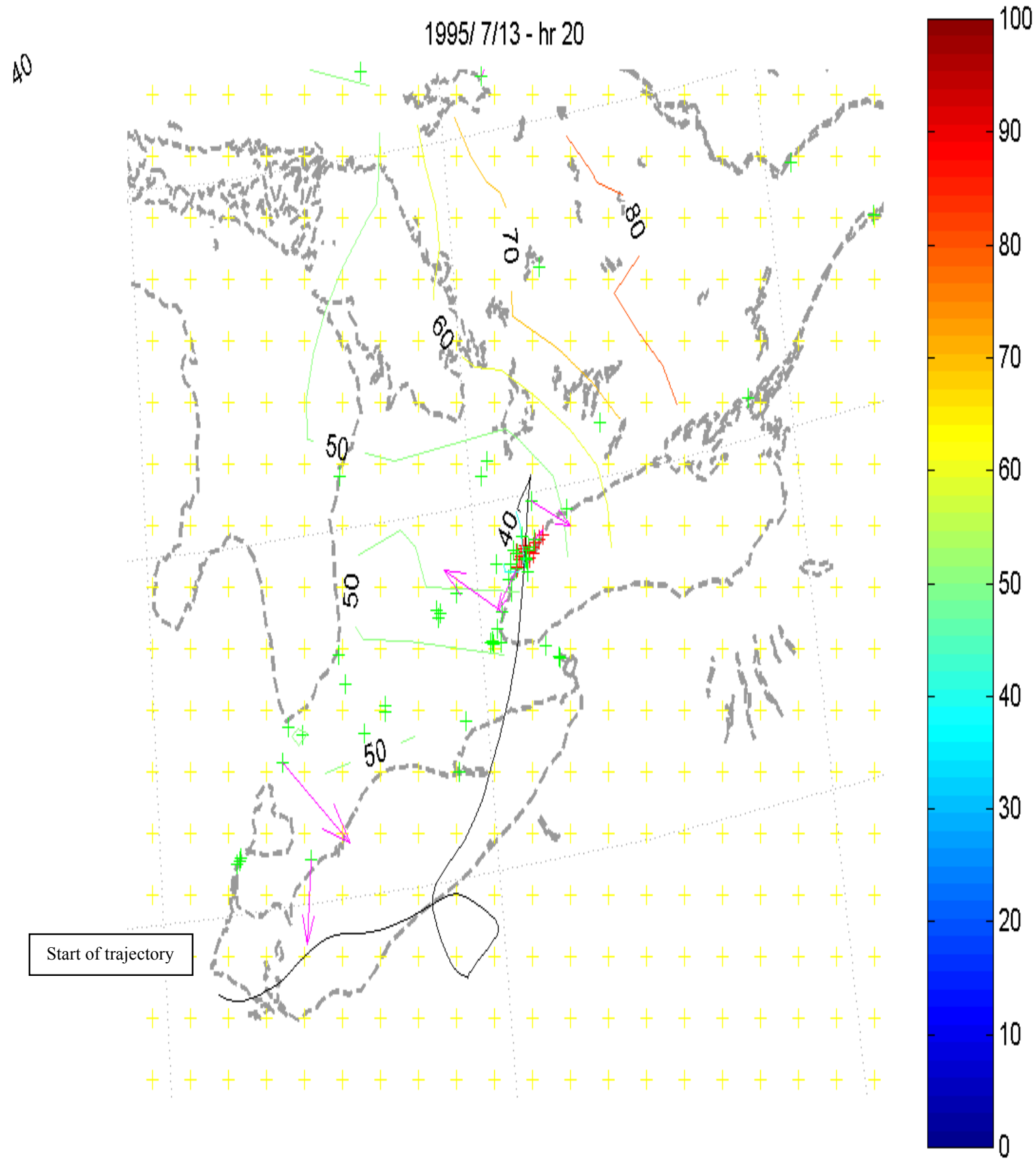

Figure 4.96: Photochemical trajectory for case 039. Observed ozone concentrations (contour values) are for 20 LST on July 13. 


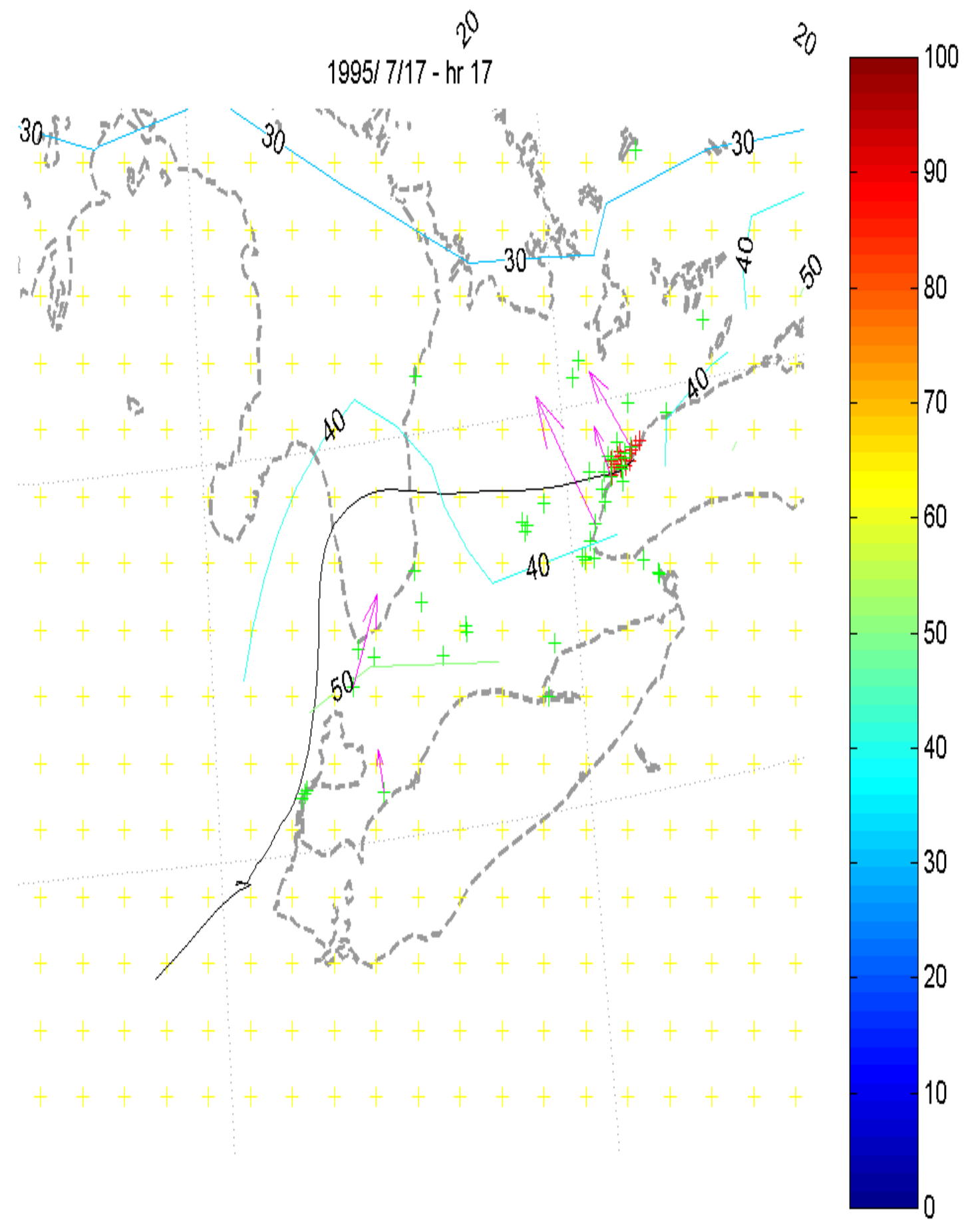

Figure 4.97: Photochemical trajectory for case 035 . Observed ozone concentrations (contour values) are for 17 LST on July 17. 

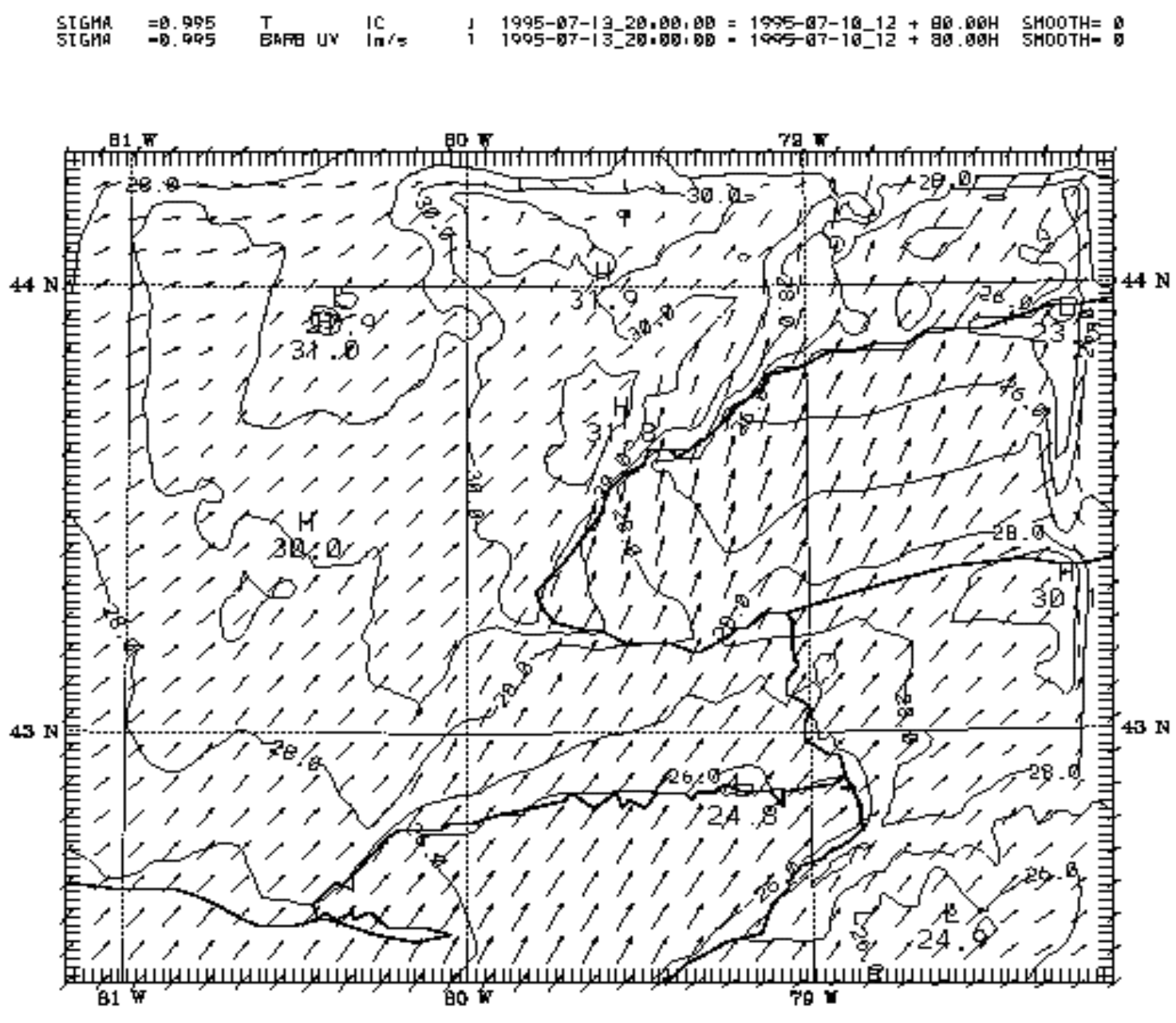

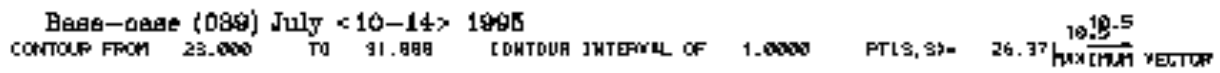

Figure 4.98: Simulated temperature and wind-vector fields. 


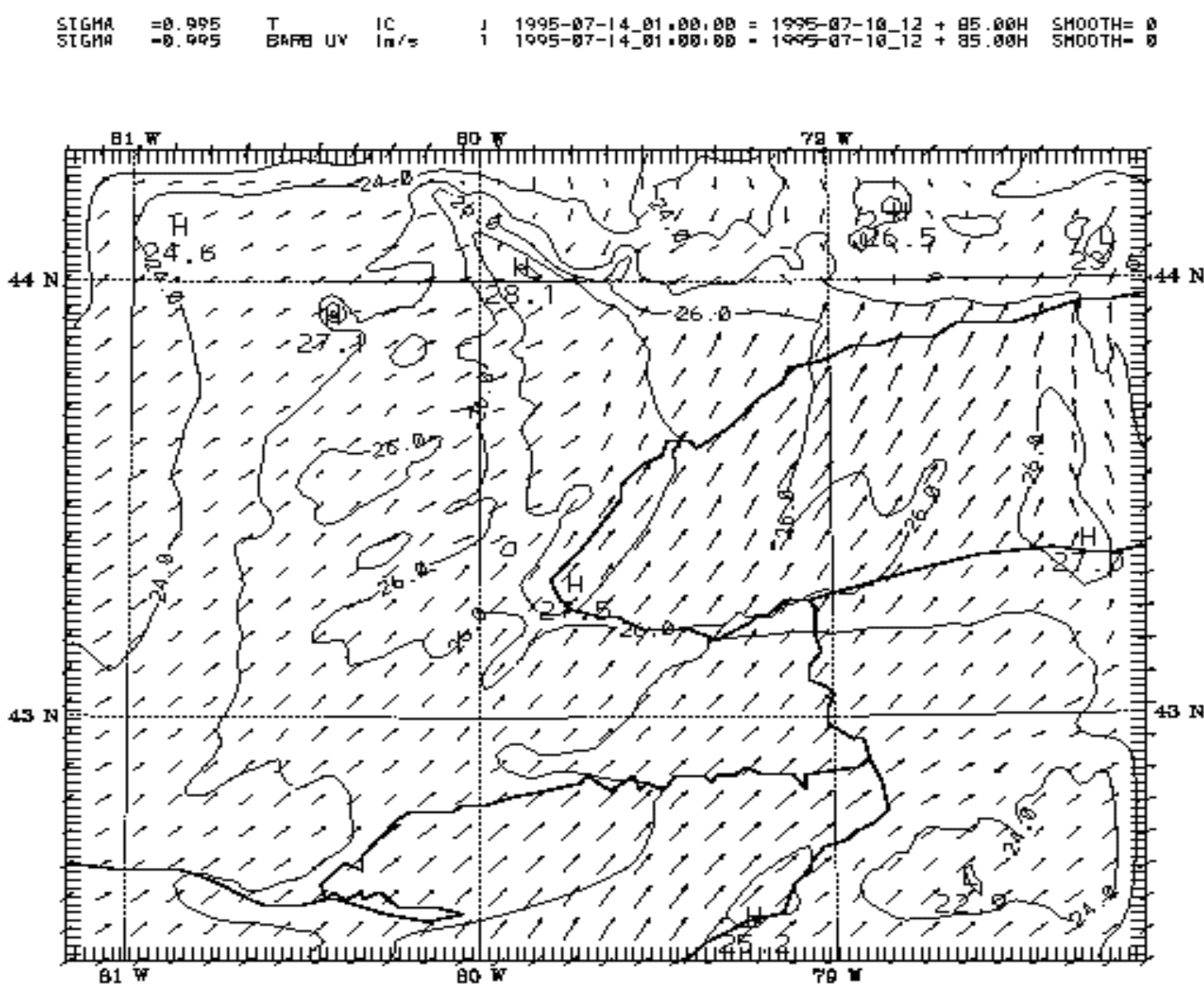

Be日e-0age (089) July $<10-14>1995$
contoup From 22.000

Figure 4.99: Simulated temperature and wind-vector fields. 
Ozone Concentration along trajectories

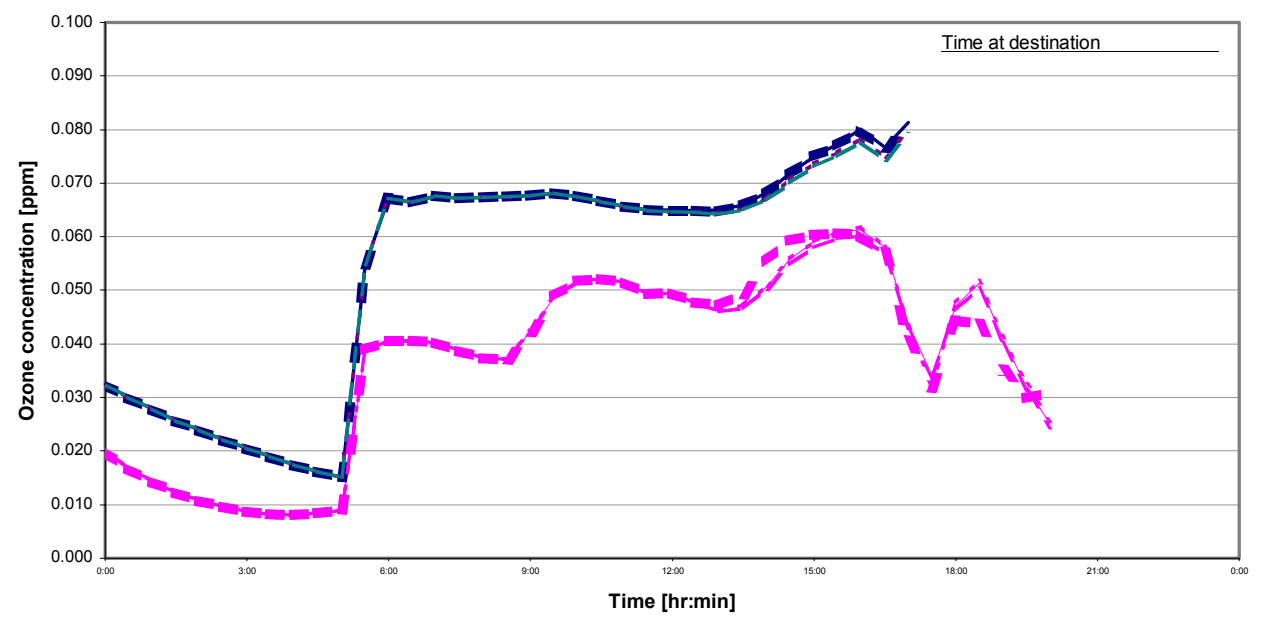

Figure 4.100: Simulated ozone concentrations (ppm) along trajectories 039 (bottom) and 035 (top). Solid line is base case, thick broken line is case A, thin short-broken line is case B, and thin long-broken line is case C. See text for discussion of these cases.

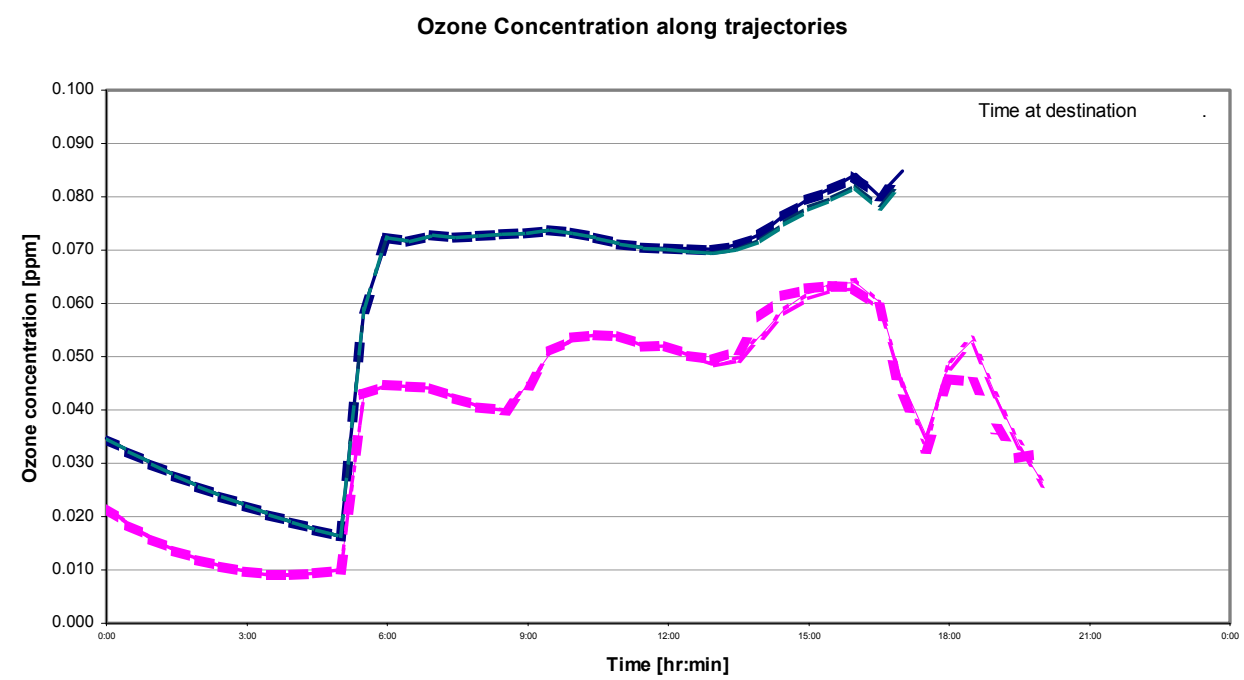

Figure 4.101: Simulated ozone concentrations (ppm) along trajectories 039 (bottom) and 035 (top). This set was simulated with doubled initial mixing ratios. Solid line is base case, thick broken line is case A, thin short-broken line is case B, and thin long-broken line is case C. See text for discussion of these cases. 


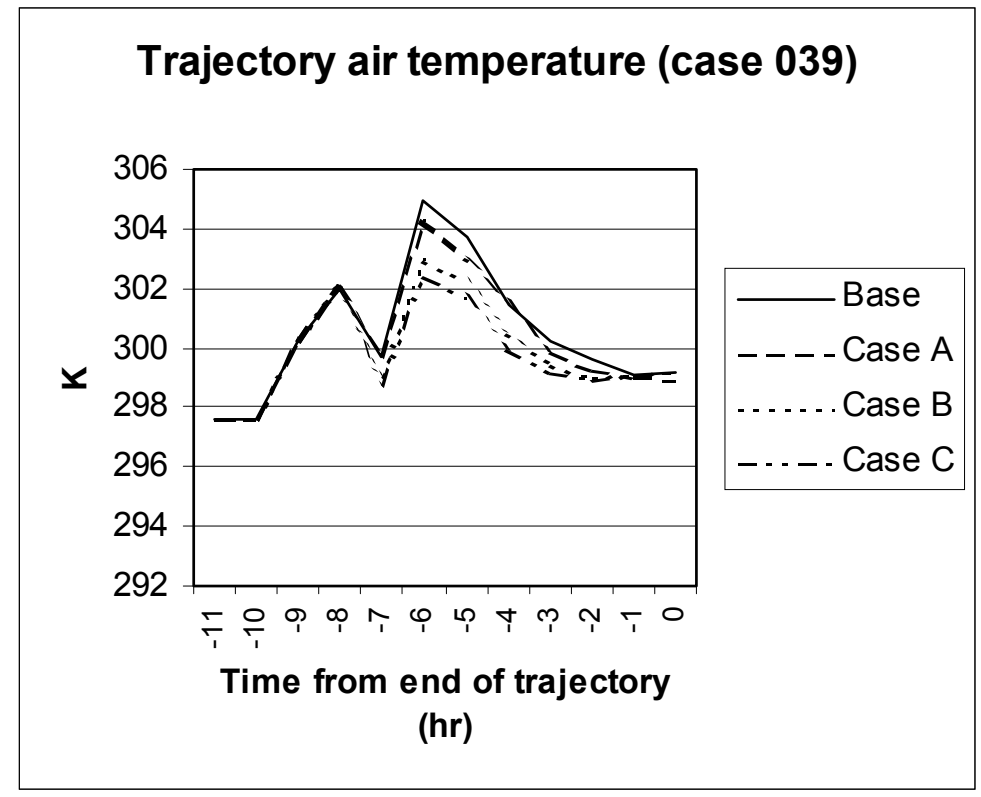

Figure 4.102: Air temperature ( $2 \mathrm{~m}$ above ground) for last 12 hours of trajectory.

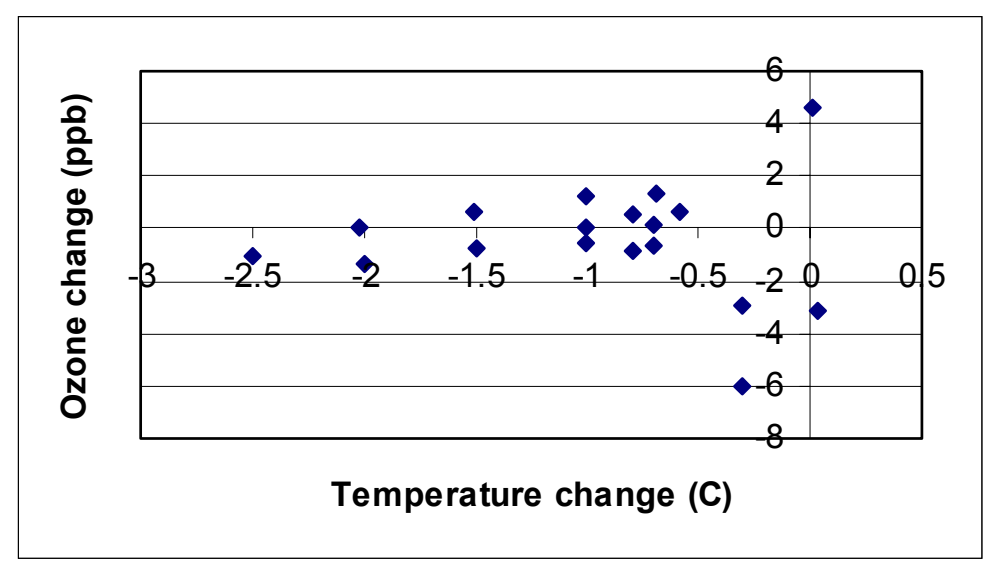

Figure 4.103: Scatter plot of ozone changes and temperature changes for case 039 . 


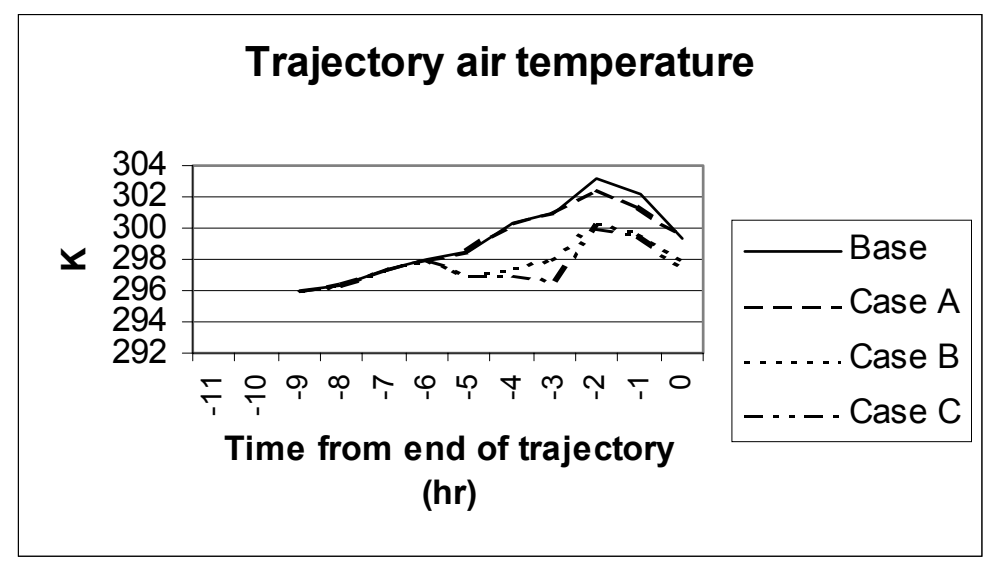

Figure 4.104: Air temperature ( $2 \mathrm{~m}$ above ground) for last 10 hours of trajectory.

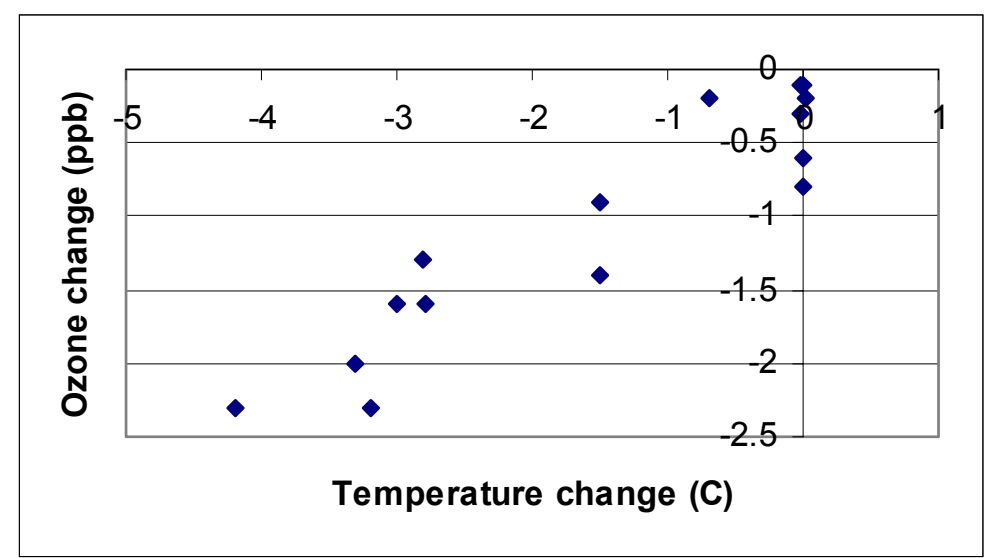

Figure 4.105: Scatter plot of ozone change vs. temperature change for case 035 . 


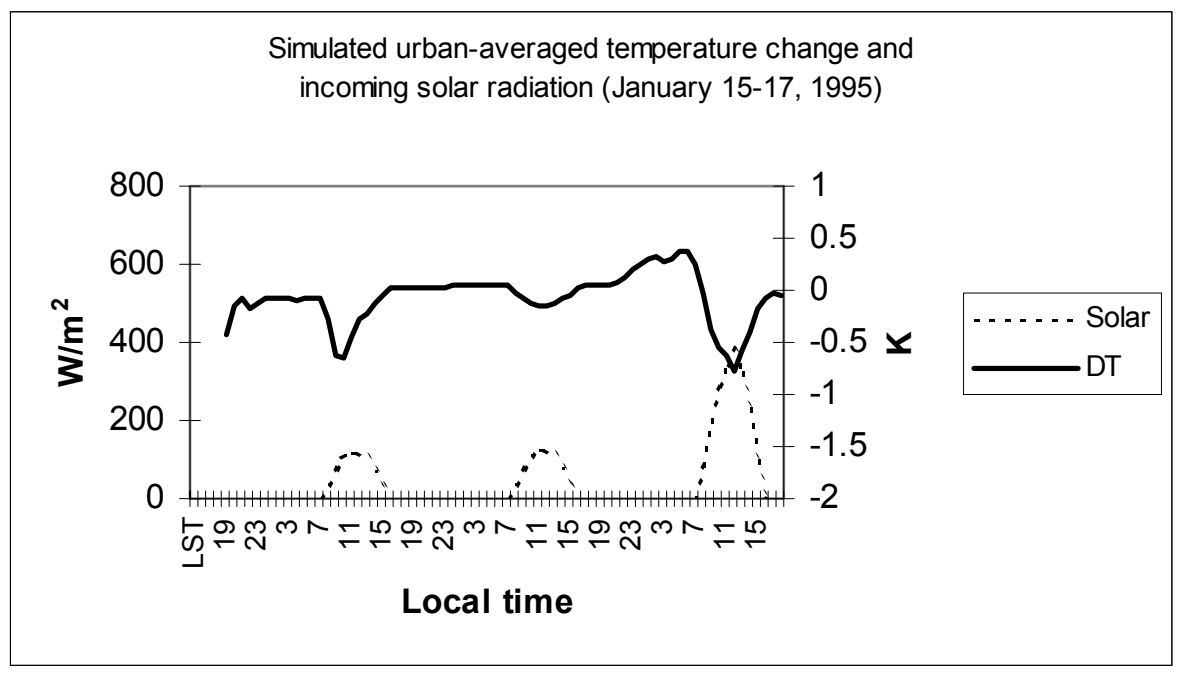

Figure 4.106: Simulated air temperature change and solar radiation.

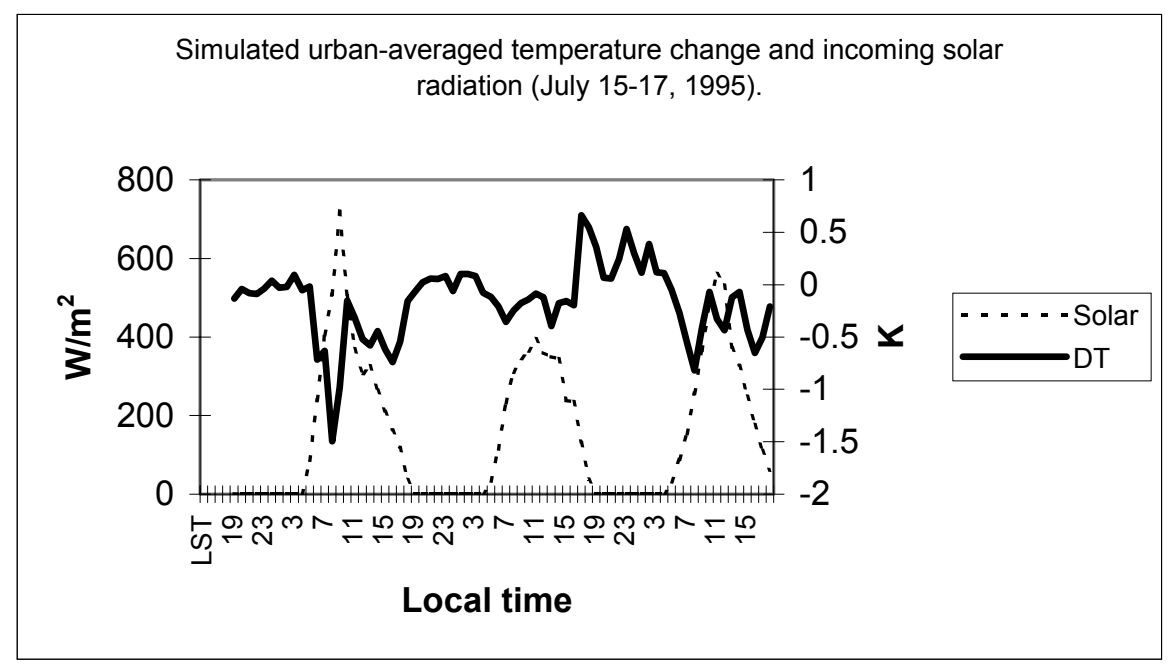

Figure 4.107: Simulated air temperature change and solar radiation. 